\title{
The exercise-induced oxidative stress paradox in COPD
}

Citation for published version (APA):

Mercken, E. (2009). The exercise-induced oxidative stress paradox in COPD. [Doctoral Thesis, Maastricht University]. https://doi.org/10.26481/dis.20090213em

Document status and date:

Published: 01/01/2009

DOI:

10.26481/dis.20090213em

Document Version:

Publisher's PDF, also known as Version of record

\section{Please check the document version of this publication:}

- A submitted manuscript is the version of the article upon submission and before peer-review. There can be important differences between the submitted version and the official published version of record.

People interested in the research are advised to contact the author for the final version of the publication, or visit the DOI to the publisher's website.

- The final author version and the galley proof are versions of the publication after peer review.

- The final published version features the final layout of the paper including the volume, issue and page numbers.

Link to publication

\footnotetext{
General rights rights.

- You may freely distribute the URL identifying the publication in the public portal. please follow below link for the End User Agreement:

www.umlib.nl/taverne-license

Take down policy

If you believe that this document breaches copyright please contact us at:

repository@maastrichtuniversity.nl

providing details and we will investigate your claim.
}

Copyright and moral rights for the publications made accessible in the public portal are retained by the authors and/or other copyright owners and it is a condition of accessing publications that users recognise and abide by the legal requirements associated with these

- Users may download and print one copy of any publication from the public portal for the purpose of private study or research.

- You may not further distribute the material or use it for any profit-making activity or commercial gain

If the publication is distributed under the terms of Article $25 \mathrm{fa}$ of the Dutch Copyright Act, indicated by the "Taverne" license above, 
The exercise-induced oxidative stress paradox in COPD 
(C) Evi M. Mercken, Maastricht 2008

ISBN: 9789052788012

Cover design: Roger Bartholomé

Layout: Evi Mercken

Production: Datawyse / Universitaire Pers Maastricht

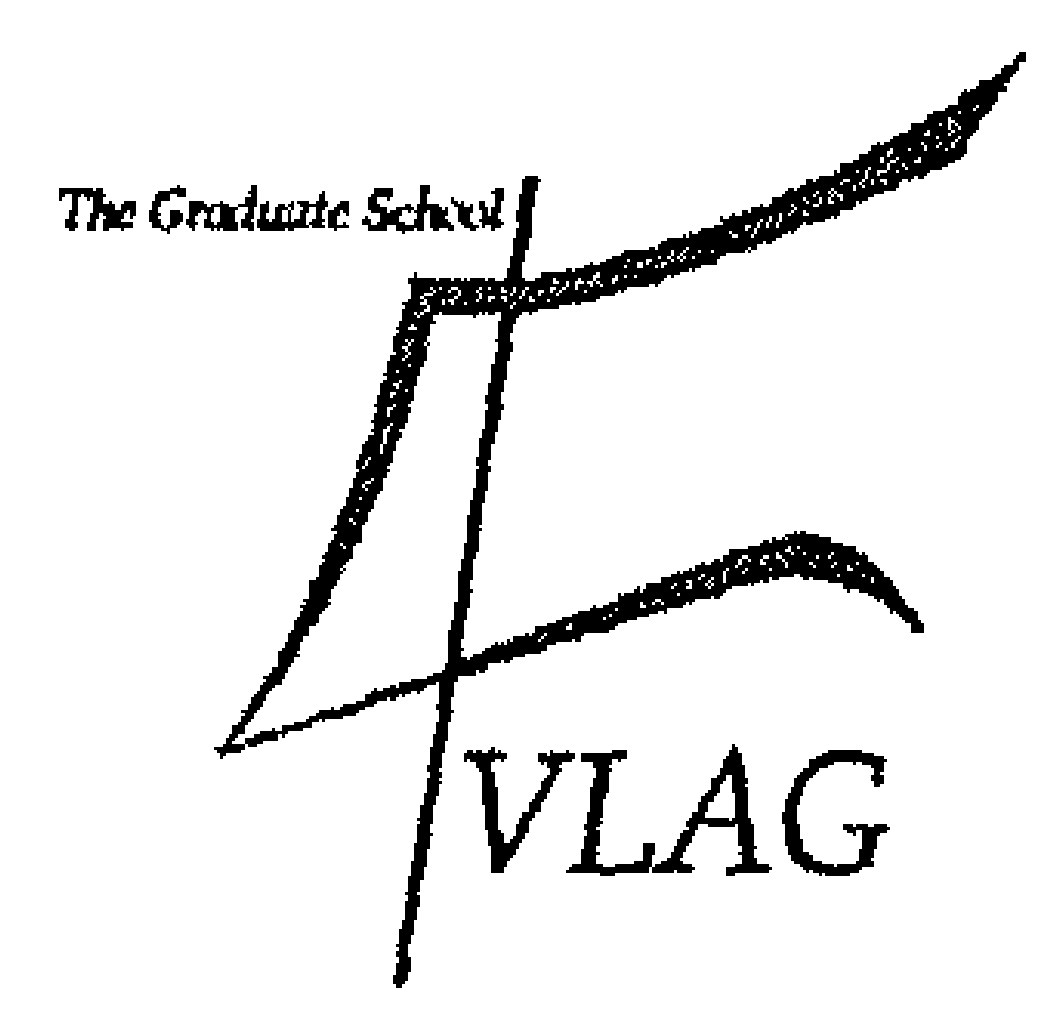

nutim

The studies presented in this thesis were funded by Danone Research-Centre for Specialised Nutrition and by a University Hospital Grant (profileringsfonds) performed within the NUTRIM School for Nutrition, Toxicology \& Metabolism of the Facuity of Health, Medicine and Life Sciences at Maastricht University Medical Center+ which participates in the Graduate School VLAG (Food Technology, Agrobiotechnology, Nutrition and Health Sciences), accredited by the Royal Netherlands Academy of Arts and Sciences (KNAW).

Financially support for printing of this thesis has kindly been provided by Danone Research-Centre for Specialised Nutrition, Stichting Pulmonologie, CIRO-Horn/Stichting Proteion, Pfizer bv/BoehringerIngelheim, GlaxoSmithKline and Astra Zeneca. 


\title{
The exercise-induced oxidative stress paradox in COPD
}

\author{
PROEFSCHRIFT \\ ter verkrijging van de graad van doctor \\ aan de Universiteit Maastricht, \\ op gezag van de Rector Magnificus, Prof. mr. G.P.M.F. Mols, \\ volgens het besluit van het College van Decanen, \\ in het openbaar te verdedigen \\ op vrijdag 13 februari 2009 om 14.00 uur
}

door

\section{Evi M Mercken}

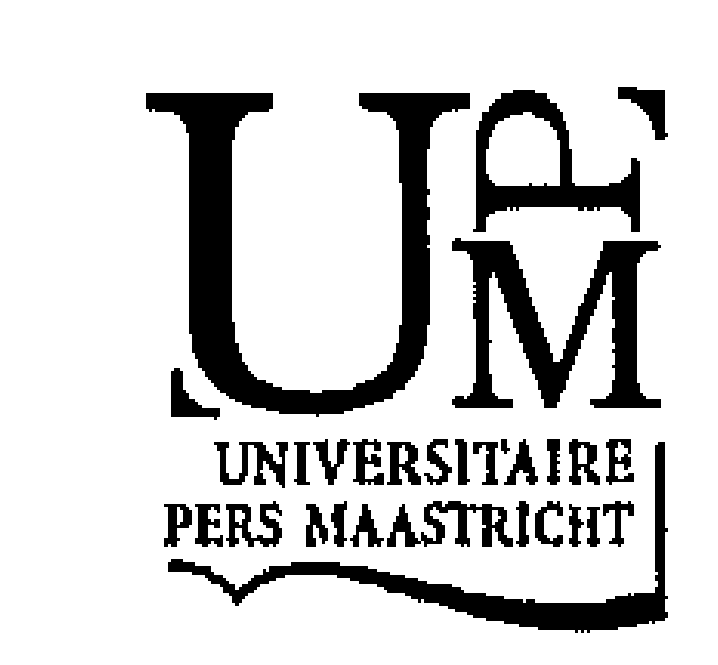




\section{Promotores}

Prof. dr. ir. A.M.W.J. Schols

Prof. dr. E.F.M. Wouters

\section{Copromotor}

Dr. ir. G.J. Hageman

\section{Beoordelingscommissie}

Prof. dr. F.J. van Schooten (voorzitter)

Prof. dr. E. Blaak

Prof. dr. B.K. Pedersen (University of Copenhagen, Denmark)

Prof. dr. C. Préfaut (INSERM, Montpellier, France)

Prof. dr. C.D.A. Stehouwer 
Als sterren konden spreken,

Als sterren konden zien,

Zou je dan heel eventjes willen zwaaien,

En twinkelen als een groet,

Zodat ik hier beneden weet,

Dat het goed met je gaat.

Opgedragen aan mijn oma 


\section{Contents}

Chapter 1 General introduction 9

$\begin{array}{lll}\text { Chapter } 2 \text { Rehabilitation decreases exercise-induced oxidative stress in } & 19\end{array}$ chronic obstructive pulmonary disease

Chapter $3 \quad$ Systemic and pulmonary oxidative stress after single leg exer- $\quad 45$ cise in COPD

Chapter 4 Reduced NF-KB mediated gene expression in skeletal muscle of 61 patients with $C O P D$ in response to acute exercise

Chapter 5 Acute exercise triggers muscle UCP3 in COPD: adaptive 85 mechanism against lipotoxicity?

Chapter 6 Dichloroacetate reduces exercise-induced systemic stress 101 response in COPD

$\begin{array}{lll}\text { Chapter } 7 & \text { General discussion and future directions } & 117\end{array}$

$\begin{array}{lll}\text { Chapter } 8 & \text { Summary } & 129\end{array}$

$\begin{array}{lll}\text { Chapter } 9 & \text { Samenvatting } & 133\end{array}$

$\begin{array}{lll}\text { Appendices Dankwoord } & 137\end{array}$

$\begin{array}{ll}\text { List of publications } & 141\end{array}$

$\begin{array}{ll}\text { Curriculum vitae } & 143\end{array}$ 


\section{CHAPTER 1}

\section{General introduction}

Chronic obstructive pulmonary disease (COPD) is characterized by progressive and irreversible airflow obstruction. COPD is a major public health problem and its prevalence keeps increasing yearly. No effective therapeutic strategy currently exists. COPD is associated not only with an abnormal pulmonary inflammatory process but also by extra-pulmonary manifestations including systemic inflammation and skeletal muscle weakness (for review see (1)). Peripheral muscle dysfunction is a prominent and disabling systemic feature of patients with COPD and is characterized by specific anatomic changes (e.g. shift in fiber type composition and muscle fiber atrophy) and functional changes (e.g. decreased strength, decreased endurance and altered metabolic enzyme activities) (2). Peripheral muscle dysfunction significantly contributes to exercise intolerance and impaired quality of life in these patients (2). Importantly, reduced muscle mass is also a strong predictor of mortality in COPD, independent of the degree of lung function impairment (3). Currently, pulmonary rehabilitation and anabolic hormones have been investigated as therapeutic strategies of peripheral muscle dysfunction. The scientific rationale for undertaking pulmonary rehabilitation for patients with COPD is well established since it has been consistently shown in Cochrane reviews that it relieves dyspnea and improves exercise capacity and health-related quality of life (HRQL) in spite of irreversible abnormalities in lung function $(4,5)$. Exercise training has been shown to be the cornerstone of a pulmonary rehabilitation program in patients with moderate to severe COPD (6-8). To optimize the training stimulus during pulmonary rehabilitation, it is important to tailor exercise training programs to individual patients based on appropriate phenotyping and function tests. Several interventions (i.e. endurance training, interval training and resistance training) or a combination thereof can be applied $(9,10)$. It is generally acknowledged that endurance types of exercise (i.e. treadmill walking and ergometry cycling) are indicated for patients with moderate COPD who have a cardio-circulatory limitation during a symptom-limited incremental exercise test, while interval types of exercise are indicated for patients with severe COPD who are ventilatory limited at the end of a symptom-limited incremental exercise test (11). Whole body endurance training at a high intensity resulted in significant improvements in $\mathrm{HRQL}$, exercise capacity and peripheral muscle force in COPD patients $(10,12,13)$. In practice, however, patients are not always able to execute high intensity endurance exercises because of obvious symptoms of dyspnea and leg fatigue (14). For these patients, who generally suffer from severe muscle weakness or profound ventilatory limitation to exercise, resis- 
tance training is advised. Resistance training, an exercise modality in which small muscle groups are trained by repetitively lifting heavy weights has been reported to induce only moderate cardiac and ventilatory responses (15). Combination of both training interventions was shown to have complementary effects (i.e. effect on strength and endurance) $(10,16)$. Therefore, the combination of resistance and endurance training is advised in pulmonary rehabilitation in advanced COPD.

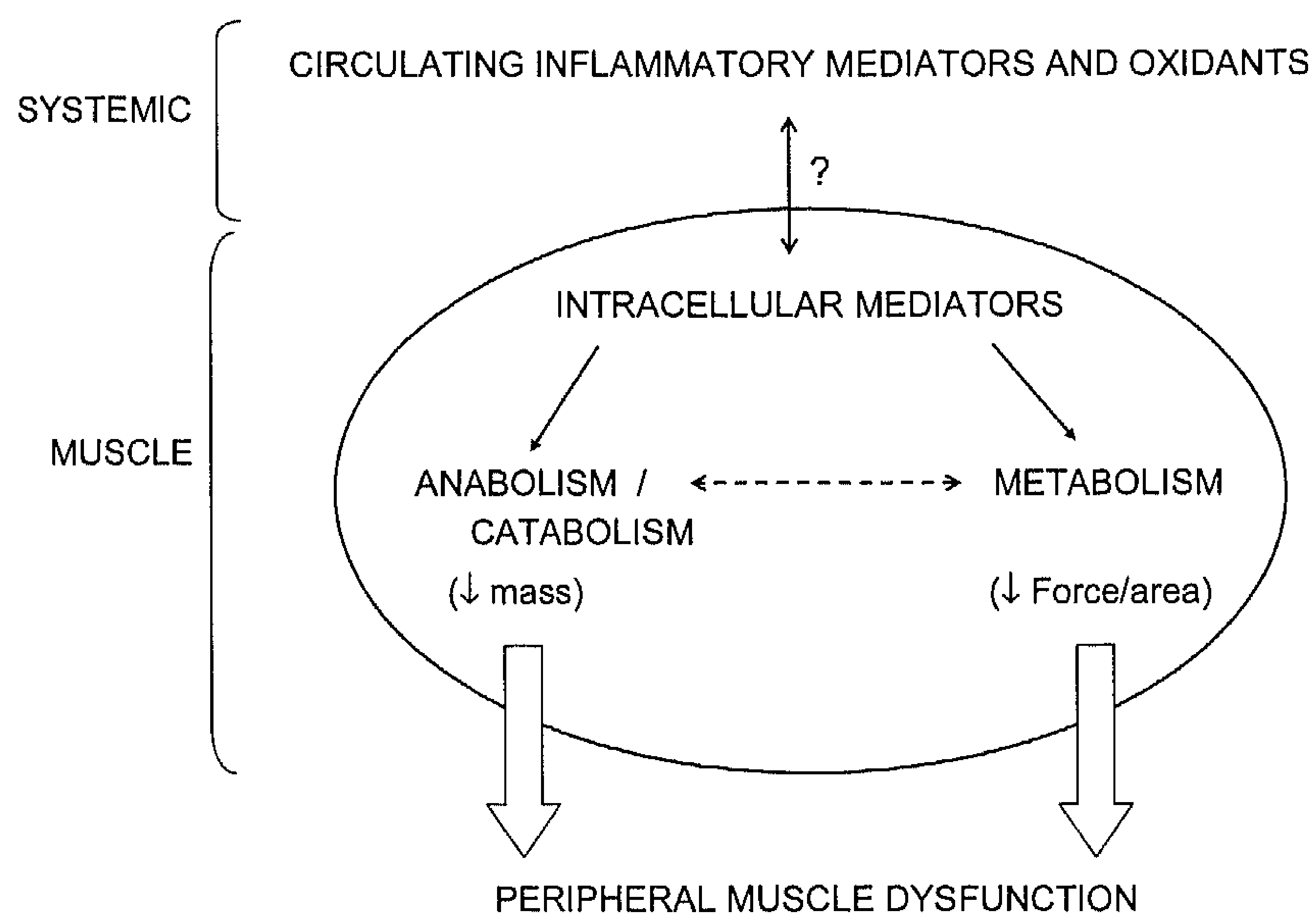

Figure 1. Model of peripheral muscle dysfunction in COPD.

Several mechanisms for peripheral muscle dysfunction have been proposed but the precise contribution of each is yet unknown. Chronic inflammation and oxidative stress are prominent features of COPD and may be implicated in the etiology of peripheral muscle dysfunction $(17,18)$ (see Figure 1). Increased levels of circulating cytokines (interleukin (IL)-6,-8, and tumor necrosis factor- $\alpha$ (TNF- $\alpha$ )) and acutephase proteins (C-reactive protein (CRP)) have been reported in stable COPD patients at rest, reflecting a low-grade systemic inflammation in these patients (1923). Moreover, elevated CRP levels and cytokines are associated with impaired exercise capacity in patients with $\operatorname{COPD}(24,25)$. It is expected that physical exercise will further increase this inflammatory response. However, contradictory results have been reported for the exercise-induced inflammatory response in COPD (26- 
28). At present, limited information is available regarding exercise as modulator of the systemic inflammatory response and also locally in skeletal muscle of patients with COPD.

Several investigations have shown that markers of oxidative stress are increased in patients with COPD and even more pronounced during exacerbations $(29,30)$. Oxidative stress refers to an imbalance in the pro- and antioxidant status in favour of the former. Increased production of reactive oxygen species (ROS) and/or reactive nitrogen species (RNS) can cause oxidative modifications of proteins, lipids and DNA. Exercise training may be beneficial for patients with COPD, in part by improving exercise intolerance (endurance and strength), but paradoxically, exercise is known, if sufficiently intense, to elicit an oxidative stress response in healthy subjects (for review see (31)). The paradox arises if under these circumstances exercise is advisable to COPD patients. Recent evidence indicates that exercise results in increased systemic and muscle oxidative stress in patients with moderate-tosevere COPD (32-35), strongly suggesting that these patients are frequently exposed to oxidative damage as they perform their daily living activities. In addition, an impairment of the adaptive response to reduce oxidative stress has also been described in COPD patients $(36,37)$, thus amplifying the deleterious effects of ROS. These data are indicative of increased oxidative stress in COPD, especially during exercise, being the result of enhanced oxidant formation and/or impaired antioxidant capacity.

Besides the detrimental effects of ROS, there is increasing evidence that ROS have a critical role in muscle adaptation to exercise-induced oxidative stress by modulating gene expression via redox-sensitive transcription pathways (38-40). One of the most important signaling pathways that could be modulated by ROS involves the transcription factor nuclear protein $\mathrm{KB}(\mathrm{NF}-\mathrm{KB}$ ) (for review see (41)). NF- $\mathrm{KB}$ is involved in a wide variety of physiological processes such as immunity and inflammatory responses, antioxidant defense, as well as cell growth and survival. Chronic activation of this signaling pathway by oxidative stress has been suggested to play a role in the etiology of the systemic features of COPD including muscle wasting and altered insulin sensitivity (42-44). Paradoxically, evidence exists that an acute bout of exercise potently activates NF-kB signaling in skeletal muscle of healthy subjects. The functions of exercise-stimulated increases in NF-KB activity are currently unknown, but it is suggested that NF- $\mathrm{KB}$ acts as a beneficial mediator of exercise-induced adaptations to cellular stress. Thus far, the physiological role of $\mathrm{NF}-\mathrm{KB}$ pathway during exercise is still elusive in COPD.

In addition, there is substantial evidence to support the notion that impaired muscle oxidative capacity (as shown by reduced activity of the enzymes citrate synthase and hydroxyacetyl-CoA dehydrogenase $(45,46)$ ) may contribute to peripheral 
Chapter 1

muscle dysfunction in patients with COPD. Besides a disturbed oxidant/antioxidant balance also an impaired oxidative capacity can result in increased muscle lipid peroxidation. Indeed, increased levels of intramuscular lipid peroxidation products have been reported for COPD at baseline and in response to exercise $(35,47)$. Emerging literature strongly supports the notion that uncoupling protein-3 (UCP3) plays a role in the protection of mitochondria against lipotoxicity, since it is capable of reducing ROS production by lowering the mitochondrial membrane potential and/or the removal of fatty acid anions from the mitochondrial matrix (48-50). Accordingly, Gosker et al. (51) previously showed that muscle UCP3 levels are increased by exercise training in COPD patients with a blunted response of the $\beta$ oxidation, suggesting that UCP3 was upregulated in response to an insufficient capacity to oxidize free fatty acids. Until now, the effect of acute exercise on muscular UCP 3 in COPD is still lacking.

The metabolic consequences of changes in oxidative capacity in COPD are reflected in alterations in muscle energy status. Pouw et al. (52) found higher inosine monophosphate levels, which were negatively related with ATP/ADP ratios, indicative for an imbalance between the utilization and resynthesis of ATP in resting muscle of patients with COPD. Moreover, a significant muscle adenine nucleotide loss during exercise has been demonstrated in patients with COPD suggesting that ATP resynthesis is unable to meet the energy demands of exercise even at the low absolute exercise intensities COPD patients can achieve (53). Recently, it has been shown in COPD patients that by modulating skeletal muscle oxidative energy metabolism using dichloroacetate (DCA) infusion before a maximal exercise challenge, blood lactate and ammonia accumulation decreased and exercise performance improved (54). However, this study did not address possible effects on exercise-induced oxidative stress. It can be hypothesized that by increasing muscle energy status in COPD, DCA could additionally decrease oxidative stress. This modulation of oxidative stress could also play a role in the therapeutic effect of DCA. 


\section{AIM AND OUTLINE OF THE THESIS}

The overall aim of this thesis was to evaluate the effects of acute and prolonged exercise on pulmonary, systemic and muscle oxidative stress, and inflammatory responses in patients with COPD.

The primary aims of this thesis are:

- To evaluate the 'exercise paradox' by exploring the effect of pulmonary rehabilitation on exercise-induced oxidative stress in COPD.

- To establish test protocols to examine exercise-induced oxidative stress and systemic inflammatory responses in COPD.

- To explore potential differential effects on NF-KB mediated gene expression in response to acute exercise in COPD versus healthy controls.

- To examine the effect of acute exercise on muscular UCP3 gene expression in patients with COPD compared to healthy controls.

- To assess the effect of a pharmacological agent that specifically target skeletal muscle oxidative energy metabolism on systemic exercise-induced oxidative stress and inflammation in COPD patients.

Despite the clear health benefits of exercise training in COPD, exercise-induced oxidative stress can adversely affect outcome in COPD. For that reason, it is important to understand whether or not exercise training during a pulmonary rehabilitation program can reduce exercise-induced oxidative stress. Therefore, Chapter 2 presents the effects of maximal and submaximal exercise and the effect of rehabilitation on systemic and pulmonary oxidative stress. Besides commonly used oxidative stress markers such as malondialdehyde, the comet assay in peripheral blood mononuclear cells was introduced as a new method. The comet assay is a sensitive technique for analyzing ROS-induced DNA damage. Whether peripheral skeletal muscle is a potential source of exercise-induced oxidative stress and inflammation was investigated in two ways. Chapter 3 describes a study aimed at investigating the effect of a constant work rate single leg ergometer test on oxidative stress and inflammation in patients with COPD. The advantage of this exercise modality is that during a localized quadriceps exercise, work is performed almost exclusively by one muscle group, which minimizes cardiac and ventilatory stress responses (55). Additionally, this exercise test reflects the metabolic stress during resistance type of exercise training that is recommended for COPD patients with severe ventilatory impairment. In Chapter 4, NF-kB mediated gene expression, inflammation, survival and muscle differentiation as well as the antioxidant status was examined in skeletal muscle of patients with COPD versus healthy controls in response to an acute bout of exercise. Muscle biopsies of the vastus lateralis were obtained before, immedi- 
Chapter 1

ately after and $2 \mathrm{~h}$ after a submaximal cycle ergometer test of standardized duration and exercise intensity. Besides a disturbed muscle oxidant/antioxidant balance, an impaired oxidative capacity (46) could result in increased muscle lipid peroxidation and this could be exaggerated in response to an acute exercise bout. In Chapter 5, we tested the hypothesis that in COPD patients muscle gene expression of UCP3 is upregulated during acute exercise as an adaptation to a blunted response of the antioxidant defense system and $\beta$-oxidation. The effect of dichloroacetate (DCA), a pharmacological agent known to activate muscle pyruvate dehydrogenase complex, on systemic exercise-induced oxidative stress and inflammation was examined in COPD patients in Chapter 6. Finally, in Chapter 7, a general discussion of this thesis, together with some further prospects is presented. 
General introduction

\section{REFERENCES}

1. Agusti $A G$, Noguera A, Sauleda J, Sala E, Pons J, and Busquets X. Systemic effects of chronic obstructive pulmonary disease. Eur Respir J 2003;21(2):347-60.

2. Skeletal muscle dysfunction in chronic obstructive pulmonary disease. A statement of the American Thoracic Society and European Respiratory Society. Am J Respir Crit Care Med 1999;159(4 Pt 2):S1-40.

3. Schols AM, Slangen $J$, Volovics $L$, and Wouters EF. Weight loss is a reversible factor in the prognosis of chronic obstructive pulmonary disease. Am J Respir Crit Care Med 1998;157(6 Pt 1):1791-7.

4. Lacasse $Y$, Goldstein R, Lasserson TJ, and Martin S. Pulmonary rehabilitation for chronic obstructive pulmonary disease. Cochrane Database Syst Rev 2006;(4):CD003793.

5. Lacasse Y, Martin S, Lasserson TJ, and Goldstein RS. Meta-analysis of respiratory rehabilitation in chronic obstructive pulmonary disease. A Cochrane systematic review. Eura Medicophys 2007:43(4):475-85.

6. Spruit MA, Troosters $T$, Trappenburg JC, Decramer M, and Gosselink R. Exercise training during rehabilitation of patients with COPD: a current perspective. Patient Educ Couns 2004;52(3):243-8.

7. Franssen FM, Broekhuizen $R$, Janssen PP, Wouters EF, and Schols AM. Limb muscle dysfunction in COPD: effects of muscle wasting and exercise training. Med Sci Sports Exerc 2005;37(1):2-9.

8. Wouters EF, Creutzberg EC, and Schols AM. Systemic effects in COPD. Chest 2002;121/5 Suppl):127S-130S.

9. Spruit MA, Gosselink R, Troosters T, De Paepe K, and Decramer M. Resistance versus endurance training in patients with COPD and peripheral muscle weakness. Eur Respir $J$ 2002;19(6):1072-8.

10. Bernard S, Whittom F, Leblanc P, Jobin J, Belleau R, Berube C, Carrier G, and Maltais F. Aerobic and strength training in patients with chronic obstructive pulmonary disease. Am J Respir Crit Care Med 1999;159(3):896-901.

11. Coppoolse R, Schols AM, Baarends EM, Mostert R, Akkermans MA, Janssen PP, and Wouters $E F$. Interval versus continuous training in patients with severe COPD: a randomized clinical trial. Eur Respir J 1999;14(2):258-63.

12. Lacasse $Y$, Wong E, Guyatt GH, King D, Cook DJ, and Goldstein RS. Meta-analysis of respiratory rehabilitation in chronic obstructive pulmonary disease. Lancet 1996;348(9035):1115-9.

13. O'Donnell DE, McGuire M, Samis $L$, and Webb KA. General exercise training improves ventilatory and peripheral muscle strength and endurance in chronic airflow limitation. Am J Respir Crit Care Med 1998;157(5 Pt 1):1489-97.

14. Maltais F, LeBlanc $P$, Jobin J, Berube $C$, Bruneau J, Carrier $L$, Breton MJ, Falardeau $G$, and Belleau $R$. Intensity of training and physiologic adaptation in patients with chronic obstructive pulmonary disease. Am J Respir Crit Care Med 1997;155(2):555-61.

15. Richardson RS, Sheldon J, Poole DC, Hopkins SR, Ries AL, and Wagner PD. Evidence of skeletal muscle metabolic reserve during whole body exercise in patients with chronic obstructive pulmonary disease. Am J Respir Crit Care Med 1999;159(3):881-5.

16. Ortega F, Toral J, Cejudo $P$, Villagomez R, Sanchez $H$, Castillo J, and Montemayor T. Comparison of effects of strength and endurance training in patients with chronic obstructive pulmonary disease. Am J Respir Crit Care Med 2002;166(5):669-74.

17. Berton $E$, Antonucci $R$, and Palange $P$. Skeletal muscle dysfunction in chronic obstructive pulmonary disease. Monaldi Arch Chest Dis 2001;56(5):418-22. 
18. Agusti AG. Systemic effects of chronic obstructive pulmonary disease. Proc Am Thorac Soc 2005;2(4):367-70; discussion 371-2.

19. van Helvoort $H A$, van de Pol MH, Heijdra $Y F$, and Dekhuijzen PN. Systemic inflammatory response to exhaustive exercise in patients with chronic obstructive pulmonary disease. Respir Med 2005.

20. Godoy I, Campana AO, Geraldo RR, Padovani $C R$, and Paiva SA. Cytokines and dietary energy restriction in stable chronic obstructive pulmonary disease patients. Eur Respir $J$ 2003;22(6):920-5.

21. Eid AA, lonescu AA, Nixon LS, Lewis-Jenkins V, Matthews SB, Griffiths TL, and Shale DJ. Inflammatory response and body composition in chronic obstructive pulmonary disease. $A m \mathrm{~J}$ Respir Crit Care Med 2001;164(8 Pt 1):1414-8.

22. Di Francia $M$, Barbier $D$, Mege $J \mathrm{~L}$, and Orehek J. Tumor necrosis factor-alpha levels and weight loss in chronic obstructive pulmonary disease. Am J Respir Crit Care Med 1994;150(5 Pt 1):1453-5.

23. Schols AM, Buurman WA, Staal van den Brekel AJ, Dentener MA, and Wouters EF. Evidence for a relation between metabolic derangements and increased levels of inflammatory mediators in a subgroup of patients with chronic obstructive pulmonary disease. Thorax 1996;51(8):81924.

24. Broekhuizen R, Wouters EF, Creutzberg EC, and Schols AM. Raised CRP levels mark metabolic and functional impairment in advanced COPD. Thorax 2006;61(1):17-22.

25. Yende S, Waterer GW, Tolley EA, Newman AB, Bauer DC, Taaffe DR, Jensen R, Crapo R, Rubin $S$, Nevitt $M$, Simonsick EM, Satterfield $S$, Harris $T$, and Kritchevsky SB. Inflammatory markers are associated with ventilatory limitation and muscle dysfunction in obstructive lung disease in well functioning elderly subjects. Thorax 2006;61(1):10-6.

26. Koechlin C, Couillard A, Cristol JP, Chanez P, Hayot M, Le Gallais D, and Prefaut C. Does systemic inflammation trigger local exercise-induced oxidative stress in COPD? Eur Respir $J$ 2004;23(4):538-44.

27. Rabinovich RA, Figueras M, Ardite E, Carbo N, Troosters T, Filella X, Barbera JA, FernandezCheca JC, Argiles JM, and Roca J. Increased tumour necrosis factor-alpha plasma levels during moderate-intensity exercise in COPD patients. Eur Respir $J$ 2003;21(5):789-94.

28. van Helvoort HA, Heijdra YF, Thijs HM, Vina J, Wanten GJ, and Dekhuijzen PN. ExerciseInduced Systemic Effects in Muscle-Wasted Patients with COPD. Med Sci Sports Exerc 2006;38(9):1543-1552.

29. Sahin U, Unlu M, Ozguner F, Sutcu R, Akkaya A, and Delibas N. Lipid peroxidation and glutathione peroxidase activity in chronic obstructive pulmonary disease exacerbation: prognostic value of malondialdehyde. J Basic Clin Physiol Pharmacol 2001;12(1):59-68.

30. Rahman I, Skwarska E, and MacNee W. Attenuation of oxidant/antioxidant imbalance during treatment of exacerbations of chronic obstructive pulmonary disease. Thorax 1997;52(6):5658.

31. Alessio HM. Exercise-induced oxidative stress. Med Sci Sports Exerc 1993;25(2):218-24.

32. Heunks $L M$, Vina $J$, van Herwaarden $C L$, Folgering $H T$, Gimeno A, and Dekhuijzen PN. Xanthine oxidase is involved in exercise-induced oxidative stress in chronic obstructive pulmonary disease. Am J Physiol 1999;277(6 Pt 2):R1697-704.

33. Vina J, Servera E, Asensi M, Sastre J, Pallardo FV, Ferrero JA, Garcia-De-La-Asuncion J, Anton $\mathrm{V}$, and Marin J. Exercise causes blood glutathione oxidation in chronic obstructive pulmonary disease: prevention by $\mathrm{O} 2$ therapy. J Appl Physiol 1996;81(5):2198-202.

34. Koechlin C, Couillard A, Simar D, Cristol JP, Bellet H, Hayot M, and Prefaut C. Does oxidative stress alter quadriceps endurance in chronic obstructive pulmonary disease? Am J Respir Crit Care Med 2004;169(9):1022-7. 
35. Couillard A, Maltais F, Saey D, Debigare R, Michaud A, Koechlin C, LeBlanc $P$, and Prefaut $C$. Exercise-induced quadriceps oxidative stress and peripheral muscle dysfunction in patients with chronic obstructive pulmonary disease. Am J Respir Crit Care Med 2003;167(12):1664-9.

36. Engelen MP, Schols AM, Does JD, Deutz NE, and Wouters EF. Altered glutamate metabolism is associated with reduced muscle glutathione levels in patients with emphysema. Am J Respir Crit Care Med 2000;161(1):98-103.

37. Rabinovich RA, Ardite E, Troosters T, Carbo N, Alonso J, Gonzalez de Suso JM, Vilaro J, Barbera JA, Polo MF, Argiles JM, Fernandez-Checa JC, and Roca J. Reduced muscle redox capacity after endurance training in patients with chronic obstructive pulmonary disease. Am J Respir Crit Care Med 2001;164(7):1114-8.

38. Ammendola R, Fiore F, Esposito F, Caserta G, Mesuraca M, Russo T, and Cimino F. Differentially expressed mRNAs as a consequence of oxidative stress in intact cells. FEBS Lett 1995;371(3):209-13.

39. Jackson MJ, McArdle A, and McArdle F. Antioxidant micronutrients and gene expression. Proc Nutr Soc 1998;57(2):301-5.

40. Lander HM, Milbank AJ, Tauras JM, Hajjar DP, Hempstead BL, Schwartz GD, Kraemer RT, Mirza UA, Chait BT, Burk SC, and Quilliam LA. Redox regulation of cell signalling. Nature 1996;381(6581):380-1.

41. Pantano $C$, Reynaert NL, van der Vliet $A$, and Janssen-Heininger $Y M$. Redox-sensitive kinases of the nuclear factor-kappaB signaling pathway. Antioxid Redox Signal 2006;8(9-10):1791-806.

42. Langen RC, Schols AM, Kelders MC, Wouters EF, and Janssen-Heininger YM. Inflammatory cytokines inhibit myogenic differentiation through activation of nuclear factor-kappaB. Faseb $J$ 2001;15(7):1169-80.

43. Cai $D$, Frantz JD, Tawa NE, Jr., Melendez PA, Oh BC, Lidov HG, Hasselgren PO, Frontera WR, Lee J, Glass DJ, and Shoelson SE. IKKbeta/NF-kappaB activation causes severe muscle wasting in mice. Cell 2004:119(2):285-98.

44. Reid MB, and Durham WJ. Generation of reactive oxygen and nitrogen species in contracting skeletal muscle: potential impact on aging. Ann N Y Acad Sci 2002;959:108-16.

45. Maltais F, Simard AA, Simard C, Jobin J, Desgagnes $P$, and LeBlanc P. Oxidative capacity of the skeletal muscle and lactic acid kinetics during exercise in normal subjects and in patients with COPD. Am J Respir Crit Care Med 1996;153(1):288-93.

46. Maltais $F$, LeBlanc $P$, Whittom $F$, Simard $C$, Marquis $K$, Belanger $M$, Breton $M J$, and Jobin $J$. Oxidative enzyme activities of the vastus lateralis muscle and the functional status in patients with COPD. Thorax 2000;55(10):848-53.

47. Allaire $J$, Maltais $F$, LeBlanc $P$, Simard $P M$, Whittom $F$, Doyon JF, Simard $C$, and Jobin $J$. Lipofuscin accumulation in the vastus lateralis muscle in patients with chronic obstructive pulmonary disease. Muscle Nerve 2002;25(3):383-9.

48. Korshunov SS, Skulachev VP, and Starkov AA. High protonic potential actuates a mechanism of production of reactive oxygen species in mitochondria. FEBS Lett 1997;416(1):15-8.

49. Schrauwen $P_{1}$ and Hesselink MK. The role of uncoupling protein 3 in fatty acid metabolism: protection against lipotoxicity? Proc Nutr Soc 2004;63(2):287-92.

50. Brand MD. Uncoupling to survive? The role of mitochondrial inefficiency in ageing. Exp Gerontol 2000;35(6-7):811-20.

51. Gosker HR, Schrauwen P, Broekhuizen R, Hesselink MK, Moonen-Kornips E, Ward KA, Franssen FF, Wouters EF, and Schols AM. Exercise training restores uncoupling protein-3 content in limb muscles of patients with chronic obstructive pulmonary disease. Am $J$ Physiol Endocrinol Metab 2005. 
Chapter 1

52. Pouw EM, Schols AM, van der Vusse GJ, and Wouters EF. Elevated inosine monophosphate levels in resting muscle of patients with stable chronic obstructive pulmonary disease. Am J Respir Crit Care Med 1998;157(2):453-7.

53. Steiner MC, Evans R, Deacon SJ, Singh SJ, Patel P, Fox J, Greenhaff PL, and Morgan MD. Adenine nucleotide loss in the skeletal muscles during exercise in chronic obstructive pulmonary disease. Thorax 2005.

54. Calvert LD, Shelley R, Singh SJ, Greenhaff PL, Bankart J, Morgan MD, and Steiner MC. Dichloroacetate Enhances Performance and Reduces Blood Lactate during Maximal Cycle Exercise in COPD. Am J Respir Crit Care Med 2008.

55. Richardson RS. Skeletal muscle dysfunction vs. muscle disuse in patients with COPD. J Appl Physiol 1999;86(5):1751-3. 


\title{
CHAPTER 2
}

\section{Rehabilitation decreases exercise-induced oxidative stress in chronic obstructive pulmonary disease}

\begin{abstract}
The effect of exercise at different intensities as well as the effect of intensive supervised pulmonary rehabilitation on oxidative stress was studied for chronic obstructive pulmonary disease (COPD). Eleven COPD patients and eleven healthy agematched controls performed a maximal and submaximal exercise cycle ergometry test at $60 \%$ of peak workload. COPD patients performed these tests before and after 8 weeks of pulmonary rehabilitation. Measurements were done before, immediately after and 4 hours after both exercise tests. At rest, increased oxidative stress was observed in patients compared to controls, as measured by urinary malondialdehyde (MDA) $(p<0.05)$ and hydrogen peroxide $\left(\mathrm{H}_{2} \mathrm{O}_{2}\right)$ in breath condensate $(p<0.05)$. In healthy controls, a significant increase in urinary MDA was observed 4 hours after both exercise tests $(p=0.05)$, whereas $\mathrm{H}_{2} \mathrm{O}_{2}$ significantly increased immediately after maximal exercise $(p<0.05)$. In COPD patients, before rehabilitation, reactive oxygen species (ROS)-induced DNA damage in peripheral blood mononuclear cells, urinary MDA and plasma uric acid were significantly increased after both exercise tests $(p<0.05)$, whereas no significant increase was observed in plasma MDA. In contrast, exhaled $\mathrm{H}_{2} \mathrm{O}_{2}$ was only significantly increased after maximal exercise $(p<0.02)$. Although after rehabilitation peak workload was increased by $24 \%$, a similar oxidative stress response was found. Remarkably, a decrease in ROS-induced DNA damage was detected after exercise at submaximal intensity despite increased exercise duration of $73 \%$. In summary, COPD patients had increased pulmonary and systemic oxidative stress both at rest and induced by exercise. In addition, pulmonary rehabilitation increased exercise capacity and was associated with reduced exercise-induced oxidative stress.
\end{abstract}

Evi M. Mercken ${ }^{1}$, Geja J. Hageman², Annemie M.W.J. Schols', Marco A. Akkermans ${ }^{3}$, Aalt Bast ${ }^{4}$, and Emiel F.M. Wouters'. Departments of ${ }^{1}$ Respiratory Medicine, ${ }^{2}$ Health Risk Analysis and Toxicology and ${ }^{4}$ Pharmacology and Toxicology, University of Maastricht, and ${ }^{3}$ Asthma Center Hornerheide, Horn, the Netherlands. Am J Respir Crit Care Med 2005; 172: 994-1001. 
Chapter 2

\section{INTRODUCTION}

Several studies have shown an increased systemic oxidative stress response after strenuous exercise in patients with chronic obstructive pulmonary disease (COPD) (1-3). This was derived from increased lipid peroxidation, measured as thiobarbituric acid reactive substances (TBARs), and increased protein oxidation (1-3). Additional evidence supporting increased exercise-induced systemic oxidative stress in COPD patients is still lacking, especially possible differential effects of exercise at different intensities. Moreover, no studies are presently available that have evaluated the effect of exercise on pulmonary oxidative stress. Dekhuijzen et al. (4) reported increased hydrogen peroxide $\left(\mathrm{H}_{2} \mathrm{O}_{2}\right)$ in exhaled breath condensate (EBC) in COPD patients compared to healthy participants, which was further increased during acute exacerbations. Therefore, as a first step, the present study was designed to examine the changes in exercise-induced systemic and pulmonary oxidative stress response at maximal and submaximal exercise levels in COPD patients and in healthy age-matched controls. As an additional marker of systemic oxidative stress, the comet assay in peripheral blood mononuclear cells (PBMCs) was introduced as a new method and yet unexplored in COPD. It is a sensitive technique for analysing reactive oxygen species (ROS)-induced DNA damage in peripheral blood mononuclear cells (PBMCS). The comet assay detects double- and single-strand breaks, incomplete excision repair sites, cross-links and alkali-labile sites $(5,6)$. In addition to the comet assay, plasma and urine malondialdehyde (MDA) were determined as markers of systemic oxidative stress. Furthermore, uric acid in plasma was measured as an indicator of xanthine-oxidase activity. Pulmonary oxidative stress in COPD patients was assessed by analysing $\mathrm{H}_{2} \mathrm{O}_{2}$ concentration in $\mathrm{EBC}$ (4).

A major component of pulmonary rehabilitation to improve physical performance and health related quality of life is exercise training $(7,8)$. However, exerciseinduced increases in oxidative stress may adversely affect outcome in $\operatorname{COPD}(3,9)$. For that reason, it is important to understand whether or not exercise training during a pulmonary rehabilitation program can reduce exercise-induced oxidative stress. Therefore, the second aim of this study was to evaluate the effects of pulmonary rehabilitation on markers of exercise-induced oxidative stress in patients with COPD.

\section{METHODS}

\section{Study Population}

Eleven clinically stable patients with stage II-IV according to the Global Initiative for Chronic Obstructive Lung Disease guidelines were consecutively recruited on 
admission to a pulmonary rehabilitation center (Asthma Center Hornerheide, Horn, The Netherlands) and participated in an in-patient pulmonary rehabilitation program on weekdays over 8 weeks $(10,11)\left(\mathrm{FEV}_{1}<60 \%\right.$ predicted and $\mathrm{FEV}_{1} / \mathrm{FVC}<70 \%$ and $<10 \%$ predicted improvement in $\mathrm{FEV}_{1}$ after $\beta_{2}$-agonist inhalation) Additional information on the rehabilitation program is available in the online supplement. All patients were ex-smokers, were not depleted (12), did not use oxygen supplementation, and had not experienced respiratory tract infection or exacerbation of their disease for at least 4 weeks prior to the study. Exclusion criteria were no other chronic diseases such as rheumatoid arthritis and chronic colitis. Also patients with diabetes, cardiovascular diseases, renal diseases, liver diseases or mental diseases were excluded from the study. Eleven healthy age-matched non-smoking participants were recruited as the control group. In addition, all participants were questioned on their dietary habits to ensure that none were taking antioxidants or vitamin supplements. Furthermore, all patients received anticholinergic and $\beta_{2-}$ agonists as bronchodilator therapy as well as inhaled corticosteroids. Three patients also received theophylline and one patient was on oral corticosteroid therapy. This maintenance medication remained unchanged during the study. Written informed consent was obtained from all participants, and the study was approved by the medical ethics committee of the University Hospital Maastricht.

\section{Study Design}

The participants were instructed to abstain from strenuous physical activity on the test day. Moreover, COPD patients were not allowed to take antioxidants or vitamin supplements during the rehabilitation program. At the beginning of the study, all participants underwent pulmonary function testing, anthropometric measurements and they had to wear a physical activity monitor during 9 consecutive days. First, they completed an incremental cycle ergometry exercise test until exhaustion and after four days a submaximal constant work rate exercise test was performed at $60 \%$ of the maximal power output achieved on the incremental exercise test. Peripheral venous blood, urine samples and samples for measurements of breath condensate $\mathrm{H}_{2} \mathrm{O}_{2}$ were obtained at baseline, immediately after and 4 hours after both exercise tests. All tests were performed and samples were collected at the same time point of the day. The same procedure was strictly followed at the end of the pulmonary rehabilitation program for COPD patients.

\section{Pulmonary Function Tests}

All participants underwent flow volumes including measurements of $F E V_{1}$ and FVC with the highest value from at least three properly performed measurements being used for analysis. Also lung volumes and diffusion capacity were obtained in COPD patients. Residual volume (RV) and total lung capacity (TLC) were assessed by whole-body plethysmography and diffusion capacity for carbon monoxide (Dlco) 
was measured by using the single breath method (Masterlab, Jaeger, Würzburg, Germany). The values obtained were expressed as a percentage of the reference value (13).

\section{Level of Physical Activity}

The daily physical activity level was assessed using the Physical Activity Monitor (Pam) accelerometer. Pam (type AM 100, Pam B.V., the Netherlands) is a smallsized, lightweight unidirectional accelerometer. This accelerometer provides a valid and reliable method to estimate the energy expenditure of the whole body during walking patterns. (see the online supplement for additional information).

\section{Exercise Capacity}

Participants performed an incremental (10 Watt/minute) cycle ergometry test as described previously (14). Expired gases were analysed using breath-by-breath analysis through a breathing mask (Oxygen- $\beta$, Jaeger, Würzburg, Germany). Simultaneously, heart rate was registered every minute (Polar electro Cy, Kempele, Finland).

The submaximal exercise test was performed at $60 \%$ of the peak workload achieved during the incremental exercise test. The patients were instructed to cycle as long as possible but for a maximum of 30 minutes. For the control group the endurance time was standardized at 12 minutes, which was the mean endurance time of the COPD patients at baseline. Also oxygen consumption and heart rate were monitored as described in the incremental exercise test. Antecubital venous blood samples were taken before and at the end of both exercise tests to analyse lactate. Plasma lactate was determined enzymatically using an automated system (Cobas Mira ${ }^{\circledR}$, Roche, Basel Switzerland).

\section{Sample Preparation}

Venous blood samples $(10 \mathrm{ml})$ were drawn into ethylenediaminetetraacetic acid (EDTA)-containing tubes (Venoject). All blood samples were immediately put on ice, and kept on ice during sample preparation. Plasma was obtained by centrifugation $\left(800 \times g\right.$ for 10 minutes at $4^{\circ} \mathrm{C}$ ) and stored at $-80^{\circ} \mathrm{C}$ until analysis. Urine samples were collected in sterile containers and two $10 \mathrm{ml}$ aliquots of urine were stored at $20^{\circ} \mathrm{C}$ until further analysis. Plasma, urine and breath samples of one patient, gathered before and after rehabilitation, were processed in the same run for (bio)chemical analyses.

\section{Comet Assay}

The comet assay (single-cell gel electrophoresis) was adapted from the method of Singh and colleagues (15) with minor modifications. After removal of the plasma ( $800 \mathrm{xg}$ for 10 minutes at $4^{\circ} \mathrm{C}$ ), the volume of the remaining blood was brought to 
$15 \mathrm{ml}$ with cold phosphate-buffered saline (PBS) and layered on an equal volume of Lymphoprep medium in a $50 \mathrm{ml}$ tube with a filter (Greiner) of peripheral blood mononuclear cells (PBMCs). After centrifugation at $800 \times g$ for 30 minutes at $4^{\circ} \mathrm{C}$, gradient-separated PBMCs were recovered, resuspended in $10 \mathrm{ml}$ cold PBS and centrifuged again at $250 \times \mathrm{g}$ for 10 minutes at $4^{\circ} \mathrm{C}$. The cells were resuspended in 1 $\mathrm{ml}$ cold PBS. For the analysis of DNA damage, $10 \mu \mathrm{l}$ of the cell suspension was mixed with $90 \mu \mathrm{l}$ of $1 \%$ low-melting-point agarose (LMPA) of $37^{\circ} \mathrm{C}$ and layered onto pre-chilled agarose-coated (1.5\% agarose in PBS) microscope slides. The slides were covered with a coverslip and kept at $4^{\circ} \mathrm{C}$ for 5 minutes to allow the LMPA to solidify. Then the coverslips were removed and the slides were immersed in a jar containing cold lysing solution (2.5 M NaCl, $100 \mathrm{mM} \mathrm{Na}_{2}$ EDTA, $10 \mathrm{mM}$ Tris (pH 10), $1 \%$ Triton $\mathrm{X}-100,10 \% \mathrm{DMSO}$ ). For reasons of stability of the DNA during lysis, the PBMCs were kept at $4^{\circ} \mathrm{C}$ for a period of maximally 6 weeks (16). All samples of one patient taken before rehabilitation were processed in one run, and samples taken after rehabilitation in a separate run. After lysis, the slides were drained and placed in a horizontal ice-cold electrophoresis box filled with fresh alkaline electrophoresis buffer of $4^{\circ} \mathrm{C}\left(10 \mathrm{~N} \mathrm{NaOH}, 200 \mathrm{mM} \mathrm{Na}_{2} \mathrm{EDTA} \mathrm{pH} 12.5-13.5\right)$ for 20 minutes to allow for DNA unwinding and expression of alkali-labile sites. The electrophoresis was subsequently conducted at $4^{\circ} \mathrm{C}$, for 20 minutes, at $25 \mathrm{~V}$ and $300 \mathrm{~mA}$. After electrophoresis, the slides were washed three times with cold neutralization buffer $(0.4 \mathrm{M}$ Tris $\mathrm{pH} 7.5$ ) and stored at $4^{\circ} \mathrm{C}$ until further analysis. All of these steps were conducted under dim light to prevent the occurrence of additional DNA damage. For microscope analysis, $50 \mu \mathrm{l}$ ethidium bromide $(20 \mu \mathrm{g} / \mathrm{ml})$ was added to each slide and fifty randomly selected cells were analysed from each sample. Comet measurements were made by image analysis using a fluorescence microscope and the Comet Assay III software (Perceptive Instruments). ROS-induced DNA damage was measured as tail moment (based on the product of the percentage of DNA in the tail and tail length). A representative comet image is shown in Figure E1 in the online supplement. Median, mean and standard error of the mean of tail moment were calculated from each sample. Median of each sample was taken since data had a non-normal distribution. 


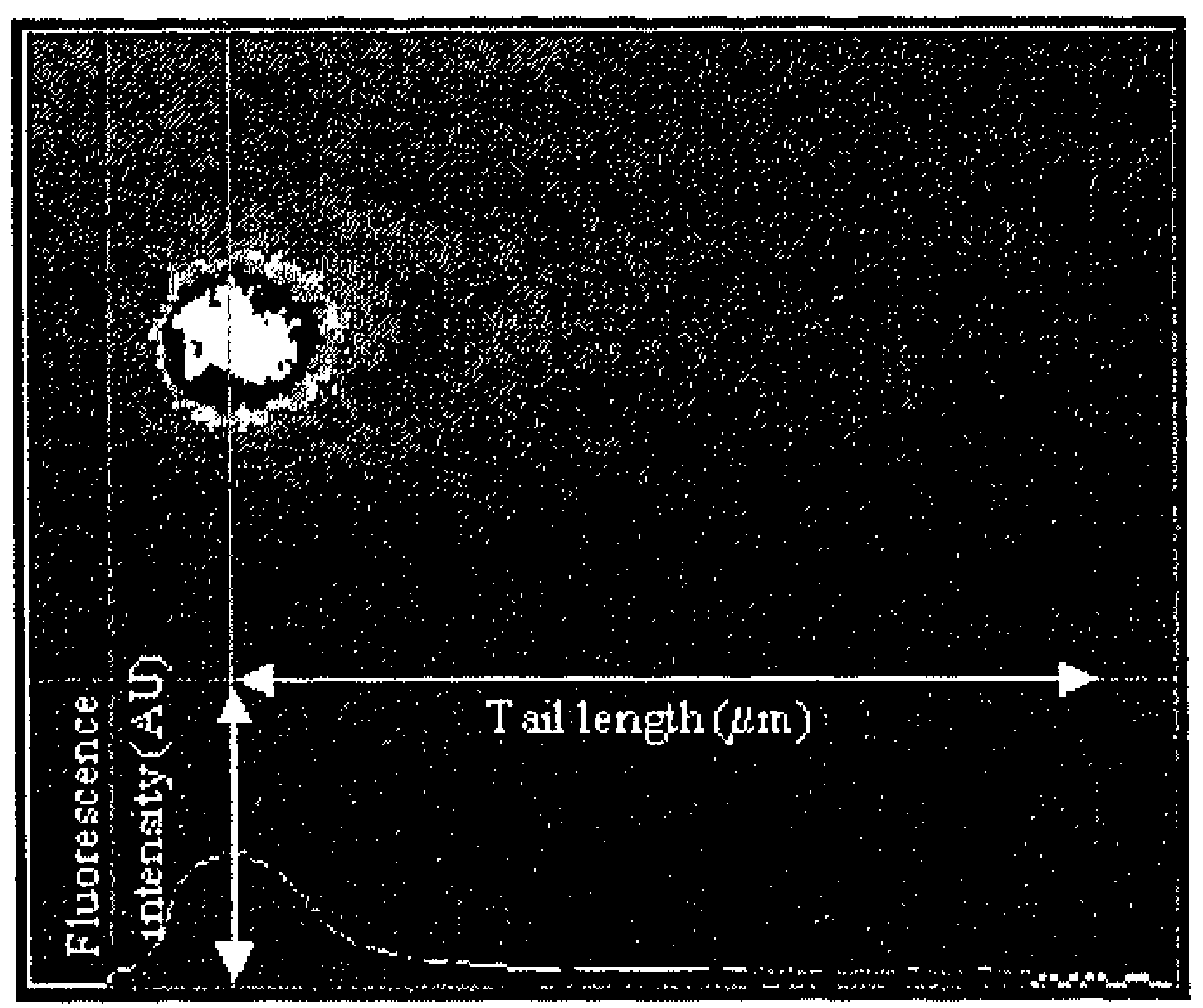

Online Figure E1. Representative comet image and comet measurements Tail Moment $=$ Tail Length $(\mu \mathrm{m}){ }^{*}$ Tail DNA (\%) (Tail DNA = Tail fluorescence / Total fluorescence)

\section{MDA in Plasma and Urine}

The determination of MDA was assayed by measuring TBARs according to the high-performance liquid chromatography (HPCL) method described by Lepage et al. (17). The urinary MDA concentration was corrected for creatinine content. Creatinine in urine samples was measured in triplicate using the Jaffé reaction as previously described (18). The values of MDA in urine are expressed per mmol creatinine. Additional details for these measurements are provided in the online supplement.

\section{Plasma Uric Acid}

An aliquot of $150 \mu$ of plasma was deproteinized with $10 \%(w / v)$ trichloroacetic acid (TCA), centrifuged and uric acid was assayed by a HPLC method described by Lux et al. (19) using a Hypersil BDS C18 end-capped column (125 x $4 \mathrm{~mm}$, particle size $\mu \mathrm{m}$, Agilent). Additional details on this method are available in the online supplement.

\section{Collection of EBC and Measurement of $\mathrm{H}_{2} \mathrm{O}_{2}$}

The collection of EBC was performed using a commercially available condenser as previously described (20). Participants were asked to breath at a normal frequency and tidal volume for a period of 10 minutes. The EBC samples were immediately divided into aliquots, stored at $-80^{\circ} \mathrm{C}$ and thawed at room temperature just before analysis.

EBC $\mathrm{H}_{2} \mathrm{O}_{2}$ was measured by means of horseradish peroxidase-catalysed oxidation of tetramethylbenzidine according to the method previously described by Gallati and 
Pracht and modified for microtiter plate-based analysis (21). All samples were measured in duplicate and a separate standard curve for $\mathrm{H}_{2} \mathrm{O}_{2}$ was constructed for each assay. Mean values were used for subsequent statistical analysis. Additional detail on the method for making these measurements is provided in the online supplement.

\section{Statistical Analyses}

All data are expressed as mean \pm SEM. Between-group comparisons were analysed using the Mann-Whitney U-test. The Wilcoxon signed rank-test was used to evaluate the effect of the maximal and submaximal exercise-induced oxidative stress response within the groups and the effect of pulmonary rehabilitation on oxidative stress in COPD patients. Non-parametric tests were used because the normality assumption was not obtained. A difference with $p<0.05$ was considered statistically significant. Statistical analyses were analyzed with SPSS for Windows (Version 11.0; SPSS Inc., Chicago, II, USA).

\section{RESULTS}

\section{Anthropometric and Spirometric Data}

As shown in table 1, anthropometric data were not significantly different between COPD patients and control participants. The COPD group showed a moderate to severe airflow obstruction with an $\mathrm{FEV}_{1}$ of $39.4 \pm 4.1 \%$ predicted. In patients, FVC, TLC and RV were significantly $(p<0.05)$ improved after rehabilitation, while BMI and FFMI were not significantly different and within the normal range (12). The Pam Score for healthy controls classified them moderately active, whereas the COPD patients had a low activity level (Table E1 in the online supplement). Physical activity level of COPD patients was significantly $(+19 \%, p<0.05)$ increased after rehabilitation. 
Table 1. Characteristics of healthy control subjects and patients with chronic obstructive pulmonary disease before and after the pulmonary rehabilitation program

\begin{tabular}{|c|c|c|c|c|}
\hline & $\begin{array}{l}\text { Healthy Control } \\
\text { Subjects }\end{array}$ & $\begin{array}{l}\text { Patients with } \\
\text { COPD }\end{array}$ & COPD before & COPD after \\
\hline Sex, M/F & $5 / 6$ & $6 / 5$ & & \\
\hline Age, years & $59.7 \pm 1.5$ & $56.7 \pm 2.0$ & & \\
\hline Pack-years of smoking & $1.9 \pm 3.6$ & $33.2 \pm 3.7^{*}$ & & \\
\hline Pam Score & $34.2 \pm 6.8$ & & $14.5 \pm 2.5^{\dagger}$ & $17.2 \pm 2.8^{\ddagger}$ \\
\hline BMI, $\mathrm{kg} / \mathrm{m}^{2}$ & $26.3 \pm 1.1$ & & $25.6 \pm 1.6$ & $25.6 \pm 1.3$ \\
\hline FFMI, $\mathrm{kg} / \mathrm{m}^{2}$ & $18.7 \pm 0.9$ & & $17.5 \pm 0.7$ & $17.4 \pm 0.5$ \\
\hline $\mathrm{FEV}_{1}, \%$ predicted & $111.1 \pm 4.6$ & & $39.4 \pm 4.1^{*}$ & $43.8 \pm 4.6$ \\
\hline FVC, $\%$ predicted & $117.2 \pm 5.6$ & & $76.6 \pm 3.2^{*}$ & $93.1 \pm 4.9^{\S}$ \\
\hline TLC, $\%$ predicted & & & $136.5 \pm 5.4$ & $131.4 \pm 6.3^{\ddagger}$ \\
\hline RV, \% predicted & & & $230.1 \pm 19.7$ & $198.7 \pm 14.8^{8}$ \\
\hline DLco, \% predicted & & & $61.1 \pm 5.9$ & $74.0 \pm 9.5$ \\
\hline
\end{tabular}

Definition of abbreviations: $\mathrm{BMI}=$ body mass index; $\mathrm{COPD}=$ chronic obstructive pulmonary disease DLCO = diffusion capacity; FFMI = fat-free mass index; Pam = Physical Activity Monitor; RV = residual volume; $T L C=$ total lung capacity. Data are presented as mean \pm SEM. *Significant difference compared with the healthy control subjects, $p<0.001$ (Mann-Whitney). ${ }^{\dagger}$ Significant difference compared with the healthy control subjects, $p<0.01$ (Mann-Whitney). ${ }^{\ddagger}$ Significant difference compared with values before rehabilita-

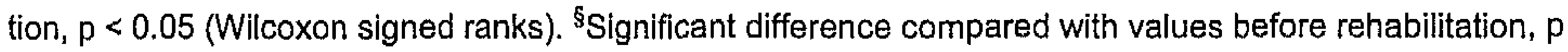
$<0.01$ (Wilcoxon signed ranks).

\section{Exercise Capacity}

The results of both exercise tests are presented in Table 2. One patient was excluded from the submaximal exercise test because of respiratory infection, which occurred a few days after the maximal exercise test. As expected, exercise capacity was severely impaired in the COPD patients when compared with healthy controls $(p<0.001)$. Also peak lactate was significantly lower in COPD patients than in healthy controls $(p<0.01)$. Nevertheless, the COPD patients exceeded their maximum voluntary ventilation ( $\mathrm{E} / \mathrm{MVV}>100 \%$ ), as a consequence of their ventilatory limitation, maximum exercise intensity was reached, whereas the heart rate reserve was preserved. The healthy controls were within the normal range for these two parameters. Additional details on these measurements are provided in the online supplement. The COPD patients responded to the rehabilitation program by a significant increase in peak workload $(+24 \%, p<0.01)$, maximal $\mathrm{VO}_{2}(+19 \%, p<$ $0.05)$ and exercise duration time $(+73 \%, p<0.05)$. 
Table 2. Exercise characteristics of healthy control subjects and patients with chronic obstructive pulmonary disease before and after the pulmonary rehabilitation program

\begin{tabular}{|c|c|c|c|}
\hline & \multicolumn{3}{|l|}{ Healthy control } \\
\hline & Subjects & COPD Before & COPD After \\
\hline & $(n=11)$ & $(n=11)$ & $(n=11)$ \\
\hline \multicolumn{4}{|l|}{ Incremental exercise } \\
\hline Peak workload, watt & $201.7 \pm 16.6$ & $68.3 \pm 7.4^{*}$ & $84.8 \pm 8.8^{\ddagger}$ \\
\hline Peak $\mathrm{O}_{2}, \mathrm{~mL} / \mathrm{min}$ & $2120 \pm 182$ & $1060 \pm 74^{*}$ & $1265 \pm 83^{\S}$ \\
\hline Peak lactate, $\mathrm{mmol} / \mathrm{L}$ & $5.9 \pm 0.6$ & $3.1 \pm 0.4^{\dagger}$ & $3.2 \pm 0.5$ \\
\hline Peak HR, beat/min & $159 \pm 4$ & $126 \pm 9^{\dagger}$ & $129 \pm 7$ \\
\hline HRreserve, \% & $0.3 \pm 2.5$ & $22.7 \pm 5.0^{\star}$ & $20.3 \pm 3.6$ \\
\hline Peak $E_{1} L / m i n$ & $81.0 \pm 7.2$ & $45.4 \pm 3.8^{\star}$ & $53.6 \pm 4.7$ \\
\hline Peak $r$ E/MVV & $0.66 \pm 0.04$ & $1.21 \pm 0.15^{*}$ & $1.26 \pm 0.13$ \\
\hline \multicolumn{4}{|c|}{ Constant work-rate exercise } \\
\hline Duration time, minutes & $11.5 \pm 0.5$ & $12.2 \pm 3.3$ & $21.2 \pm 3.6^{5}$ \\
\hline $\mathrm{rO}_{2}, \mathrm{~mL} / \mathrm{min}$ & $1700 \pm 160$ & $986 \pm 88^{\dagger}$ & $1082 \pm 78$ \\
\hline$\Delta$ Lactate, $\mathrm{mmol} / \mathrm{L}$ & $2.4 \pm 0.4$ & $2.1 \pm 0.8$ & $1.2 \pm 0.4$ \\
\hline$H R$, beat/min & $140.1 \pm 4.0$ & $126.4 \pm 10.9$ & $125.0 \pm 12.2$ \\
\hline
\end{tabular}

Definition of abbreviations: $\mathrm{COPD}=$ chronic obstructive pulmonary disease; $\mathrm{HR}=$ heart rate; $\mathrm{MVV}=$ maximum voluntary ventilation. Data are presented as mean \pm SEM. "Significant difference compared with the healthy control subjects, $p<0.001$ (Mann-Whitney). ${ }^{\dagger}$ Significant difference compared with the healthy control subjects, $p<0.01$ (Mann-Whitney). ${ }^{\ddagger}$ Significant difference compared with before rehabilitation, $p<0.02$ (Wilcoxon signed ranks). ${ }^{\S}$ Significant difference compared with before rehabilitation, $p<0.02$ (Wilcoxon signed ranks)

Oxidative Stress Markers compared between Patients with COPD and Healthy Control Subjects

\section{Systemic and pulmonary oxidative stress markers at rest}

Because of variation between electrophoresis runs, it is not possible to apply data for detection of differences in baseline values between patients and control subjects for ROS-induced DNA damage. Baseline values of plasma MDA were not significantly different between both groups. In contrast, urinary MDA excretion was significantly higher in the COPD patients compared with the healthy controls $(p<0.05$ respectively; Table 3). No significant difference in the baseline values of plasma uric acid was found between both groups (Table 3). $\mathrm{H}_{2} \mathrm{O}_{2}$ in breath condensate, considered to be a pulmonary oxidative stress marker, was also significantly increased in the COPD patients compared to the healthy controls at baseline $(p<0.05$; Table 3$)$. 
Chapter 2

Table 3. Oxidative stress markers in healthy age-matched control subjects and patients with chronic obstructive pulmonary disease at rest

\begin{tabular}{lcc}
\hline & $\begin{array}{c}\text { Healthy control } \\
\text { Subjects } \\
(n=11)\end{array}$ & $\begin{array}{c}\text { COPD } \\
(n=11)\end{array}$ \\
\hline Plasma MDA, $\mu \mathrm{mol} / \mathrm{L}$ & $0.47 \pm 0.03$ & $0.56 \pm 0.07$ \\
Urinary MDA, $\mu \mathrm{mol} / \mathrm{mmol}$ creatinine & $0.28 \pm 0.04$ & $0.38 \pm 0.02^{*}$ \\
Plasma Uric acid, $\mu \mathrm{M}$ & $238 \pm 17$ & $279 \pm 22$ \\
Exhaled $\mathrm{H}_{2} \mathrm{O}_{2}, \mu \mathrm{mol} / \mathrm{min}$ & $0.005 \pm 0.001$ & $0.020 \pm 0.041^{\circ}$ \\
\hline
\end{tabular}

Definition of abbreviations: $\mathrm{COPD}=$ chronic obstructive pulmonary disease; MDA = malondialdehyde. Data are presented as mean \pm SEM of the two baseline values measured in both groups. *Significant difference compared with the healthy control subjects, $p<0.05$ (Mann-Whitney).

\section{Exercise-induced systemic and pulmonary oxidative stress}

The comet assay was applied to measure ROS-induced DNA damage (tail moment) in PBMCs. In COPD patients, a significant increase in ROS-induced DNA damage was observed immediately after the maximal exercise test, which was not returned to baseline values after 4 hours $(p<0.05$; Figure 1$)$. After the submaximal exercise test, the same pattern of DNA damage was seen ( $p<0.01$; Figure 1$)$. In contrast, no significant effect for ROS-induced DNA damage was found after both exercise tests for the control group (Figure 1).

\section{Maximal exercise}

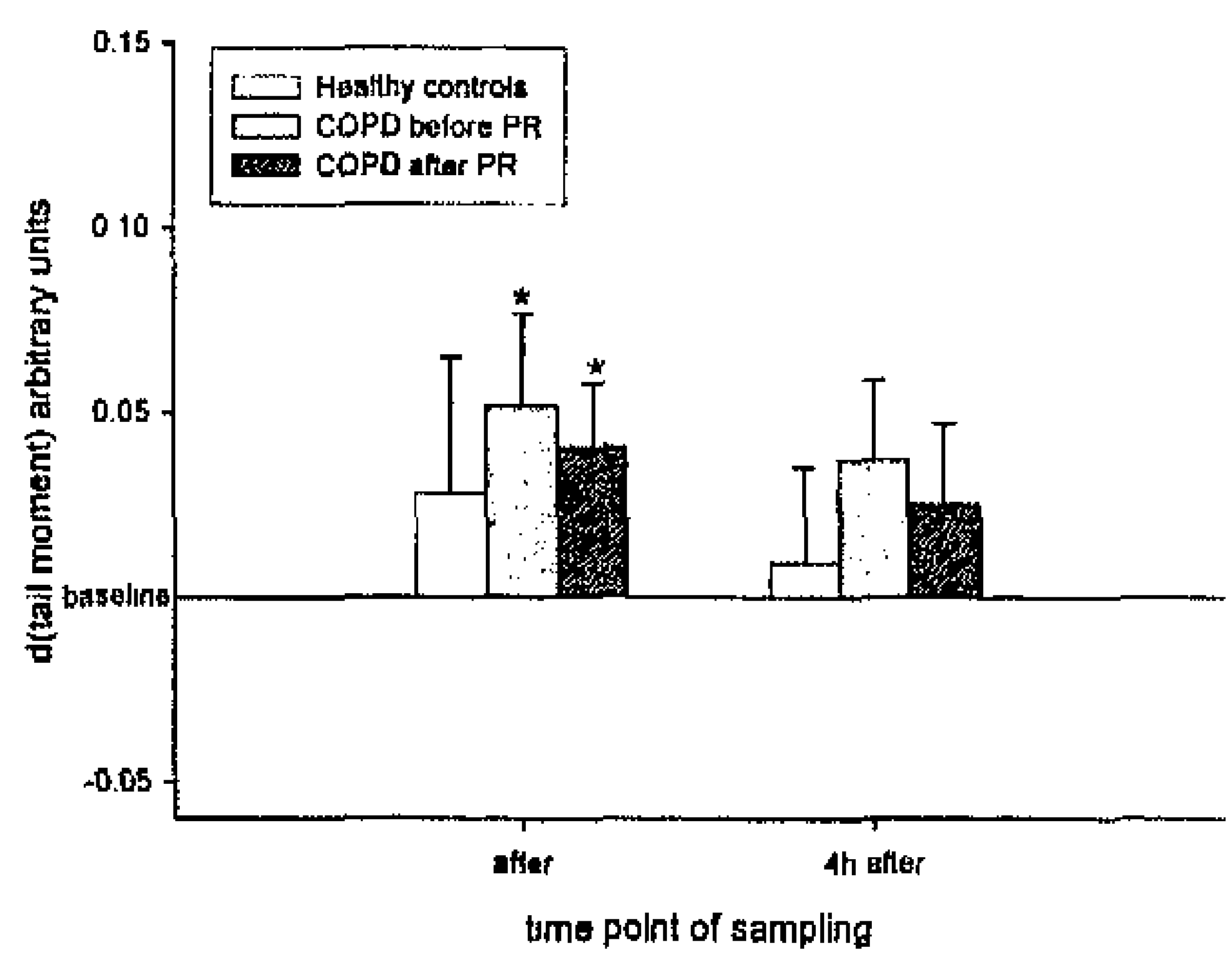

\section{Submaximal exercise}

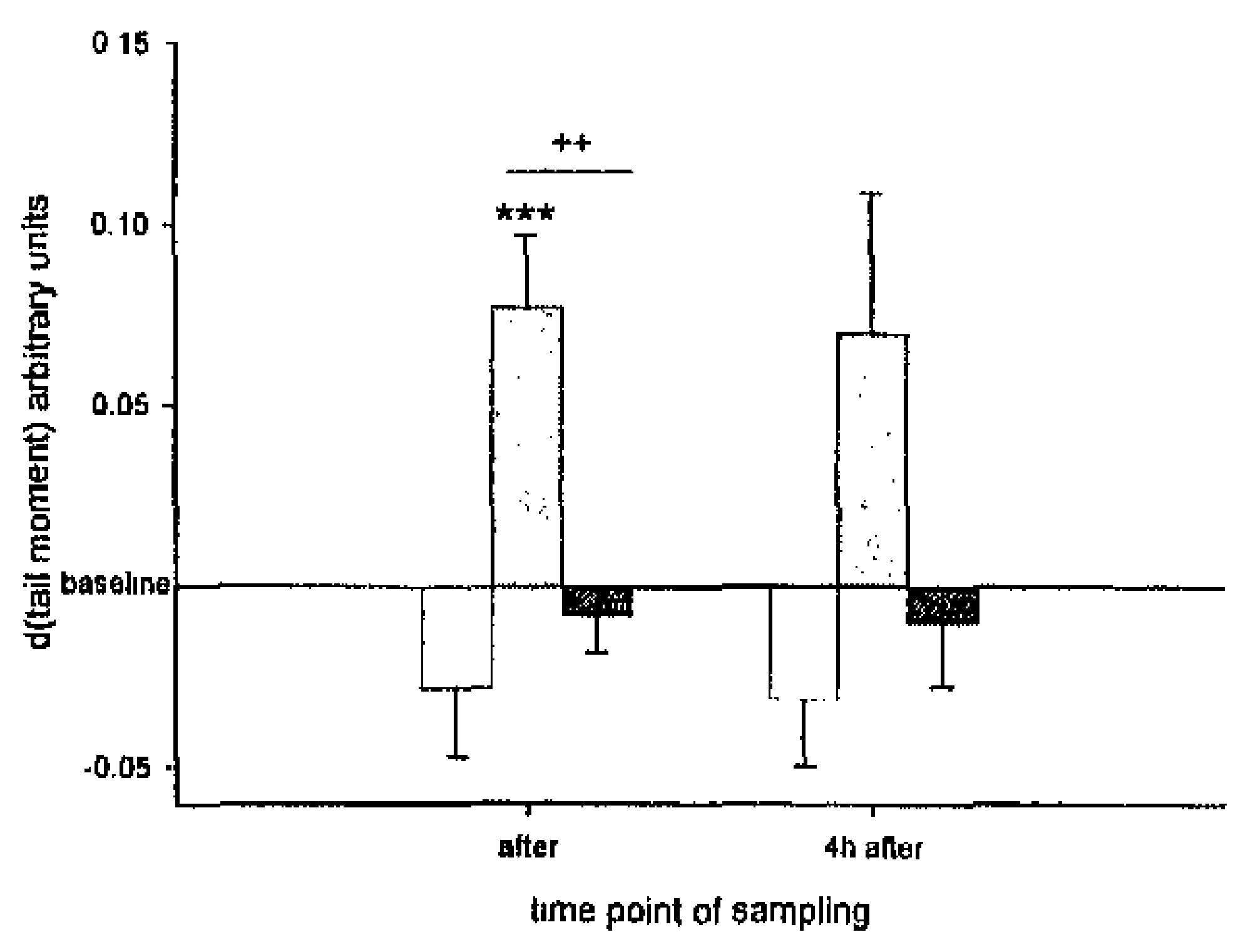

Figure 1. Reactive oxygen species-induced DNA damage (tail moment) in peripheral blood mononuclear cells before and after pulmonary rehabilitation (PR) at different time points after the maximal and submaximal exercise test. Data represent differences with baseline values. Values are expressed as mean \pm SEM. $p<0.05 ; " p<0.01$ significantly different from baseline values (Wilcoxon signed ranks); ${ }^{++} p<0.02$ significantly different from values before PR (Wilcoxon signed ranks). COPD = chronic obstructive pulmonary disease. 
In addition to measurements of MDA in plasma, we also determined MDA in urine since urinary MDA is considered to be a marker of 'whole body' oxidative stress. We found no significant increase in plasma MDA after the maximal or submaximal exercise test for both groups (data not shown). Conversely, immediately after and 4 hours after the maximal exercise test, the concentration of MDA in urine was significantly elevated in the COPD patients $(p<0.05, p<0.02$ respectively; Figure 2$)$. Also, immediately after the submaximal exercise test we observed a significant increase in urinary MDA ( $p<0.05$; Figure 2). In healthy controls, a significant increase in urinary MDA was found only 4 hours after both exercise tests $(p=0.05$; Figure 2).

\section{Maximal exercise}

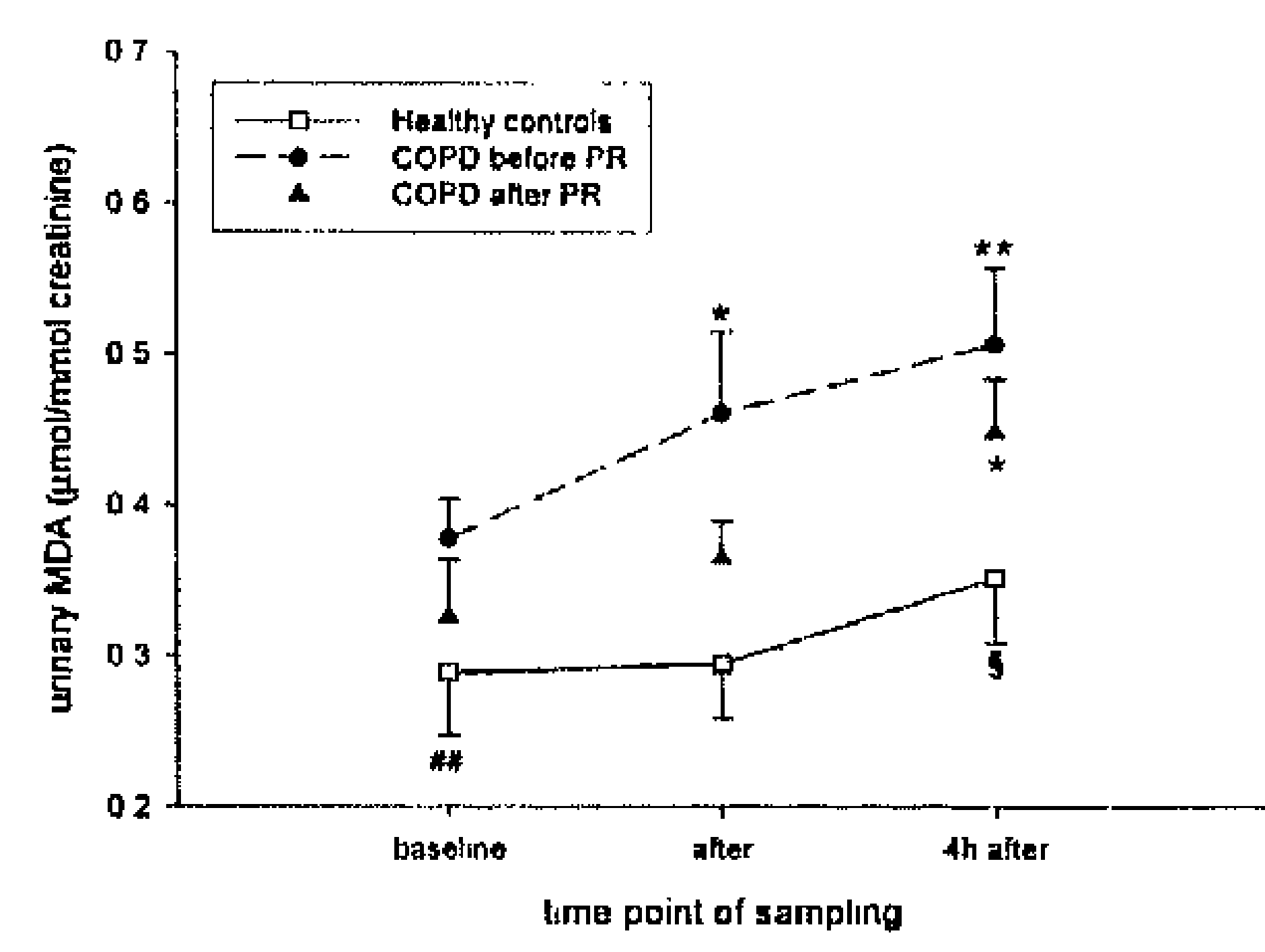

\section{Submaximal exercise}

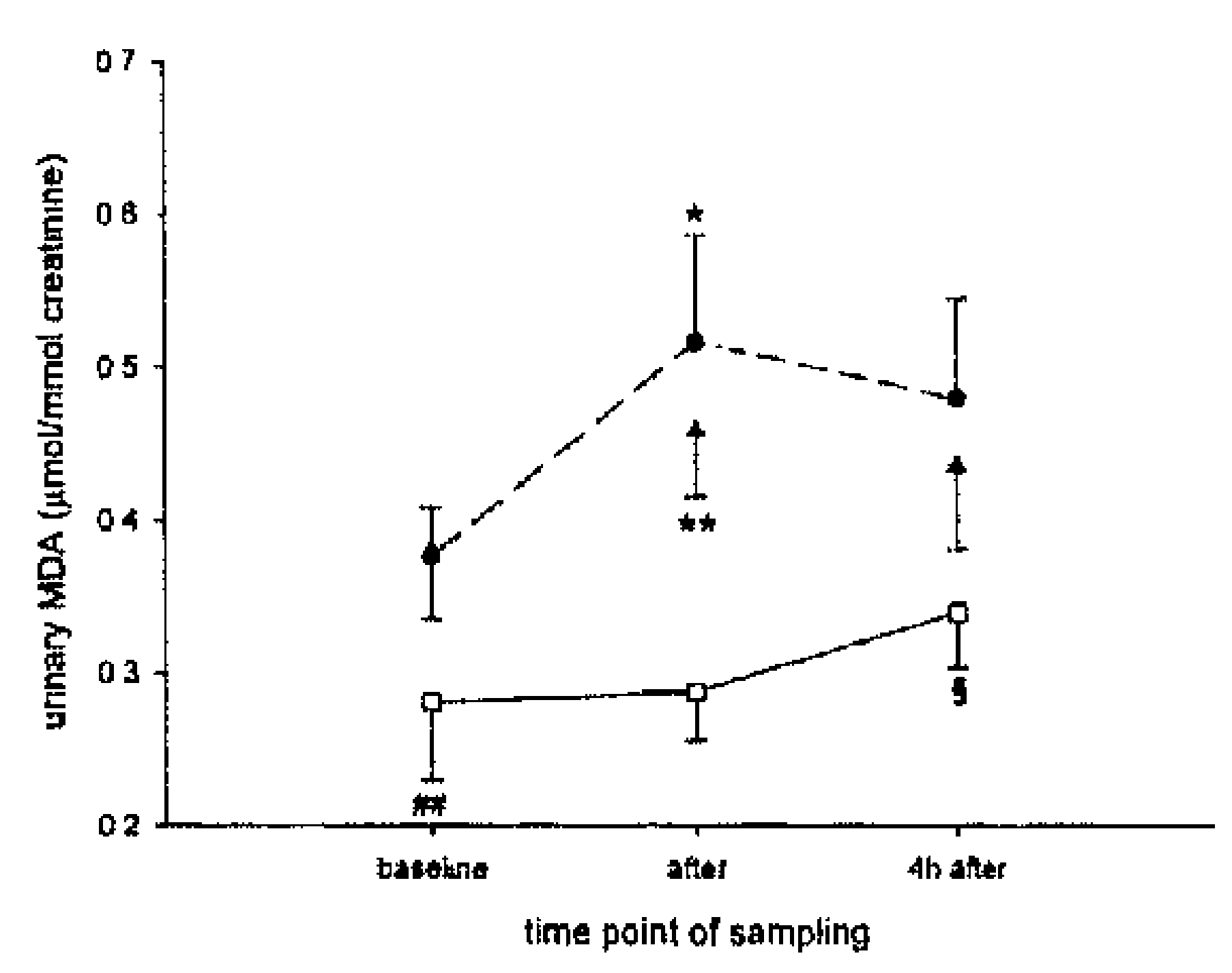

Figure 2. Concentration of urinary malondialdehyde (MDA) before and after pulmonary rehabilitation $(P R)$ at different time points after the maximal and submaximal exercise test. Values are expressed as mean \pm SEM. " $p<0.05 ; " p<0.02 ;{ }^{\S} p=0.05$ significantly different from baseline values (Wilcoxon signed ranks); ${ }^{\prime} p<0.02$ significantly different between healthy control subjects and subjects with COPD before PR (Mann-Whitney). There were no statistically significant differences between values before and after PR.

Plasma uric acid was assessed as a marker of xanthine-oxidase activity. Plasma uric acid in COPD patients was significantly increased 4 hours after the maximal and submaximal exercise tests ( $p<0.01 ; p<0.05$ respectively; Figure 3 ). In healthy controls, a significant increase was observed only 4 hours after the maximal exercise test, while immediately after the submaximal exercise test a significant decrease in plasma uric acid was found ( $<<0.02 ; p<0.01$ respectively; Figure 3 ). Moreover, the exercise-induced increase in plasma uric acid was significantly different between COPD patients and healthy controls immediately after and 4 hours after the submaximal exercise test $(p<0.05$, Figure 3$)$. 


\section{Maximal exercise}

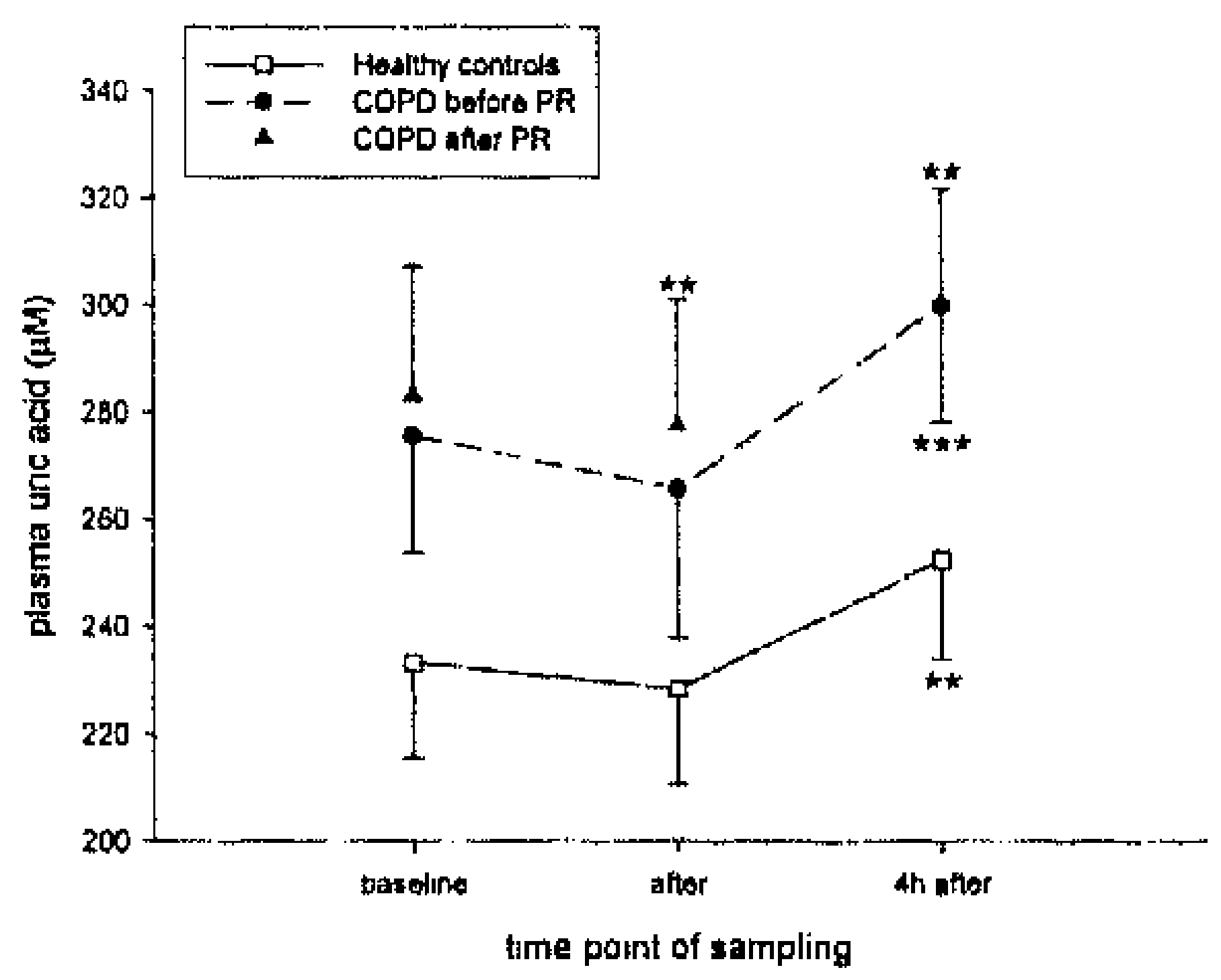

\section{Submaximal exercise}

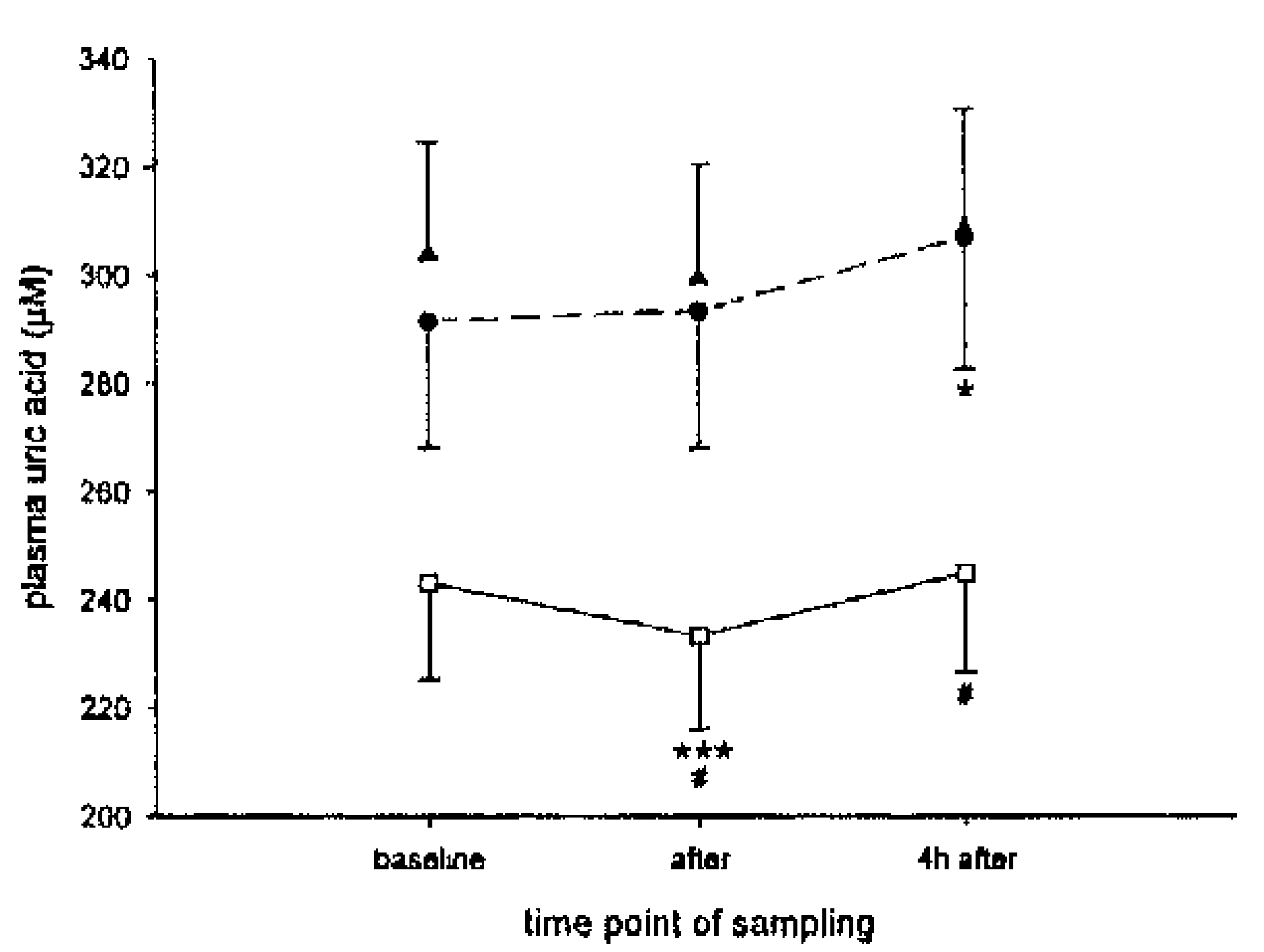

Figure 3. Concentration of plasma uric acid before and after pulmonary rehabilitation (PR) at different time points after the maximal and submaximal exercise test. Values are expressed as mean \pm SEM. $p<0.05 ; " p<0.02 ; "$ p $<0.01$ significantly different from baseline values (Wilcoxon signed ranks); $" \mathrm{p}<0.05$ significantly different between healthy control subjects and subjects with COPD before PR (Mann-Whitney). There were no statistically significant differences between values before and after PR.

Exhaled $\mathrm{H}_{2} \mathrm{O}_{2}$ was determined as an index of exercise-induced pulmonary oxidative stress. In COPD patients, mean production of $\mathrm{H}_{2} \mathrm{O}_{2}$ was significantly elevated 4 hours after the maximal exercise test relative to baseline, whereas for healthy controls a significant increase was observed immediately after the maximal exercise test $(p<0.02 ; p<0.05$ respectively; Figure 4$)$. In contrast, we found no significant effect on exhaled $\mathrm{H}_{2} \mathrm{O}_{2}$ production after the submaximal exercise test for both groups (Figure 4). Exhaled $\mathrm{H}_{2} \mathrm{O}_{2}$ production was significantly different between patients and controls 4 hours after both exercise tests $(p<0.01 ; p<0.05$ respectively; Figure 4). 


\section{Maximal exercise}

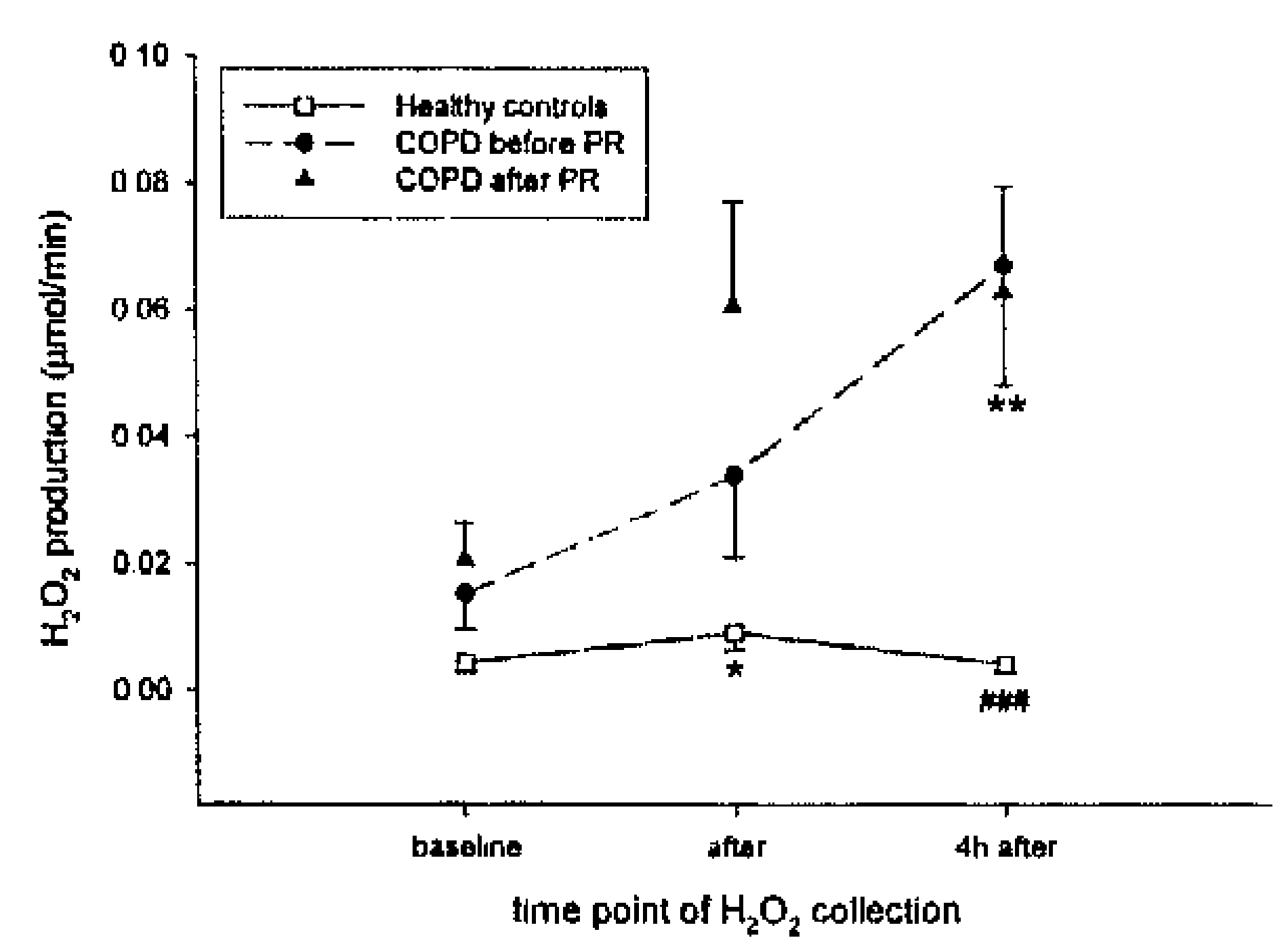

\section{Submaximal exercise}

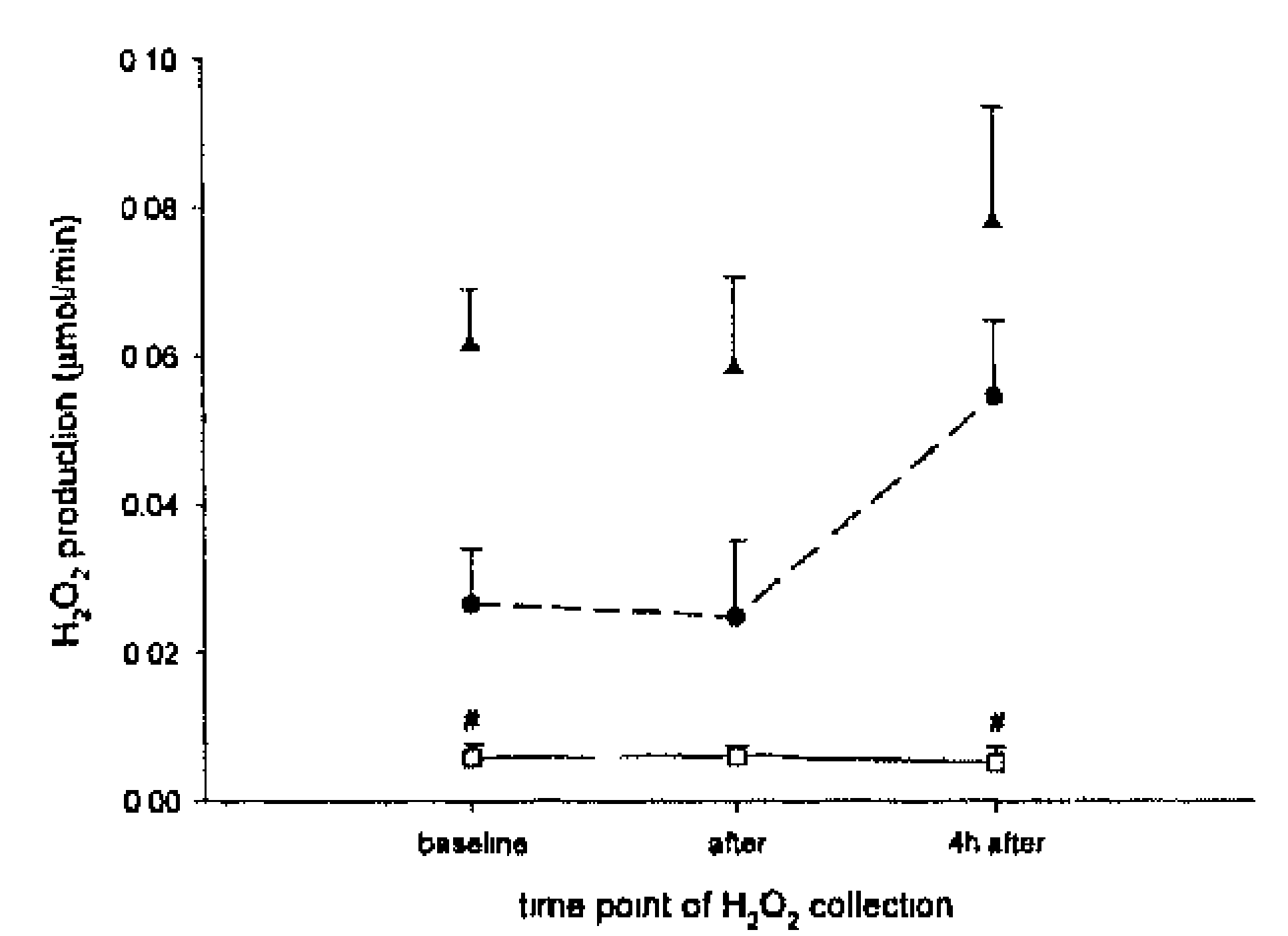

Figure 4. Production of hydrogen peroxide $\left(\mathrm{H}_{2} \mathrm{O}_{2}\right)$ measured in exhaled breath condensate before and after pulmonary rehabilitation (PR) at different time points after the maximal and submaximal exercise test. Values are expressed as mean \pm SEM. $p<0.05 ; " p<0.02$ significantly different from baseline values (Wilcoxon signed ranks); ${ }^{\#} p<0.05$; $p<0.01$ significantly different between healthy control subjects and subjects with COPD before PR (Mann-Whitney). There were no statistically significant differences between values before and after PR.

\section{Exercise-induced Oxidative Stress after Rehabilitation in Patients with COPD}

A significant increase in ROS-induced DNA damage was found immediately after the maximal exercise test $(p<0.05$; Figure 1$)$, which was similar to values observed before rehabilitation. In contrast to the data obtained before rehabilitation, we found no significant increase of ROS-induced DNA damage after the submaximal exercise test (Figure 1). Moreover, the differences with baseline values immediately after the submaximal exercise were significantly lower compared to values obtained before rehabilitation $(p<0.02$; Figure 1).

After rehabilitation, we found no significant increase in plasma MDA after the maximal and submaximal exercise test (data not shown). For the maximal exercise test, we only observed a significant effect of urinary MDA 4 hours after exercise, whereas immediately after the submaximal exercise test a significant effect was found $(p<$ $0.05 ; p<0.02$ respectively; Figure 2). After rehabilitation, changes in plasma uric acid found after the maximal exercise test were similar to those observed before rehabilitation. In contrast to data obtained before rehabilitation, we detected no significant increase in plasma uric acid after the submaximal exercise test (Figure 3).

In addition, we observed no significant increase in pulmonary $\mathrm{H}_{2} \mathrm{O}_{2}$ production after the maximal and submaximal exercise test. Remarkably, baseline values of the submaximal exercise test were significantly higher when compared with baseline values of the maximal exercise test $(p<0.01$; Figure 4$)$. 


\section{DISCUSSION}

Oxidative Stress Markers Compared between Patients with COPD and Healthy Control Subjects

\section{Systemic and pulmonary oxidative stress markers at rest.}

In the present study, the resting values of plasma MDA were not significantly different between both groups. This result is in agreement with previous studies $(2,22)$. In contrast, increased oxidative stress at rest was observed in COPD patients compared to healthy age-matched controls, as measured by urinary MDA. Plasma and urinary MDA, biomarkers of lipid peroxidation induced by oxidative stress, were determined using HPLC which allows a good separation between MDA-TBA and other TBARs and minimizes spectrophotometric interference (23). In accordance with other studies, the pulmonary oxidative stress marker $\mathrm{H}_{2} \mathrm{O}_{2}$ in breath condensate was significantly higher in the COPD patients $(4,24,25)$. This implies that COPD patients have a persistent increased pulmonary oxidative burden. Although statistical significance was not reached, plasma uric acid concentration was slightly increased in the COPD patients.

\section{Exercise-induced systemic and pulmonary oxidative stress.}

This study is the first to demonstrate a significant increase in ROS-induced DNA strand breaks in PBMCs of COPD patients after exercise. In contrast, in the healthy controls, no significant increase in ROS-induced DNA damage was observed after both exercise tests. The comet assay has already been applied to evaluate systemic oxidative stress in healthy participants at various intensities and durations of exercise. Several studies have demonstrated exercise-induced DNA damage at 2472 hours following exhaustive treadmill running or a marathon race (26-28). It was also reported that no enhanced DNA damage was found in healthy controls after moderate exercise that did not exceed the anaerobic threshold (29). The fact that DNA damage in this study was found immediately after exercise in COPD patients indicates that it is likely to be a consequence of exercise-induced ROS (30). This is remarkable because in previous studies with healthy participants oxidative DNA damage was detected at later time points after exercise suggesting that it might be a consequence of exercise-induced tissue injury and inflammation $(26,27,29,31)$. In the present study, we found no significant changes in plasma MDA from baseline values after the maximal and submaximal exercise test, in contrast to reports (1-3) that indicate increased plasma MDA after exercise in COPD patients. Exercise had no significant effects either on plasma MDA in the healthy controls. Results from earlier studies investigating the changes in plasma MDA after exercise have also been inconclusive, some studies showed an effect of exercise on plasma MDA (32, 
$33)$, whereas other studies found no effect $(34,35)$. Possible explanations for the discrepancy may be due to the methodologies used in the different studies, the time points examined, level of training of the participants or differences in exercise conditions. Our results indicate that the ROS production during both exercise tests was not extensive enough to detect a significant increase in plasma MDA after exercise, because once aldehydes, like MDA, are formed and enter the circulation they are rapidly excreted.

In contrast to plasma levels, in COPD patients, the MDA excretion in urine, as a marker of 'whole body' oxidative stress, was significantly elevated immediately after both exercise tests and also 4 hours after the maximal exercise test, providing evidence for exercise-induced oxidative damage. Potential sources for increased ROS generation during exercise include leakage from the mitochondrial electron transport system (36), the xanthine oxidase/dehydrogenase system $(1,37)$ and the inflammatory response. In healthy controls, a significant increase was observed only 4 hours after both exercise tests. This delayed effect on urinary MDA excretion after exercise might be related to exercise-induced tissue injury. Until now, no other studies have examined the effect of exercise on urinary MDA in COPD patients. In the present study, the absence of an immediate exercise-induced systemic oxidative stress response in healthy controls is probably due to the fact that the duration of the exercise tests was too short to cause immediate exercise-induced oxidative damage. The duration of the submaximal exercise test in the control group was standardized at 12 minutes, since otherwise the difference in duration could have been too large compared to the COPD patients. It is also likely that in healthy controls the antioxidant defence system is able to cope with an increased production of ROS generated by those two exercise tests. However, in patients with COPD, apparently the antioxidant defence system can be overwhelmed by the ROS leading to an increased systemic oxidative stress response after exercise.

In our study, plasma uric acid, as a marker of xanthine oxidase activity, was significantly increased 4 hours after the maximal and submaximal exercise test, whereas in healthy controls, a significant increase was observed only 4 hours after the maximal exercise test. This finding is consistent with previous studies reporting increased plasma uric acid in response to strenuous exercise in healthy controls $(38,39)$. It is expected that the activation of xanthine oxidase is more prominent for the maximal exercise test, since during strenuous exercise, in combination with insufficient oxygen supply, ATP is consumed faster than it can be regenerated, resulting in a build-up of AMP. Further, in the muscle cells, AMP is continuously degraded to hypoxanthine that may be converted to xanthine and subsequently to uric acid by xanthine oxidase. Xanthine oxidase uses molecular oxygen as an electron acceptor resulting in the formation of superoxide radicals (40). Whereas under aerobic conditions, this reaction may be catalysed by xanthine dehydrogenase, which uses NAD as electron acceptor, rather than xanthine oxidase (41). In 
addition, immediately after the submaximal exercise test a significant decrease in plasma uric acid was observed in healthy controls. This was reported earlier by Hellsten et al. (38) who found that uric acid was extracted by the muscle immediately after termination of strenuous exercise, in part via uptake from plasma.

In the present study, we observed that $\mathrm{H}_{2} \mathrm{O}_{2}$ concentration in the EBC of COPD patients was significantly increased 4 hours after the maximal exercise test, whereas in healthy controls a slight, but significant increase immediately after maximal exercise was found, indicating an enhanced production of ROS in the airways of these participants. In contrast, we found no significant increase after the submaximal exercise test for both groups. This suggests that exercise-induced pulmonary oxidative stress measured by $\mathrm{H}_{2} \mathrm{O}_{2}$ seems to be more related to exercise intensity than to duration. A likely explanation for this effect can be attributed to the differences in pulmonary ventilatory recruitment between the maximal and submaximal exercise test. As ventilatory demands increase more during the maximal compared to the submaximal exercise test, patients with COPD tend to breath more shallow and with higher frequency, resulting in dynamic lung hyperinflation. This results in increased physiologic dead space ventilation, which is attendant with a drop in alveolar oxygen partial pressure, causing hypoxia. Consequently, decreased alveolar oxygen could induce lung inflammation (42-44), which may lead to the increased $\mathrm{H}_{2} \mathrm{O}_{2}$ production that was observed in COPD patients 4 hours after the maximal exercise test. Earlier, Schleiss et al. (45) reported that the hydrogen peroxide concentration in exhaled air is dependent on expiratory flow rates, as $\mathrm{H}_{2} \mathrm{O}_{2}$ levels increased with decreasing flow rates, although in animal experiments changes in minute ventilation and breathing pattern did not alter $\mathrm{H}_{2} \mathrm{O}_{2}$ exhalation (46). In our study we did not control expiratory flow rates. However, assuming that the expiratory flow rate increases after exercise and in particular after the maximal exercise test, our data are likely to be an underestimation of the $\mathrm{H}_{2} \mathrm{O}_{2}$ production and are therefore still valid.

\section{Exercise-induced Oxidative Stress after Rehabilitation in Patients with COPD}

After rehabilitation, we observed a similar increase in DNA damage and plasma uric acid levels after the maximal exercise test as we did before rehabilitation. An additional finding was that the concentration of plasma uric acid slightly, but significantly decreased immediately after the maximal exercise test. The most striking finding in the present study was that after rehabilitation we did not detect a significant increase in ROS-induced DNA damage after the submaximal exercise test. This decrease in ROS-induced DNA damage may be attributable to an improved training status of the COPD patients, since the patients had an increased exercise capacity and physical activity level, as indicated by the Pam Score, after rehabilitation. This is in line with a previous study (31), which reported that the extent of DNA damage 
was dependent on the training status of the healthy participants, as trained participants had less DNA damage compared to untrained participants after exercise.

Based on these results we can conclude that intensive supervised pulmonary rehabilitation reduces exercise-induced DNA damage, when performed at moderate intensity. Moreover, the submaximal exercise test seems to be more discriminative to evaluate the effect of pulmonary rehabilitation.

After rehabilitation, there were no statistically significant changes in plasma MDA after both exercise tests. For urinary MDA, results were similar to those observed before rehabilitation, with the exception of the maximal exercise test for which we found no longer a significant increase immediately after the exercise test.

In general, we observed a tendency for a decrease in systemic exercise-induced oxidative stress after rehabilitation, when also taking into account that the intensity and duration were higher after rehabilitation. This could be a consequence of an improved oxidative metabolism or an increased capacity of endogenous antioxidative systems. Previously, Rabinovich et al. (47) reported that patients with COPD had a reduced ability to adapt to endurance training, as reflected by a lower capacity to synthesise reduced glutathione. The reduced exercise-induced oxidative stress response may be attributable to an improved oxidative metabolism rather than to an upregulation of antioxidant defences, although we cannot rule out the possibility that the effects were caused by the induction of antioxidant adaptations. Further studies are needed to clarify the mechanisms involved in the exerciseinduced oxidative stress response and possible adaptations after pulmonary rehabilitation.

After rehabilitation, we observed no significant increase in exhaled $\mathrm{H}_{2} \mathrm{O}_{2}$ after both exercise tests, despite a significant increase in intensity and duration. This effect would probably be more pronounced if we had measured at similar intensity and duration before and after rehabilitation. Another striking effect deriving from the data presented is that baseline pulmonary $\mathrm{H}_{2} \mathrm{O}_{2}$ production at the submaximal exercise test was significantly higher compared to data obtained from the maximal exercise test. This effect was also found before rehabilitation, but was not significant. It can be speculated that the increased baseline $\mathrm{H}_{2} \mathrm{O}_{2}$ production might be due to the fact that the patients performed the submaximal exercise test after the weekend. The patients spent the weekend at home and life style factors, especially passive smoking behaviour may have been different from those in the pulmonary rehabilitation center.

\section{Methodological Considerations/ Limitations of the Study}

In this study, the maximal and submaximal exercise tests were not performed at similar workload and duration time (isotime) before and after rehabilitation. However, measurements of oxidative stress at isotime would probably have led to even more pronounced differences between measurements before and after rehabilita- 
tion, because it has been suggested that oxidative stress increases with the intensity and duration of the exercise.

\section{Conclusions}

In conclusion, the present study clearly indicates that patients with COPD, when compared to age-matched healthy controls, are characterised by increased systemic and pulmonary oxidative stress markers both at rest as well as induced by exercise. This suggests that healthy controls are able to tolerate exercise more effectively than COPD patients. Moreover, this study showed for the first time that intensive supervised pulmonary rehabilitation was associated with decreased systemic exercise-induced oxidative stress, especially after submaximal exercise. This decrease was accompanied by a significantly improved exercise capacity in COPD patients after rehabilitation. The observed improvement may be attributable to adaptive responses involving a more efficient oxidative metabolism or an increased capacity of endogenous antioxidative systems. The possible mechanisms underlying improved exercise capacity and decreased exercise-induced oxidative stress after intensive supervised pulmonary rehabilitation, and the outcome of specific nutritional or pharmacological modulation on exercise-induced oxidative stress, will be subject of further investigations

\section{ACKNOWLEDGMENT}

The authors thank Marie-Jose Drittij and Marc Fischer for the technical assistance. We thank Dr. Joan Does, Jerôme Jansen, Tom Sneijders, Anne Jonkers and Remco Coelen for their outstanding work supervising the exercise tests. We also thank the staff of the Lung Function and Laboratory for their skilful support during the study. 


\section{REFERENCES}

1. Heunks LM, Vina J, van Herwaarden CL, Folgering HT, Gimeno A, and Dekhuijzen PN. Xanthine oxidase is involved in exercise-induced oxidative stress in chronic obstructive pulmonary disease. Am J Physiol 1999;277(6 Pt 2):R1697-704.

2. Couillard A, Koechlin C, Cristol JP, Varray A, and Prefaut C. Evidence of local exerciseinduced systemic oxidative stress in chronic obstructive pulmonary disease patients. Eur Respir J 2002;20(5):1123-9.

3. Koechlin C, Couillard A, Simar D, Cristol JP, Bellet H, Hayot M, and Prefaut C. Does oxidative stress alter quadriceps endurance in chronic obstructive puimonary disease? Am J Respir Crit Care Med 2004;169(9):1022-7.

4. Dekhuijzen PN, Aben KK, Dekker I, Aarts LP, Wielders PL, van Herwaarden CL, and Bast A. Increased exhalation of hydrogen peroxide in patients with stable and unstable chronic obstructive pulmonary disease. Am J Respir Crit Care Med 1996;154(3 Pt 1):813-6.

5. Speit G, Dennog C, and Lampl L. Biological significance of DNA damage induced by hyperbaric oxygen. Mutagenesis 1998;13(1):85-7.

6. Hartmann A, Agurell E, Beevers C, Brendler-Schwaab S, Burlinson B, Clay P, Collins A, Smith $A$, Speit $G$, Thybaud $V$, and Tice RR. Recommendations for conducting the in vivo alkaline Comet assay. 4th International Comet Assay Workshop. Mutagenesis 2003;18(1):45-51.

7. Goldstein RS, Gort EH, Stubbing D, Avendano MA, and Guyatt GH. Randomised controlled trial of respiratory rehabilitation. Lancet 1994;344(8934):1394-7.

8. Ries AL, Kaplan RM, Limberg TM, and Prewitt LM. Effects of pulmonary rehabilitation on physiologic and psychosocial outcomes in patients with chronic obstructive pulmonary disease. Ann Intern Med 1995;122(11):823-32.

9. Couillard A, Maltais F, Saey D, Debigare $R$, Michaud A, Koechlin $C$, LeBlanc $P$, and Prefaut $C$. Exercise-induced quadriceps oxidative stress and peripheral muscle dysfunction in patients with chronic obstructive pulmonary disease. Am J Respir Crit Care Med 2003;167(12):1664-9.

10. Pauwels RA, Buist AS, Calverley PM, Jenkins CR, and Hurd SS. Global strategy for the diagnosis, management, and prevention of chronic obstructive pulmonary disease. NHLBI/WHO Global Initiative for Chronic Obstructive Lung Disease (GOLD) Workshop summary. Am J Respir Crit Care Med 2001;163(5):1256-76.

11. Fabbri LM, and Hurd SS. Global Strategy for the Diagnosis, Management and Prevention of COPD: 2003 update. Eur Respir J 2003;22(1):1-2.

12. Baarends EM, Schols AM, Mostert R, and Wouters EF. Peak exercise response in relation to tissue depletion in patients with chronic obstructive pulmonary disease. Eur Respir $J$ 1997;10(12):2807-13.

13. Quanjer PH, Tammeling GJ, Cotes JE, Pedersen OF, Peslin R, and Yernault JC. Lung volumes and forced ventilatory flows. Report Working Party Standardization of Lung Function Tests, European Community for Steel and Coal. Official Statement of the European Respiratory Society. Eur Respir J Supp/ 1993;16:5-40.

14. Franssen FM, Wouters EF, Baarends EM, Akkermans MA, and Schols AM. Arm mechanical efficiency and arm exercise capacity are relatively preserved in chronic obstructive pulmonary disease. Med Sci Sports Exerc 2002;34(10):1570-6.

15. Singh NP, McCoy MT, Tice RR, and Schneider EL. A simple technique for quantitation of low levels of DNA damage in individual cells. Exp Cell Res 1988;175(1):184-91.

16. Tice RR, Agurell E, Anderson D, Burlinson B, Hartmann A, Kobayashi H, Miyamae $Y$, Rojas E, Ryu JC, and Sasaki YF. Single cell gel/comet assay: guidelines for in vitro and in vivo genetic toxicology testing. Environ Mol Mutagen 2000;35(3):206-21. 
17. Lepage G, Munoz G, Champagne $J$, and Roy CC. Preparative steps necessary for the accurate measurement of malondialdehyde by high-performance liquid chromatography. Anal Biochem 1991;197(2):277-83.

18. Falco GL, Lloret SM, Gomez FB, Cabeza AS, Legua CM. Creatinine determination in urine samples by batchwise kinetic procedure and flow injection analysis using the Jaffe reaction: chemometric study. Talanta 2001;55:1079-1089.

19. Lux O, Naidoo D, and Salonikas C. Improved HPLC method for the simultaneous measurement of allantoin and uric acid in plasma. Ann Clin Biochem 1992;29 (Pt 6):674-5.

20. Larstad $M$, Ljungkvist $G$, Olin $A C$, and Toren $K$. Determination of malondialdehyde in breath condensate by high-performance liquid chromatography with fluorescence detection. $J$ Chromatogr B Analyt Technol Biomed Life Sci 2002;766(1):107-14.

21. Gallati $\mathrm{H}$, and Pracht I. Horseradish peroxidase: kinetic studies and optimization of peroxidase activity determination using the substrates $\mathrm{H} 2 \mathrm{O} 2$ and 3,3,5,5'-tetramethylbenzidine. $J$ Clin Chem Clin Biochem 1985;23(8):453-60.

22. Agacdiken $A$, Basyigit $I$, Ozden $M$, Yildiz $F$, Ural $D$, Maral $H$, Boyaci $H$, llgazli $A$, and Komsuoglu $B$. The effects of antioxidants on exercise-induced lipid peroxidation in patients with COPD. Respirology 2004;9(1):38-42.

23. Halliwell $B$, and Chirico $S$. Lipid peroxidation: its mechanism, measurement, and significance. Am J Clin Nutr 1993;57(5 Suppl):715S-724S; discussion 724S-725S.

24. Nowak D, Kasieiski $M$, Antczak $A$, Pietras $T$, and Bialasiewicz P. Increased content of thiobarbituric acid-reactive substances and hydrogen peroxide in the expired breath condensate of patients with stable chronic obstructive pulmonary disease: no significant effect of cigarette smoking. Respir Med 1999;93(6):389-96.

25. Kostikas K, Papatheodorou G, Psathakis K, Panagou $P$, and Loukides $S$. Oxidative stress in expired breath condensate of patients with COPD. Chest 2003;124(4):1373-80.

26. Hartmann A, Pfuhler $S$, Dennog $C$, Germadnik D, Pilger A, and Speit G. Exercise-induced DNA effects in human leukocytes are not accompanied by increased formation of 8-hydroxy-2'deoxyguanosine or induction of micronuclei. Free Radic Biol Med 1998;24(2):245-51.

27. Tsai $\mathrm{K}, \mathrm{Hsu} T \mathrm{~T}, \mathrm{Hsu} \mathrm{KM}$, Cheng $\mathrm{H}$, Liu TY, Hsu CF, and Kong CW. Oxidative DNA damage in human peripheral leukocytes induced by massive aerobic exercise. Free Radic Biol Med 2001;31(11):1465-72.

28. Mastaloudis A, Yu TW, O'Donnell RP, Frei B, Dashwood RH, and Traber MG. Endurance exercise results in DNA damage as detected by the comet assay. Free Radic Biol Med 2004;36(8):966-75.

29. Hartmann A, Plappert U, Raddatz K, Grunert-Fuchs M, and Speit G. Does physical activity induce DNA damage? Mutagenesis 1994;9(3):269-72.

30. Moller $\mathrm{P}$, and Wallin $\mathrm{H}$. Adduct formation, mutagenesis and nucleotide excision repair of DNA damage produced by reactive oxygen species and lipid peroxidation product. Mutat Res 1998;410(3):271-90.

31. Niess AM, Hartmann A, Grunert-Fuchs M, Poch B, and Speit G. DNA damage after exhaustive treadmill running in trained and untrained men. Int J Sports Med 1996;17(6):397-403.

32. Kanter MM, Nolte LA, and Holloszy JO. Effects of an antioxidant vitamin mixture on lipid peroxidation at rest and postexercise. J Appl Physiol 1993;74(2):965-9.

33. Ozbay $\mathrm{B}$, and Dulger $\mathrm{H}$. Lipid peroxidation and antioxidant enzymes in Turkish population: relation to age, gender, exercise, and smoking. Tohoku J Exp Med 2002;197(2):119-24.

34. Leaf DA, Kleinman MT, Hamilton $M$, and Barstow TJ. The effect of exercise intensity on lipid peroxidation. Med Sci Sports Exerc 1997;29(8):1036-9. 
35. Alessio HM, Hagerman AE, Fulkerson BK, Ambrose J, Rice RE, and Wiley RL. Generation of reactive oxygen species after exhaustive aerobic and isometric exercise. Med Sci Sports Exerc 2000;32(9):1576-81.

36. Chance B, Sies $\mathrm{H}$, and Boveris A. Hydroperoxide metabolism in mammalian organs. Physiol Rev 1979;59(3):527-605.

37. Pouw EM, Schols AM, van der Vusse GJ, and Wouters EF. Elevated inosine monophosphate levels in resting muscle of patients with stable chronic obstructive pulmonary disease. Am J Respir Crit Care Med 1998;157(2):453-7.

38. Hellsten $Y$, Tullson $P C$, Richter EA, and Bangsbo J. Oxidation of urate in human skeletal muscle during exercise. Free Radic Biol Med 1997;22(1-2):169-74.

39. Mastaloudis A, Leonard SW, and Traber MG. Oxidative stress in athletes during extreme endurance exercise. Free Radic Biol Med 2001;31(7):911-22.

40. Helisten $Y$. The role of xanthine oxidase in exercise. In: Sen CK, Packer L, Hanninen O, eds. Handbook of Oxidants and Antioxidants in Exercise. Amsterdam: Elsevier, 2000:153-176.

41. Sahlin $\mathrm{K}$, Ekberg $\mathrm{K}$, and Cizinsky $S$. Changes in plasma hypoxanthine and free radical markers during exercise in man. Acta Physiol Scand 1991;142(2):275-81.

42. Yu AY, Frid MG, Shimoda LA, Wiener CM, Stenmark K, and Semenza GL. Temporal, spatial, and oxygen-regulated expression of hypoxia-inducible factor- 1 in the lung. Am $J$ Physiol 1998;275(4 Pt 1):L818-26.

43. Semenza GL. HIF-1: mediator of physiological and pathophysiological responses to hypoxia. $J$ Appl Physiol 2000;88(4):1474-80.

44. Madjdpour C, Jewell UR, Kneller S, Ziegler U, Schwendener R, Booy C, Klausli L, Pasch T, Schimmer RC, and Beck-Schimmer B. Decreased alveolar oxygen induces lung inflammation. Am J Physiol Lung Cell Mol Physiol 2003;284(2):L360-7.

45. Schleiss $M B$, Holz $O$, Behnke $M$, Richter $K$, Magnussen $H$, and Jorres RA. The concentration of hydrogen peroxide in exhaled air depends on expiratory flow rate. Eur Respir $J$ 2000;16(6):1115-8.

46. Sznajder JI, Fraiman A, Hall JB, Sanders W, Schmidt G, Crawford G, Nahum A, Factor P, and Wood LD. Increased hydrogen peroxide in the expired breath of patients with acute hypoxemic respiratory failure. Chest 1989;96(3):606-12.

47. Rabinovich RA, Ardite E, Troosters T, Carbo N, Alonso J, Gonzalez de Suso JM, Vilaro J, Barbera JA, Polo MF, Argiles JM, et al. Reduced muscle redox capacity after endurance training in patients with chronic obstructive pulmonary disease. Am J Respir Crit Care Med 2001;164(7):1114-8. 
Gontister 2

Online Data Supplement for:

Rehabilitation decreases Exercise-induced Oxidative Stress in Chronic Obstructive Pulmonary Disease

Evi M. Mercken, Geja J. Hageman, Annemie MW.J. Schols, Marco A. Akkermans, Aalt Bast, and Emiel F.M. Wouters 


\section{METHODS}

\section{Study population}

Pulmonary rehabilitation program

All patients participated in a standardized inpatient pulmonary rehabilitation program, consisting of exercise training, education and when appropriate psychosocial and behavioural intervention. The physical exercise training consisted of a combination of endurance and strength training. All patients performed two activity sessions made up of 20 minutes of submaximal cycle ergometry, 20 minutes of treadmill exercise, 30 minutes of gymnastics and 1 session of unsupported arm exercise training daily. Also dynamic strength training exercises of the upper and lower extremities were implemented in the program. Because the exercise program was offered in an inpatient setting there was a thorough control on the compliance of the patients to the different aspects of the program. Furthermore, since the patients in general trained together, they exerted an additional control on the compliance of each other. The diet that was offered to the patients was standardized as follows from the inpatient setting and none of the studied COPD patients received nutritional support. Furthermore, when the patients started their rehabilitation program, they were not allowed to smoke in or outside the rehabilitation centre. During the rehabilitation period, the patients $\mathrm{HbCO}$ was measured several times to see if the patients had smoked. None of patients included in the study had an elevated $\mathrm{HbCO}$.

\section{Level of physical activity}

Participants had to wear the Personal Activity Monitor (Pam) accelerometer during 9 consecutive days. The Pam could easily be clipped to the belt or clothes and was attached to the right hip. It measures the acceleration in both horizontal and vertical direction. Furthermore, Pam has the ability to store data continuously for 112 days and has computer-uploading capabilities through a special website (www.pam.com). In this way, Pam users can observe the physical activity pattern of recent days/weeks.

\section{Malondialdehyde in plasma and urine}

The determination of malondialdehyde (MDA) was assayed by measuring the thiobarbituric acid reactive material according to the high-performance liquid chromatography (HPCL) method described by Lepage et al. (E1). A $200 \mu \mathrm{l}$ plasma or urine sample was added to $1 \mathrm{ml}$ of a reagent [containing $0.12 \mathrm{M} \mathrm{TBA}, 0.32 \mathrm{M}$ ophosphoric acid, and $0.01 \%$ (mass/vol) EDTA, $0.68 \mathrm{mM}$ butylated hydroxytoluene (BHT)]. After this, the mixture was incubated for $1 \mathrm{~h}$ at $100^{\circ} \mathrm{C}$ in a water bath. After cooling, the MDA-products were extracted with $500 \mu$ butanol. Malondialdehyde 
Chapter 2

was then determined using HPLC (Agilent, Palo Alto, CA) and $30 \mu \mathrm{l}$ of the butanol layer were injected and separated on a Nucleosil C18 column (150 X $3.2 \mathrm{~mm})$ particle size $5 \mu \mathrm{m}$ (Supelco, PA). Samples were eluted with $65 \%$ (vol $/ \mathrm{vol}$ ), $0.05 \%$ trifluoracetic acid (TFA) in MilliQ and $35 \%$ (vol/vol) methanol. The MDA-TBA complex was detected with a fluorescence detector with excitation and emission wavelengths of 532 and $553 \mathrm{~nm}$, respectively. A calibration curve was constructed using malonaldehyde bis(diethylacetal) as standard. The urinary MDA concentrations were corrected for creatinine content. Creatinine in urine samples was measured in triplicate using the Jaffé reaction as described by Falco et al. (E2). Briefly, creatinine reacts with the alkaline picrate to form a coloured complex, which is measured at $492 \mathrm{~nm}$. The values of MDA in urine are expressed per mmol creatinine.

\section{Plasma uric acid}

An aliquot of $150 \mu$ of plasma was deproteinized by mixing with a equal volume of $10 \%(\mathrm{w} / \mathrm{v})$ trichloroacetic acid (TCA), centrifuged $\left(800 \times \mathrm{g}\right.$ for 5 minutes at $\left.4^{\circ} \mathrm{C}\right)$ and uric acid was assayed by a HPLC method described by Lux et al. (E3) with minor modification. Twenty-five $\mu$ l of the deproteinized plasma was injected on the HPLC. The system (Agilent, Palo Alto, CA, USA) consisted of an Hypersil BDS C-18 endcapped column, $125 \times 4 \mathrm{~mm}$, particle size $5 \mu \mathrm{m}$ (Agilent, Palo Alto, CA, USA) with a mobile phase of $5 \mathrm{mM}$ sodium phosphate buffer $\mathrm{pH}=3.3$. Detection was performed using a variable wavelength detector set on a wavelength of $292 \mathrm{~nm}$. The uric acid concentration was calculated using a calibration curve of uric acid.

\section{Collection of exhaled breath and measurement of $\mathrm{H}_{2} \mathrm{O}_{2}$}

Exhaled breath condensate (EBC) hydrogen peroxide $\left(\mathrm{H}_{2} \mathrm{O}_{2}\right)$ was measured by means of horseradish peroxidase-catalysed oxidation of tetramethylbenzidine according to the method previously described by Gallati and Pracht and modified for microtiter plate-based analysis (E4). Briefly, $100 \mu \mathrm{l}$ 3,3',5,5'-tetramethylbenzidine (dissolved in $0.2 \mathrm{M}$ citrate buffer, $\mathrm{pH} 3.95$ ) and $10 \mu \mathrm{l}$ of $50 \mathrm{U} / \mathrm{ml}$ horseradish peroxidase (HRP; Sigma Chemicals) were added to $50 \mu \mathrm{l} E B C$. The reaction mixture was incubated for $20 \mathrm{~min}$ at room temperature. Subsequently, the reaction mixture was acidified to $\mathrm{pH} 1$ with $20 \mu \mathrm{l}$ of $2 \mathrm{M}$ sulphuric acid. The absorbance of the reaction product was measured spectrophotometrically at $450 \mathrm{~nm}$. 


\section{RESULTS}

\section{Anthropometric and Spirometric Data}

Pam utilizes a unique and patented universal index, known as the "Pam Score" (Table $\mathrm{E} 1$ ). It is the ratio between the amount of energy you use while active and the amount of energy you use while at rest, multiplied by $100 \%$.

Table E1. The suggested range of daily Pam Scores for each activity level, segmented by age category.

\begin{tabular}{lllll}
\hline Age & $<20 \mathrm{yr}$ & $20-40 \mathrm{yr}$ & $40-60 \mathrm{yr}$ & $>65 \mathrm{yr}$ \\
\hline Activity level & Pam Score & & & \\
Low & $<30$ & $<20$ & $<15$ & $<10$ \\
Light & $30-40$ & $20-30$ & $15-25$ & $10-20$ \\
Medium & $40-60$ & $30-40$ & $25-35$ & $20-30$ \\
Active & $60-80$ & $40-60$ & $35-50$ & $30-45$ \\
Very Active & $80-100$ & $60-80$ & $50-70$ & $45-60$ \\
Extremely Active & $>100$ & $>80$ & $>70$ & $>60$ \\
\hline
\end{tabular}

\section{Exercise capacity}

COPD patients exceeded their maximum voluntary ventilation ( $1 \mathrm{~F}$ E/MVV > 100\%), as a consequence of their ventilatory limitation, maximum exercise intensity was reached, whereas the heart rate reserve was preserved. The healthy controls were within the normal range for these two parameters. Peak ventilatory (VE) reserve was calculated as $100 \%-\left(100^{*}\right.$ peak VE)/(FEV 1 . 37.5) (E5, E6) and peak heart rate (HR) reserve was calculated as 100\%-(100*peak HR)/(220-age) (E5). 


\section{REFERENCES}

E1. Lepage G, Munoz G, Champagne J, and Roy CC. Preparative steps necessary for the accurate measurement of malondialdehyde by high-performance liquid chromatography. Anal Biochem 1991;197(2):277-83.

E2. Falco GL, Lloret SM, Gomez FB, Cabeza AS, Legua CM. Creatinine determination in urine samples by batchwise kinetic procedure and flow injection analysis using the Jaffe reaction: chemometric study. Talanta 2001;55:1079-1089.

E3. Lux O, Naidoo D, and Salonikas C. Improved HPLC method for the simultaneous measurement of allantoin and uric acid in plasma. Ann Clin Biochem 1992;29 ( Pt 6):674-5.

E4. Gallati $\mathrm{H}$, and Pracht I. Horseradish peroxidase: kinetic studies and optimization of peroxidase activity determination using the substrates $\mathrm{H} 2 \mathrm{O} 2$ and 3,3',5,5'-tetramethylbenzidine. $J$ Clin Chem Clin Biochem 1985;23(8):453-60.

E5. Wasserman K, Hansen JE, Sue DY, Whipp BJ, Casaburi R. Principles of exercise testing and interpretation. $2^{\text {nd }}$ ed. Philadelphia: Lea \& Febiger; 1994.

E6. Carter R, Peavler M, Zinkgraf S, Williams J, Fields S. Predicting maximal exercise ventilation in patients with chronic obstructive pulmonary disease. Chest 1987;92:253-9. 


\title{
CHAPTER 3
}

\section{Systemic and pulmonary oxidative stress after single leg exercise in COPD}

\begin{abstract}
Background: The aim of this study was to disentangle the contribution of muscular versus pulmonary oxidative stress during endurance exercise in patients with COPD. Methods: Fifteen COPD patients and 10 healthy age-matched controls performed a continuously submaximal single leg ergometer test $(40 \%$ of peak workload) for 20 minutes or until they stopped (Tlim). Venous blood, urine samples and exhaled breath condensate were sampled before, immediately and $2 \mathrm{~h}$ after exercise. Results: Tlim was lower in COPD than controls $(p<0.01)$. No exerciseinduced systemic inflammation (IL-6, TNF- $\alpha$ ) was found in the groups. Urinary malondialdehyde $(M D A)$ and uric acid $(p<0.05)$ as well as erythrocyte GSSG/GSH $(p=0.08)$ were increased in COPD compared to controls after exercise. Despite the relatively low cardioventilatory response to this localized muscle exercise, hydrogen peroxide $\left(\mathrm{H}_{2} \mathrm{O}_{2}\right)$ in breath condensate significantly increased in COPD $(p<0.01)$. NF$\kappa B$ DNA binding activity of $p 50$ in peripheral blood mononcytes was elevated after exercise in both COPD $(p<0.01)$ and controls $(p<0.05)$, whereas p65 protein was not altered. Conclusion: COPD patients showed increased pulmonary and systemic oxidative stress after localized leg muscle exercise compared to healthy controls without evidence of increased levels of systemic inflammation.
\end{abstract}

Evi M. Mercken ${ }^{1}$, Harry R. Gosker ${ }^{1}$, Erica P. Rutten ${ }^{2}$, Emiel F. Wouters ${ }^{1,2}$, Aalt Bast ${ }^{3}$, Geja J. Hageman ${ }^{4}$ and Annemie M. Schols ${ }^{1}$. Departments of ${ }^{1}$ Respiratory Medicine, ${ }^{3}$ Pharmacology and Toxicology and ${ }^{4}$ Health Risk Analysis and Toxicology, Maastricht University, Maastricht, School for Nutrition, Toxicology and Metabolism (NUTRIM) and ${ }^{2}$ Centre for Integrated Rehabilitation Organ Failure (CIRO), Horn, The Netherlands. Submitted. 


\section{INTRODUCTION}

Peripheral muscle dysfunction is common in chronic obstructive pulmonary disease (COPD). Previous studies showed that peripheral muscle strength and endurance $e^{1-3}$ are reduced and susceptible to fatigue ${ }^{4}$ in patients with COPD compared to healthy subjects. Understanding the underlying mechanisms of peripheral muscle impairment in COPD is clinically relevant since skeletal muscle dysfunction is linked to disability and impaired quality of life. ${ }^{5}$ Chronic inflammation and oxidative stress may be implicated in the etiology of peripheral muscle dysfunction. ${ }^{6}$ Increased systemic and pulmonary oxidative stress has consistently been reported in patients with severe COPD after constant work rate cycle exercise. ${ }^{7,8}$ This type of exercise however stresses the whole body and limitations of the ventilatory system in COPD patients in particular. ${ }^{9}$ Moreover, under these circumstances, it is difficult to disentangle the relative contribution of lungs versus muscles to the exercise-induced oxidative stress in COPD.

We assumed that a localized limb exercise may obviate exercise-induced ventilatory and cardiac stress and thus be an ideal exercise modality to study the contribution of skeletal muscle to exercise-induced oxidative stress in COPD. Recently, Couillard and colleagues indeed provided evidence for localized quadriceps exercise-induced systemic and muscle oxidative stress in patients with $\mathrm{COPD}^{2,10}$, but no data were reported regarding the pulmonary oxidative stress response. Furthermore, in these studies endurance time was tested on an exercise bench according to the technique of Serres et al. ${ }^{3}$ In this model, the movement is based on knee extension and flexion in regular pace with periods of rest in between. A more suitable model to study exercise endurance time is the model of Andersen et al. ${ }^{11}$ in which knee extension is performed continuously. The aim of the present study was therefore to investigate if and to what extent systemic inflammation and oxidative stress as well as pulmonary oxidative stress are differentially triggered by contracting peripheral muscle of COPD patients versus healthy controls and whether this stress response is associated with peripheral reduced muscle endurance in COPD.

\section{MATERIALS AND METHODS}

\section{Study population}

Fifteen stable patients who met GOLD criteria for COPD were recruited on admission to the Centre for Integrated Rehabilitation Organ failure (CIRO), Horn, The Netherlands. ${ }^{12}$ All patients were ex-smokers and had not experienced a respiratory tract infection or exacerbation of their disease for at least 4 weeks prior to the study. Exclusion criteria were rheumatoid arthritis, chronic colitis, diabetes, cardiovascular 
diseases, renal diseases, liver diseases or mental diseases. None of the subjects were taking antioxidants or vitamin supplements. All patients received standardized medical treatment according to the GOLD guidelines including anticholinergic, $\beta_{2^{-}}$ agonists and inhaled corticosteroids. Two patients also received theophylline and oral corticosteroids as maintenance therapy. Ten healthy sedentary age-matched non-smoking control subjects were recruited through newspaper advertisements. Written informed consent was obtained from all participants, and the study was approved by the medical ethics committee of the University Hospital Maastricht.

\section{Subject characteristics}

Body composition ${ }^{13}$, pulmonary function ${ }^{14}$, and Physical Activity Scale for the Elderly questionnaire ${ }^{15}$ were determined as described previously.

\section{Exercise capacity}

Participants performed an incremental and a day later a submaximal cycling exercise test ( $80 \%$ of peak workload) as described previously. ${ }^{16} \mathrm{~A}$ week later, they performed a maximal and 3 days later a submaximal single leg ergometer test $(40 \%$ of peak workload) for which subjects were instructed to cycle for $20 \mathrm{~min}$. The exercise equipment and methodology were designed based on the model of Andersen et al. ${ }^{11}$ The duration time of the exercise test was called 'limit time' (Tlim). Venous blood, urine samples and exhaled breath condensate samples were obtained at baseline, immediately and $2 \mathrm{~h}$ after the exercise test. Blood lactate was analyzed (Cobas Mira; Roche, Basel, Switzerland). Dyspnea and muscle fatigue were evaluated using the Borg scale (0 to 10).

\section{Markers of systemic inflammation and oxidative stress}

Venous blood samples were drawn into EDTA-containing tubes (Venoject). Plasma was obtained by centrifugation $\left(800 \times g\right.$ for 10 minutes at $4^{\circ} \mathrm{C}$ ) and stored at $-80^{\circ} \mathrm{C}$ until analysis. The volume of the remaining blood was brought to $15 \mathrm{ml}$ with cold phosphate-buffered saline and layered on an equal volume of Lymphoprep medium in a 50-ml tube with a filter (Greiner) of peripheral blood mononuclear cells (PBMCs). After centrifugation at $800 \times \mathrm{g}$ for $30 \mathrm{~min}$ at $4^{\circ} \mathrm{C}$, gradient-separated PBMCs were recovered, resuspended in 10-ml cold PBS, and centrifuged again at $250 \times \mathrm{g}$ for $10 \mathrm{~min}$ at $4^{\circ} \mathrm{C}$. The cells were resuspended in $1 \mathrm{ml}$ cold PBS and centrifuged at $800 \times g$ for $5 \mathrm{~min}$ and the pellet was used to prepare nuclear extracts for $\mathrm{NF}-\mathrm{KB}$ determination. Nuclear extracts were prepared as described by Hofmann et al. ${ }^{17}$ Urine samples were stored at $-20^{\circ} \mathrm{C}$ until further analysis. Plasma IL-6 and TNF- $\alpha$ concentrations were determined using a quantitative high-sensitivity enzyme-linked immunosorbent assay (ELISA) kit (R\&D Systems, Minneapolis, MN, USA). Urinary MDA and uric acid were assessed by HPCL. ${ }^{18,19}$ Erythrocyte glu- 
tathione was measured in its reduced (GSH) and oxidized (GSSG) form. ${ }^{20}$ The GSSG-to-GSH ratio, another marker of oxidative stress was calculated. NF-KB concentrations were determined in nuclear extracts of peripheral blood mononuclear cells (TransAM NF-kB p50 and p65 transcription Factor Assay Kit; Active Motif Europe, Rixensart, Belgium).

\section{Markers of pulmonary oxidative stress}

Exhaled breath condensate (EBC) was collected as described previously. ${ }^{21}$ Hydrogen peroxide $\left(\mathrm{H}_{2} \mathrm{O}_{2}\right)$ was measured by means of horseradish peroxidase-catalyzed oxidation of tetramethylbenzidine. ${ }^{22}$

\section{Statistical analyses}

All data are expressed as mean \pm SEM. Differences between patients and controls were tested using Student's $t$-test for independent samples. When normality was not obtained, a Mann-Whitney U-test was used. The Wilcoxon signed rank test was used to evaluate the effect of single leg exercise on biological markers within subgroups. Differences between the exercise tests (single leg ergometer, maximal and submaximal cycle exercise) were determined by ANOVA with post hoc LSD test. A $p$-value of $\leq 0.05$ was considered statistically significant. Statistical analyses were analyzed with SPSS for Windows (version 13.0; SPSS, Inc., Chicago, IL).

\section{RESULTS}

\section{Subject characteristics}

As shown in Table 1, the COPD group was characterized by moderate to severe airflow obstruction with a FEV ${ }_{1}$ of $46.6 \pm 5.2 \%$ predicted. Physical activity assessed by PASE score was significantly lower in COPD patients compared to control subjects $(p<0.001)$. 
Table 1. Characteristics of the study population

\begin{tabular}{lcc}
\hline & $\begin{array}{c}\text { Controls } \\
(n=10)\end{array}$ & $\begin{array}{c}\text { COPD patients } \\
(n=15)\end{array}$ \\
\hline Sex, M/F & $4 / 6$ & $10 / 5$ \\
Age, yr & $55.5 \pm 1.8$ & $56.5 \pm 2.3$ \\
Pack-yr & $11.9 \pm 5.0$ & $38.0 \pm 6.2$ \\
BMI, $\mathrm{kg} / \mathrm{m}^{2}$ & $27.6 \pm 1.4$ & $24.6 \pm 1.1$ \\
FFMl, kg/m ${ }^{2}$ & $17.3 \pm 0.7$ & $15.9 \pm 0.4$ \\
FEV,$\%$ pred. & $115.9 \pm 7.0$ & $46.6 \pm 5.2^{*}$ \\
FVC, \% pred. & $126.1 \pm 10.0$ & $112.8 \pm 8.6$ \\
FEV $/$ FVC, \% pred. & $78.3 \pm 1.5$ & $35.2 \pm 2.5^{*}$ \\
PASE & $235.3 \pm 16.0$ & $85.1 \pm 9.4^{*}$ \\
\hline
\end{tabular}

Definition of abbreviations: BMI: body mass index; FFMI: fat-free mass index; PASE: Physical Activity Scale for the Elderly. Data are presented as mean \pm SEM. " $p<0.001$ compared with healthy control subjects.

\section{Single leg ergometer test}

The results of the submaximal single leg ergometer test are presented in Table 2. All healthy controls except for one reached the 20-min time limit whereas only 5 COPD patients were able to complete the entire duration of the test. Workload and quadriceps endurance (Tlim) were significantly lower in COPD patients compared to controls ( $p<0.001$ and $p<0.01$ respectively). Ventilation ( $\dot{V} E / M V V)$ was significantly higher in COPD compared to controls $(p<0.001)$, whereas the heart rate reserve was similar between both groups. Subjective assessment of muscle fatigue showed greater leg fatigue in COPD compared to controls $(p<0.05)$, whereas perceived breathlessness was not significantly different between the groups. 
Chapter 3

Table 2. Physiological response to submaximal single leg ergometer test

\begin{tabular}{|c|c|c|}
\hline & $\begin{array}{l}\text { Controls } \\
(n=10)\end{array}$ & $\begin{array}{l}\text { COPD patients } \\
\qquad(n=15)\end{array}$ \\
\hline Workload, W & $15.6 \pm 1.6$ & $6.4 \pm 1.0^{\text {t.*n }}$ \\
\hline Tlim, min & $19.0 \pm 1.0$ & $11.0 \pm 1.8^{\star *}$ \\
\hline \multicolumn{3}{|l|}{$\mathrm{VO}_{2}, \mathrm{~mL} / \mathrm{min}$} \\
\hline Rest & $493.7 \pm 49.6$ & $366.8 \pm 44.1$ \\
\hline End-exercise & $867.0 \pm 67.2$ & $610.6 \pm 62.2$ \\
\hline \multicolumn{3}{|l|}{$\dot{\mathrm{V}} \mathrm{CO}_{2}, \mathrm{~mL} / \mathrm{min}$} \\
\hline Rest & $390.0 \pm 54.6$ & $304.4 \pm 43.0$ \\
\hline End-exercise & $770.7 \pm 64.5$ & $560.9 \pm 64.4$ \\
\hline \multicolumn{3}{|l|}{ HR reserve, \% } \\
\hline End-exercise & $42.4 \pm 6.7$ & $41.5 \pm 2.9$ \\
\hline \multicolumn{3}{|l|}{$\dot{V} E / M V N$} \\
\hline End-exercise & $0.22 \pm 0.01$ & $0.57 \pm 0.09^{* * *}$ \\
\hline \multicolumn{3}{|l|}{$\mathrm{SaO}_{2}, \%$} \\
\hline Rest & $96.3 \pm 0.9$ & $96.5 \pm 0.6$ \\
\hline End-exercise & $97.0 \pm 0.8$ & $96.8 \pm 0.5$ \\
\hline \multicolumn{3}{|l|}{ RER } \\
\hline End-exercise & $0.89 \pm 0.02$ & $0.91 \pm 0.02$ \\
\hline$\Delta$ Lactate, $\mathrm{mmol} / \mathrm{L}$ & $0.80 \pm 0.28$ & $0.98 \pm 0.22$ \\
\hline$\Delta$ Dyspnea Borg Score & $0.5 \pm 0.8$ & $1.8 \pm 0.4$ \\
\hline$\Delta$ Leg fatigue Borg Score & $0.9 \pm 0.8$ & $1.6 \pm 0.3^{\star}$ \\
\hline
\end{tabular}

Definition of abbreviations: Tlim: limit time; HR: heart rate; $\mathrm{MW}$ : maximum voluntary ventilation; $\mathrm{SaO}_{2}$ : oxygen saturation; RER: respiratory exchange ratio. Data are presented as mean $\pm S E M$. " $p<0.05$, " $p<0.01, " * * 0.001$ compared with healthy control subjects.

\section{Comparison between whole body and local exercise}

Physiological responses to whole body exercise tests (maximal and submaximal cycle exercise) and submaximal localized quadriceps exercise (single leg ergometer test) are compared in Table 3. In COPD, the single leg ergometer test resulted in significantly lower peak $\dot{V} \mathrm{O}_{2}$, peak $\dot{V} \mathrm{CO}_{2}$ (both; $p<0.001$ ) and higher oxygen saturation ( $p<0.01$ and $p<0.05$ respectively) compared to whole body maximal and submaximal cycle exercise tests. Moreover, voluntary ventilation (VE/MVV) was significantly lower after single leg ergometer test compared to maximal cycle exercise, whereas the heart rate reserve was more preserved after the single leg ergometer test (both; $p<0.01$ ) in COPD. For COPD, dyspnea perception $(p<0.01)$ and to a lesser extent also leg fatigue perception $(p<0.05)$ during single leg exercise were less when compared to whole body exercise. 
Table 3. Comparison between local versus whole body exercise tests in COPD

\begin{tabular}{|c|c|c|c|}
\hline $\operatorname{COPD}(n=15)$ & $\begin{array}{l}\text { Single leg } \\
\text { exercise }\end{array}$ & $\begin{array}{c}\text { Maximal cycle } \\
\text { exercise }\end{array}$ & $\begin{array}{c}\text { Submaximal cycle } \\
\text { exercise }\end{array}$ \\
\hline Tlim, minutes & $11.0 \pm 1.8$ & - & $8.3 \pm 1.6$ \\
\hline$\dot{V} \mathrm{O}_{2}, \mathrm{~mL} / \mathrm{min}$ & $610.6 \pm 62.6$ & $1231.1 \pm 110.6^{* * *}$ & $1228.9 \pm 89.1^{* * \star *}$ \\
\hline$\dot{\mathrm{V}} \mathrm{CO}_{2}, \mathrm{~mL} / \mathrm{min}$ & $560.9 \pm 64.4$ & $1184.4 \pm 111.0^{* * *}$ & $1200.7 \pm 83.9^{* * *}$ \\
\hline $\mathrm{SaO}_{2}, \%$ & $96.6 \pm 0.6$ & $92.1 \pm 1.0^{* *}$ & $93.2 \pm 0.7^{*}$ \\
\hline \multicolumn{4}{|l|}{$\mathrm{HR}$, beat/min } \\
\hline Rest & $82.6 \pm 5.2$ & $67.9 \pm 3.2$ & - \\
\hline End-exercise & $96.4 \pm 4.9$ & $95.1 \pm 11.6$ & - \\
\hline \multicolumn{4}{|l|}{ HR reserve, $\%$} \\
\hline End-exercise & $41.5 \pm 2.9$ & $21.4 \pm 2.7^{* *}$ & - \\
\hline \multicolumn{4}{|l|}{$\dot{V} E, L / m i n$} \\
\hline Rest & $15.0 \pm 1.9$ & $13.9 \pm 1.0$ & - \\
\hline End-exercise & $29.4 \pm 2.7$ & $46.4 \pm 3.8$ & - \\
\hline \multicolumn{4}{|l|}{$\dot{V} E / M W V$} \\
\hline End-exercise & $0.57 \pm 0.09$ & $0.95 \pm 0.31^{* *}$ & - \\
\hline$\Delta$ Dyspnea Borg Score & $1.8 \pm 0.4$ & $5.0 \pm 0.7^{n *}$ & $4.9 \pm 0.5^{n *}$ \\
\hline$\Delta$ Leg fatigue Borg Score & $1.6 \pm 0.3$ & $3.3 \pm 0.7$ & $3.9 \pm 0.5^{\star}$ \\
\hline
\end{tabular}

Definition of abbreviations: HR: heart rate; MVV: maximum voluntary ventilation. Data are presented as mean \pm SEM. ${ }^{*} p<0.05, " p<0.01,{ }^{* *} p<0.001$ compared with single leg exercise.

\section{Markers of systemic inflammation and oxidative stress}

At baseline, only IL-6 was significantly higher in COPD compared to controls $(0.7 \pm$ 0.2 controls vs. $2.0 \pm 0.4$ COPD; $p<0.01$ ). Systemic as well as pulmonary oxidative stress markers at baseline did not differ between both groups. No exercise-induced inflammatory changes were observed in both groups (data not shown). As shown in Figure 1, urinary MDA was significantly elevated immediately after exercise in COPD patients whereas in controls, a significant decrease was found $2 \mathrm{~h}$ after exercise (both $p<0.05$ ). Additionally, a significant difference in the response to exercise in urinary MDA between both groups was observed $(p<0.02)$. Urinary uric acid was significantly increased immediately after exercise in COPD $(p<0.05$; Figure 2). Moreover, the exercise-induced uric acid response was significantly higher in COPD compared to controls $(p<0.05)$. 

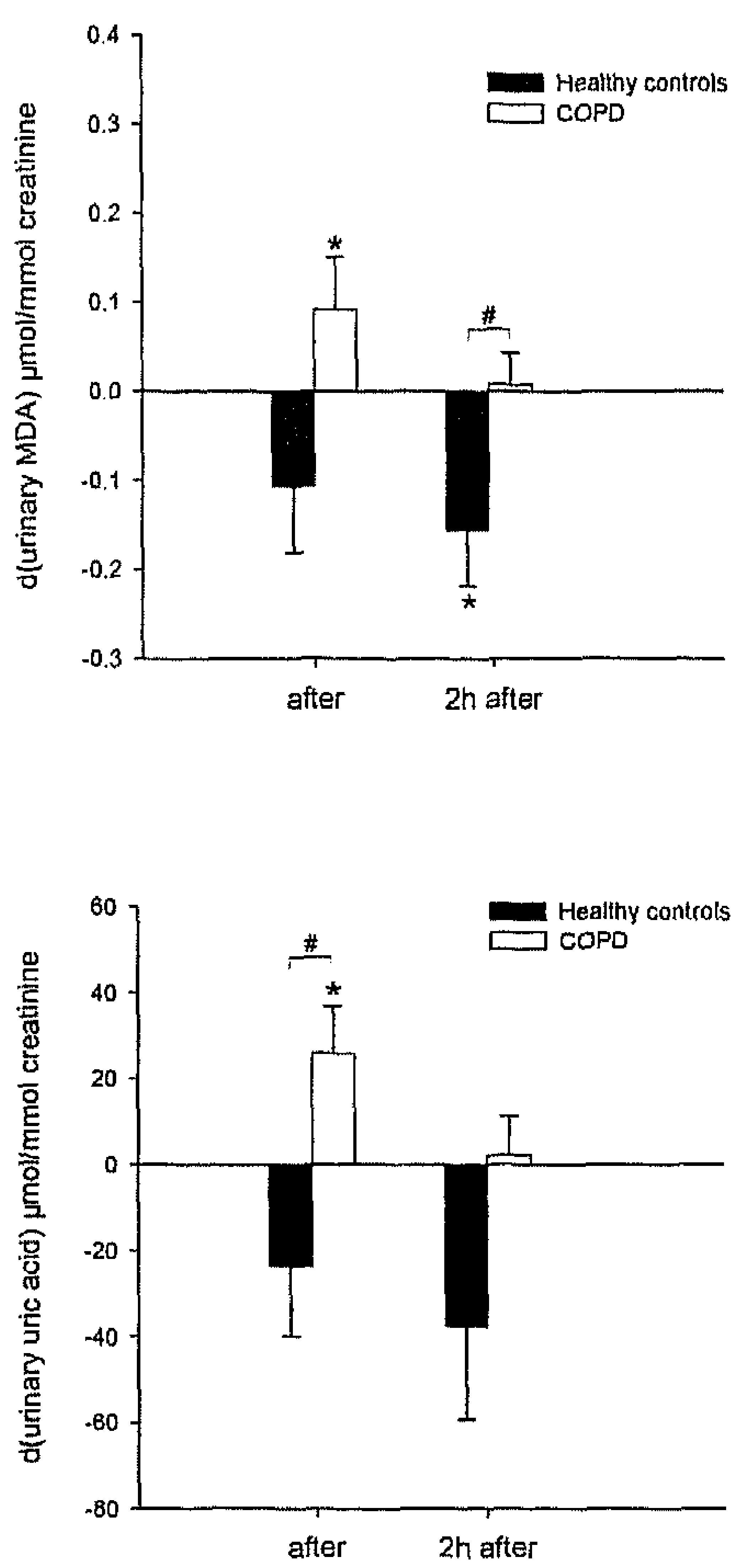

Figure 1. Concentration of urinary malondialdehyde (MDA) in healthy control subjects and COPD patients immediately after and $2 \mathrm{~h}$ after submaximal single leg exercise. Data represent differences with baseline values. Values are expressed as mean \pm SEM. " $p<0.05$ significantly different from baseline values; $p<0.02$ significantly different between the groups.
Figure 2. Concentration of urinary uric acid in healthy control subjects and COPD patients immediately after and $2 \mathrm{~h}$ after submaximal single leg exercise. Data represent differences with baseline values. Values are expressed as mean \pm SEM. ${ }^{*}<0.05$ significantly different from baseline values; " $p<0.05$ significantly different between the groups.

Furthermore, in control subjects erythrocyte GSH levels decreased $2 \mathrm{~h}$ after exercise $(p<0.05$; Figure $3 A)$, whereas in COPD GSSG levels and the GSSG-to-GSH ratio tended to be increased immediately after exercise (both $p=0.08$; Figure $3 B+3 C$ ). In COPD, $\mathrm{H}_{2} \mathrm{O}_{2}$ concentration in exhaled breath condensate (EBC) was significantly elevated immediately and $2 \mathrm{~h}$ after exercise (both $p<0.01$; Figure 4 ), whereas for controls no significant effect of exhaled $\mathrm{H}_{2} \mathrm{O}_{2}$ concentration was observed. 


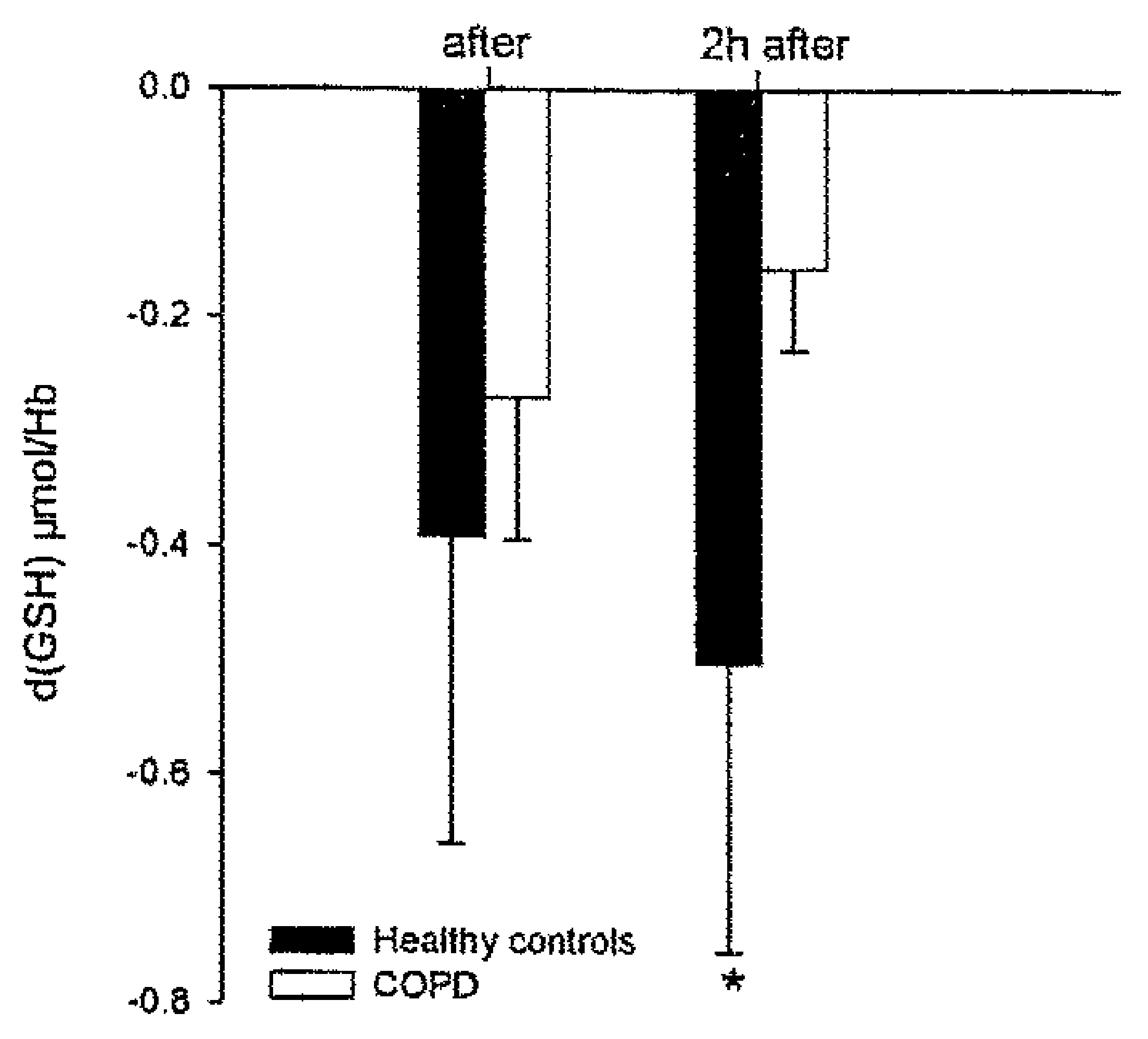

C.

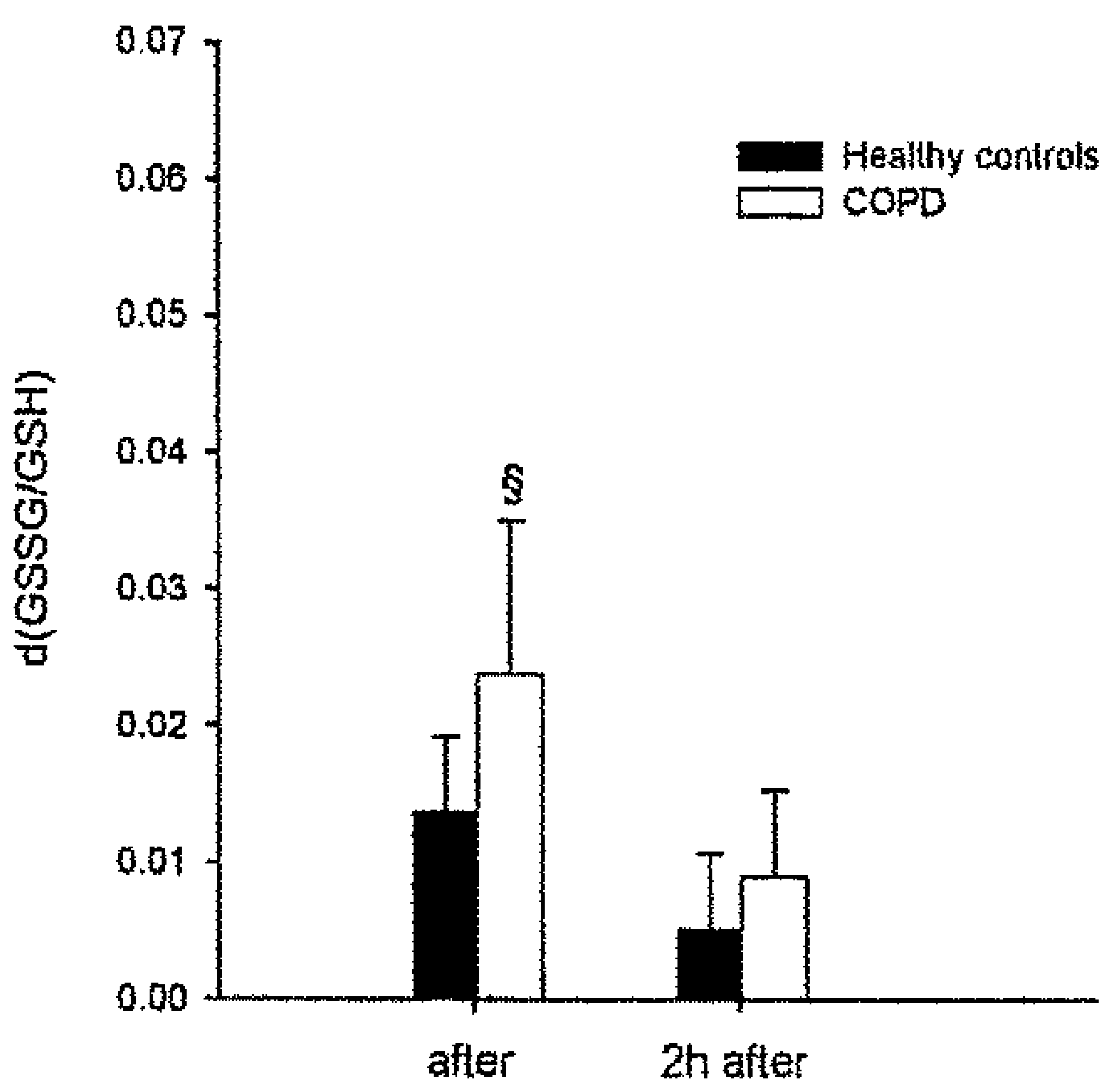

B.

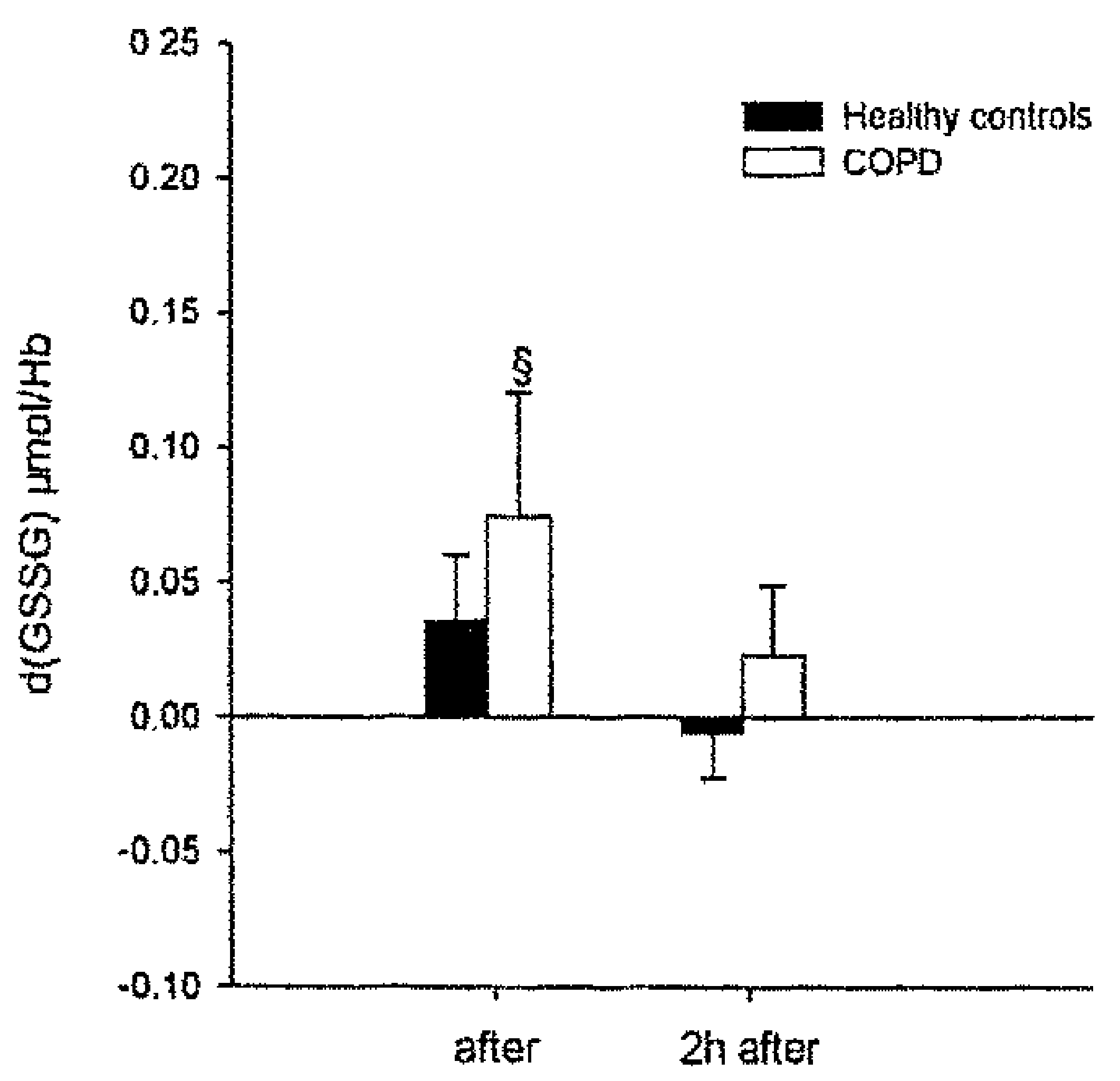

Figure 3. Erythrocyte GSH levels (A), GSSG levels (B) and GSSG/GSH ratio (C) in healthy control subjects and COPD patients immediately after and $2 \mathrm{~h}$ after submaximal single leg exercise. Data represent differences with baseline values. Values are expressed as mean $\pm S E M$. $p<0.05,{ }^{k} p=0.08$ significantly different from baseline values. 
Chapter 3

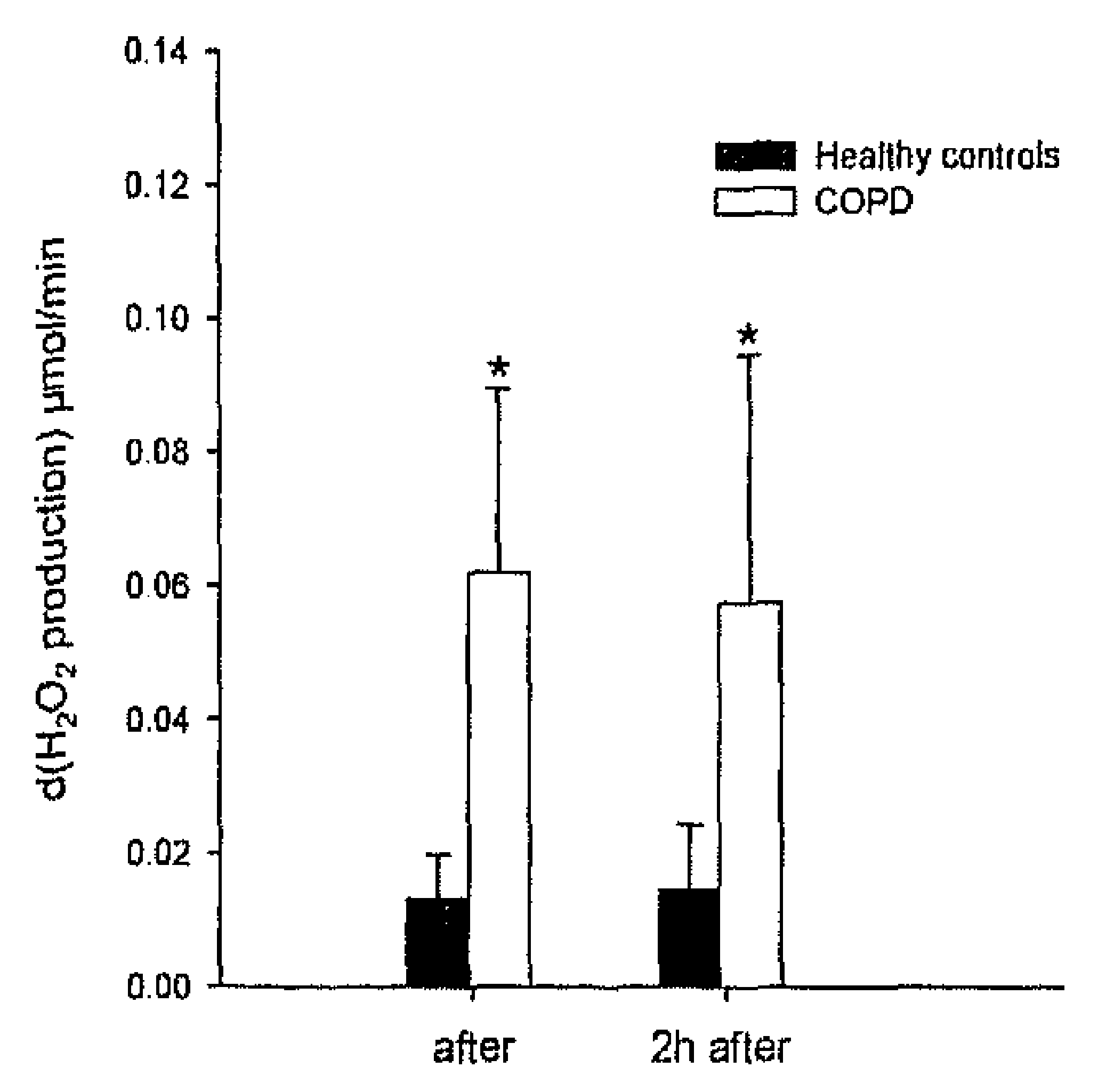

Figure 4. Production of hydrogen peroxide $\left(\mathrm{H}_{2} \mathrm{O}_{2}\right)$ measured in exhaled breath condensate in healthy control subjects and COPD patients immediately after and $2 \mathrm{~h}$ after submaximal single leg exercise. Data represent differences with baseline values. Values are expressed as mean \pm SEM. $p<0.01$ significantly different from baseline values.

\section{NF-KB nuclear translocation}

As shown in Figure 5, basal NF-kB DNA binding activity of p50 and p65 in PBMCs did not differ between the groups. $2 \mathrm{~h}$ after exercise, NF-kB DNA binding activity of p50 in PBMCs significantly increased to a similar extent in controls and COPD $(p<0.05$ and $p<0.01$ respectively), whereas exercise did not alter $p 65$ protein in both groups.

A.

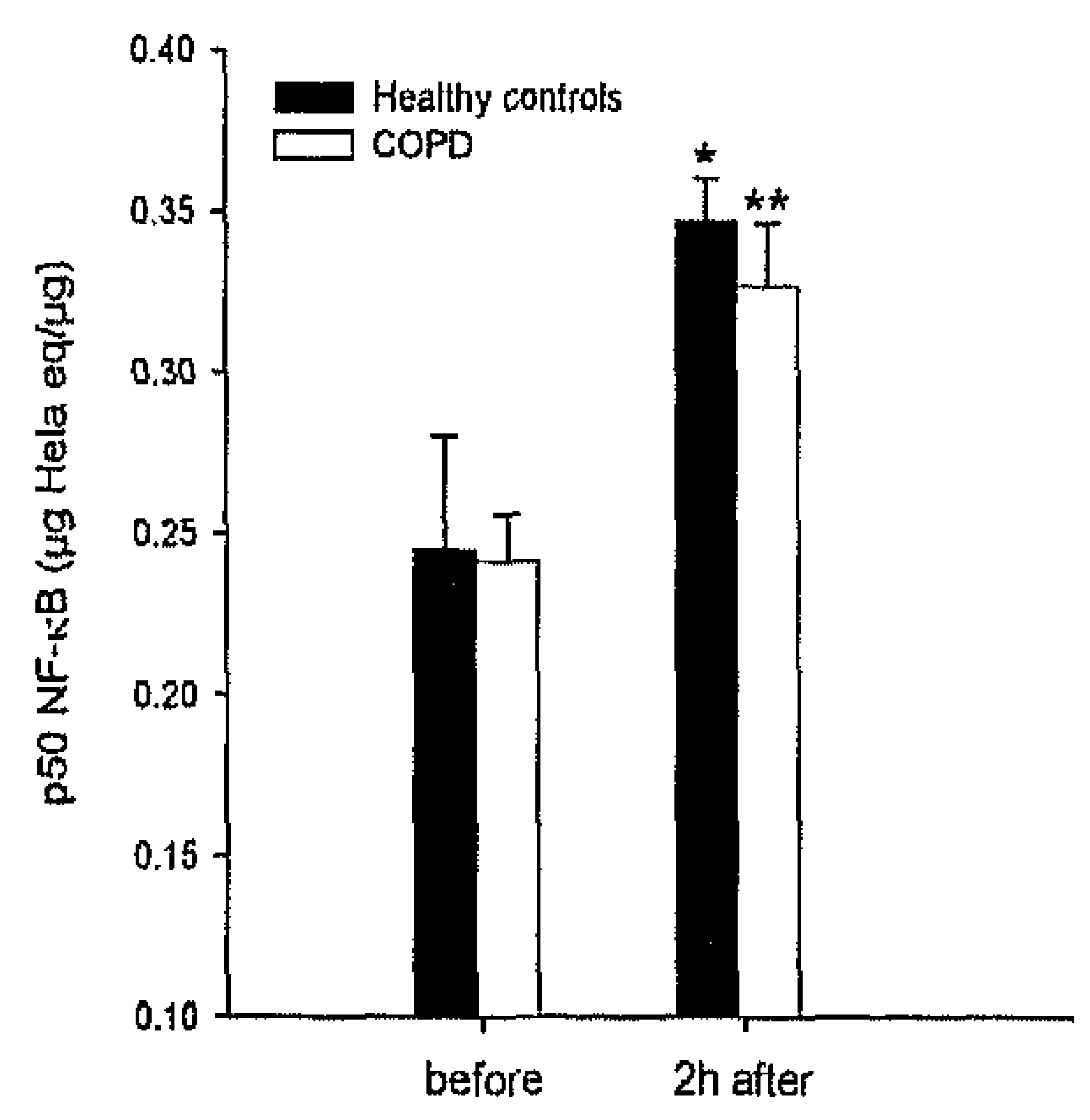

B.

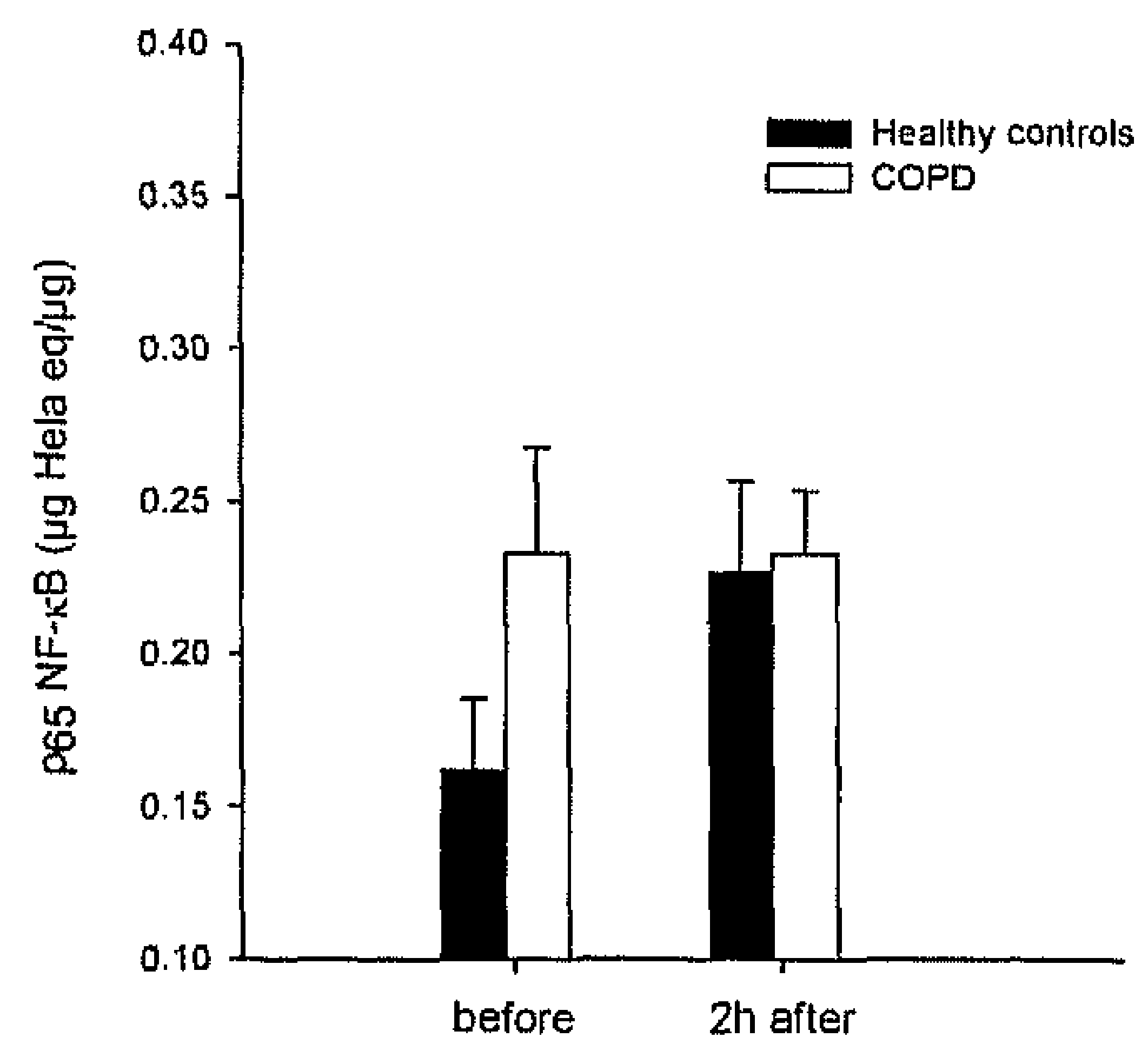

Figure 5. NF-KB DNA binding activity of $p 50(A)$ and $p 65(B)$ was determined in peripheral blood mononuclear cells in healthy control subjects and COPD patients $2 \mathrm{~h}$ after submaximal single leg exercise. Values are expressed as mean \pm SEM. " $p<0.05, " p<0.01$ significantly different from baseline values. 


\section{DISCUSSION}

The results of this study indicate that quadriceps endurance is impaired in clinically stable COPD patients compared to healthy controls. In addition, patients with COPD showed a greater susceptibility to local exercise-induced systemic and pulmonary oxidative stress without evidence of increased levels of systemic inflammation during exercise.

\section{Validity of the local endurance test}

To study muscle endurance (Tlim), we used a local continuous work quadriceps exercise test based on the model of Andersen et al. ${ }^{11}$ In COPD, the increase in dyspnea, ventilation and heart rate after this single leg exercise was of small amplitude, whereas muscle fatigue was the main factor limiting exercise. This response pattern indicates that continuously localized exercise minimizes cardiorespiratory responses and nicely reflects muscle response to exercise. Conversely, during whole body cycling exercise, impairment of ventilatory function represented the main limiting factor for exercise capacity. This paralleled the differences in observed subjective perception of leg fatigue and dyspnea during the different exercise modalities in patients and controls.

\section{Local exercise-induced systemic inflammatory and oxidative stress response}

In accordance with a previous study ${ }^{23}$, plasma inflammatory cytokine levels were unchanged by the exercise test in both groups, suggesting that local muscle exercise does not induce systemic inflammation. However, COPD patients showed an increased systemic oxidative stress response after exercise compared to controls as measured by elevated urinary MDA and urinary uric acid levels. In healthy controls, the ubiquitous antioxidant GSH decreased $2 \mathrm{~h}$ after exercise. Previously, it has been shown that limb skeletal muscle mass of COPD patients is reduced compared to controls. ${ }^{1} 24$ Therefore, it is feasible that GSH demand during exercise was lower in COPD compared to controls. Although statistical significance was not reached, GSSG and GSSG-to-GSH ratio slightly increased in COPD following exercise which indicates an increased oxidative stress response after localized exercise in COPD. This finding is in agreement with previous studies that reported increased GSSG-to-GSH ratio after exhaustive whole body exercise. ${ }^{7,25} \mathrm{~A}$ reduced endurance of the quadriceps occurs in a substantial number of patients with COPD. In the present study, different patterns were observed for exercise-induced NF-kB DNA binding activity of p50 and p65 in PBMCs but no differences between the two groups. Only DNA binding activity of the p50 subunit was significantly elevated $2 \mathrm{~h}$ after exercise in both COPD and controls. This indicates that after a local exercise the induced NF-KB DNA binding consist mostly of p50 homodimers. It is well appre- 
Chapter 3

ciated that p50 homodimers can act as suppressors of NF-KB dependent inflammatory cytokine transcription. ${ }^{26}$ This is in agreement with the present finding that plasma inflammatory cytokine levels were unchanged by the exercise test in both groups.

Remarkably, even despite the low cardioventilatory responses, we observed that $\mathrm{H}_{2} \mathrm{O}_{2}$ concentration in the EBC of patients with COPD was significantly elevated immediately and $2 \mathrm{~h}$ after local exercise, whereas in controls no significant increase was observed, indicating an enhanced production of ROS in the airways of these patients. Previously, we showed that $\mathrm{H}_{2} \mathrm{O}_{2}$ concentration was increased in COPD patients after maximal whole body cycling exercise ${ }^{8}$, which could be explained by the increased ventilatory responses during this exercise modality. However, in the present study, the immediate increase of $\mathrm{H}_{2} \mathrm{O}_{2}$ concentration in EBC of COPD patients after local exercise is likely to be derived from a different mechanism since a local exercise is attended by less pronounced increased ventilatory responses. Until now, no other studies have investigated the effect of exercise on $\mathrm{H}_{2} \mathrm{O}_{2}$ concentration in EBC. However, basal differences have been attributed to an enhanced activity of xanthine oxidase $(X O)$ in the lungs COPD. ${ }^{27,}{ }^{28}$ Additionally, an increased number of inflammatory cells have been found in the bronchoalveolar lavage fluid of stable COPD patients compared to healthy non-smokers. ${ }^{29}$ Still, it could be speculated that $X O$ activity in epithelial cells of COPD patients is increased after exercise compared to controls leading to the immediate increase in $\mathrm{H}_{2} \mathrm{O}_{2}$ concentration in COPD observed in this study. Moreover, it could be hypothesized that the pulmonary inflammatory response is intensified in COPD after exercise. The immediate increased $\mathrm{H}_{2} \mathrm{O}_{2}$ concentration may also originate from enhanced and/or inappropriate NADPH oxidase activation (for review $\mathrm{see}^{30}$ ). Further research will have to elucidate whether these or other mechanisms also play a role in the exerciseinduced $\mathrm{H}_{2} \mathrm{O}_{2}$ concentration.

It has been suggested that oxidative stress plays a role in peripheral muscle dysfunction in patients with COPD. However, no correlations were observed between markers of oxidative stress and quadriceps endurance in COPD. This is in contrast with a previous study showing an inverse relationship between muscle lipid peroxidation and oxidized proteins with quadriceps endurance in COPD. ${ }^{2}$

\section{Systemic inflammation and oxidative stress at rest}

In the present study, resting values of plasma IL- 6 were increased in clinically stable COPD patients compared to controls ${ }^{31}$, reflecting a low-grade systemic inflammation in these patients. However, no differences in basal plasma TNF- $\alpha$ between both groups were observed. Conflicting results have been reported regarding the proinflammatory cytokine TNF- $\alpha$ in plasma of COPD patients. ${ }^{23,32}$ Contrary to previous studies, no differences in oxidative stress markers (urinary MDA, urinary uric acid 
and $\mathrm{H}_{2} \mathrm{O}_{2}$ in breath condensate) were noted in COPD patients compared to con. trols. ${ }^{8,22}$ These discrepancies may be attributable to a difference in disease severty in terms of an altered oxidant/antioxidant balance. with the patients of the present study less severely affected than those of our previous study." Additionally, no differences between reduced GSH and oxidized GSSG levels were observed between both groups, which are in agreement with the results of previous studies."

${ }^{33}$ Moreover, no differences in NF-kB DNA binding activity of $\mathrm{p} 50$ and $\mathrm{p} 65$ were found between the two groups. Data regarding DNA binding activity of both subunits in PBMCs of COPD were not previously avallable.

In summary, the results of this study strongly suggest that COPD patients have a more pronounced exercise-induced systemic oxidative stress response to localized leg muscle exercise without evidence of increased levels of systemic inflammation compared to healthy controls when tested at a similar relative intensity. Moreover, despite the low cardioventilatory responses after a localized exercise, COPD showed a greater susceptibility to local pulmonary oxidative stress response than controls. Future studies are indicated to study the effects of antioxidant modulation on the acute exercise-induced oxidative stress response as well as the long term effects of nutritional or pharmacological modulation as adjunct to exercise training on skeletal muscle endurance capacity.

\section{ACKNOWLEDGEMENTS}

They thank the staff of the Lung Function and Laboratory for their skillful support during the study. The authors also thank Marc Fischer and Roger Bartholome for the technical assistance. Supported by Numico Research (EM) and by an award from the Netherlands Asthma Foundation 3.2.05.038 (HG).

\section{ABBREVIATION LIST}

COPD: chronic obstructive pulmonary disease

CIRO: Centre for Integrated Rehabilitation Organ failure

EBC: exhaled breath condensate

ELISA: enzyme-linked immunosorbent assay

GSH: reduced glutathione

GSSG: oxidized glutathione

$\mathrm{H}_{2} \mathrm{O}_{2}$ : hydrogen peroxide

MDA: malondialdehyde

PBMCs: peripheral blood mononuclear cells

Tlim: muscle endurance

XO: xanthine oxidase 


\section{REFERENCES}

1. Bernard $S$, LeBlanc $P$, Whittom $F$, et al. Peripheral muscle weakness in patients with chronic obstructive pulmonary disease. Am J Respir Crit Care Med 1998; 158(2):629-634.

2. Couillard A, Maltais $F$, Saey $D$, et al. Exercise-induced quadriceps oxidative stress and peripheral muscle dysfunction in patients with chronic obstructive pulmonary disease. Am J Respir Crit Care Med 2003; 167(12):1664-1669.

3. Serres I, Gautier V, Varray A, et al. Impaired skeletal muscle endurance related to physical inactivity and altered lung function in COPD patients. Chest 1998; 113(4):900-905.

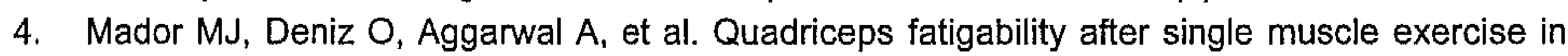
patients with chronic obstructive pulmonary disease. Am J Respir Crit Care Med 2003; 168(1):102-108.

5. Skeletal muscle dysfunction in chronic obstructive pulmonary disease. A statement of the American Thoracic Society and European Respiratory Society. Am J Respir Crit Care Med 1999; 159(4 Pt 2):S1-40.

6. Agusti AG. Systemic effects of chronic obstructive pulmonary disease. Proc Am Thorac Soc 2005; 2(4):367-370; discussion 371-362.

7. Vina J, Servera E, Asensi M, et al. Exercise causes blood glutathione oxidation in chronic obstructive pulmonary disease: prevention by 02 therapy. J Appl Physiol 1996; 81(5):21982202.

8. Mercken EM, Hageman GJ, Schols $A M$, et al. Rehabilitation decreases exercise-induced oxidative stress in chronic obstructive pulmonary disease. Am J Respir Crit Care Med 2005; 172(8):994-1001.

9. Richardson RS, Leek BT, Gavin TP, et al. Reduced mechanical efficiency in chronic obstructive pulmonary disease but normal peak VO2 with small muscle mass exercise. Am J Respir Crit Care Med 2004; 169(1):89-96.

10. Couillard A, Koechlin C, Cristol JP, et al. Evidence of local exercise-induced systemic oxidative stress in chronic obstructive pulmonary disease patients. Eur Respir J 2002; 20(5):1123-1129.

11. Andersen $P$, Adams RP, Sjogaard $G$, et al. Dynamic knee extension as model for study of isolated exercising muscle in humans. J Appl Physiol 1985; 59(5):1647-1653.

12. Fabbri LM, Hurd SS. Global Strategy for the Diagnosis, Management and Prevention of COPD: 2003 update. Eur Respir J 2003; 22(1):1-2.

13. Schols AM, Wouters EF, Soeters PB, et al. Body composition by bioelectrical-impedance analysis compared with deuterium dilution and skinfold anthropometry in patients with chronic obstructive pulmonary disease. Am J Clin Nutr 1991; 53(2):421-424.

14. Quanjer PH, Tammeling GJ, Cotes JE, et al. Lung volumes and forced ventilatory flows. Report Working Party Standardization of Lung Function Tests, European Community for Steel and Coal. Official Statement of the European Respiratory Society. Eur Respir J Suppl 1993; 16540.

15. Washburn RA, McAuley E, Katula J, et al. The physical activity scale for the elderly (PASE): evidence for validity. J Clin Epidemiol 1999; 52(7):643-651.

16. Franssen FM, Wouters EF, Baarends EM, et al. Arm mechanical efficiency and arm exercise capacity are relatively preserved in chronic obstructive pulmonary disease. Med Sci Sports Exerc 2002; 34(10):1570-1576.

17. Hofmann MA, Schiekofer $S$, Isermann B, et al. Peripheral blood mononuclear cells isolated from patients with diabetic nephropathy show increased activation of the oxidative-stress sensitive transcription factor NF-kappaB. Diabetologia 1999; 42(2):222-232. 
18. Lepage $G$, Munoz $G$, Champagne J, et al. Preparative steps necessary for the accurate measurement of malondialdehyde by high-performance liquid chromatography. Anal Biochem 1991; 197(2):277-283.

19. Lux O, Naidoo D, Salonikas C. Improved HPLC method for the simultaneous measurement of allantoin and uric acid in plasma. Ann Clin Biochem 1992; 29 ( Pt 6)674-675.

20. Vandeputte C, Guizon I, Genestie-Denis I, et al. A microtiter plate assay for total glutathione and glutathione disulfide contents in cultured/isolated cells: performance study of a new miniaturized protocol. Cell Biol Toxicol 1994; 10(5-6):415-421.

21. Larstad $M$, Ljungkvist $G$, Olin $A C$, et al. Determination of malondialdehyde in breath condensate by high-performance liquid chromatography with fluorescence detection. J Chromatogr $B$ Analyt Technol Biomed Life Sci 2002; 766(1):107-114.

22. Dekhuijzen PN, Aben KK, Dekker l, et al. Increased exhalation of hydrogen peroxide in patients with stable and unstable chronic obstructive pulmonary disease. Am J Respir Crit Care Med 1996; 154(3 Pt 1):813-816.

23. Koechlin $C$, Couillard $A, C$ ristol JP, et al. Does systemic inflammation trigger local exerciseinduced oxidative stress in COPD? Eur Respir J 2004; 23(4):538-544.

24. Engelen MP, Schols AM, Does JD, et al. Skeletal muscle weakness is associated with wasting of extremity fat-free mass but not with airflow obstruction in patients with chronic obstructive pulmonary disease. Am J Clin Nutr 2000; 71(3):733-738.

25. Heunks LM, Vina J, van Herwaarden $C L$, et al. Xanthine oxidase is involved in exerciseinduced oxidative stress in chronic obstructive pulmonary disease. Am J Physiol 1999; 277(6 Pt 2):R1697-1704.

26. Ghosh S, May MJ, Kopp EB. NF-kappa B and Rel proteins: evolutionarily conserved mediators of immune responses. Annu Rev Immunol 1998; 16225-260.

27. Pinamonti $S$, Muzzoli $M$, Chicca $M C$, et al. Xanthine oxidase activity in bronchoalveolar lavage fluid from patients with chronic obstructive pulmonary disease. Free Radic Biol Med 1996; 21(2):147-155.

28. Ichinose $M$, Sugiura $H$, Yamagata $S$, et al. Xanthine oxidase inhibition reduces reactive nitrogen species production in COPD airways. Eur Respir J 2003; 22(3):457-461.

29. Linden $M$, Rasmussen JB, Piitulainen $E$, et al. Airway inflammation in smokers with nonobstructive and obstructive chronic bronchitis. Am Rev Respir Dis 1993; 148(5):1226-1232.

30. van der Vliet A. NADPH oxidases in lung biology and pathology: Host defense enzymes, and more. Free Radic Biol Med 2007.

31. Broekhuizen R, Wouters EF, Creutzberg EC, et al. Raised CRP levels mark metabolic and functional impairment in advanced COPD. Thorax 2006; 61(1):17-22.

32. Rabinovich RA, Figueras $M$, Ardite $E_{1}$ et al. Increased tumour necrosis factor-alpha plasma levels during moderate-intensity exercise in COPD patients. Eur Respir J 2003; 21(5):789-794.

33. Van Helvoort HA, Heijdra YF, Thijs HM, et al. Exercise-Induced Systemic Effects in MuscleWasted Patients with COPD. Med Sci Sports Exerc 2006; 38(9):1543-1552. 


\title{
CHAPTER 4
}

\section{Reduced NF-kB mediated gene expression in skeletal muscle of patients with COPD in response to acute exercise}

\begin{abstract}
Background: NF-kB activation and oxidative stress are physiological responses of skeletal muscle to exercise but may be impaired in patients with COPD and decreased exercise capacity. To test this hypothesis we investigated NF-kB activity and expression of NF- $\mathrm{kB}$ regulated genes in quadriceps muscle of COPD patients and healthy controls at rest and after an acute exercise bout. Methods: Quadriceps specimens were obtained before, immediately and $2 \mathrm{~h}$ after a standardized cycle ergometer test ( $10 \mathrm{~min}$ at $70 \%$ of peak workload) from 7 COPD patients and 7 controls. NF-KB DNA binding activity in skeletal muscle and peripheral blood mononuclear cells (PBMCs) was determined using electrophoretic mobility shift assay and ELISA respectively. mRNA expression and protein carbonylation were measured by real-time PCR and Western blot, respectively. Results: In COPD, only IL-6 mRNA was increased in skeletal muscle after exercise, whereas in controls IL-6, I $\mathrm{KB} \alpha$, TNF- $\alpha$ and IL-1 $1 \beta$ mRNA were increased. Moreover, only in controls mRNA transcripts encoding superoxide dismutase, thioredoxin, heme oxygenase 1 and heat shock protein70 were upregulated after exercise. Exercise-induced mRNA levels of anti-apoptotic Bcl2 were lower in COPD compared to controls. Basal muscle protein oxidation was higher in COPD than in controls, but attenuated in response to exercise. No exercise-induced changes in NF-KB DNA binding activity in skeletal muscle and PBMCs of both groups were detected. However, basal NF$\kappa B$ activity in PBMCs was lower in COPD compared to controls. Conclusion: Skeletal muscle of COPD patients is characterized by an impaired response to acute exercise of a set of NF-kB regulated genes encoding inflammatory cytokines, antioxidants, stress proteins and survival factors.
\end{abstract}

Evi M. Mercken ${ }^{1}$, Geja J. Hageman', Ramon C.J. Langen', Emiel F.M. Wouters ${ }^{1,3}$ and Annemie M.W.J. Schols'. Departments of 'Respiratory Medicine, "Health Risk Analysis and Toxicology, Nutrition and Toxicology Research Institute Maastricht (NUTRIM), Maastricht University, Maastricht, ${ }^{3}$ Centre for Integrated Rehabilitation Organ Failure (CIRO), Horn, The Netherlands. Submitted. 
Chapter 4

\section{INTRODUCTION}

Chronic inflammation and oxidative stress are prominent features of chronic obstructive pulmonary disease (COPD) and may be implicated in the etiology of peripheral muscle dysfunction and muscle wasting.[1] Whereas the transient inflammatory response in the circulation and muscle following exercise is wellestablished in healthy controls, limited information is available regarding exercise as modulator of the inflammatory response in skeletal muscle of patients with COPD. In contrast exercise-induced oxidative stress has been well documented in the pulmonary, blood and muscle compartments of patients with COPD. $[2,3]$

Different mechanisms could contribute to augmented formation of reactive oxygen species (ROS) in response to exercise including mitochondrial respiration, NADPH oxidase and xanthine oxidase. The presence of ROS not only results in tissue damage, but recent research indicates a critical role in muscle adaptation by modulating gene expression. A major redox-sensitive transcriptional regulator is nuclear factor protein $\mathrm{KB}(\mathrm{NF}-\mathrm{kB})$.[4] Sustained activation of NF-KB by oxidative stress has been suggested to play a central role in the etiology of the systemic features of COPD.[5] In particular, a growing body of evidence from experimental models supports the involvement of NF-kB in the pathogenesis of muscle wasting. $[6,7]$ In contrast, transient activation of NF-KB is also involved in a wide variety of physiological processes such as antioxidant defense, cell growth, survival and differentiation as well as in immunity and inflammatory responses. In particular, NF- $\mathrm{kB}$ mediates gene expression of superoxide dismutase (SOD) and thioredoxin (TrX) which provide cellular protection to oxidative stress.[8, 9] Additionally, expression of the stress proteins heme oxygenase 1 ( $\mathrm{HO}-1)$ and heat shock protein-70 ( Hsp70) involves regulation by $\mathrm{NF}-\mathrm{KB}$ and yields cellular protection against oxidative damage.[10, 11] NF-kB also mediates the expression of $\mathrm{Bc} / 2$ protein which is involved in cell survival as well as the expression of the myogenic differentiation factor (MyoD).[12, 13] Furthermore, NF-KB is an important regulator of cytokines (IL-6, TNF- $\alpha$ and IL-1 $\beta$ ).

Thus far, the physiological role of NF-KB pathway activation during exercise is still elusive in COPD. Therefore, the purpose of this study was to investigate if NF-KB is activated in peripheral blood mononuclear cells and if $\mathrm{NF}-\mathrm{kB}$ activity is induced and $\mathrm{NF}-\mathrm{KB}$ mediated gene expression is upregulated in skeletal muscle of patients with COPD in response to an acute exercise bout. To evaluate this, quadriceps muscle biopsies were obtained from patients with COPD and healthy age-matched controls before and after standardized cycle ergometry. 
NF-kB mediated gene expression

\section{MATERIALS AND METHODS}

\section{Study population}

Seven clinically stable male patients with moderate COPD as defined by GOLD guidelines participated in this study.[14] All patients were ex-smokers and had not experienced respiratory tract infection or exacerbation of their disease for at least 4 weeks prior to the study. Exclusion criteria were rheumatoid arthritis, chronic colitis, diabetes, cardiovascular diseases, renal diseases, liver diseases or mental diseases. Seven healthy sedentary age-matched non-smoking participants were recruited as control group. All patients received standardized medical treatment according to the GOLD guidelines (see online supplement). Written informed consent was obtained from all participants and the study was approved by the medical ethics committee of the University Hospital Maastricht.

\section{Study design}

Participants performed an incremental cycle ergometer test and four days later a submaximal constant work rate exercise test. Venous blood and muscle biopsies were obtained at baseline, immediately after and 2 hours after the submaximal exercise test. The test was performed and samples were collected at the same time point of the day.

\section{Anthropometry and spirometry}

Body composition and flow volumes were determined as described previously (see online supplement).[15, 16]

\section{Exercise capacity}

Based on the outcome of the incremental (10 Watt/minute) cycle ergometer test, patients performed a submaximal $(70 \%$ of peak workload) cycle ergometer test as described previously for a standardized duration of 10 minutes (see online supplement).[17]

\section{Muscle biopsies}

Percutaneous biopsy specimens of vastus lateralis muscle of the dominant leg at baseline and immediately after exercise and of the non-dominant leg 2 hours after exercise were obtained as described by Bergström.[18] This time point was chosen based on the literature to determine the early gene response after an acute bout of exercise.[19] 
Chapter 4

\author{
Markers of systemic inflammation and oxidative stress \\ Details on sample preparation are provided in the online supplement. Plasma IL-6, \\ TNF- $\alpha$ and $\mathrm{IL}-1 \beta$ concentrations were determined using a quantitative high- \\ sensitivity enzyme-linked immunosorbent assay (ELISA) kit (R\&D Systems, Min- \\ neapolis, MN, USA). Levels of systemic protein carbonyls were measured by means \\ of an ELISA.[20]
}

\title{
NF-KB DNA-binding
}

NF-KB concentrations were determined in nuclear extracts of peripheral blood mononuclear cells (PBMCs) or muscle biopsies (see online supplement), and protein concentrations were determined using the method of Bradford (Biorad).

NF-KB p50 DNA-binding was determined in equal amounts of protein from nuclear extracts of PBMCs (TransAM NF-kB p50 transcription Factor Assay Kit; Active Motif Europe, Rixensart, Belgium). Alternatively, for nuclear extracts from biopsies electrophoretic mobility shift assay (EMSA) was used to analyze RelA DNA binding to an oligonucleotide containing a $\mathrm{KB}$ consensus sequence (Santa Cruz, Santa Cruz, CA, USA). $50 \mu \mathrm{g}$ of nuclear protein was used per binding reaction and protein-DNA complexes were resolved on a $5 \%$ polyacrylamide gel in $0.25 \mathrm{X}$ Tris-borate-EDTA buffer at $120 \mathrm{~V}$ for 2 hours. Gels were dried and exposed to film (X-Omat Blue XB-1, Kodak, Rochester, NY, USA). Shifted complexes were quantified by phosphorimager analysis (Biorad, Hercules, CA, USA). Supershift reactions were performed by pre-incubation of the nuclear extracts with an antibody specific to the RelA subunit of NF-kB (Santa cruz, Santa cruz, CA, USA).

\section{Skeletal muscle analysis}

mRNA levels of FOX01, I $\mathrm{kB} \alpha, \mathrm{IL}-6, \mathrm{TNF}-\alpha, \mathrm{IL}-1 \beta, \mathrm{MnSOD}, \mathrm{Trx}, \mathrm{HO}-1, \mathrm{Hsp} 70, \mathrm{Bcl} 2$ and $M y O D$ were determined by quantitative real-time $P C R$, and muscle protein carbonylation was determined by Western blot. Details on the methods and primer sequences (Table E1) are provided in the online supplement.

\section{Statistical analyses}

Data are presented as mean \pm SEM. Between-group comparisons were analyzed using the Mann-Whitney $U$ test and the Wilcoxon signed rank test was used to evaluate the effect of submaximal exercise within the groups. For analysis of baseline gene expression the $\Delta \mathrm{Ct}$ was used and for the effect of exercise on gene expression the $\Delta \Delta \mathrm{Ct}$. Nonparametric tests were used because the normality assumption was not obtained. A difference with $p \leq 0.05$ was considered statistically significant. Statistical analyses were analyzed with SPSS for Windows (version 13.0; SPSS, Inc., Chicago, IL). 
NF-kB mediated gene expression

\section{RESULTS}

\section{Baseline and exercise characteristics of the study population}

The subject characteristics are presented in Table 1. Mean FEV 1 of the COPD patients was $50.6 \pm 5.7 \%$ predicted. The anthropometric data did not show any significant differences between patients and healthy controls.

Table 1. Characteristics of the study population

\begin{tabular}{lcc}
\hline & $\begin{array}{c}\text { Healthy control subjects } \\
(\mathrm{n}=7)\end{array}$ & $\begin{array}{c}\text { Patients with COPD } \\
(\mathrm{n}=7)\end{array}$ \\
\hline Age, yr & $60.7 \pm 1.0$ & $61.9 \pm 1.4$ \\
Pack-yr of smoking & $11.6 \pm 4.5$ & $31.4 \pm 8.7$ \\
BMI, kg/m & $26.8 \pm 1.3$ & $25.0 \pm 1.3$ \\
FFMl, kg/m ${ }^{2}$ & $18.5 \pm 0.5$ & $17.2 \pm 0.6$ \\
FEV,$\%$ predicted & $108.5 \pm 9.7$ & $50.6 \pm 5.7^{* *}$ \\
FVC, \% predicted & $113.9 \pm 9.5$ & $96.1 \pm 7.6$ \\
Inflammation & & \\
IL-6 (pg/mL) & $1.93 \pm 0.25$ & $2.43 \pm 0.28$ \\
TNF- $\alpha$ (pg/mL) & $1.97 \pm 0.15$ & $1.95 \pm 0.13$ \\
IL-1 $\beta$ (pg/mL) & $0.31 \pm 0.02$ & $0.35 \pm 0.03$ \\
Oxidative stress & & \\
Carbonyls (nM) & $0.03 \pm 0.01$ & $0.10 \pm 0.03^{*}$ \\
\hline
\end{tabular}

Definitions of abbreviations: $\mathrm{COPD}=$ chronic obstructive pulmonary disease; $\mathrm{BMI}=$ body mass index;

$\mathrm{FFMI}=$ fat-free mass index. Data are presented as mean \pm SEM.

Significant difference compared with healthy control subjects, $" p<0.05 ; " p<0.01$.

The results of the exercise tests are presented in Table 2. As expected, peak exercise capacity was decreased in COPD patients when compared with healthy control subjects $(111 \pm 16$ vs. $238 \pm 16 \% ; p<0.01)$. During incremental cycle ergometry patients reached their ventilatory threshold whereas heart rate reserve was significantly higher compared to the healthy controls $(p<0.01)$. Baseline forkhead transcription factor 01 (FOXO1) mRNA expression was not different between both groups and as expected FOXO1 mRNA was significantly and to the same extent upregulated during the submaximal exercise test $(p<0.05)$. This indicates that the exercise intensity of the chosen exercise test was sufficient to induce transcriptional changes in both patients and controls. 
Chapter 4

Table 2. Exercise characteristics of healthy subjects and patients with chronic obstructive pulmonary disease

\begin{tabular}{lcc}
\hline & $\begin{array}{c}\text { Healthy control subjects } \\
(n=7)\end{array}$ & $\begin{array}{c}\text { Patients with COPD } \\
(n=7)\end{array}$ \\
\hline Incremental exercise & $238.3 \pm 16.3$ & $111.4 \pm 15.7^{* *}$ \\
Peak workload, W & $2440 \pm 136$ & $1353 \pm 107^{* *}$ \\
Peak $\dot{V} O_{2,}$ ml/min & $166 \pm 6$ & $133 \pm 2^{* *}$ \\
Peak HR, beat/min & $-0.4 \pm 3.5$ & $16.1 \pm 1.3^{* *}$ \\
HR reserve, \% & $93.5 \pm 5.3$ & $57.1 \pm 5.9^{* *}$ \\
Peak $\dot{V} E$, L/min & $20.8 \pm 10.8$ & $-1.3 \pm 8.7$ \\
$\dot{V} E$ reserve, \% & & \\
Constant work-rate exercise & $166.9 \pm 11.4$ & $78.4 \pm 10.9^{* *}$ \\
Workload, W & $1939 \pm 270$ & $1177 \pm 150$ \\
$\dot{V} \mathrm{O}_{2,}$ ml/min & $72.3 \pm 7.1$ & $43.6 \pm 4.0^{*}$ \\
$\dot{V} E$. L/min & $8.8 \pm 0.2$ & $8.6 \pm 0.2$ \\
$\Delta C t$ FOXO1 & $2.1 \pm 0.44^{\ddagger}$ & $1.6 \pm 0.25^{\ddagger}$ \\
$2^{-\Delta \Delta C l}$ FOXO1 &
\end{tabular}

Definitions of abbreviations: $\mathrm{COPD}=$ chronic obstructive pulmonary disease; $\mathrm{HR}=$ heart rate; $\mathrm{MVV}=$ maximum voluntary ventilation; $\triangle \mathrm{Ct} F O X O 1=$ baseline $\mathrm{mRNA}$ levels forkhead transcription factor $01 ; 2^{-}$ $\Delta \triangle \mathrm{Cl}=$ fold changes. Data are presented as mean $\pm \mathrm{SEM}$.

SSignificant difference compared with healthy control subjects, $p<0.02$.

"Significant difference compared with healthy control subjects, $p<0.01$.

FSignificant difference compared with baseline, $p<0.05$.

\section{Markers of systemic inflammation and oxidative stress}

As expected (according to disease severity and body composition of the patients) at baseline, no significant differences of plasma inflammatory markers were observed between COPD patients and healthy controls (Table 1). Also in line with previous studies, COPD patients showed increased levels of protein oxidation compared to healthy controls $(p<0.05$; Table 1$)$. In the healthy control group but not in the patients the exercise bout resulted in elevated systemic IL-6 levels $2 h$ after exercise $(1.93 \pm 0.25$ before vs. $2.22 \pm 0.152 h$ after exercise; $p<0.05)$.

\section{NF-KB DNA binding activity}

As shown in Figure $1 \mathrm{~A}$, the basal NF-KB DNA binding activity in peripheral blood mononuclear cells was significantly lower in COPD patients compared to healthy controls $(p<0.05)$. No effect of exercise on NF- $\mathrm{kB}$ in peripheral blood mononuclear cells was observed in both groups. Furthermore, no exercise-induced changes in NF-KB DNA binding activity in skeletal muscle of both groups could be detected (Figure 1B). 
A.

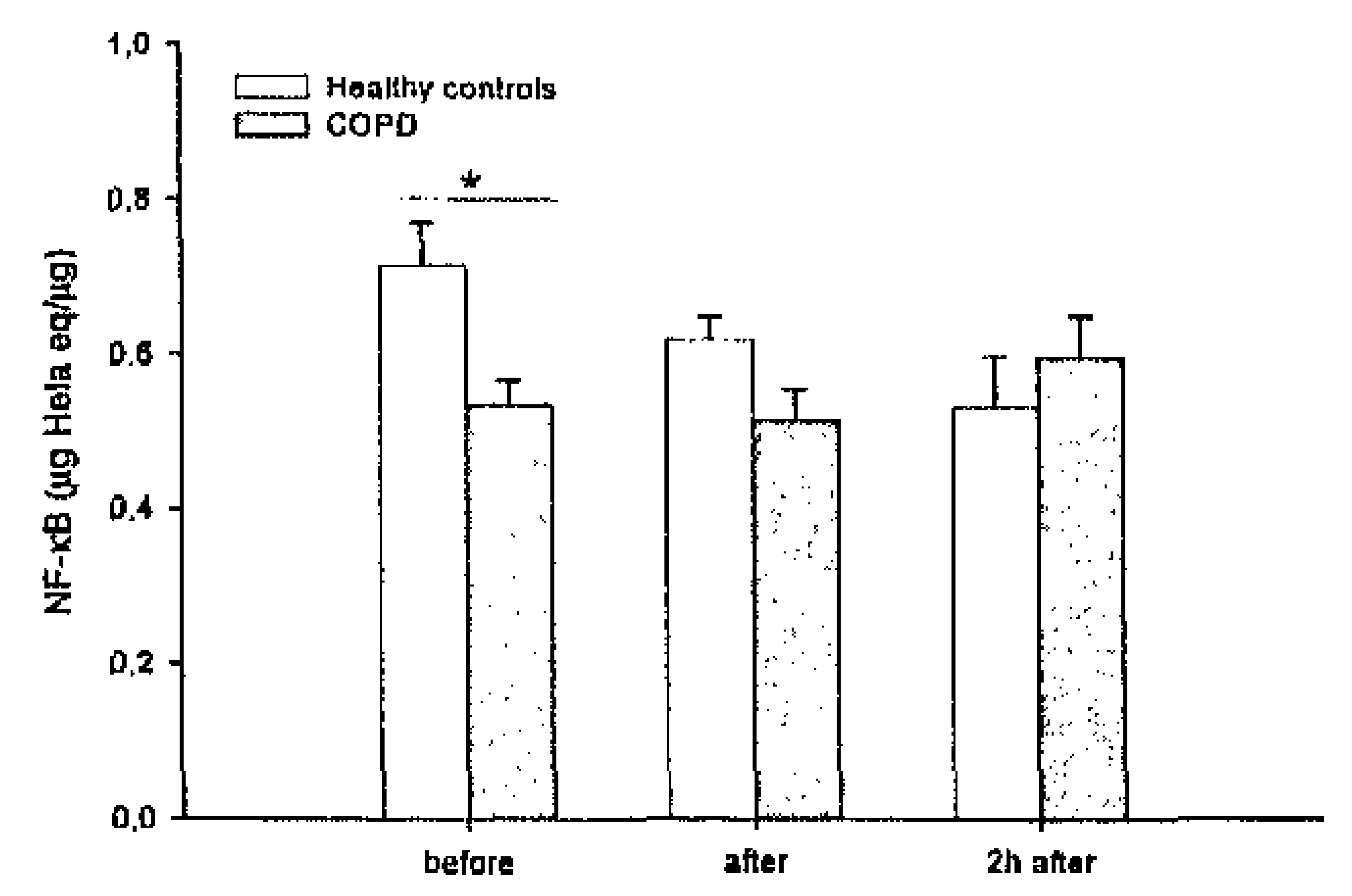

B.

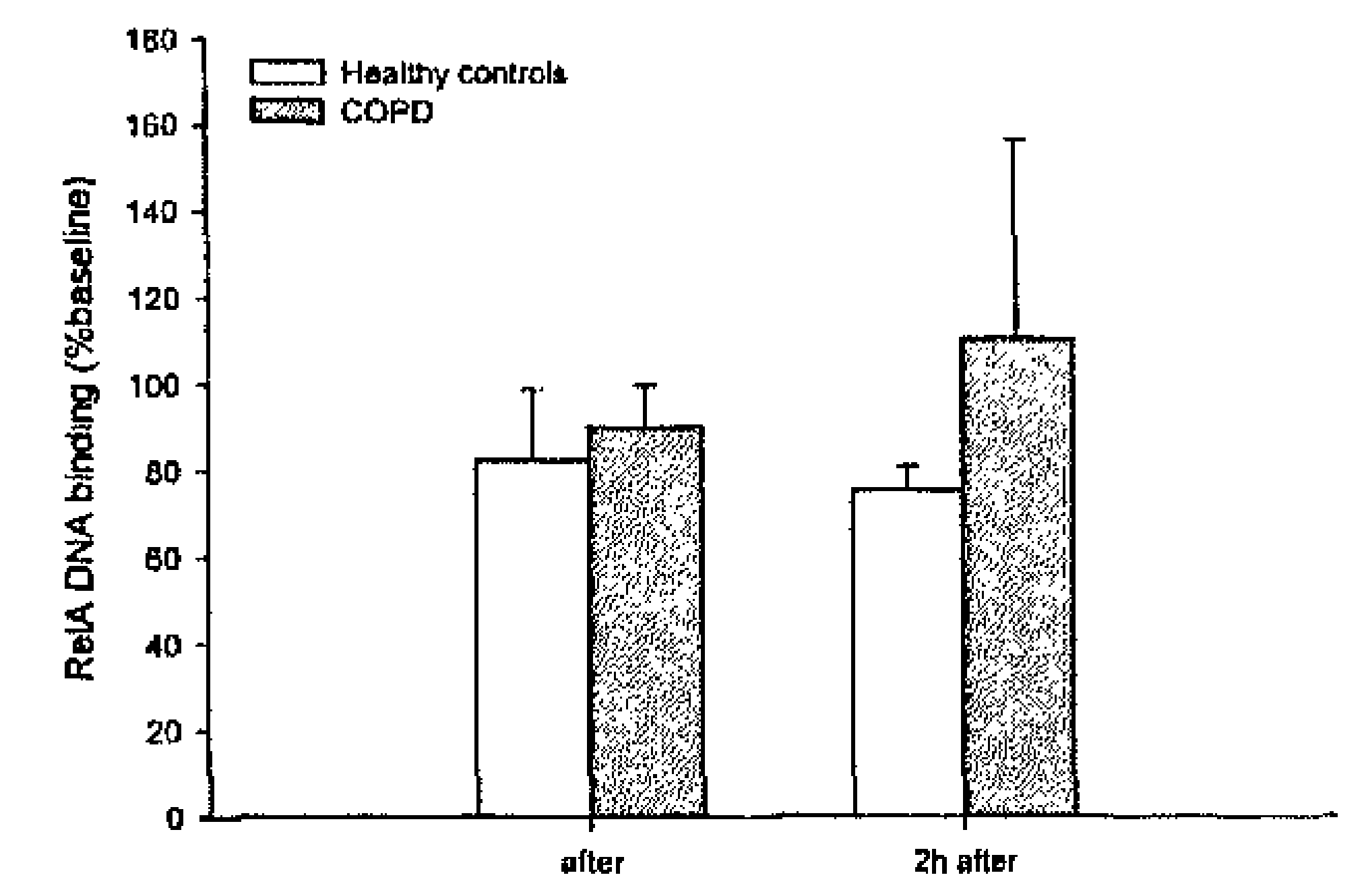

Figure 1. NF-KB DNA-binding activity was determined in (A) peripheral blood mononuclear cells and $(B)$ skeletal muscle in healthy control subjects and patients with COPD before, immediately after, and $2 \mathrm{~h}$ after exercise. $p<0.05$ significantly different between healthy control subjects and COPD patients. Values are expressed as mean \pm SEM; healthy controls ( $\square$ ) and COPD (国).

\section{$\mathrm{NF}-\mathrm{kB}$ related gene expression}

In this study, all genes were normalized to GAPDH, although similar results were obtained using Cyclophilin A as housekeeping gene (data not shown). Between group comparison revealed that at baseline, only MyoD mRNA content was significantly decreased in COPD compared to controls $(9.6 \pm 0.2 \Delta$ Ct controls vs. $10.5 \pm$ $0.3 \triangle \mathrm{Ct}$ COPD; $\mathrm{p}<0.05$ ).

Exercise-induced cytokine response. Healthy controls: As shown in Figure 2, muscle I $\mathrm{kB} \alpha \mathrm{mRNA}$ levels increased 1.5-fold immediately after exercise. IL-6, TNF- $\alpha$ and IL-1 $\beta$ mRNA levels increased 27-, 2.5- and 5.5-fold respectively. Also $2 \mathrm{~h}$ after exercise a 2-fold increase of IL-6 mRNA levels was observed. Patients: Only IL-6 mRNA levels were increased (20-fold) immediately after exercise. Moreover, the response of IL-1 $\beta$ to exercise was significantly lower in COPD than in healthy controls ( $p<0.05$; Figure 2). In both groups, there was no significant correlation between the changes in plasma cytokines and the increases in cytokine muscle mRNA levels. 

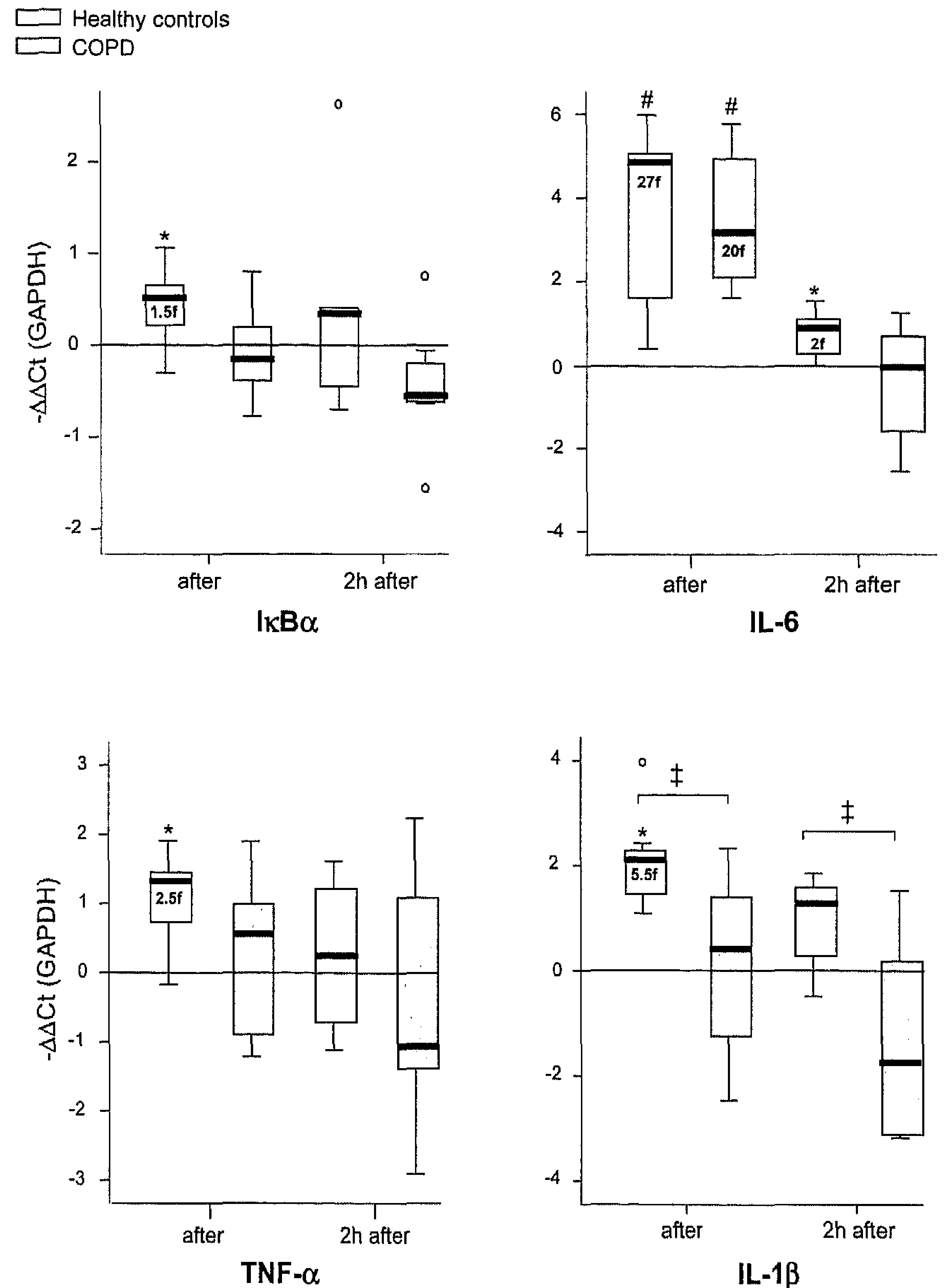

Figure 2. Relative gene expression of muscle $\mathrm{I} \mathrm{KB} \alpha$ and cytokines IL-6, TNF- $\alpha$ and IL-1 $\beta$ in COPD patients and healthy controls at different time points after the exercise test. $A-\Delta \Delta C$ t value above 0 indicates increased gene expression. Fold changes are presented in boxes $(f)$ : $p<0.05$; $" p<0.02$ significantly different from baseline values; ${ }^{\dagger} p<0.05$ significantly different between healthy control subjects and subjects with COPD. Values are expressed as mean \pm SEM; outliers (0); healthy controls ( $\square$ ) and COPD (四). 
Exercise-induced antioxidants response. Two hours after exercise, MnSOD mRNA levels increased 2-fold in healthy controls (Figure 3). No changes in MnSOD were observed in skeletal muscle of COPD. In contrast, Trx mRNA levels decreased 0.7fold in COPD patients immediately after exercise (Figure 3 ). This decrease tended to be significant $(p=0.091)$. Additionally, Trx response significantly differed between COPD and healthy controls after exercise $(p<0.05)$.
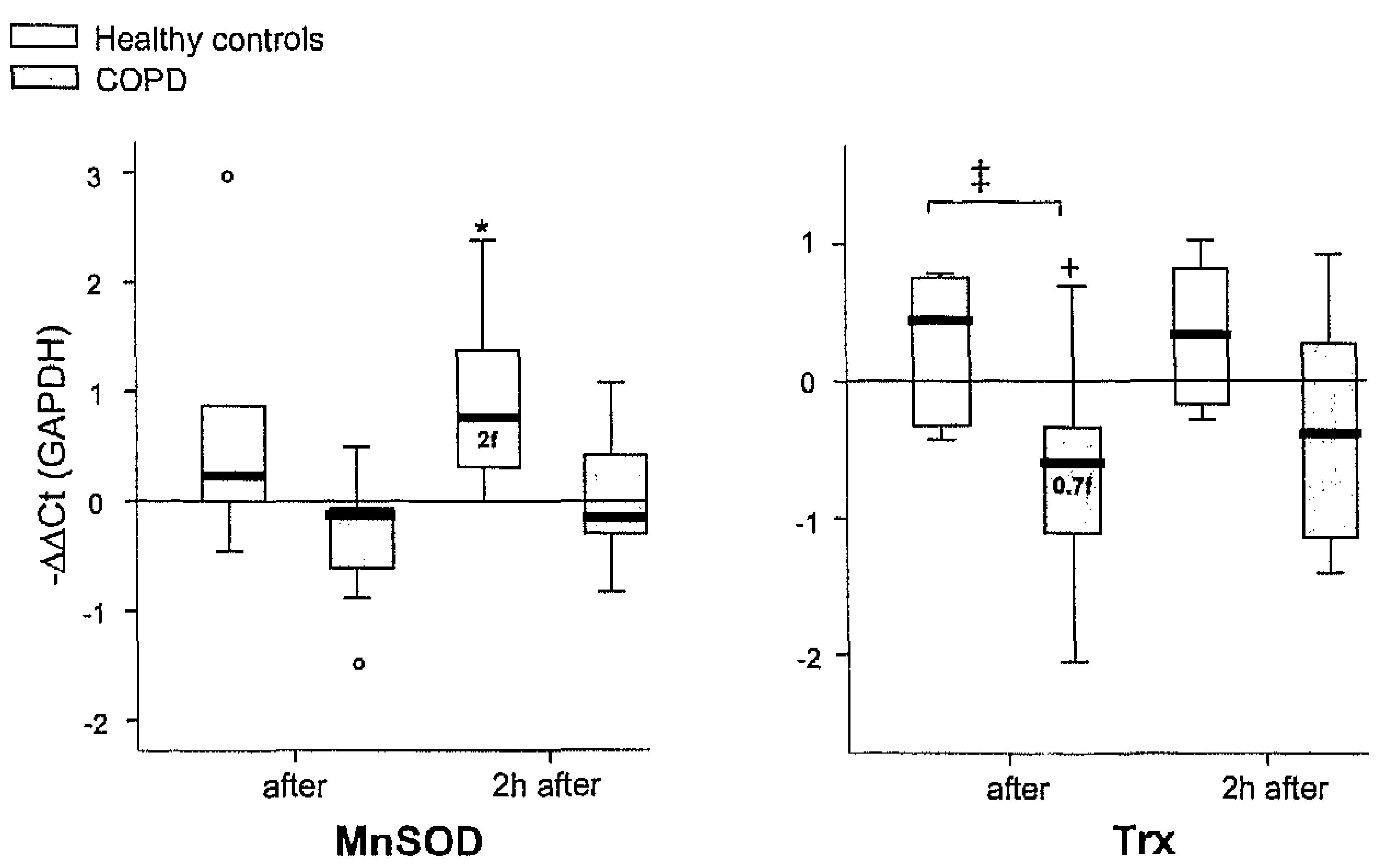

Figure 3. Relative gene expression of muscle antioxidant genes Mn-superoxide dismutase (MnSOD) and thioredoxin ( $T r x$ in COPD patients and healthy controls at different time points after the exercise test. $A-\triangle \Delta C t$ value above 0 indicates increased gene expression. Fold changes are presented in boxes (f): $p<0.05 ;{ }^{+} p=0.091$ significantly different from baseline values; ${ }^{\ddagger} p<0.05$ significantly different between healthy control subjects and subjects with COPD. Values are expressed as mean \pm SEM; outliers (O); healthy controls $(\square)$ and COPD (回).

Exercise-induced stress proteins. HO-1 mRNA increased 3.5-fold only in healthy controls $2 \mathrm{~h}$ after exercise ( $p<0.05$; Figure 4$)$. Moreover, immediately after exercise Hsp70 mRNA levels increased in healthy controls ( $p<0.05$; Figure 4 ) but no changes were observed in skeletal muscle of COPD. 

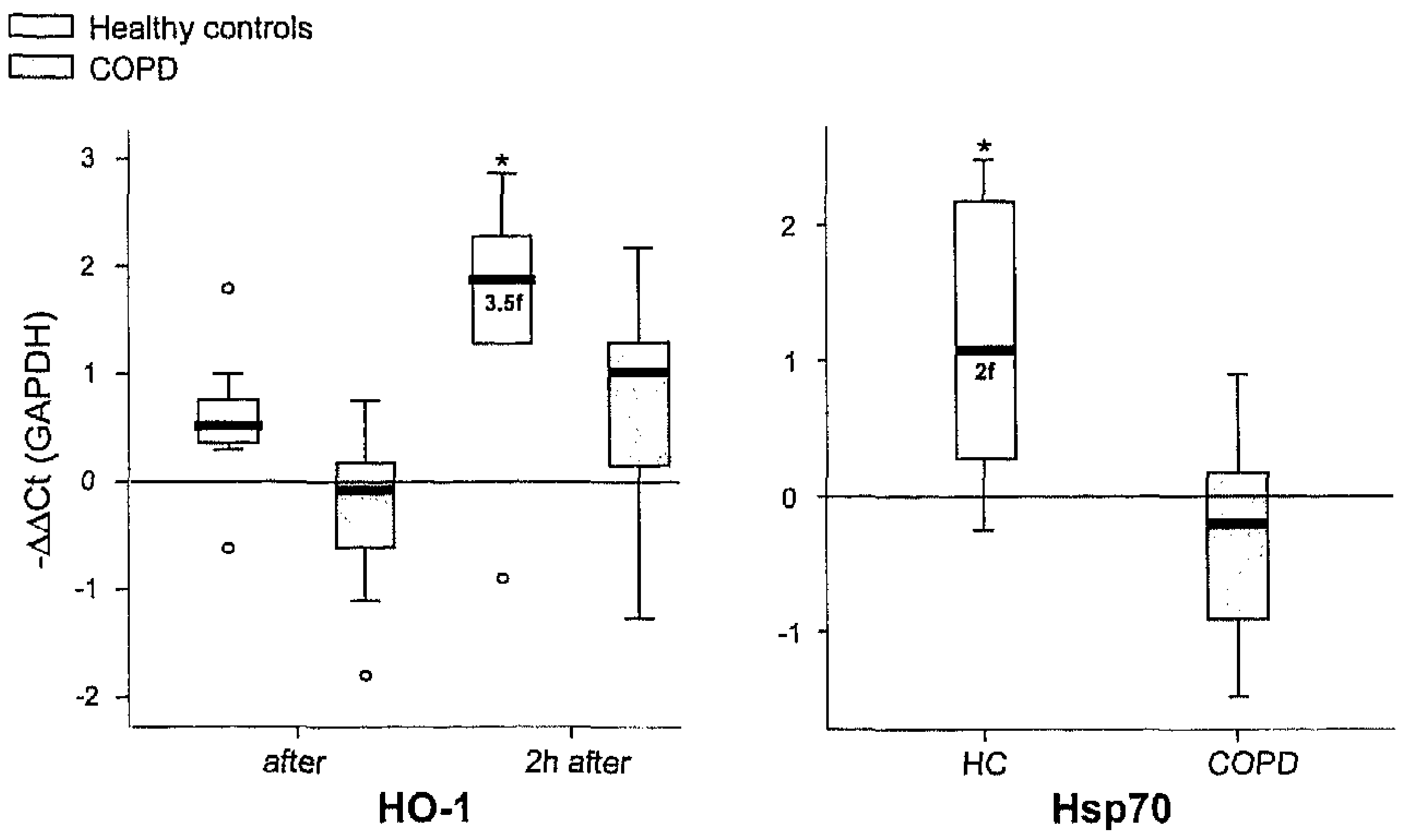

Figure 4. Relative gene expression of muscle stress proteins, heme oxygenase-1 (HO-1) and heat shock protein 70 (Hsp70) in COPD patients and healthy controls at different time points after the exercise test. $A-\Delta \Delta C$ t value above 0 indicates increased gene expression. Fold changes are presented in boxes $(f):$ : $p<0.05$ significantly different from baseline values. Values are expressed as mean \pm SEM; outliers (O); healthy controls ( $\square$ ) and COPD (

Exercise-induced apoptosis and myogenic differentiation related genes. No significant exercise-induced change in Bcl2 mRNA expression was observed in any groups (Figure 5). However, Bcl2 response significantly differed between COPD and healthy controls after exercise $(p=0.05$; Figure 5). For MyoD mRNA expression, no exercise-induced changes were observed in both groups (data not shown). 


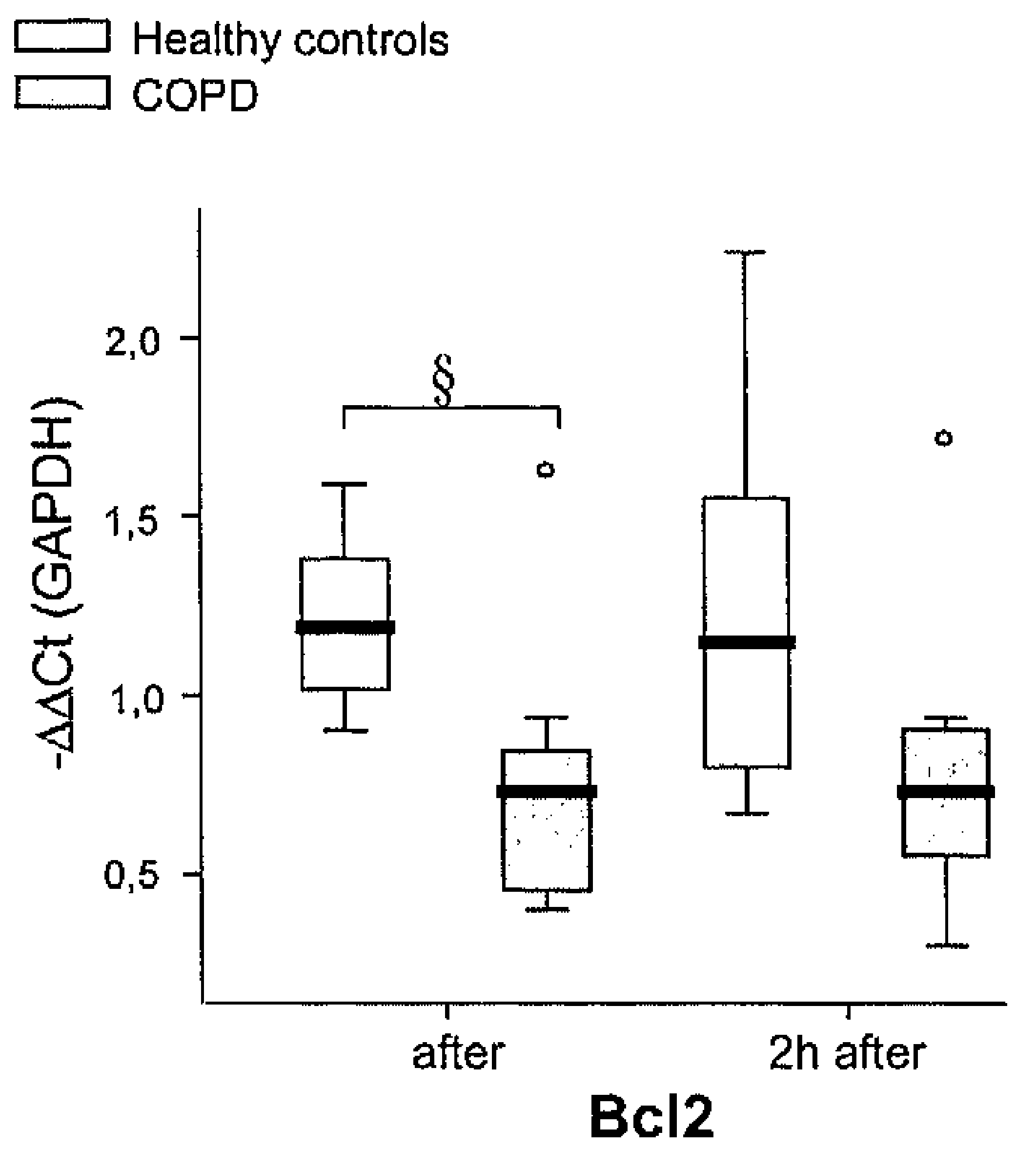

Figure 5. Relative gene expression of muscle apoptosis related $B c 12$ in COPD patients and healthy controls at different time points after the exercise test. $A-\Delta \Delta C t$ value above 0 indicates increased gene expression. ${ }^{5} \mathrm{p}<0.05$ significantly different between healthy control subjects and subjects with COPD. Values are expressed as mean \pm SEM; outliers $(0)$; healthy controls $(\square)$ and COPD (㖥).

\section{Marker of muscle oxidative stress}

Representative immunoblots of protein oxidation (detected as total carbonyls) in skeletal muscle of control subjects and patients with COPD are shown in Figure 6A. Four to five bands with molecular weight ranging from 20 to $68 \mathrm{kD}$ were detected in both groups. The migration pattern of these bands was similar between the two groups. Mean values of cumulative carbonyl band intensity in patients with COPD were significantly higher at baseline compared to healthy controls $(p<0.05$; Figure $6 \mathrm{~B})$. Moreover, $2 \mathrm{~h}$ after exercise, total protein carbonylation levels were significantly lower in COPD patients compared to healthy controls ( $p<0.05$; Figure $6 B$ ). 
A.

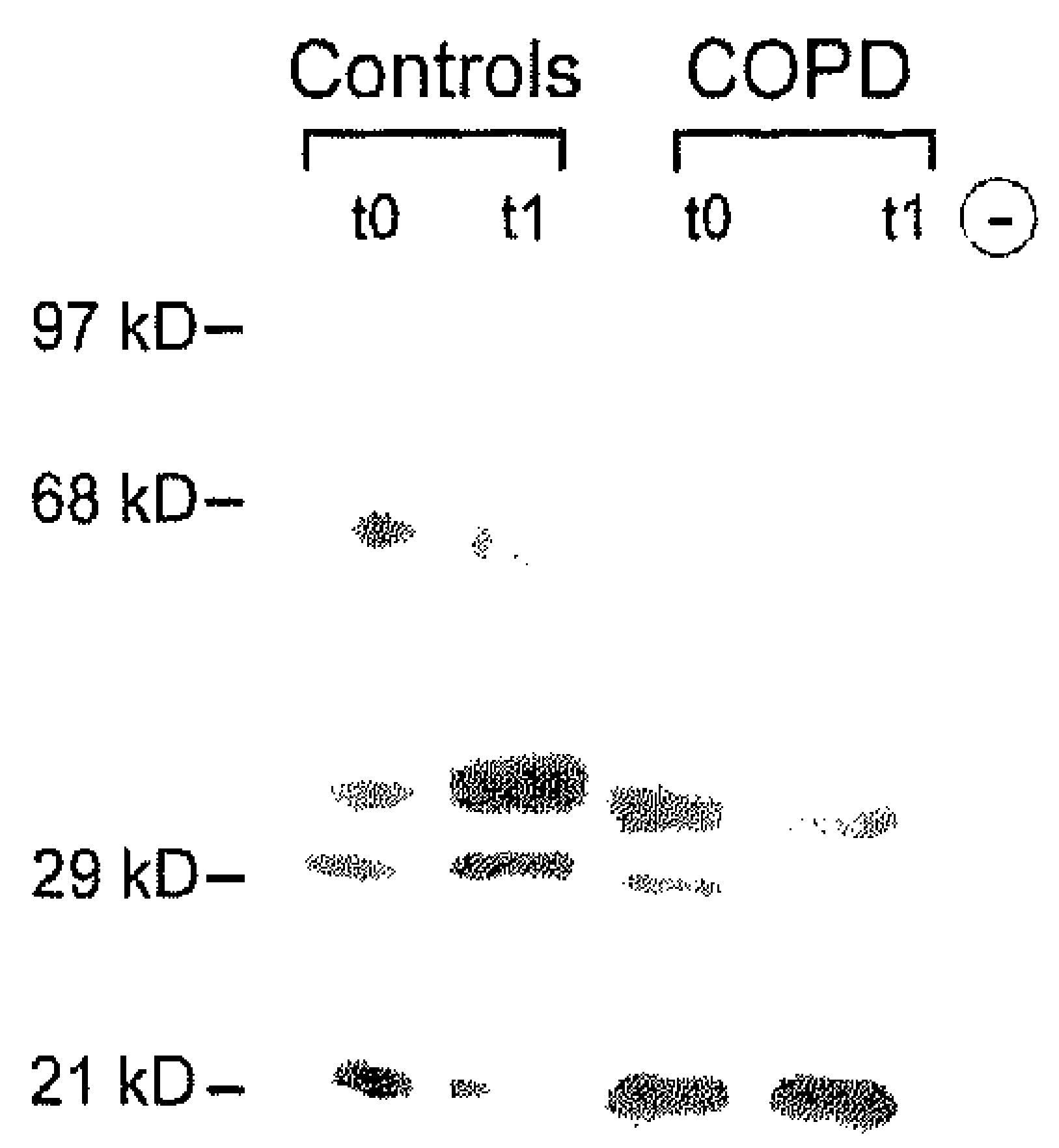

B.

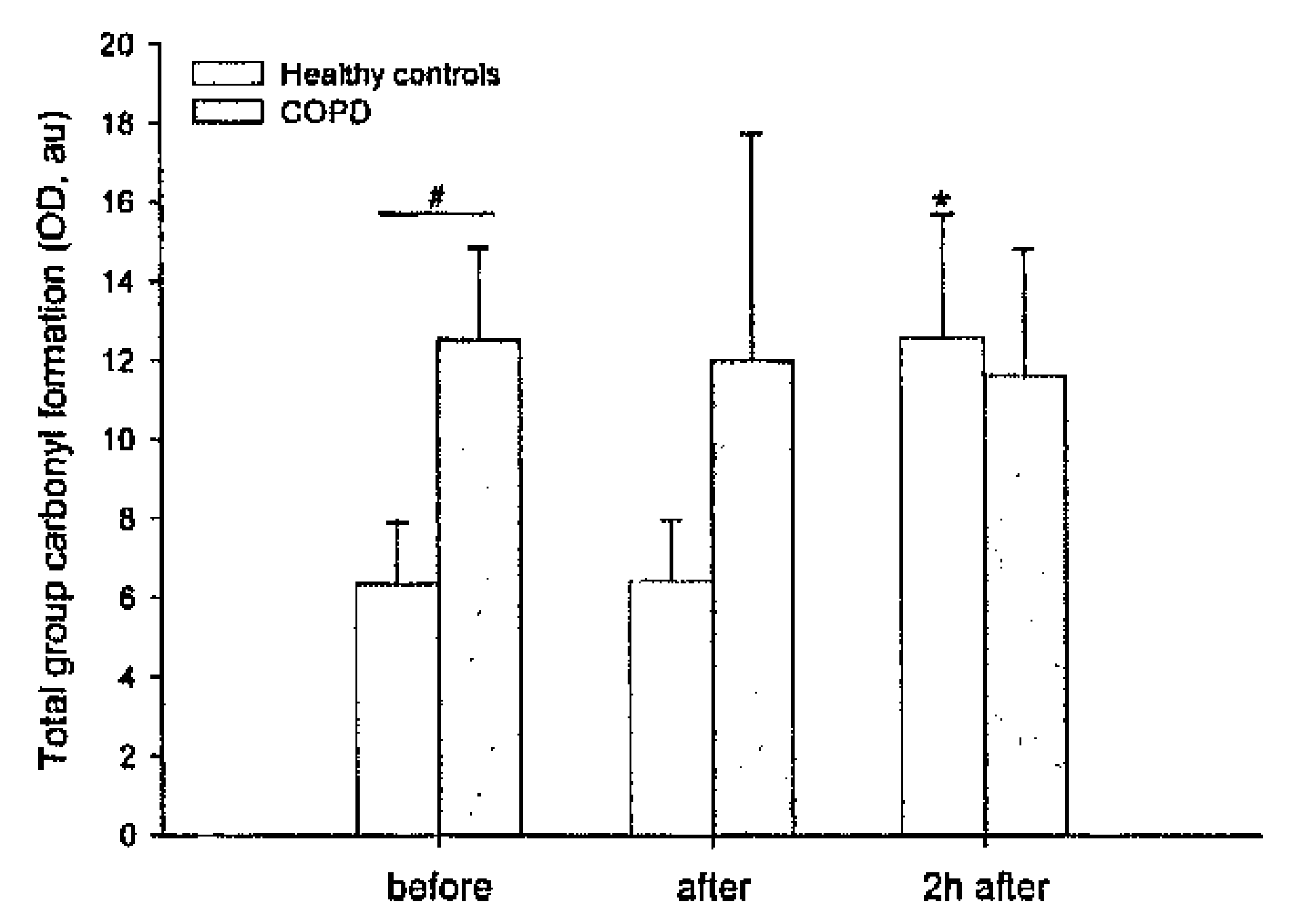

Figure 6. (A) Representative immunoblots of muscle protein carbonyl groups in healthy controls and patients with COPD before $(\mathrm{t} 0$ ) and $2 \mathrm{~h}$ after exercise ( $\mathrm{t} 1$ ). Four to five bands with molecular weight varying from 20 to $68 \mathrm{kD}$ were detected in both groups. Negative control (underivatized protein) is also shown. (B) Mean values of total carbonyl optical densities in skeletal muscles of healthy controls $(\square)$ and patients with COPD (圆). " p<0.05 significantly different from baseline values; $" \mathrm{p}<0.05$ significantly different between healthy control subjects and subjects with COPD.

\section{DISCUSSION}

The data in this study reveal that in patients with moderate COPD and in absence of muscle wasting or an enhanced systemic inflammatory response, NF- $\mathrm{KB}$ activity in PBMCs is diminished. Reduced basal NF-KB activity in PBMCs coincided with a consistently blunted exercise-induced response of NF-KB mediated gene expression in skeletal muscle.

$\mathrm{NF}-\mathrm{KB}$ is a critical intracellular mediator of inflammatory cytokines, antioxidants and survival factors. Limited information is available regarding the exercise-induced inflammatory response in patients with COPD. In contrast to earlier studies in patients with severe COPD and muscle atrophy, we did not find elevated basal plasma inflammatory cytokine levels (IL-6, TNF- $\alpha$ and IL-1 $1 \beta$ ) in this moderate COPD study group.[21, 22] Furthermore, plasma inflammatory cytokine levels were unchanged by the exercise test in COPD patients, suggesting that exercise did not induce systemic inflammation. Contradictory results have been reported for the exercise-induced inflammatory response in COPD.[21, 23] These discrepancies could be due to differences in patient population, study design and methodology. $A$ 
striking feature of our study was the markedly reduced basal levels of NF-KB activity in peripheral blood mononuclear cells in COPD patients compared to healthy controls. Reduced NF-KB DNA binding activity might be explained by the therapeutic use of glucocorticoids which have been shown to be potent inhibitors of activation of NF-KB through multiple mechanisms.[24] Alternatively, higher levels of endogenous steroids such as cortisol might be present in COPD.

Intriguingly, muscle $\mid \kappa B \alpha$ gene expression was only significantly upregulated after exercise in healthy controls, indicative of an increased NF-KB activation in healthy controls after exercise.[25] In line with the increased $I \kappa B \alpha$ expression in healthy controls, muscle IL- 6 , TNF- $\alpha$ and IL-1 $1 \beta$ mRNA gene expression increased after exercise indicating an inflammatory response in exercised muscle of healthy controls. Exercise-induced increases in muscle inflammatory cytokines, particularly IL-6 mRNA gene expression have been reported previously in healthy subjects.[26] In the present study, however, no significant changes were observed in muscle TNF- $\alpha$ and IL-1 $1 \beta$ mRNA expression after exercise in patients with COPD in agreement with a previous study.[23] In contrast to TNF- $\alpha$ and IL-1 $\beta$, muscle IL- 6 was increased immediately after exercise in COPD, although this increase was attenuated in comparison to healthy controls. Furthermore, the upregulated transcription of cytokines in skeletal muscle was not reflected in increased plasma cytokine levels. This can be explained by a different time-frame required for protein synthesis, but may also indicate that cytokines produced by skeletal myocytes act in a paracrine/autocrine fashion.[27] Although several studies have associated proinflammatory cytokines to skeletal muscle injury that occurs with strenuous exercise, there is evidence that under normal physiological conditions these cytokines contribute to repair processes. Opposing evidence from experimental studies regarding the role of TNF- $\alpha$ and inflammatory signalling in regeneration has been documented. It appears that, depending on timing, duration, magnitude and composition of the inflammatory response, muscle regeneration may beneficially or detrimentally be affected by TNF- $\alpha$ in a nuclear factor NF-KB-dependent fashion.[28, 29] Expression of IL-1 $\beta$ mRNA has also been linked to muscle tissue repair and regeneration.[30] Therefore, it is tempting to hypothesize that the observed higher expression of these inflammatory cytokines mediated by NF-KB in healthy controls may be a requirement for the remodelling and regeneration processes following exercise. Thus, the attenuated response observed in COPD may reflect the impaired regenerative capacity of skeletal muscles and may ultimately contribute to muscle wasting. This attenuated regenerative capacity may also be reflected by the decreased muscle mRNA levels of MyoD in COPD patients at baseline, since MyoD has a key role in regulating muscle differentiation and regeneration.[31] No exercise-induced significant differences were observed for this gene in both groups. This however 
could be due to the timing of the biopsies, since MyoD mRNA expression has been reported to peak between 4-12 hours after exercise and not as early as 2 hours.[32] Another class of NF-KB regulated genes that rapidly responds to ROS/inflammation includes antioxidant enzymes, such as MnSOD and Trx. The inability of muscle of COPD patients to respond to acute exercise was also apparent from the expression of these antioxidant genes. To date, no studies are available that have evaluated the effect of exercise on muscle MnSOD and Trx mRNA expression in COPD. MnSOD mRNA expression was increased in exercised muscle of healthy controls only. In addition, Trx showed a tendency to be lower in skeletal muscle of COPD than healthy controls. Despite the increased expression of antioxidants, healthy controls showed enhanced levels of muscle protein carbonylation $2 \mathrm{~h}$ after exercise. A likely explanation for the absence of an increase in protein carbonylation in COPD patients after exercise might be attributed to the already elevated levels at rest. With respect to stress proteins with antioxidant properties, the present investigation indicates a reduced exercise-induced expression of $\mathrm{HO}-1$ and $\mathrm{Hsp} 70$ at mRNA level in skeletal muscle of patients with COPD when compared to healthy controls. No comparison with other studies is possible since data regarding the effects of an acute exercise on HO-1 or Hsp70 expression in skeletal muscle of COPD are not available in literature. Both stress proteins appear to be highly inducible by exercise and represent a major factor acting against exercise-induced oxidative stress.[19, 33] The protective effects of $\mathrm{HO}-1$ activity have been attributed to the antioxidant properties of its byproducts (biliverdin, carbon monoxide and ferritin). It is still controversial as to how exercise-generated ROS induce upregulation of Hsp70. Taken together, these data show that COPD patients have a reduced muscle antioxidant defense system in response to exercise when compared to healthy controls.

It has also been suggested that NF-kB plays an important role in programmed cell death or apoptosis.[34] Conflicting results have been reported regarding the incidence of apoptosis in skeletal muscles from patients with COPD.[35, 36] In the present study, the anti-apoptotic protein $\mathrm{Bcl} 2$ response was significantly lower in COPD than in healthy controls after exercise. This might imply that skeletal muscle from COPD patients is less well protected from apoptosis, although more markers of survival and apoptosis should be measured to properly address this hypothesis.

Strikingly, despite the activation of the NF-KB regulated genes in response to exercise, the present study showed no exercise-induced changes in NF-KB DNA binding activity in skeletal muscle of both groups. Results from earlier studies investigating NF-KB activity have been contradictory, demonstrating either increased activity after an acute exercise $[37,38]$ or a reduction in NF-kB nuclear binding activity after exercise.[39] Differences in duration of the exercise protocols likely explain differences between studies. Nevertheless, alterations in the expression of NF-KB regulated genes are not solely governed by translocation, but also by post-translational 
modification of RelA. For instance, phosphorylation [40] and acetylation [41] strongly enhance transcriptional activity of RelA, which may explain the increased expression of NF-KB target genes observed in healthy controls in absence of alterations in DNA binding activity.

\section{Limitations of the study}

A limitation of the present study is the relatively small number of subjects studied. Because this was a complex study design that involved multiple muscle biopsies, recruitment typically was difficult. Moreover, we studied clinically and weight stable COPD patients with moderate disease and normal fat-free mass to exclude potential changes in muscle NF-KB activity resulting from disease exacerbations or pulmonary cachexia. Yet, despite the relatively small number of subjects studied, we found consistent results in terms of a blunted exercise-induced response of NF-KB mediated gene expression in skeletal muscle. We were also able to detect betweengroup comparisons of the exercise response.

\section{Conclusions}

These data clearly reveal differential NF-kB mediated gene expression of skeletal muscle in response to exercise in patients with moderate COPD compared to healthy age-matched controls. The impaired response to exercise in COPD patients is reflected by a blunted expression of inflammatory cytokines, antioxidants, heat shock proteins and survival factors. Further research is needed to delineate the specific role of redox-regulated pathways in exercise-induced adaptations in COPD as well as the modulating effect of rehabilitation.

\section{ACKNOWLEDGEMENTS}

The authors thank Joan Does and Herman-Jan Pennings for obtaining the muscle biopsies. They thank the staff of the Lung Function and Laboratory for their skillful support during the study. They also thank Marco Kelders for technical assistance. 


\section{REFERENCES}

1. Agusti AG. Systemic effects of chronic obstructive pulmonary disease. Proc Am Thorac Soc. 2005;2(4):367-70; discussion 71-2.

2. Couillard A, Maltais $F$, Saey $D$, et al. Exercise-induced quadriceps oxidative stress and peripheral muscle dysfunction in patients with chronic obstructive pulmonary disease. $A m \mathrm{~J}$ Respir Crit Care Med. 2003;167(12):1664-9.

3. Mercken EM, Hageman GJ, Schols AM, et al. Rehabilitation decreases exercise-induced oxidative stress in chronic obstructive pulmonary disease. Am J Respir Crit Care Med. 2005;172(8):9941001.

4. Pantano $C$, Reynaert NL, van $\operatorname{der}$ Vliet $A$, et al, Redox-sensitive kinases of the nuclear factorkappaB signaling pathway. Antioxid Redox Signal. 2006;8(9-10):1791-806.

5. Reid MB, Durham WJ. Generation of reactive oxygen and nitrogen species in contracting skeletal muscle: potential impact on aging. Ann N Y Acad Sci. 2002;959:108-16.

6. Cai D, Frantz JD, Tawa NE, Jr., et al. IKKbeta/NF-kappaB activation causes severe muscle wasting in mice. Cell. 2004;119(2):285-98.

7. Langen RC, Schois AM, Kelders MC, et al. Inflammatory cytokines inhibit myogenic differentiation through activation of nuclear factor-kappaB. Faseb J. 2001;15(7):1169-80.

8. Hollander J, Fiebig R, Gore $\mathrm{M}$, et al. Superoxide dismutase gene expression is activated by a single bout of exercise in rat skeletal muscle. Pflugers Arch. 2001;442(3):426-34.

9. Zhang J, Velsor LW, Patel JM, et al. Nitric oxide-induced reduction of lung cell and whole lung thioredoxin expression is regulated by NF-kappaB. Am J Physiol. 1999;277(4 Pt 1):L787-93.

10. Barreiro $E$, Comtois $A S$, Mohammed $S$, et al. Role of heme oxygenases in sepsis-induced diaphragmatic contractile dysfunction and oxidative stress. Am J Physiol Lung Cell Mol Physiol. 2002;283(2):L476-84.

11. Pattwell DM, McArdle A, Morgan JE, et al. Release of reactive oxygen and nitrogen species from contracting skeletal muscle cells. Free Radic Biol Med. 2004;37(7):1064-72.

12. Ivanov VN, Deng G, Podack ER, et al. Pleiotropic effects of $B c l-2$ on transcription factors in $T$ cells: potential role of NF-kappa B p50-p50 for the anti-apoptotic function of Bcl-2. Int Immunol. 1995;7(11):1709-20.

13. Guttridge DC, Mayo MW, Madrid LV, et al. NF-kappaB-induced loss of MyoD messenger RNA: possible role in muscle decay and cachexia. Science. 2000;289(5488):2363-6.

14. Fabbri LM, Hurd SS. Global Strategy for the Diagnosis, Management and Prevention of COPD: 2003 update. Eur Respir J. 2003;22(1):1-2.

15. Schols AM, Wouters EF, Soeters PB, et al. Body composition by bioelectrical-impedance analysis compared with deuterium dilution and skinfold anthropometry in patients with chronic obstructive pulmonary disease. Am J Clin Nutr. 1991;53(2):421-4.

16. Quanjer PH, Tammeling GJ, Cotes JE, et al. Lung volumes and forced ventilatory flows. Report Working Party Standardization of Lung Function Tests, European Community for Steel and Coal. Official Statement of the European Respiratory Society. Eur Respir I Suppl. 1993;16:540.

17. Franssen FM, Wouters EF, Baarends EM, et al. Arm mechanical efficiency and arm exercise capacity are relatively preserved in chronic obstructive pulmonary disease. Med Sci Sports Exerc. 2002;34(10):1570-6.

18. Bergström J. Muscle electrolytes in man: determination by neutron activation analysis on needle biopsy specimens: a study on normal subjects, kidney patients and patients with chronic diarrhoea. Scand J Clin Lab Invest. 1962;14:1-110. 
19. Pilegaard $H_{1}$ Ordway $G A$, Saltin $B$, et al. Transcriptional regulation of gene expression in human skeletal muscle during recovery from exercise. Am J Physiol Endocrinol Metab. 2000;279(4):E806-14.

20. Buss $\mathrm{H}$, Chan TP, Sluis KB, et al. Protein carbonyl measurement by a sensitive ELISA method. Free Radic Biol Med. 1997;23(3):361-6.

21. Koechlin $C$, Couillard A, Cristol JP, et al. Does systemic inflammation trigger local exerciseinduced oxidative stress in COPD? Eur Respir J. 2004;23(4):538-44.

22. Vogiatzis I, Stratakos G, Simoes DD, et al. Effects of rehabilitative exercise on peripheral muscle TNF-alpha, IL-6, IGF-I and MyoD expression in COPD patients. Thorax. 2007.

23. Rabinovich RA, Figueras $M$, Ardite $E$, et al. Increased tumour necrosis factor-alpha plasma levels during moderate-intensity exercise in COPD patients. Eur Respir J. 2003;21(5):789-94.

24. Barnes PJ, Adcock I. Anti-inflammatory actions of steroids: molecular mechanisms. Trends Pharmacol Sci. 1993;14(12):436-41.

25. Chiao PJ, Miyamoto $S$, Verma IM. Autoregulation of I kappa $B$ alpha activity. Proceedings of the National Academy of Sciences of the United States of America. 1994;91(1):28-32.

26. Ostrowski $K$, Rohde $T$, Zacho $M$, et al. Evidence that interleukin- 6 is produced in human skeletal muscle during prolonged running. J Physiol. 1998;508 ( Pt 3):949-53.

27. Steensberg $A$, Keller C, Starkie RL, et al. IL-6 and TNF-alpha expression in, and release from, contracting human skeletal muscle. Am J Physiol Endocrinol Metab. 2002;283(6):E1272-8.

28. Langen RC, Schols AM, Kelders MC, et al. Tumor necrosis factor-alpha inhibits myogenesis through redox-dependent and -independent pathways. Am J Physiol Cell Physiol. 2002;283(3):C714-21.

29. Langen RC, Van Der Velden JL, Schols AM, et al. Tumor necrosis factor-alpha inhibits myogenic differentiation through MyoD protein destabilization. Faseb J. 2004;18(2):227-37.

30. Mackiewicz Z, Hukkanen M, Povilenaite D, et al. Dual effects of caspase-1, interleukin-1 beta, tumour necrosis factor-alpha and nerve growth factor receptor in inflammatory myopathies. Clin Exp Rheumatol. 2003;21(1):41-8.

31. $\mathrm{Li} L$, Olson EN. Regulation of muscle cell growth and differentiation by the MyoD family of helix-loop-helix proteins. Adv Cancer Res. 1992;58:95-119.

32. Raue U, Slivka D, Jemiolo B, et al. Myogenic Gene Expression at Rest and Following a Bout of Resistance Exercise in Young (18-30 y) and Old (80-89 y) Women. J Appl Physiol. 2006.

33. Febbraio MA, Koukoulas I. HSP72 gene expression progressively increases in human skeletal muscle during prolonged, exhaustive exercise. J App/ Physiol. 2000;89(3):1055-60.

34. Perkins ND. The Rel/NF-kappa B family: friend and foe. Trends Biochem Sci. 2000;25(9):434-40.

35. Gosker HR, Kubat B, Schaart G, et al. Myopathological features in skeletal muscle of patients with chronic obstructive pulmonary disease. Eur Respir J. 2003;22(2):280-5.

36. Agusti AG, Sauleda J, Miralles $C$, et al. Skeletal muscle apoptosis and weight loss in chronic obstructive pulmonary disease. Am J Respir Crit Care Med. 2002;166(4):485-9.

37. Ji LL, Gomez-Cabrera MC, Steinhafel N, et al. Acute exercise activates nuclear factor (NF)kappaB signaling pathway in rat skeletal muscle. Faseb J. 2004;18(13):1499-506.

38. Ho RC, Hirshman MF, Li Y, et al. Regulation of IkappaB kinase and NF-kappaB in contracting adult rat skeletal muscle. Am J Physiol Cell Physiol. 2005;289(4):C794-801.

39. Durham WJ, Li YP, Gerken E, et al. Fatiguing exercise reduces DNA binding activity of NFkappaB in skeletal muscle nuclei. J Appl Physiol. 2004;97(5):1740-5.

40. Zhong H, Voll RE, Ghosh S. Phosphorylation of NF-kappa B p65 by PKA stimulates transcriptional activity by promoting a novel bivalent interaction with the coactivator CBP/p300. Molecular cell. 1998;1(5):661-71. 
Chapter 4

41. Chen LF, Greene WC. Regulation of distinct biological activities of the NF-kappaB transcription factor complex by acetylation. Journal of molecular medicine (Berlin, Germany). 2003;81(9):549-57. 
NF- $\mathrm{KB}$ mediated gene expression

\section{Online Data Supplement:}

Reduced NF-KB mediated gene expression in skeletal muscle of patients with COPD in response to acute exercise

Evi M. Mercken, Geja J. Hageman, Ramon C.J. Langen, Emiel F.M. Wouters and Annemie M.W.J. 


\section{MATERIALS AND METHODS}

\section{Study population}

All patients were ex-smokers and had not experienced respiratory tract infection or exacerbation of their disease for at least 4 weeks prior to the study. Clinically and weight stable COPD patients with moderate disease and normal fat-free mass were included to exclude potential changes in muscle NF-KB activity resulting from disease exacerbations or pulmonary cachexia. This group also reflects the COPD population for which exercise training is indicated as integrated part of disease management. In addition, all participants were questioned on their dietary habits to ensure that none were taking antioxidants or vitamin supplements. All patients received anticholinergic and $\beta 2$-agonists as bronchodilator therapy, five patients received inhaled corticosteroids and one patient theophylline. None were treated with oral corticosteroids.

\section{Anthropometry and spirometry}

Body composition was determined by bioelectrical impedance analysis (BIA; Xitron technologies, San Diego, CA, USA) as described previously (E1). All participants underwent flow volumes including measurements of $F E V_{1}$ and $F V C$ with the highest value from at least three properly performed measurements being used for analysis. The values obtained were expressed as a percentage of the reference value (E2).

\section{Exercise capacity}

Participants performed an incremental (10 Watt/minute) cycle ergometer test as described previously (E3). Expired gases were analyzed using breath-by-breath analysis through a breathing mask (Oxygen- $\beta$, Jaeger, Würzburg, Germany). Peak ventilatory $\left(V^{\prime} E\right)$ reserve was calculated as $100 \%-\left(100 \times\right.$ peak $\left.V^{\prime} E\right) /\left(F E V_{1} \times 37.5\right)$ and peak heart rate $(H R)$ reserve was calculated as $100 \%-(100 \times$ peak $\mathrm{HR}) /(220$ age) (E4, E5). The submaximal exercise test was performed at $70 \%$ of peak workload achieved during the incremental exercise test. This exercise protocol was chosen since it is comparable with regular exercise training as part of pulmonary rehabilitation. The endurance time was standardized at 10 minutes.

\section{Markers of systemic inflammation and oxidative stress}

Venous blood samples $(10 \mathrm{ml})$ were drawn into ethylenediaminetetraacetic acid (EDTA)-containing tubes (Venoject). All blood samples were immediately put on ice, and kept on ice during sample preparation. Plasma was obtained by centrifugation $\left(800 \times g\right.$ for 10 minutes at $\left.4^{\circ} \mathrm{C}\right)$ and stored at $-80^{\circ} \mathrm{C}$ until analysis. 


\section{Preparation of nuclear extracts}

PBMCs After removal of the plasma, the blood was brought to $15 \mathrm{ml}$ with cold phosphate-buffered saline (PBS) and layered on an equal volume of Lymphoprep medium in a 50-ml tube with a filter (Greiner) of peripheral blood mononuclear cells (PBMCs). After centrifugation at $800 \times \mathrm{g}$ for $30 \mathrm{~min}$ at $4^{\circ} \mathrm{C}$, gradient-separated PBMCs were recovered, resuspended in 10-ml cold PBS, and centrifuged again at $250 \times \mathrm{g}$ for $10 \mathrm{~min}$ at $4^{\circ} \mathrm{C}$. The cells were resuspended in $1 \mathrm{ml}$ cold PBS and centrifuged at $800 \times g$ for $5 \mathrm{~min}$ and the pellet was used to prepare nuclear extracts for NF-KB determination. Nuclear extracts were prepared as described by Hofmann et al. (E6).

Skeletal muscle. Frozen muscle was homogenized in ice-cold buffer A $(20 \mathrm{mM}$ HEPES pH 7.8, $20 \mathrm{mM} \mathrm{KCl}, 4 \mathrm{mM} \mathrm{MgCl}_{2}, 0.2 \mathrm{mM}$ EDTA pH 8.0, $1 \mathrm{mM}$ DTT, $0.2 \mathrm{mM}$ NaVanadate, $0.4 \mathrm{mM}$ PMSF, $0.3 \mathrm{mg} / \mathrm{ml}$ Leupeptin, $0.2 \mathrm{mM} \mathrm{NaFl}$ ). After homogenizing samples were kept on ice for 15 minutes and incubated on a rotating platform at $4^{\circ} \mathrm{C}$ for 45 minutes. Buffer B (Nonidet P40) was added, samples were mixed vigorously and centrifuged for 5 minutes at $14000 \mathrm{rpm}$. Supernatant was removed (=cytoplasmatic fraction), pellets were washed in buffer $A+B$, mixed and centrifuged. Supernatant was removed and nuclei were lysed in buffer $C$ (100 mM HEPES pH $7.8,100 \mathrm{mM} \mathrm{KCl}, 600 \mathrm{mM} \mathrm{NaCl}, 0.2 \mathrm{mM}$ EDTA pH 8.0, 20\% glycerol, $1 \mathrm{mM}$ DTT, $0.2 \mathrm{mM} \mathrm{NaVanadate,} 0.4 \mathrm{mM}$ PMSF, $0.2 \mathrm{mM} \mathrm{NaFI}$ ) by a 20 minute incubation at a rotating platform at $4^{\circ} \mathrm{C}$. Samples were centrifuged $(5 \mathrm{~min}$ at $14000 \mathrm{rpm})$, supernatant was transferred to a new eppendorf tube and stored at $-80^{\circ} \mathrm{C}$.

\section{Skeletal muscle analysis}

Gene expression analyses by quantitative real-time $P C R$. Biopsies were analyzed for FOX01, IkB $\alpha, I L-6, T N F-\alpha, I L-1 \beta$, MnSOD, Trx, HO-1, Hsp70, Bcl2 and MyoD expression. For this, total RNA was isolated from $\sim 60 \mathrm{mg}$ of muscle tissue which was homogenized (POLYTRON ${ }^{\circledR}$ PT 2100, Kinemaitca AG) in presence of TRlzol ${ }^{\circledR}$ reagent (Gibco BRL). Total RNA was extracted according to the manufacturer's instructions. The RNeasy ${ }^{\circledR}$ Mini Kit (Qiagen) was used to purify total RNA from salts and residual DNA. Total RNA concentration was determined spectrophotometrically. cDNA was generated from $0.4 \mu \mathrm{g}$ of total RNA according to the manufacturer's instructions using the Bio-Rad iScript cDNA synthesis kit (Bio-Rad Laboratories, Hercules, CA). Aliquots were used for real-time PCR on the BioRad MyiQ iCycler Single Color real-time PCR detection system using $1 Q^{T M} S^{T} B^{\circledR}$ Green Supermix, containing all ingredients; iTaq Polymerase, dNTPs, SYBR ${ }^{\circledR}$ Green I and buffers. GAPDH, Cyclophilin A and $\beta$-actin were used as housekeeping genes and all reactions were performed in duplicate. The expression of $\beta$-actin appeared to be influenced by exercise, as described previously, but GAPDH and Cyclophilin A were stable in response to exercise (E7). Therefore, $\beta$-actin was left out in the further 
Chapter 4

analyses. To avoid inter-assay variability, all samples were analyzed together in one single real-time PCR run. The data were analyzed using $\Delta \mathrm{Ct}$ and $\Delta \Delta \mathrm{Ct}$ (E8-E10). To compare the relative gene expression between COPD patients and healthy controls at baseline $\Delta \mathrm{Ct}$ was used. The $\Delta \Delta \mathrm{Ct}$ was used to calculate relative changes in gene expression within each group as a result of the exercise test. Fold changes were calculated using the $2^{-\Delta \Delta C t}$ method. PCR primers are shown in Table E1.

Table E1. Primer sequences.

\begin{tabular}{lll}
\hline Target mRNA & Forward primer $\left(5^{\prime} \rightarrow 3^{\prime}\right)$ & Reverse primer $\left(5^{\prime} \rightarrow 3^{\prime}\right)$ \\
\hline FOX01 & CGCCCTCGAACTAGCTCAAA & GCGGGTACACCATAGAATGCA \\
IkB $\alpha$ & CTACACCTTGCCTGTGAGCA & TCCTGAGCATTGACATCAGC \\
IL-6 & CCAGGAGCCCAGCTATGAAC & CCCAGGGAGAAGGCAACTG \\
TNF- $\alpha$ & TCAATCGGCCCGACTATCTC & CAGGGCAATGATCCCAAAGT \\
IL-1 3 & CTGAGCTCGCCAGTGAAATG & TTTAGGGCCATCAGCTTCAAA \\
MnSOD & GTGGTCCATGAAAAAGCAGATGA & CACAAGCCAAACGACTTCCA \\
Trx & TGTGGATGACTGTCAGGATGTTG & TTGTCCCTTCTTAAAAAACTGGAAT \\
HO-1 & CTTCTTCACCTTCCCCAACA & GCTCTGGTCCTTGGTGTCAT \\
Hsp70 & TCGAGGTGGCCGTTAGTTG & AGGCGAGCGACGTTAGGA \\
Bcl2 & TCGCCCTGTGGATGACTGA & CAGAGACAGCCAGGAGAAATCA \\
MyoD & CACAGCGCGGTTTTTCC & TGAACCTAGCCCCTCAAGGTT
\end{tabular}

Definition of abbreviations: FOXO1: forkhead transcription factor O1; MnSOD: Mn-superoxide dismutase; Trx: thioredoxin; HO-1: heme oxygenase 1; Hsp70: heat shock protein-70; MyoD: myogenic differentiation factor.

Western blotting. Frozen muscle samples were homogenized in an aqueous buffer containing Tris- $\mathrm{HCl}(20 \mathrm{mM}), \mathrm{NaCl}(150 \mathrm{mM})$, Nonidet $\mathrm{P}-40(1 \% \mathrm{v} / \mathrm{v})$, Dithiothreitol $(1 \mathrm{mM})$, Sodium orthovanadate $(1 \mathrm{mM})$, Phenylmethylsulphonyl fluoride $(1 \mathrm{mM})$, Leupeptin $(10 \mu \mathrm{g} / \mathrm{ml})$ and Aprotenin $(1 \%)(\mathrm{pH}=7.4)$. Samples were then centrifuged at $10.000 \times \mathrm{g}$ at $4^{\circ} \mathrm{C}$ for $30 \mathrm{~min}$. The pellet was discarded and the supernatant was designated as a crude homogenate. Total muscle protein level in each sample was determined with the Bradford (Biorad Inc., Hercules, CA) technique. Changes in protein carbonylation in crude homogenates were detected using a commercial kit (Oxyblot kit; Chemicon International Inc.). To evaluate the selectivity of carbonyl measurements, muscle protein samples also underwent protein carbonyl detection procedure without the derivatization step (negative control). The blots were scanned with an imaging densitometer and optical densities (OD) of protein bands were quantified using Image Master VDS (Amersham Pharmacia Biotech, Uppsala, Sweden) software. Total carbonyls in each muscle sample were calculated by adding OD of individual carbonylated protein bands. 
NF-KB mediated gene expression

\section{REFERENCES}

E1. Schols AM, Wouters EF, Soeters PB, and Westerterp KR. Body composition by bioelectricalimpedance analysis compared with deuterium dilution and skinfold anthropometry in patients with chronic obstructive pulmonary disease. Am J Clin Nutr 1991;53(2):421-4.

E2. Quanjer PH, Tammeling GJ, Cotes JE, Pedersen OF, Peslin R, and Yernault JC. Lung volumes and forced ventilatory flows. Report Working Party Standardization of Lung Function Tests, European Community for Steel and Coal. Official Statement of the European Respiratory Society. Eur Respir J Supp/ 1993:16:5-40.

E3. Franssen FM, Wouters EF, Baarends EM, Akkermans MA, and Schols AM. Arm mechanical efficiency and arm exercise capacity are relatively preserved in chronic obstructive pulmonary disease. Med Sci Sports Exerc 2002;34(10):1570-6.

E4. Carter R, Peavler M, Zinkgraf S, Williams J, and Fields S. Predicting maximal exercise ventilation in patients with chronic obstructive pulmonary disease. Chest 1987;92(2):253-9.

E5. Wasserman K, Hansen J, Sue D, Whipp B, and Casaburi R. Principles of exercise testing and interpretation. $2^{\text {nd }}$ ed. Philadelphia: Lea \& Febiger 1994.

E6. Hofmann MA, Schiekofer $S$, Isermann B, Kanitz $M$, Henkels $M$, Joswig M, Treusch A, Morcos $M$, Weiss T, Borcea V, Abdel Khalek AK, Amiral J, Tritschler $H$, Ritz E, Wahl P, Ziegler R, Bierhaus $A$, and Nawroth PP. Peripheral blood mononuclear cells isolated from patients with diabetic nephropathy show increased activation of the oxidative-stress sensitive transcription factor NF-kappaB. Diabetologia 1999;42(2):222-32.

E7. Lundby C, Nordsborg N, Kusuhara K, Kristensen KM, Neufer PD, and Pilegaard H. Gene expression in human skeletal muscle: alternative normalization method and effect of repeated biopsies. Eur J Appl Physiol 2005;95(4):351-60.

E8. Livak KJ, and Schmittgen TD. Analysis of relative gene expression data using real-time quantitative PCR and the 2(-Delta Delta C(T)) Method. Methods 2001;25(4):402-8.

E9. Schmittgen TD, and Zakrajsek BA. Effect of experimental treatment on housekeeping gene expression: validation by real-time, quantitative RT-PCR. $J$ Biochem Biophys Methods 2000;46(1-2):69-81.

E10. Mahoney DJ, Parise G, Melov S, Safdar A, and Tarnopolsky MA. Analysis of global mRNA expression in human skeletal muscle during recovery from endurance exercise. Faseb $J$ 2005;19(11):1498-500. 


\title{
CHAPTER 5
}

\section{Acute exercise triggers muscle UCP3 in COPD: adaptive mechanism against lipotoxicity?}

\begin{abstract}
Peripheral muscle dysfunction is a hallmark of chronic obstructive pulmonary disease (COPD) in which an important role for oxidative stress is evolving. We hypothesized that in COPD muscle gene expression of uncoupling protein-3 (UCP3), which protects mitochondria against lipotoxicity, is upregulated during acute exercise as an adaptation to a blunted response of the antioxidant defense system and $\beta$-oxidation. Vastus lateralis biopsies were obtained before and $2 \mathrm{~h}$ after a $10 \mathrm{~min}$ submaximal $(70 \%$ of peak workload) cycle ergometry exercise from 7 COPD patients and 6 healthy age-matched controls. Gene expression of UCP3, PPAR $\gamma$ coactivator-1 $\alpha$ (PGC-1 $\alpha$; regulator of $\beta$-oxidation) and antioxidant $M n$-superoxide dismutase (MnSOD) were measured using RT-PCR. Lipid peroxidation (4-hydroxy2-nonenal) and over-oxidized peroxiredoxin III were determined by Western blot. UCP3 was upregulated after exercise in COPD (2-fold; $p<0.05$ ), but not in controls. Exercise induced a marked increase in PGC-1 $\alpha$ in controls (9-fold; $p<0.05$ ), but to a lower extent in COPD (6-fold; $p<0.05$ ). MnSOD was only upregulated in controls after exercise (2-fold; $p<0.05)$. COPD patients showed enhanced muscle lipid peroxidation after exercise $(p<0.05)$. These data are supportive of an inadequate response of the antioxidant and $\beta$-oxidation capacities to acute exercise leading to adaptive upregulation of UCP3 in peripheral muscle of patients with COPD.
\end{abstract}

Evi M. Mercken ${ }^{1}$, Harry R. Gosker ${ }^{1}$, Geja J. Hageman ${ }^{2}$, Emiel F.M. Wouters ${ }^{1,3}$ and Annemie M.W.J. Schols ${ }^{1}$. Departments of ${ }^{1}$ Respiratory Medicine, ${ }^{2}$ Health Risk Analysis and Toxicology, School for Nutrition, Toxicology and Metabolism (NUTRIM), Maastricht University, Maastricht, ${ }^{3}$ Centre for Integrated Rehabilitation Organ Failure (CIRO), Horn, The Netherlands. Submitted. 
Chapter 5

\section{INTRODUCTION}

Oxidative stress is a prominent feature of chronic obstructive pulmonary disease (COPD) and has been proposed as a potential mechanism of peripheral muscle dysfunction and impaired exercise tolerance (1). Increased levels of intramuscular lipid peroxidation products have been reported for COPD at baseline and in response to exercise $(2,9)$. Moreover, on the opposite side of the balance, reduced muscle antioxidant levels were observed in $\operatorname{COPD}(9,25)$. These data are indicative of increased muscular oxidative stress in COPD, especially during exercise, being the result of enhanced oxidant formation and/or impaired antioxidant capacity. Exercise in general has long been known to elicit an increase in the production of reactive oxygen species (ROS) as a result of increases in mitochondrial oxygen consumption and electron transport flux (7). With exercise the supply of free fatty acids (FFAs) to the muscles is also increased, which may lead to the accumulation of fatty acid anions in the mitochondrial matrix (29). This combination of higher ROS production and increased fatty acids anion levels enhances the risk of oxidation of these fatty acid anions (i.e. lipid peroxidation). Several defense mechanisms exist: The $\beta$-oxidation of FFAs prevents them from being oxidized in the first place. In mitochondria, superoxide anion is converted to hydrogen peroxide by manganese superoxide dismutase (MnSOD), and subsequently converted to water by the enzyme glutathione peroxidase and the thioredoxin-dependent enzyme peroxiredoxin III (Prx III) (8). The mammalian peroxiredoxin is a novel family of peroxidases and has six members expressed in several subcellular compartments. Prx 111 is specifically expressed in mitochondria (33). Finally, uncoupling protein-3 (UCP3) is considered to be a key player in the protection of mitochondria against lipotoxicity, because it is capable of reducing ROS production by lowering the mitochondrial membrane potential and/or the removal of fatty acid anions from the mitochondrial matrix $(4,18,28)$. Accordingly, we previously showed that muscle UCP3 levels increased by exercise training in COPD patients with a blunted response of the $\beta$ oxidation, suggesting that UCP3 was upregulated in response to an insufficient capacity to oxidize FFAs (14). It is likely that the peroxisome proliferator-activated receptor $\gamma$ coactivator-1 $\alpha$ (PGC-1 $\alpha)$ is involved in this impaired response of the $\beta$ oxidation, as it is a master regulator of mitochondrial oxidative capacity (31). Considering the evidence for increased muscular oxidative stress in COPD in combination with the incapability of the muscle to sufficiently improve antioxidant defense and $\beta$-oxidation in response to exercise training, we hypothesized that the exerciseinduced upregulation of antioxidants enzymes such as MnSOD and the $\beta$-oxidation is impaired resulting in a compensatory upregulation of UCP3. To test this hypothesis, quadriceps muscle biopsies were obtained before and after acute exercise from seven patients with COPD and six healthy age-matched controls. 
UCP3: adaptive mechanism against lipotoxicity?

\section{MATERIALS AND METHOD}

\section{Study population}

Seven clinically stable male patients with moderate COPD as defined by GOLD guidelines participated in the study (12). All patients were ex-smokers and had not experienced respiratory tract infection or exacerbation of their disease for at least 4 weeks prior to the study. Exclusion criteria were rheumatoid arthritis, chronic colitis, diabetes, cardiovascular diseases, renal diseases, liver diseases or mental diseases. None of the patients went through a rehabilitation program before inclusion. All patients received anticholinergic and $\beta 2$-agonists as bronchodilator therapy, five patients received inhaled corticosteroids and one patient theophylline. None were treated with oral corticosteroids. Six healthy, sedentary age-matched non-smoking males were recruited as controls. None of the subjects were taking antioxidants or vitamin supplements. Written informed consent was obtained from all participants, and the study was approved by the medical ethics committee of the University Hospital Maastricht (Maastricht, The Netherlands).

\section{Study Design}

The participants were instructed to abstain from strenuous physical activity and to consume a light breakfast on the test day and the exercise tests were performed at the same time point of the day. First, they completed an exhaustive incremental cycle ergometry test and four days later a submaximal constant work rate cycle ergometry test. This exercise protocol was chosen since it is comparable with regular exercise training as part of pulmonary rehabilitation. Biopsies of vastus lateralis were obtained at baseline and 2 hours after the submaximal exercise test. This time point was chosen to determine the early gene response after an acute bout of exercise (22).

\section{Assessment of body composition}

Body composition was determined by bioelectrical impedance analysis (BIA; Xitron technologies, San Diego, CA, USA) as described previously (27).

\section{Pulmonary Function Tests}

All participants underwent flow volumes including measurements of $F E V_{1}$ and FVC with the highest value from at least three properly performed measurements being used for analysis. The values obtained were expressed as a percentage of the reference value (24). 


\section{Exercise tests}

Participants performed an incremental (10 Watt/minute) cycle ergometry test as described previously (13). Expired gases were analyzed using breath-by-breath analysis through a breathing mask (Oxygen- $\beta$, Jaeger, Würzburg, Germany). Peak ventilatory (VE) reserve was calculated as $100 \%-(100 \times$ peak $V E) /\left(F E V_{1} \times 37.5\right)$ and peak heart rate (HR) reserve was calculated as $100 \%-(100 \times$ peak $H R) /(220-$ age) $(6,32)$. The submaximal exercise test was performed at $70 \%$ of the peak workload achieved during the incremental exercise test. The endurance time was standardized at 10 minutes. Also oxygen consumption was monitored as described in the incremental exercise test.

\section{Muscle biopsies}

Percutaneous biopsy specimens of vastus lateralis muscle of the dominant leg at baseline and the non-dominant leg post-exercise were obtained as described by Bergström (3). Muscle samples were immediately frozen in liquid nitrogen and then stored at $-80^{\circ} \mathrm{C}$ until further analysis.

\section{Skeletal muscle analyses}

Gene expression analyses by real-time PCR. Biopsies were analyzed for UCP3, PGC-1 $1 \alpha$ and MnSOD mRNA expression. For this, total RNA $(-60 \mathrm{mg})$ was isolated by means of a TRIzol ${ }^{\circledast}$ reagent (Gibco BRL), using a Polytron homogenizer (POLYTRON ${ }^{\circledR}$ PT 2100. Kinemaitca AG). Total RNA was extracted according to the manufacturer's instructions. The RNeasy ${ }^{8}$ Mini Kit (Qiagen) was used to purify total RNA from salts and residual DNA. CDNA was generated from $0.4 \mu \mathrm{g}$ of total RNA according to the manufacturer's instructions using the Bio-Rad iScript CDNA synthesis kit (Bio-Rad Laboratories, Hercules, CA). Aliquots were used for real-time PCR on the BioRad MyiQ iCycler Single Color real-time PCR detection system using ${ }^{2} Q^{T M}$ SYBR $^{\circledR}$ Green Supermix. GAPDH, Cyclophilin A and $\beta$-actin were used as housekeeping genes and all reactions were performed in duplicate. The expression of $\beta$ actin was influenced by exercise, but GAPDH and Cyclophilin A were equally stable in response to exercise. Therefore, $\beta$-actin was left out in the further analyses. We have chosen to show the results for gene expression corrected by both GAPDH and Cyclophilin A because in the literature a substantial variability of housekeeping genes following an acute exercise has been reported $(16,19)$. To avoid inter-assay variability, COPD patients as healthy controls and the two time points for each gene were run together in one single real-time PCR run. The data were analyzed using the expression $\Delta \mathrm{Ct}$ and $\Delta \Delta \mathrm{Ct}$. To compare the relative gene expression between COPD patients and healthy controls at baseline the expression $\Delta \mathrm{Ct}$ was used. The expression $\Delta \Delta \mathrm{Ct}$ was used to calculate relative changes in gene expression within 
each group as a result of the exercise test. Fold changes were calculated using the $2^{-\Delta \Delta C t}$ method. PCR primers are shown in Table 1.

Table 1. Primer sequences used for PCR analysis

\begin{tabular}{lll}
\hline & Forward & Reverse \\
\hline UCP3 & CGTGGTGATGTTCGTAACCTATG & CGGTGATTCCCGTAACATCTG \\
PGC-1 $\alpha$ & GACCAGTGCTACCTGAGAGAGACTT & GCTCGGCTCGGATTTCCT \\
MnSOD & GTGGTCCATGAAAAAGCAGATGA & CACAAGCCAAACGACTTCCA \\
\hline
\end{tabular}

Definitions of abbreviations: Uncoupling protein-3 (UCP3), PPAR $\gamma$ co-activator-1 $\alpha$ (PGC-1 $\alpha$ ); Mnsuperoxide dismutase (MnSOD)

Western blotting. Frozen muscle samples were homogenized in ice-cold Tris-EDTA buffer at $\mathrm{pH}=7.4$. Samples were then centrifuged at $10.000 \times \mathrm{g}$ at $4^{\circ} \mathrm{C}$ for $30 \mathrm{~min}$. The pellet was discarded and the supernatant was designated as a crude homogenate. Equal amounts of protein were loaded on to a $10-15 \%$ SDS PAGE gel, and electrophoresis was performed using a Mini-PROTEAN 3 Electrophoresis Cell system (Bio-Rad, USA). We used polyclonal anti-HNE antibody diluted 1:10000 (Calbiochem, San Diego, $\mathrm{CA}$ ) and polyclonal anti-peroxiredoxin- $\mathrm{SO}_{3}$ diluted 1:500 (LabFronfier, Seoul, South Korea) antibodies. The secondary antibody was horse anti-rabbit peroxidase. Detection was performed using SuperSignal West Dura Extended Duration Substrate (Pierce Boston Technology Centre, Woburn, MA, USA) on a CL-Xposure Film (Pierce Boston Technology Centre). The blots were scanned with an imaging densitometer and optical densities (OD) of protein bands were quantified using Image Master VDS (Amersham Pharmacia Biotech, Uppsala, Sweden) software. Total $4 \mathrm{HNE}$ in each muscle sample were calculated by adding $O D$ of individual protein bands.

\section{Venous blood analysis}

Determination of plasma free fatty acids (FFAs). Blood samples were drawn into EDTA-containing tubes (Venoject; Terumo Corporation, Leuven, Belgium), and plasma was obtained by centrifugation $\left(800 \times g\right.$ for $10 \mathrm{~min}$ at $\left.4^{\circ} \mathrm{C}\right)$ and stored at $80^{\circ} \mathrm{C}$ until analysis. Plasma FFAs were determined using the Wako NEFA C test kit (Wako Chemicals, Neuss, Germany).

\section{Statistical Analyses}

Data are presented as mean \pm SEM. Between-group comparisons were analyzed using the Mann-Whitney $U$ test and the Wilcoxon signed rank test was used to evaluate the effect of submaximal exercise within the groups. For analysis of baseline gene expression $\Delta \mathrm{Ct}$ was used and for the effect of exercise on gene expression $\Delta \Delta \mathrm{Ct}$. Nonparametric tests were used because the normality assumption was 
Chapter 5

not obtained. A difference with $p<0.05$ was considered statistically significant. Statistical analyses were analyzed with SPSS for Windows (version 13.0; SPSS, Inc., Chicago, IL).

\section{RESULTS}

\section{Anthropometric and Spirometric Data}

The subject characteristics are presented in Table 2. The anthropometric data did not show any significant differences between COPD patients and healthy controls. The COPD group was characterized by moderate airflow obstruction with a FEV $\mathrm{F}_{1}$ $50.6 \pm 5.7 \%$ predicted.

Table 2. Characteristics of the study population

\begin{tabular}{lcc}
\hline & $\begin{array}{c}\text { Healthy subjects } \\
(\mathrm{n}=6)\end{array}$ & $\begin{array}{c}\text { Patients with COPD } \\
(\mathrm{n}=7)\end{array}$ \\
\hline Age, $\mathrm{yr}$ & $60.7 \pm 1.0$ & $61.9 \pm 1.4$ \\
Pack-yr of smoking & $11.6 \pm 4.5$ & $31.4 \pm 8.7$ \\
$\mathrm{BMl}, \mathrm{kg} / \mathrm{m}^{2}$ & $26.8 \pm 1.3$ & $25.0 \pm 1.3$ \\
$\mathrm{FFMl}, \mathrm{kg} / \mathrm{m}^{2}$ & $18.5 \pm 0.5$ & $17.2 \pm 0.6$ \\
$\mathrm{FEV}, \%$ predicted & $108.5 \pm 9.7$ & $50.6 \pm 5.7^{*}$ \\
$\mathrm{FVC}, \%$ predicted & $113.9 \pm 9.5$ & $96.1 \pm 7.6$ \\
\hline Definitions of abbreviations: BMI = body mass index; COPD = chronic obstructive pulmonary \\
disease; FFMl = fat-free mass index; FEV ${ }_{1}=$ forced expiratory volume in $1 \mathrm{~s} ; \mathrm{FVC}=$ forced vital \\
capacity. Data are presented as mean \pm SEM.
\end{tabular}

\section{Exercise tests}

The results of the exercise tests are presented in Table 3. As expected, exercise capacity was limited in COPD patients when compared with healthy control subjects $(p<0.01)$. Although COPD patients reached their maximal voluntary ventilation (VEreserve $\approx 0$ ), this parameter was not significantly different between both groups, whereas the heart rate reserve was preserved in COPD $(p<0.01)$. Baseline plasma free fatty acids were similar between both groups, and as expected were significantly increased immediately after submaximal exercise in the healthy controls, which indicates that the exercise intensity/duration of the chosen exercise test was sufficient $(p<0.05)$. 
UCP3: adaptive mechanism against lipotoxicity?

Table 3. Exercise characteristics of healthy subjects and COPD patients

\begin{tabular}{lcc} 
& $\begin{array}{c}\text { Healthy subjects } \\
(n=6)\end{array}$ & $\begin{array}{c}\text { Patients with COPD } \\
(n=7)\end{array}$ \\
\hline Incremental exercise & & $111.4 \pm 15.7^{*}$ \\
Peak workload, W & $238.3 \pm 16.3$ & $1353 \pm 107^{*}$ \\
Peak $\dot{V} \mathrm{O}_{2}, \mathrm{~m} / \mathrm{min}$ & $2440 \pm 136$ & $133 \pm 2^{*}$ \\
Peak HR, beat/min & $166 \pm 6$ & $16.1 \pm 1.3^{*}$ \\
HR reserve, \% & $-0.4 \pm 3.5$ & $57.1 \pm 5.9^{*}$ \\
Peak $\dot{V} E$, L/min & $93.5 \pm 5.3$ & $-1.3 \pm 8.7$ \\
$\dot{V} E$ reserve, \% & $20.8 \pm 10.8$ & \\
Constant workload exercise & & $78.4 \pm 10.9^{*}$ \\
Workload, W & $166.9 \pm 11.4$ & $1177 \pm 150$ \\
$\dot{V} O_{2,}$ ml/min & $1939 \pm 270$ & $43.6 \pm 4.0^{\S}$ \\
$\dot{V} E$, L/min & $72.3 \pm 7.1$ & $86.5 \pm 53.2$ \\
$\Delta$ free fatty acids, $\mu$ mol/L & $70.5 \pm 20.1^{\ddagger}$ & \\
\hline
\end{tabular}

Definitions of abbreviations: $\mathrm{COPD}=$ chronic obstructive pulmonary disease; $\mathrm{HR}=$ heart rate. Data are presented as mean \pm SEM.

"Significant difference compared with the healthy control subjects, $p<0.01$.

\$Significant difference compared with the healthy control subjects, $p<0.02$.

†Significant difference compared with baseline, $p<0.05$.

\section{Gene expression}

Basal gene expression. In COPD, significantly decreased baseline mRNA content of UCP3 (-0.6 $\pm 0.2 \Delta$ Ct controls vs. $0.5 \pm 0.4 \Delta$ Ct COPD; $p<0.05)$, normalized to Cyclophilin A, were observed. PGC-1 $\alpha$ and MnSOD mRNA levels were similar in patients with COPD and healthy controls. The same pattern was found when glyceraldehyde 3-phosphate dehydrogenase (GAPDH) was used as housekeeper.

Exercise-induced gene expression. Relative gene expression of UCP3, MnSOD and PGC- $1 \alpha$ are shown in Figure 1. In COPD patients, we observed a 2-fold increase of UCP3 mRNA levels ( $p<0.05$ ), normalized to Cyclophylin $A$, in response to exercise, whereas no difference of UCP3 gene expression was found in the controls. Moreover, UCP3 response tended to be higher in COPD than in healthy controls after exercise $(p=0.073)$. The same tendency was observed with GAPDH. Exercise induced a 2-fold increase in MnSOD mRNA levels in the healthy controls $(p<0.05)$, but no changes were observed in the COPD patients. In addition, the MnSOD response tended to be lower in COPD than controls $(p=0.073)$. These results were consistent for both housekeepers. With Cyclophylin A, PGC-1 $\alpha$ mRNA levels increased 6- and 9-fold after exercise in COPD patients and healthy controls, respectively (both $\mathrm{p}<0.05$ ). Moreover, with GAPDH the PGC- $1 \alpha$ response in the healthy controls was significantly higher than in COPD patients $2 h$ after exercise $(p<0.05)$. 

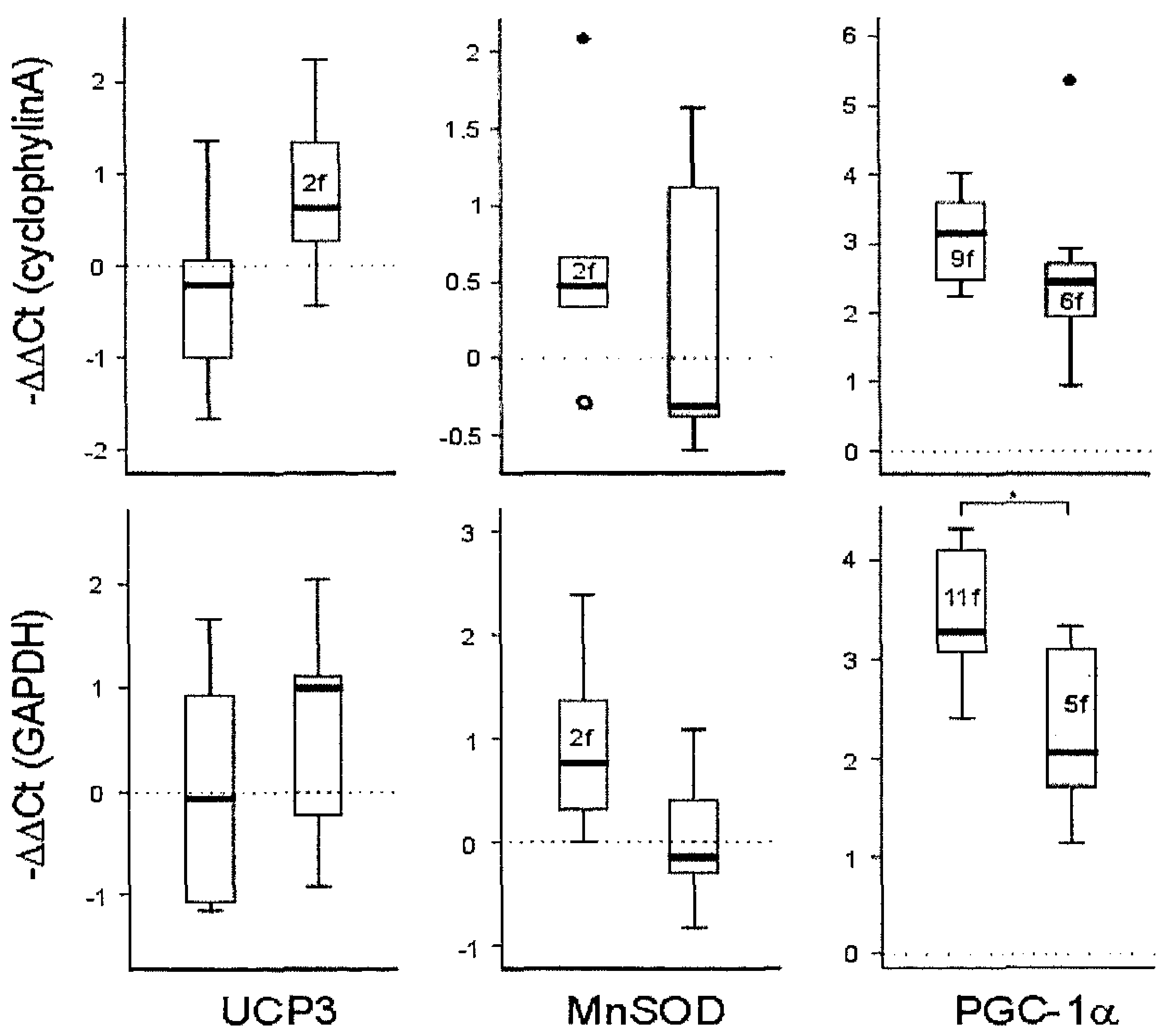

Figure 1. Relative gene expression of uncoupling protein-3 (UCP3), Mn-superoxide dismutase (MnSOD) and peroxisome proliferator-activated receptor $\gamma$ coactivator-1 $\alpha$ (PGC-1 $\alpha$ ) in COPD patients and healthy controls $(H C)$ before and $2 \mathrm{~h}$ after exercise. " $p<0.05$ significantly different from baseline values; ${ }^{*}<0.05,{ }_{p}^{\ddagger}=0.073$ significantly different between healthy control subjects and subjects with COPD.

\section{Markers of muscle oxidative stress}

As illustrated in Figure 2A, the anti-HNE antibody detected several protein bands, with apparent molecular weights ranging from 30 to $98 \mathrm{kD}$, in the muscles of both patients and control subjects. The skeletal muscles of patients with COPD showed higher levels of HNE-protein adducts $2 \mathrm{~h}$ after exercise $(p<0.05$; Figure $2 B)$. However, there were no correlations between UCP3 mRNA expression and HNE levels. No differences could be detected in the expression of over-oxidized Prx III between COPD patients and control subjects. Additionally, exercise did not induce any significant change in over-oxidized Prx III in either patients or controls (data not shown). 
A.

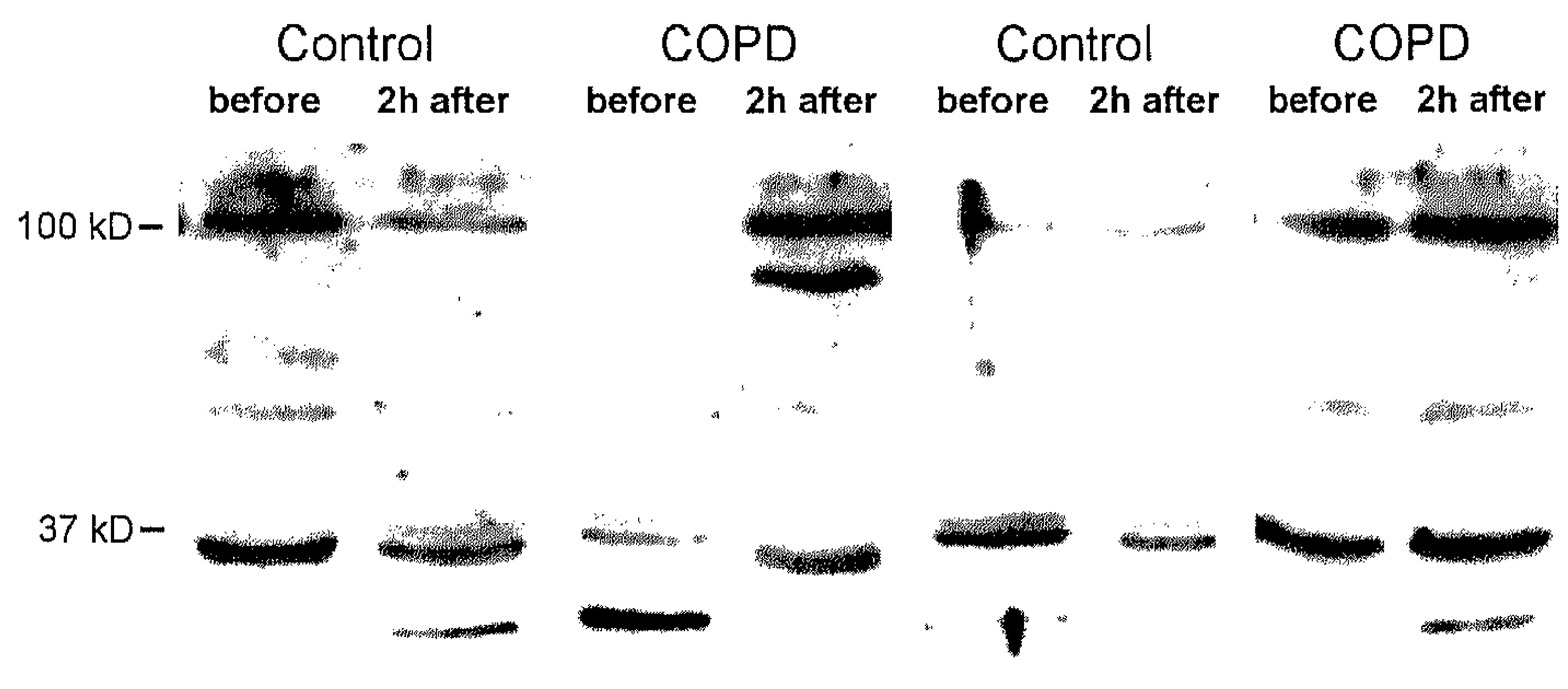

B.

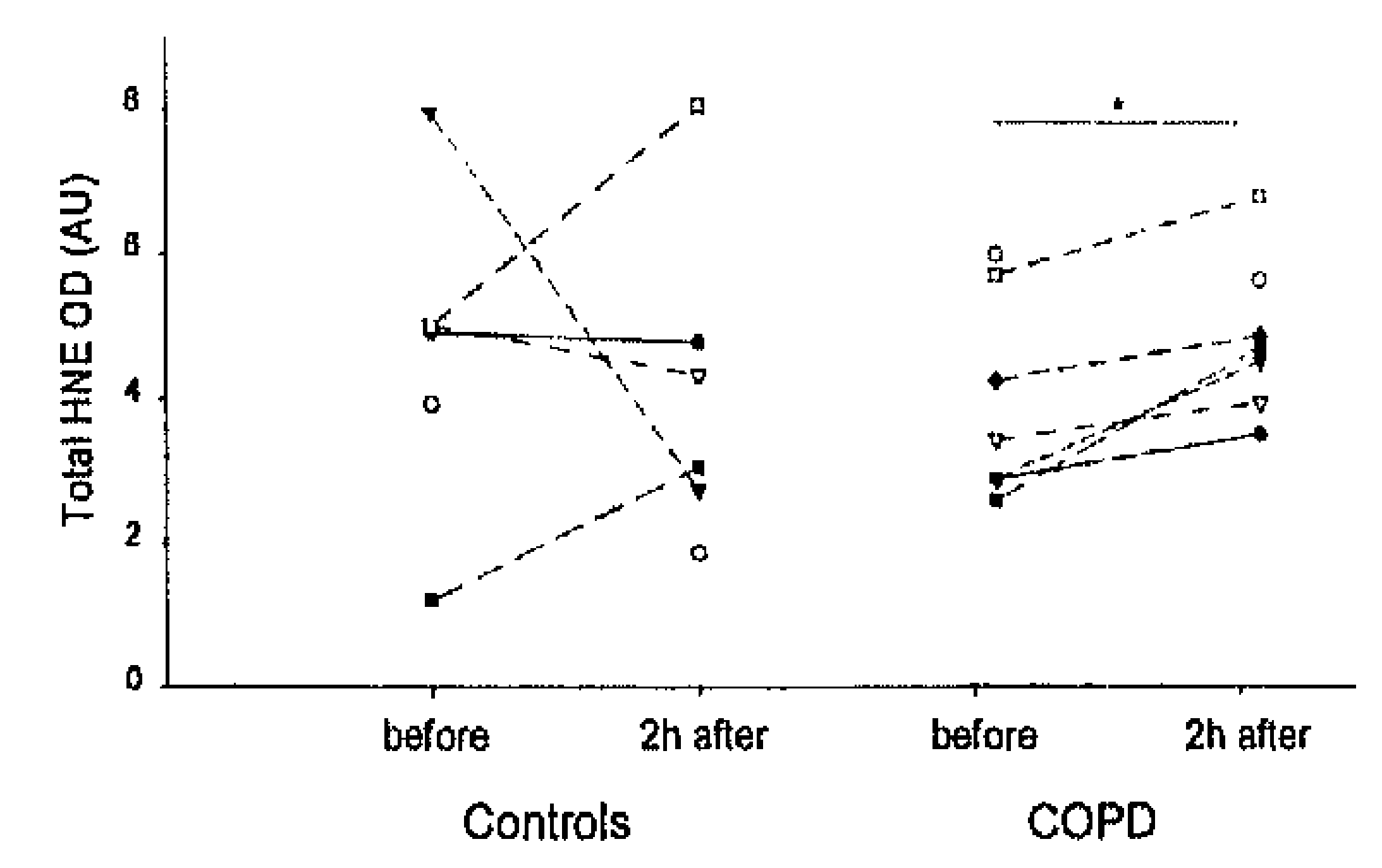

Figure 2. (A) Representative examples of lipid peroxidation (detected with anti-HNE antibody) in vastus lateralis biopsies of healthy controls and patients with COPD before and after exercise. Several HNE-protein adducts were detected. (B) Individual values of total HNE optical densities in skeletal muscles of healthy controls and patients with COPD. ${ }^{*} p<0.05$ significantly different compared with values before exercise.

\section{DISCUSSION}

The main finding of the present study is that an acute bout of exercise upregulate UCP3 gene transcription in skeletal muscle of COPD, but not in healthy controls, despite the higher absolute workload in healthy control subjects. This response is associated with a blunted upregulation of MnSOD and PGC-1 $\alpha$ gene transcription in COPD in combination with enhanced intramuscular lipid peroxidation, as assessed by $4-H N E$. These findings are supportive of a role for UCP3 in protecting the muscle cell against ROS-induced lipotoxicity. 
It has been proposed that UCP3 plays a role in lowering the ROS production (4) (see also Figure 3 ). The mitochondrial electron transport chain is a major nonenzymatic source for the formation of ROS (7). One to two percent of total oxygen consumed leaks away in the form of superoxide anions. ROS production, especially of superoxide, is increased during exercise as a result of the build-up of a proton gradient across the inner mitochondrial membrane through increased mitochondrial oxygen consumption and electron transport flux. Consequently, the enhanced formation of superoxide may in turn result in lipid peroxidation (21). It has been suggested that UCP3, through mild uncoupling, decreases the mitochondrial membrane potential and hence attenuates the rise in ROS production $(4,11,18)$. This negative feedback loop would protect the cell against ROS-induced cellular damage. In the present study, baseline UCP3 mRNA levels in the limb muscle of patients with COPD were reduced compared to healthy controls, which is in agreement with previous studies $(15,26)$. However, in contrast to healthy subjects, only COPD patients responded to an acute exercise by increasing skeletal muscle UCP3 gene expression which was accompanied by a blunted induction of MnSOD. The absence of an immediate increased UCP3 expression after exercise in healthy controls could be explained by the fact that their antioxidant defense system, in particular MnSOD, is able to cope with the increased production of ROS generated during the exercise test. The mitochondrial isoform MnSOD has the ability to eliminate superoxide that arises from the electron transport chain to generate hydrogen peroxide. Consequently, hydrogen peroxide is degraded by Prx III and glutathione peroxidase. In the present study, COPD patients showed increased intramuscular lipid peroxidation after exercise compared to healthy controls, as assessed by 4HNE adduct proteins. This finding is in agreement with a previous study who observed increased muscle thiobarbituric acid reactive substances in COPD patients after local exercise (9). However, in the current study, an acute bout of exercise did not induce any change in the over-oxidized Prx IIl levels in the groups. Hence, the increased muscle lipid peroxidation observed after exercise in patients with COPD could be related to the reduced MnSOD mRNA expression. It has been suggested that both superoxide and lipid peroxidation breakdown products, such as 4-HNE, activate UCP3 thereby lowering the mitochondrial membrane potential and attenuate the rise in ROS production (21). Apart from a role in lowering ROS production, UCP3 has also been postulated to play a role in fatty acid metabolism, serving as a fatty acid anion exporter from the mitochondrial matrix (10) (see also Figure 3). Fatty acids entering the mitochondrial matrix are normally oxidized through fatty acid $\beta$-oxidation. Interestingly, 3-hydroxyacyl-CoA dehydrogenase (HAD), a key enzyme of the $\beta$-oxidation of fatty acids, has consistently been shown to be reduced in COPD patients compared to healthy controls, which implies a reduced fatty acid oxidation in COPD (20). PGC-1 $\alpha$ is considered a master regulator of mitochondrial biogenesis and metabolism, including the components of the fatty acid $\beta$-oxidation, 
especially in response to exercise $(23,31)$. In this study, PGC-1 $\alpha$ mRNA expression was indeed significantly increased $2 \mathrm{~h}$ after exercise in COPD patients as well in the healthy control subjects, but interestingly, this response was significantly lower in COPD. Exercise is known to increase plasma FFAs and due to the blunted PGC-1 $\alpha$ response observed in this study and as a result of an impaired oxidative capacity in COPD, it is likely that the fatty acid supply to the muscle exceeds its oxidizing capacity (20). As consequence, cytosolic fatty acids will accumulate and flip-flop into the mitochondrial matrix as fatty acid anions where they can neither be metabolized nor cross the mitochondrial membrane (30). These fatty acid anions are prone to be attacked by superoxide inevitably leading to muscle lipid peroxidation, which we indeed observed in COPD. Upregulation of UCP3 could prevent the accumulation of fatty acid anions in the mitochondrial matrix (17) and/or lower the proton gradient across the inner mitochondrial membrane, thereby reducing ROS production (5) and the risk of lipid peroxidation. 


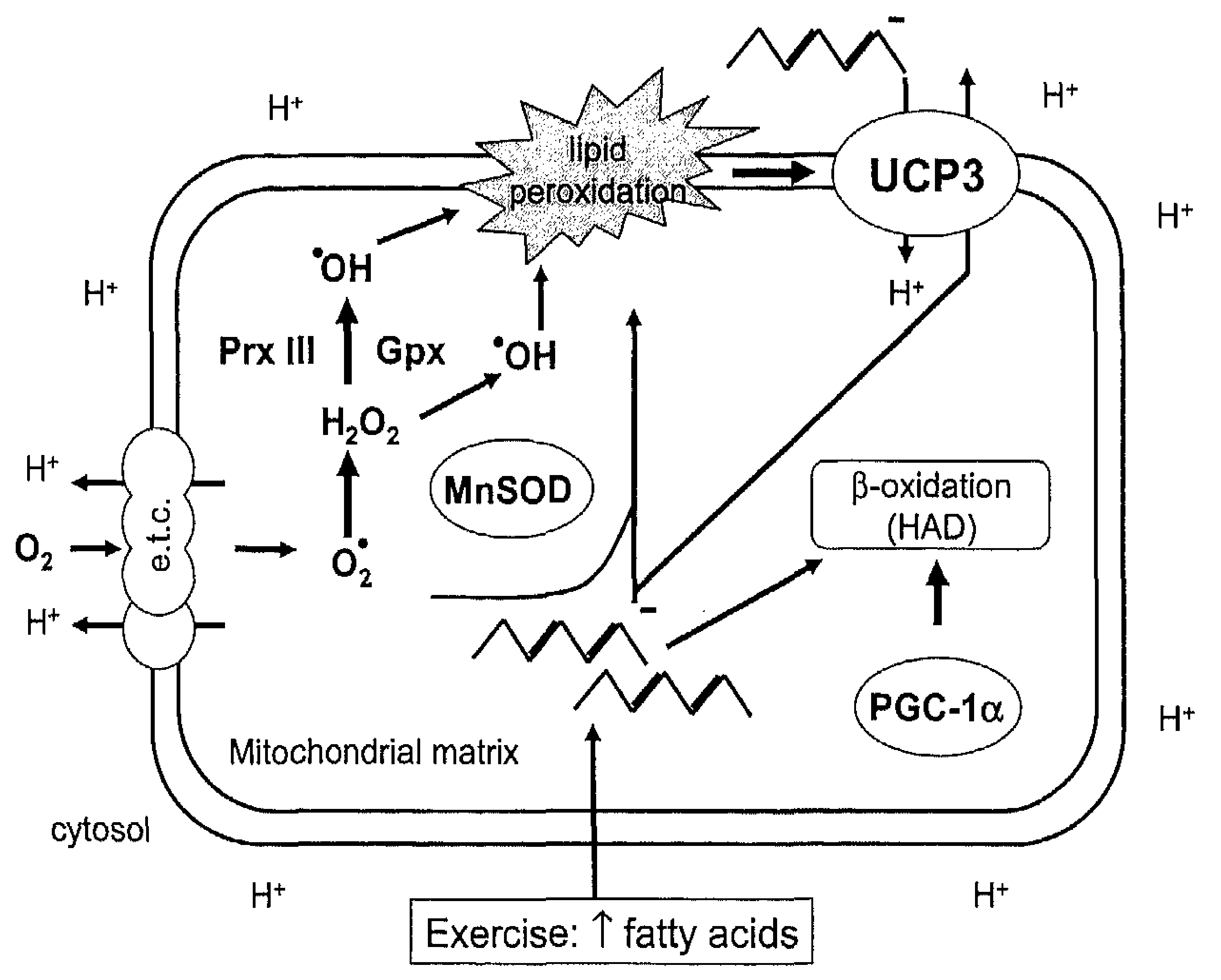

Figure 3. Schematic model of mitochondrial lipid peroxidation. 1) ROS production. Superoxide $\left(\mathrm{O}_{2}{ }^{\circ}\right)$ is generated primarily by the electron transport chain (ETC). Superoxide is dismutated to hydrogen peroxide $\left(\mathrm{H}_{2} \mathrm{O}_{2}\right)$ by Mn-superoxide dismutase (MnSOD). UCP3 attenuates superoxide production through mild uncoupling, thereby decreasing mitochondrial membrane potential. The enzyme peroxiredoxin III (Prx III) and glutathione peroxidase (Gpx) degrades $\mathrm{H}_{2} \mathrm{O}_{2}$ to water $\left(\mathrm{H}_{2} \mathrm{O}\right)$ and thereby decreases hydroxyl radical formation and subsequent muscular lipid peroxidation products. 2) Accumulation of fatty acid anions. Free fatty acids (FFAs) entering the mitochondrial matrix will be oxidized through fatty acid $\beta$-oxidation, which is regulated by peroxisome proliferator-activated receptor $\gamma$ coactivator-1 $\alpha$ (PGC-1 $\alpha$ ). Exercise increases plasma FFAs and if the supply of FFAs to the muscle exceeds the capacity to oxidize them, they will accumulate in the mitochondrial matrix as fatty acid anions. These fatty acid anions will be deprotonated by superoxide anions leading to lipid peroxidation. UCP3 acts as a fatty acid anion exporter, thereby preventing them from being peroxidized.

\section{Limitations of the study}

We found significant differences of exercise within in the groups. A main limitation of this study however is related to a relatively small sample size which may not have had enough statistical power for the between-group comparison of the exercise response. However, we still found that the exercise response of PGC-1 $\alpha$ was 
significantly different between COPD and healthy controls. Also, the UCP3 and MnSOD response tended to be different between both groups. Another limitation is that we did not assess protein levels in the present study. Although large responses on the protein level are not expected immediately after exercise we can only assume that the results found for the gene transcripts also reflect a protein response on the longer term. This study was primarily designed to investigate the acute exercise-induced effects on gene regulation.

\section{Conclusion}

Since exercise-induced muscle oxidative stress is a consistent finding for COPD, this disease provides a unique model to study the physiologic response of UCP3 to oxidative stress in vivo. Taken together, these data suggest that the impaired oxidative capacity, reflected in a blunted PGC- $1 \alpha$ response and a previously reported reduced HAD-activity, in combination with an increased production of superoxide as a result of a blunted MnSOD response, increase exercise-induced muscle lipid peroxidation. The upregulation of UCP3 mRNA in patients with COPD could very well be a compensatory mechanism against this lipotoxicity. The differences found between COPD patients and healthy controls emphasize the importance to further unravel the underlying mechanisms by which UCP3 affects the ROS-induced lipotoxicity. Eventually, this may result in novel targets for therapies for peripheral muscle dysfunction in this disease.

\section{LIST OF ABBREVIATIONS}

BIA: bioelectrical impedance analysis

COPD: chronic obstructive pulmonary disease

FFAs: free fatty acids

GAPDH: glyceraldehyde 3-phosphate dehydrogenase

HAD: 3-hydroxyacyl-CoA dehydrogenase

4-HNE: 4-hydroxy-2-nonenal

HR: heart rate

MnSOD: Mn-superoxide dismutase

OD: optical density

PGC-1 $\alpha$ : peroxisome proliferator-activated receptor $\gamma$ coactivator- $1 \alpha$

Prxlll: peroxiredoxin III

ROS: reactive oxygen species

UCP3: uncoupling protein-3

VE: ventilation per unit time 


\section{REFERENCES}

1. Agusti AG. Systemic effects of chronic obstructive pulmonary disease. Proc Am Thorac Soc 2(4): 367-70; discussion 371-2, 2005.

2. Allaire J, Maltais F, LeBlanc P, Simard PM, Whittom F, Doyon JF, Simard C, and Jobin J. Lipofuscin accumulation in the vastus lateralis muscle in patients with chronic obstructive pulmonary disease. Muscle Nerve 25(3): 383-9, 2002.

3. Bergström $\mathrm{J}$. Muscle electrolytes in man: determination by neutron activation analysis on needle biopsy specimens: a study on normal subjects, kidney patients and patients with chronic diarrhoea. Scand J Clin Lab Invest 14: 1-110, 1962.

4. Brand MD. Uncoupling to survive? The role of mitochondrial inefficiency in ageing. Exp Gerontol 35(6-7): 811-20, 2000.

5. Brand MD, Affourtit C, Esteves TC, Green K, Lambert AJ, Miwa S, Pakay JL, and Parker N. Mitochondrial superoxide: production, biological effects, and activation of uncoupling proteins. Free Radic Biol Med 37(6): 755-67, 2004.

6. Carter R, Peavler $M$, Zinkgraf $S$, Williams $J$, and Fields $S$. Predicting maximal exercise ventilation in patients with chronic obstructive pulmonary disease. Chest 92(2): 253-9, 1987.

7. Chance $B$, Sies $H_{1}$ and Boveris $A$. Hydroperoxide metabolism in mammalian organs. Physiol Rev 59(3): 527-605, 1979.

8. Costa NJ, Dahm CC, Hurrell F, Taylor ER, and Murphy MP. Interactions of mitochondrial thiols with nitric oxide. Antioxid Redox Signal 5(3): 291-305, 2003.

9. Couillard A, Maltais F, Saey D, Debigare R, Michaud A, Koechlin C, LeBlanc $P$, and Prefaut $C$. Exercise-induced quadriceps oxidative stress and peripheral muscle dysfunction in patients with chronic obstructive pulmonary disease. Am J Respir Crit Care Med 167(12): 1664-9, 2003.

10. Dulloo $A G$ and Samec $S$. Uncoupling proteins: their roles in adaptive thermogenesis and substrate metabolism reconsidered. Br J Nutr 86(2): 123-39, 2001.

11. Echtay KS, Roussel D, St-Pierre J, Jekabsons MB, Cadenas S, Stuart JA, Harper JA, Roebuck SJ, Morrison A, Pickering S, Clapham JC, and Brand MD. Superoxide activates mitochondrial uncoupling proteins. Nature 415(6867): 96-9, 2002.

12. Fabbri LM and Hurd SS. Global Strategy for the Diagnosis, Management and Prevention of COPD: 2003 update. Eur Respir J 22(1): 1-2, 2003.

13. Franssen FM, Wouters EF, Baarends EM, Akkermans MA, and Schols AM. Arm mechanical efficiency and arm exercise capacity are relatively preserved in chronic obstructive pulmonary disease. Med Sci Sports Exerc 34(10): 1570-6, 2002.

14. Gosker HR, Schrauwen $P$, Broekhuizen R, Hesselink MK, Moonen-Kornips E, Ward KA, Franssen FF, Wouters EF, and Schols AM. Exercise training restores uncoupling protein-3 content in limb muscles of patients with chronic obstructive pulmonary disease. Am J Physiol Endocrinol Metab 2005.

15. Gosker HR, Schrauwen P. Hesselink MK, Schaart G, van der Vusse GJ, Wouters EF, and Schols AM. Uncoupling protein-3 content is decreased in peripheral skeletal muscle of patients with COPD. Eur Respir J 22(1): 88-93, 2003.

16. Jemiolo $B$ and Trappe $S$. Single muscle fiber gene expression in human skeletal muscle: validation of internal control with exercise. Biochem Biophys Res Commun 320(3): 1043-50, 2004.

17. Jezek $P$, Engstova $H$, Zackova $M$, Vercesi $A E$, Costa $A D$, Arruda $P$, and Garlid KD. Fatty acid cycling mechanism and mitochondrial uncoupling proteins. Biochim Biophys Acta 1365(1-2): 319-27, 1998. 
18. Korshunov SS, Skulachev VP, and Starkov AA. High protonic potential actuates a mechanism of production of reactive oxygen species in mitochondria. FEBS Lett 416(1): 15-8, 1997.

19. Mahoney DJ, Carey K, Fu MH, Snow R, Cameron-Smith D, Parise G, and Tarnopolsky MA. Real-time RT-PCR analysis of housekeeping genes in human skeletal muscle following acute exercise. Physiol Genomics 18(2): 226-31, 2004.

20. Maltais $F$, LeBlanc $P$, Whittom $F$, Simard $C$, Marquis $K$, Belanger M, Breton MJ, and Jobin J. Oxidative enzyme activities of the vastus lateralis muscle and the functional status in patients with COPD. Thorax 55(10): 848-53, 2000.

21. Murphy MP, Echtay KS, Blaikie FH, Asin-Cayuela J, Cocheme HM, Green K, Buckingham JA, Taylor ER, Hurrell F, Hughes G, Miwa S, Cooper CE, Svistunenko DA, Smith RA, and Brand $M D$. Superoxide activates uncoupling proteins by generating carbon-centered radicals and initiating lipid peroxidation: studies using a mitochondria-targeted spin trap derived from alphaphenyl-N-tert-butylnitrone. J Biol Chem 278(49): 48534-45, 2003.

22. Pilegaard $H$, Ordway GA, Saltin $B$, and Neufer PD. Transcriptional regulation of gene expression in human skeletal muscle during recovery from exercise. Am J Physiol Endocrinol Metab 279(4): E806-14, 2000.

23. Pilegaard $H$, Saltin $B$, and Neufer PD. Exercise induces transient transcriptional activation of the PGC-1alpha gene in human skeletal muscle. J Physiol 546(Pt 3): 851-8, 2003.

24. Quanjer PH, Tammeling GJ, Cotes JE, Pedersen OF, Peslin R, and Yernault JC. Lung volumes and forced ventilatory flows. Report Working Party Standardization of Lung Function Tests, European Community for Steel and Coal. Official Statement of the European Respiratory Society. Eur Respir J Suppl 16: 5-40, 1993.

25. Rabinovich RA, Ardite E, Troosters T, Carbo N, Alonso J, Gonzalez de Suso JM, Vilaro J, Barbera JA, Polo MF, Argiles JM, Fernandez-Checa JC, and Roca J. Reduced muscle redox capacity after endurance training in patients with chronic obstructive pulmonary disease. Am J Respir Crit Care Med 164(7): 1114-8, 2001.

26. Russell AP, Somm E, Debigare R, Hartley O, Richard D, Gastaldi G, Melotti A, Michaud A, Giacobino JP, Muzzin P, LeBlanc $P$, and Maltais F. COPD results in a reduction in UCP3 long mRNA and UCP3 protein content in types I and lla skeletal muscle fibers. J Cardiopulm Rehabil 24(5): 332-9, 2004.

27. Schols AM, Wouters EF, Soeters PB, and Westerterp KR. Body composition by bioelectricalimpedance analysis compared with deuterium dilution and skinfold anthropometry in patients with chronic obstructive pulmonary disease. Am J Clin Nutr 53(2): 421-4, 1991.

28. Schrauwen $P$ and Hesselink MK. The role of uncoupling protein 3 in fatty acid metabolism: protection against lipotoxicity? Proc Nutr Soc 63(2): 287-92, 2004.

29. Schrauwen P, Hesselink MK, Vaartjes I, Kornips E, Saris WH, Giacobino JP, and Russell A. Effect of acute exercise on uncoupling protein 3 is a fat metabolism-mediated effect. $A m \mathrm{~J}$ Physiol Endocrinol Metab 282(1): E11-7, 2002.

30. Schrauwen $P$, Hinderling V, Hesselink MK, Schaart G, Kornips E, Saris WH, WesterterpPlantenga $M$, and Langhans $W$. Etomoxir-induced increase in UCP3 supports a role of uncoupling protein 3 as a mitochondrial fatty acid anion exporter. Faseb $J$ 16(12): 1688-90, 2002.

31. Vega RB, Huss JM, and Kelly DP. The coactivator PGC-1 cooperates with peroxisome proliferator-activated receptor alpha in transcriptional control of nuclear genes encoding mitochondrial fatty acid oxidation enzymes. Mol Cell Biol 20(5): 1868-76, 2000.

32. Wasserman $K$, Hansen J, Sue $D$, Whipp $B$, and Casaburi R. Principles of exercise testing and interpretation. $2^{\text {nd }}$ ed. Philadelphia: Lea \& Febiger 1994.

33. Watabe S, Hiroi T, Yamamoto $Y$, Fujioka $Y$, Hasegawa $H$, Yago N, and Takahashi SY. SP-22 is a thioredoxin-dependent peroxide reductase in mitochondria. Eur J Biochem 249(1): 52-60, 1997. 


\title{
CHAPTER 6
}

\section{Dichloroacetate reduces exercise-induced systemic stress response in COPD}

\begin{abstract}
Background: Impaired skeletal muscle function contributes to exercise intolerance in patients with chronic obstructive pulmonary disease (COPD). Exercise-induced oxidative stress may initiate or accelerate impaired muscle function. Dichloroacetate (DCA) activates muscle pyruvate dehydrogenase complex (PDC) at rest, reducing inertia in mitochondrial energy delivery at the onset of exercise and thereby diminishing anaerobic energy production. This study aimed to determine whether DCA infusion may also reduce exercise-induced systemic oxidative stress in COPD patients. Methods: A randomized, double-blind crossover design was used in which thirteen COPD patients performed maximal cycle exercise after an intravenous infusion of DCA (50mg/kg body mass) or saline (placebo). Venous blood was sampled before, immediately after, $30 \mathrm{~min}$ and $2 \mathrm{~h}$ after exercise. Urine samples were obtained before and $2 \mathrm{~h}$ after exercise. Results: Peak workload improved significantly after DCA compared to placebo $(10 \% ; p<0.01)$. Urinary uric acid after exercise was significantly lower in the DCA condition when compared to placebo, whereas no significant difference was observed for urinary malondialdehyde. Oxidized glutathione (GSSG) was significantly increased $2 \mathrm{~h}$ after exercise in the placebo condition $(\mathrm{p}<0.02)$, but not after treatment. No changes in reduced glutathione (GSH), GSSG/GSH ratio and superoxide dismutase activity were observed. Plasma IL-6 significantly increased $2 \mathrm{~h}$ after exercise only in the DCA condition $(p<0.01)$. Conclusions: This study shows that the improved performance after a pharmacological intervention known to activate PDC was accompanied by an enhanced IL-6 response and a reduced exercise-induced systemic oxidative stress.
\end{abstract}

Evi M. Mercken ${ }^{1}$, Lori D. Calvert ${ }^{2}$, Sally J. Singh ${ }^{2}$, Geja J. Hageman ${ }^{3}$, Annemie M. Schols ${ }^{1}$ and Michael C. Steiner ${ }^{2}$. Departments of ${ }^{1}$ Respiratory Medicine, ${ }^{3}$ Health Risk Analysis and Toxicology, NUTRIM School for Nutrition, Toxicology and Metabolism, Maastricht University, The Netherlands, ${ }^{2}$ Respiratory Medicine, Instititute for Lung Health, Glenfield Hospital, Leicester, United Kingdom. Submitted. 


\section{INTRODUCTION}

Peripheral skeletal muscle dysfunction is a common feature in patients with chronic obstructive pulmonary disease (COPD) and contributes to exercise intolerance, disability and poor quality of life and survival [1]. Chronic inflammation and oxidative stress have been implicated in the etiology of peripheral muscle dysfunction [2, 3]. Increased systemic oxidative stress has been demonstrated in COPD patients at rest which is further intensified after exercise [4,5]. Furthermore, a reduction in skeletal muscle mitochondrial oxidative energy capacity has been observed in COPD, which may also contribute to exercise intolerance [1, 6-8]. Additionally, it has been reported that muscle adenine nucleotide loss occurs at low exercise absolute workload in COPD [9]. This suggests that ATP resynthesis is unable to meet the energy demands of exercise even at the low work rates patients with COPD can achieve [9].

There is a delay in skeletal muscle mitochondrial ATP production at the onset of exercise, which results in the reliance on non-oxidative sources of energy production to meet this shortfall in ATP supply in the early stages of exercise. Recent evidence suggests that this metabolic inertia resides at the level of the pyruvate dehydrogenase complex (PDC), a mitochondrial multi-enzyme complex which regulates carbohydrate entry into the tricarboxylic acid cycle [10] and catalyses the irreversible oxidation of pyruvate to mitochondrial acetyl CoA.

Dichloroacetate (DCA), a pharmacological agent, increases mitochondrial aerobic energy production through the activation of PDC. The mechanism of action is by inhibition of PDC kinase [11]. DCA has been used in humans for the treatment of mitochondrial diseases and lactic acidosis [12]. Moreover, several studies have investigated the effects of DCA on skeletal muscle energy metabolism in healthy controls after exercise [13, 14]. Recently, Calvert et al. [15] demonstrated that by activating PDC blood lactate and ammonia accumulation decreased during exercise and improved maximal exercise performance in COPD. However, the effect of DCA on exercise-induced oxidative stress and inflammatory markers has not been explored in humans yet. Therefore, the purpose of this study was to assess the effect of DCA infusion on exercise-induced systemic oxidative stress and inflammation in COPD patients. We assume that metabolic stress, as indicated by significant adenine nucleotide loss, leads to oxidative stress in part through the activity of xanthine oxidase which is a known source of free radicals. Given that DCA increases mitochondrial energy production, thereby improving the supply of ATP and attenuating adenine nucleotide loss, as measured by a reduction in ammonia accumulation [16], we hypothesized that DCA would reduce exercise-induced oxidative stress. We were also interested in exploring whether modifying the meta- 
bolic response by DCA might alter the inflammatory response to exercise. We evaluated these questions by investigating the effect of DCA treatment on systemic variables of oxidative stress and inflammation during a maximal cycle exercise in COPD patients who were participating in the original trial [15].

\section{MATERIALS AND METHODS}

\section{Study population}

The decision to undertake the current investigation was made after the start of the original trial and therefore thirteen of the 18 stable COPD patients examined in the study of Calvert et al. [15] were included. Patients met clinical and spirometric GOLD criteria for COPD $[17,18]$. Patients were excluded if taking maintenance oral corticosteroids, unable to perform exercise tests, exercise desaturation $(\mathrm{SaO} 2<80 \%)$, cardiac dysfunction, exacerbation of COPD within the previous 6 weeks, or pulmonary rehabilitation within the last year. Full approval was obtained from the Leicestershire Research Ethics Committee and all participants provided informed written consent.

\section{Assessment of body composition}

Body mass index was calculated from height (measured by wall mounted stadiometer to the nearest $0.1 \mathrm{~cm}$ ) and weight (measured in light clothing to the nearest 0.1 $\mathrm{kg}($ SECA, UK)). Fat free mass (FFM) was estimated (Bodystat 1500, Bodystat Ltd, Douglas, UK) and calculated using disease-specific regression equations [19].

\section{Pulmonary function tests}

Spirometry was performed to ERS standards (Vitallograph Model R, Buckingham, UK). Predicted values were calculated from ERS regression equations [18].

\section{Study design}

Details on the study design have been reported previously [15]. Briefly, subjects performed a maximal incremental exercise test on an electrically braked cycle ergometer. After a two-week washout period, subjects repeated the exercise challenge. Prior to exercise participants received either $50 \mathrm{mg} / \mathrm{kg}$ body mass of Dichloroacetate $(D C A ; 25 \mathrm{mg} / \mathrm{ml}$, sodium salt) or an equivalent volume of normal saline as an intravenous infusion into a forearm vein over 45 minutes. Peripheral venous blood samples were taken at rest, immediately after, $30 \mathrm{~min}$ and $2 \mathrm{~h}$ after the maximal incremental exercise test. Urine samples were obtained at rest and $2 \mathrm{~h}$ after the exercise test. Moreover, arterialized-venous blood samples for lactate and 
Chapter 6

ammonia analysis were taken at different time points during and after exercise as described previously [15].

\section{Sample preparation}

Venous blood samples were drawn into ethylenediaminetetraacetic acid-containing tubes. Plasma was obtained by centrifugation ( $800 \times g$ for 10 minutes at $4^{\circ} \mathrm{C}$ ) and stored at $-80^{\circ} \mathrm{C}$ until analysis. Urine samples were collected in sterile containers and stored at $-20^{\circ} \mathrm{C}$ until further analysis.

\section{Markers of systemic oxidative stress}

Urinary malondialdehyde (MDA) and urinary were assessed by HPCL described by Lepage et al. [20] and by Lux and colleagues [21] respectively. Both urinary MDA and uric acid concentration were corrected for creatinine contents [22].

Erythrocyte superoxide dismutase (SOD) activity was determined according to the method of Sun et al. [23]. Hemoglobin $(\mathrm{Hb})$ concentration was determined [24].

Erythrocyte glutathione was measured in its reduced [25] and oxidized [26] form.

\section{Markers of systemic inflammation}

Plasma concentrations of IL- 6 and TNF- $\alpha$ were determined using a quantitative high-sensitivity enzyme-linked immunosorbent assay kit (R\&D Systems, Minneapolis, MN, USA).

\section{Statistical analysis}

Data are expressed as mean \pm SD or as mean \pm SEM. A paired $t$-test was used to test the effect of treatment on exercise-induced biological markers. Putative correlations between variables were evaluated using Pearson correlation coefficients. A difference with $p<0.05$ was considered statistically significant. Statistical analyses were analyzed with SPSS for Windows (version 13.0; SPSS, Inc., Chicago, IL).

\section{RESULTS}

\section{Patient characteristics}

Anthropometric and spirometric data are shown in Table 1. The COPD group was characterized by moderate airflow obstruction. Subjects were either ex-smokers $(n=8)$ or current smokers $(n=5)$. 
Table 1. Characteristics of the study population

\begin{tabular}{lc}
\hline & $\begin{array}{c}\text { COPD } \\
(n=13)\end{array}$ \\
\hline Age (years) & $65.8 \pm 6.5$ \\
Sex, M/F & $11 / 2$ \\
FEV $1 \%$ pred) & $48.0 \pm 15.1$ \\
FEV $1(\mathrm{~L})$ & $1.24 \pm 0.50$ \\
$\mathrm{BMI}\left(\mathrm{kg} / \mathrm{m}^{2}\right)$ & $30.3 \pm 6.2$ \\
$\mathrm{FFMl}\left(\mathrm{kg} / \mathrm{m}^{2}\right)$ & $19.8 \pm 2.6$ \\
Oxygen saturation at rest $(\%)$ & $95.2 \pm 1.7$ \\
\hline
\end{tabular}

Data are expressed as mean $\pm S D$. FEV $1=$ forced expiratory volume in 1 second; $B M l=$ body mass index: $\mathrm{FFMl}=$ fat free mass index.

\section{Exercise capacity}

The results of the incremental exercise test performed after DCA and normal saline infusion are presented in Table 2. Peak workload increased significantly after DCA treatment $(10 \% ; p<0.01)$. Moreover, both peak oxygen consumption and peak ventilation were significantly increased after DCA infusion compared with placebo ( $9 \% ; p<0.01$ and $12 \% ; p<0.02$ respectively). RER at peak exercise was significantly greater following DCA $(p<0.001)$. DCA infusion also significantly reduced blood lactate and ammonia accumulation compared to placebo $(p<0.01$ and $p<0.001$ respectively)[15].

Table 2. Exercise data from maximal cycle exercise in COPD patients after DCA and saline infusion

\begin{tabular}{lcc}
\hline COPD patients $(n=13)$ & & \\
\hline & Saline & DCA \\
\hline Peak workload (watts) & $70.0 \pm 27.6$ & $78.1 \pm 29.8^{* *}$ \\
$\dot{V}_{2}$ peak $(\mathrm{ml} / \mathrm{min})$ & $1314.9 \pm 470.0$ & $1448.6 \pm 530.9^{* \prime}$ \\
Peak $\dot{V}_{E}(\mathrm{~L} / \mathrm{min})$ & $36.9 \pm 14.0$ & $41.8 \pm 15.8^{*}$ \\
Peak $\dot{V}_{E}(\% \mathrm{MVV})$ & $89 \pm 28$ & $98 \pm 28^{*}$ \\
Peak RER & $0.92 \pm 0.06$ & $0.95 \pm 0.06^{* \cdots}$ \\
Peak HR (\%pred) & $75 \pm 9$ & $74 \pm 9$ \\
$\Delta$ Lactate & $1.46 \pm 0.74$ & $1.06 \pm 0.58^{* *}$ \\
$\Delta$ Ammonia & $32.4 \pm 13.6$ & $19.5 \pm 8.6^{* * *}$
\end{tabular}

Data are expressed as mean \pm SD. MVV: maximum voluntary ventilation (calculated as $\mathrm{FEV}_{1} \times 35$ ); RER: respiratory exchange ratio; HR: heart rate (calculated as age-220).

$" p<0.02 ; " p<0.01 ; " * p<0.001$ significantly different compared to saline. 
Chapter 6

\section{Markers of systemic oxidative stress and inflammation}

The results of the systemic oxidative stress and inflammatory markers at rest and $2 \mathrm{~h}$ after exercise following placebo and DCA infusion are shown in Table 3.

Table 3. Markers of systemic oxidative stress and inflammation in COPD patients at rest and $2 \mathrm{~h}$ after exercise following DCA and saline infusion

\begin{tabular}{lcc|cc}
\hline COPD patients $(\mathrm{n}=13)$ & \multicolumn{2}{c}{ Saline } & \multicolumn{2}{c}{ DCA } \\
\hline & before & $2 \mathrm{~h}$ after & before & $2 \mathrm{~h}$ after \\
\hline Erythrocyte GSH $(\mu \mathrm{mol} / \mathrm{gHb})$ & $6.3 \pm 0.7$ & $6.1 \pm 0.4$ & $6.4 \pm 0.9$ & $7.1 \pm 1.1$ \\
Erythrocyte GSSG & $0.64 \pm 0.07$ & $0.74 \pm 0.08^{*}$ & $0.71 \pm 0.06$ & $0.75 \pm 0.08$ \\
( $\mu$ mol/gHb) & & & & \\
Erythrocyte GSSG/GSH & $0.15 \pm 0.05$ & $0.13 \pm 0.02$ & $0.15 \pm 0.03$ & $0.12 \pm 0.02$ \\
Erythrocyte SOD (U/mgHb) & $1208 \pm 146$ & $1420 \pm 186$ & $1236 \pm 131$ & $1293 \pm 122$ \\
Plasma IL-6 (pg/ml) & $2.5 \pm 0.3$ & $3.2 \pm 0.5$ & $2.4 \pm 0.2$ & $4.5 \pm 0.7^{* *}$ \\
Plasma TNF- $\alpha(\mathrm{pg} / \mathrm{ml})$ & $2.6 \pm 0.5$ & $2.6 \pm 0.5$ & $2.5 \pm 0.5$ & $2.6 \pm 0.5$ \\
\hline
\end{tabular}

Data are expressed as mean \pm SEM. GSH: reduced glutathione; GSSG: oxidized glutathione; SOD:

superoxide dismutase.

" $p<0.02 ; " p<0.01$ significantly different from baseline values.

Baseline values of systemic oxidative stress and inflammation were not significantly different between both conditions (data not shown). Urinary uric acid was $2 \mathrm{~h}$ after exercise significantly lower in the DCA condition when compared to placebo $(p<0.05$; Figure 1A). For urinary MDA, no significant differences between both groups were observed $2 \mathrm{~h}$ after exercise (Figure $1 \mathrm{~B}$ ). 
A.

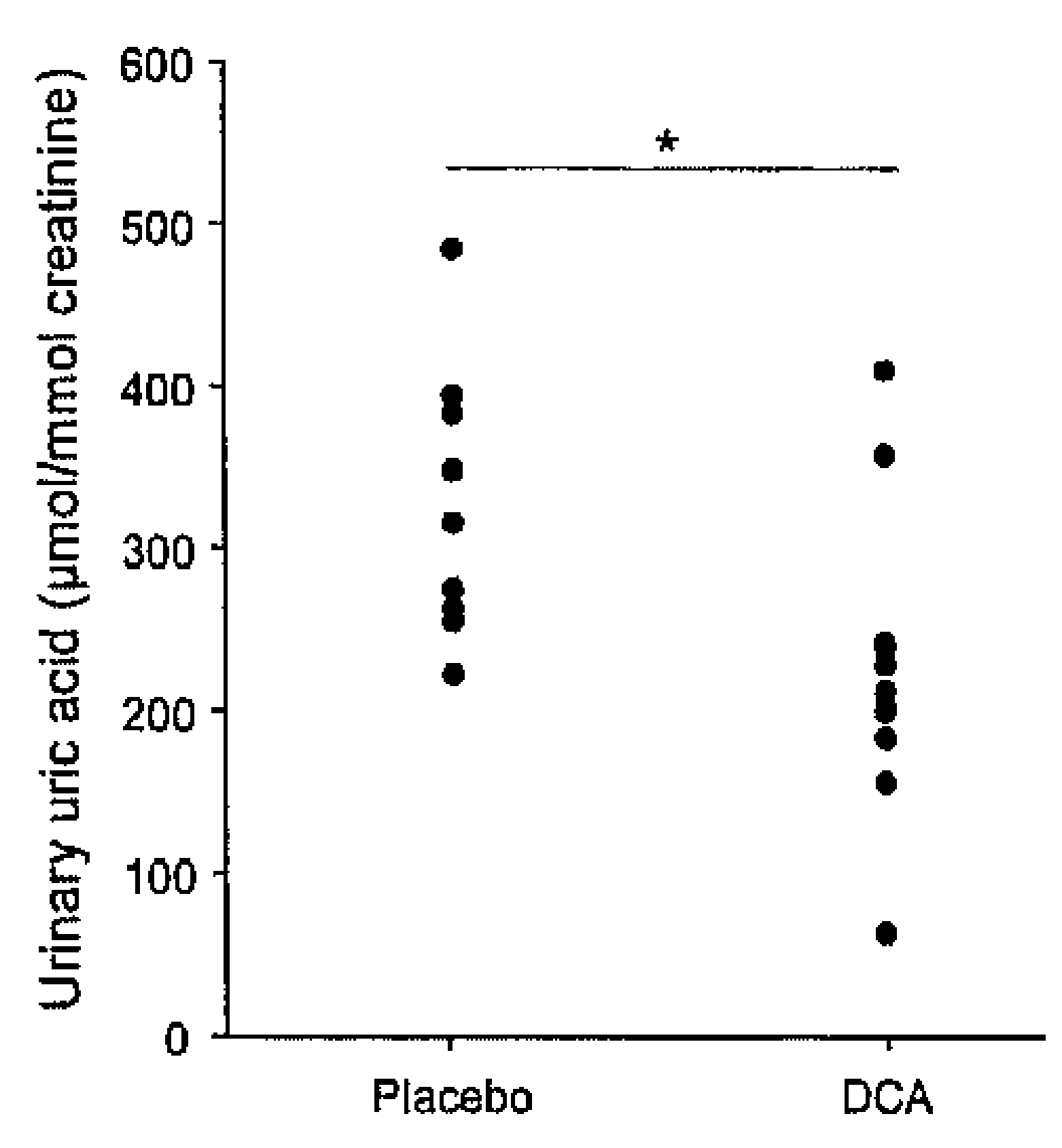

B.

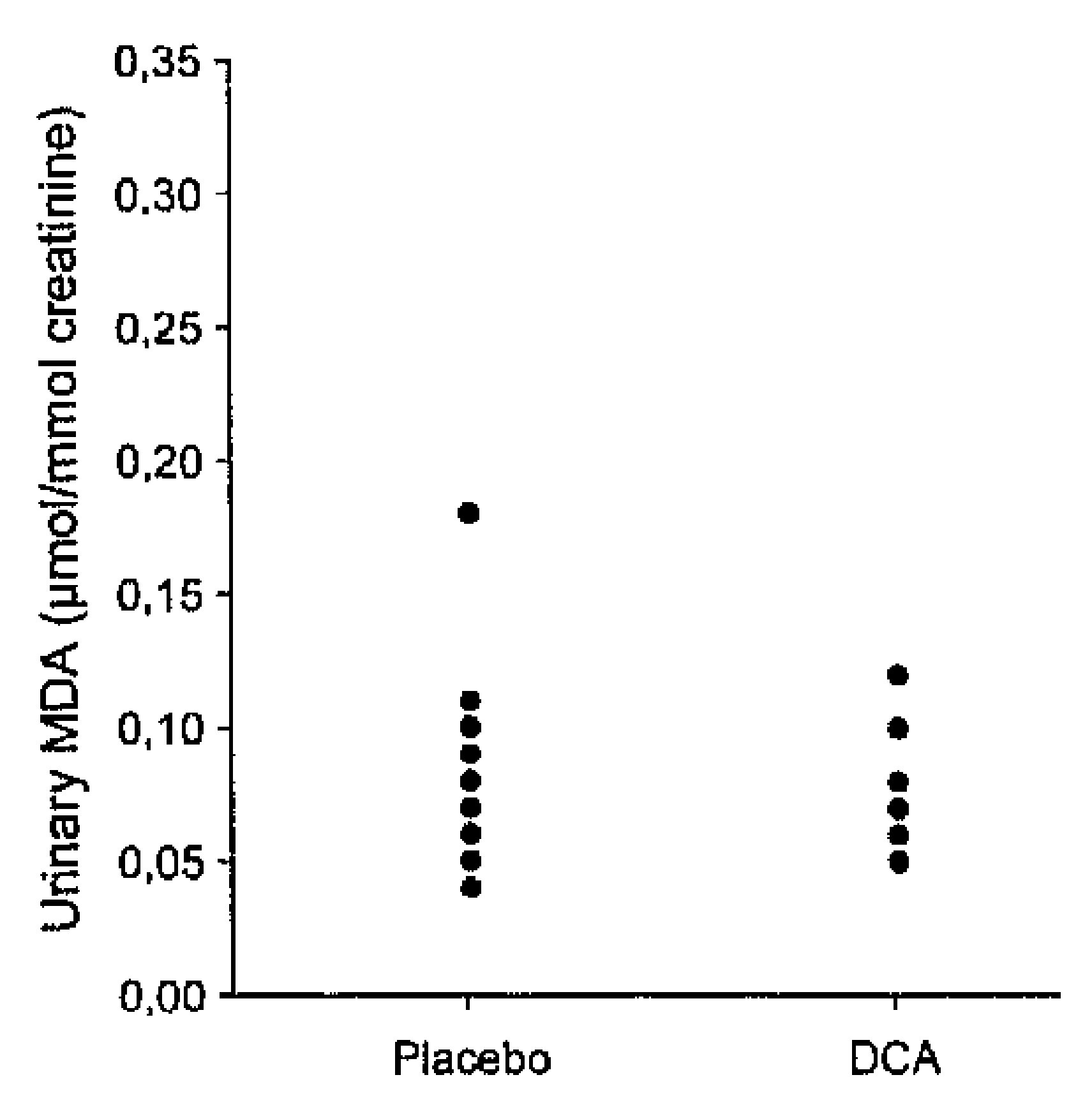

Figure 1. Concentration of urinary uric acid $(A)$ and urinary malondialdehyde (MDA) $(B) 2 \mathrm{~h}$ after exercise in placebo and DCA condition. ${ }^{*} \mathrm{p}<0.05$ significantly different $2 \mathrm{~h}$ after exercise between placebo versus DCA.

No significant effect of exercise was observed for erythrocyte GSH levels after both conditions, whereas erythrocyte GSSG levels were significantly elevated $2 \mathrm{~h}$ after exercise in the placebo condition ( $p<0.02$; Figure 2). However, levels of GSSG-toGSH ratio were unchanged after both conditions. Furthermore, no significant exercise-induced change in erythrocyte SOD activity was observed after both conditions.

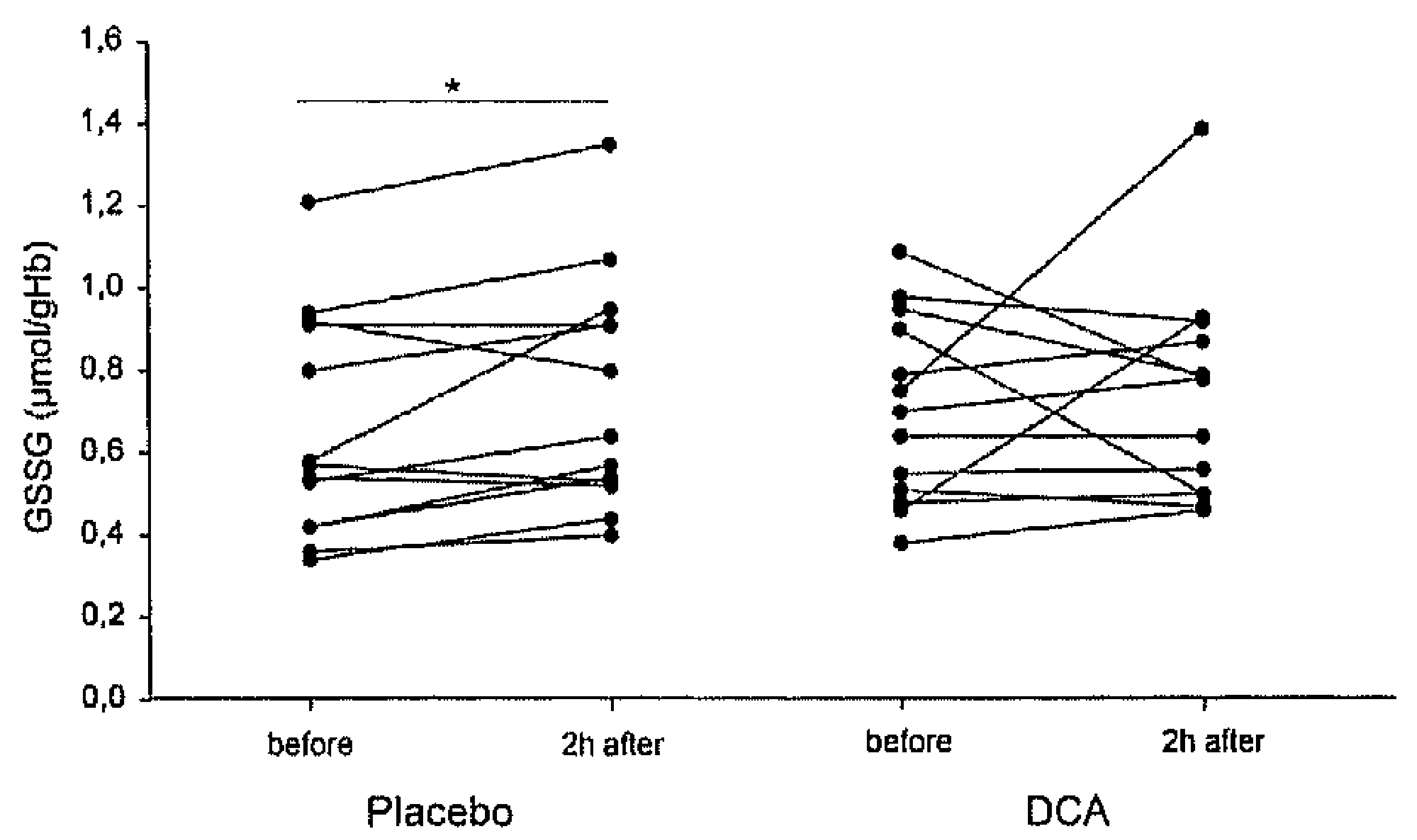

Figure 2. Effect of exercise on erythrocyte GSSG levels in placebo and DCA condition. $p<0.02$ significantly different from baseline values. 
Chapter 6

Remarkably, as shown in Figure 3, the exercise-induced IL-6 response was significantly higher in the DCA condition compared to placebo $(p<0.001)$. Moreover, IL-6 levels were significantly increased $2 \mathrm{~h}$ after exercise following DCA treatment $(p<0.01)$. No significant exercise-induced effects were observed for TNF- $\alpha$ after both conditions. However, a negative correlation was observed between exerciseinduced changes in IL-6 and TNF- $\alpha$ levels $(r=-0.80, p<0.01$; Figure 4) after DCA treatment, indicating that a rise in IL-6 might be a physiological response to attenuate exercise induced TNF- $\alpha$.

Furthermore, no significant correlations were found between changes in blood markers of the metabolic response and markers of oxidative stress and inflammation.

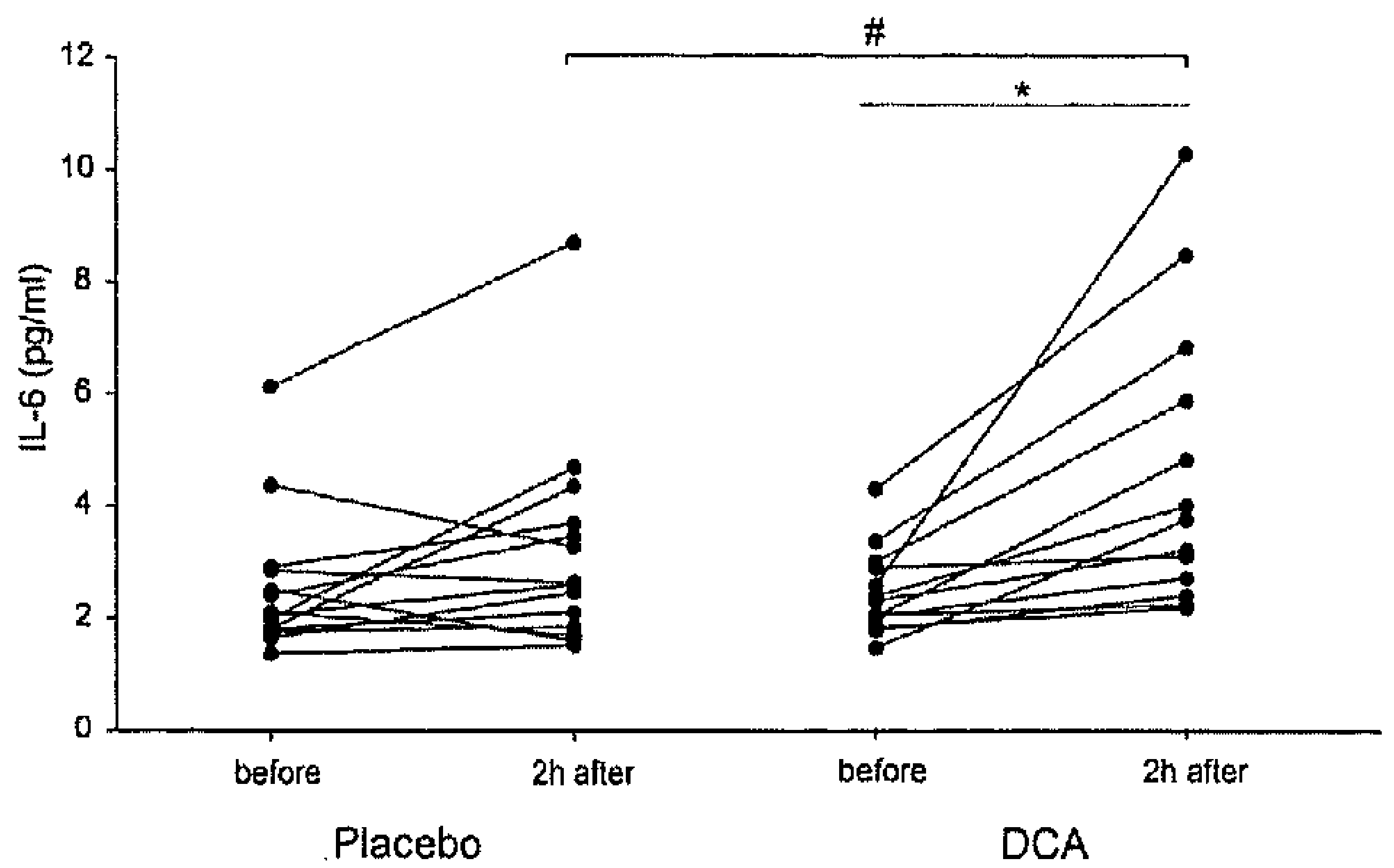

Figure 3. Effect of exercise on plasma IL-6 levels in placebo and DCA condition. " $p<0.01$ significantly different from baseline values; ${ }^{*} p<0.001$ significantly different between placebo versus DCA. 


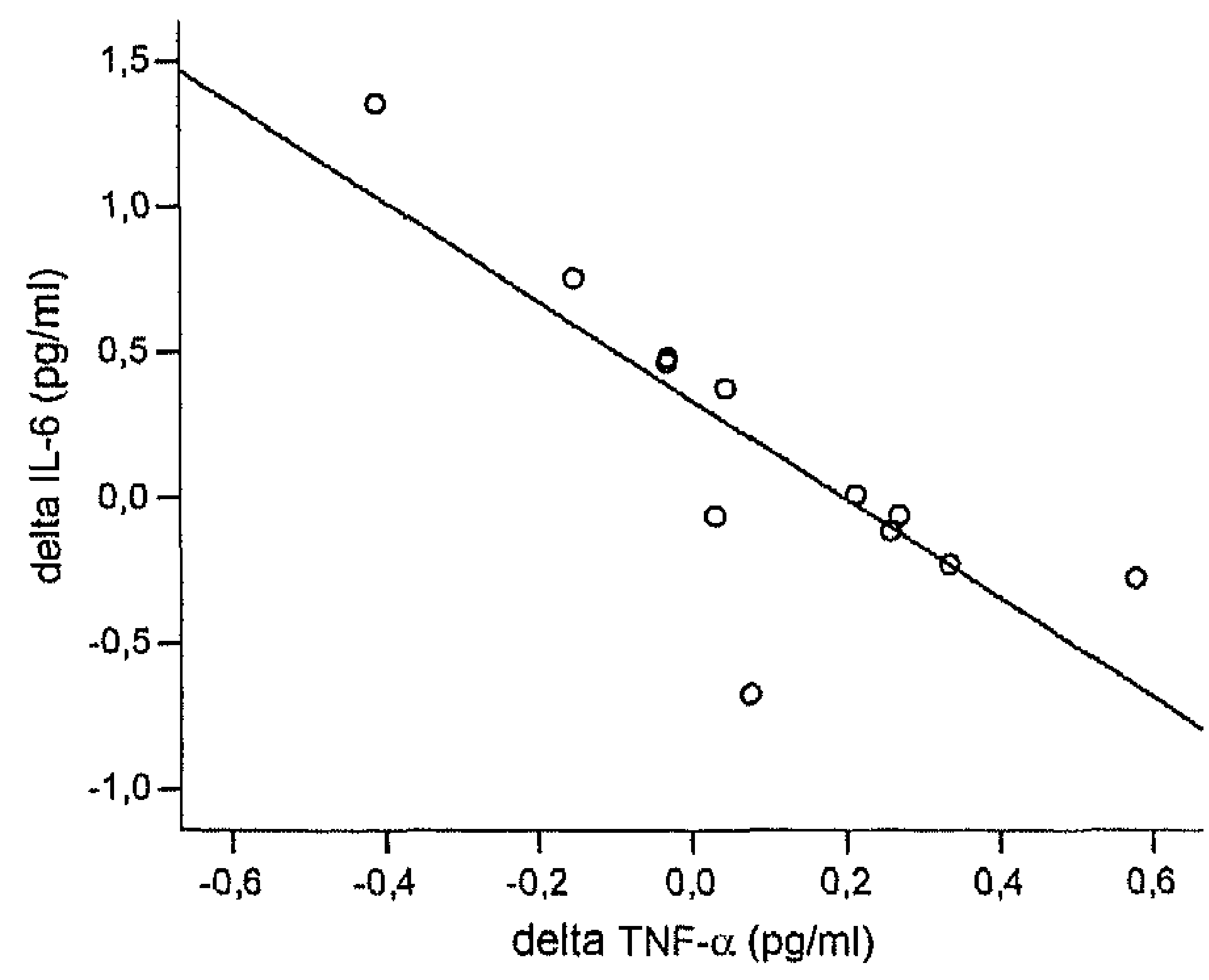

Figure 4. There was an inverse and significant correlation between exercise-induced changes in IL6 and TNF- $\alpha$ after DCA condition $(r=-0.80, p<0.01)$.

\section{DISCUSSION}

This study shows that a pharmacological intervention with DCA, which has been previously reported to improve exercise performance, also resulted in a reduced exercise-induced systemic oxidative stress and enhanced IL-6 response in patients with COPD. Another important finding of the present study was the inverse relationship between exercise-induced changes in IL- 6 and TNF- $\alpha$ levels after DCA treatment, suggesting that DCA treatment may have an anti-inflammatory effect in COPD. It is known that DCA improves the supply of ATP and thereby attenuates adenine nucleotide loss, as measured indirectly by a reduction in ammonia accumulation [15], and consequently this enhanced mitochondrial (oxidative or aerobic) energy production could play a role in decreasing the exercise-induced systemic oxidative stress and pro-inflammatory response in COPD.

During strenuous exercise, ATP is consumed at a greater rate than it can be replenished, leading to adenine nucleotide degradation, followed by increases in the plasma concentrations of hyopoxanthine, xanthine, and uric acid. Uric acid is an indicator of xanthine oxidase activity, which is seen as an important source of reactive oxygen species (ROS). In the present study, urinary uric acid after exercise was significantly lower in the DCA condition when compared to placebo which could point to an increased production of free radicals due to xanthine oxidase activity in 
the placebo group. In addition, the higher exercise-induced urinary uric acid levels after placebo condition might also reflect greater muscle adenine nucleotide loss during exercise, since the formation of uric acid is irreversible. This finding is supported by previously published data of Calvert et al. [15] who observed increased blood ammonia accumulation after placebo condition compared to DCA. This is also in keeping with previous data showing that adenine nucleotide loss occurs at low absolute exercise work rates in COPD which is associated with a rise in blood ammonia $[9,16]$. These observations indicate that ATP resynthesis is unable to meet the energy demands of exercise after placebo treatment suggesting that metabolic stress occurs in COPD patients during maximal exercise. This aberrant energy production might be countered by DCA that has been reported to activate PDC at the onset of exercise leading to an increase in the provision of mitochondrial acetyl CoA which was paralleled by an exponential rise in mitochondrial ATP production $[25,27,28]$. In the present study, urinary MDA levels were reduced after DCA infusion providing additional evidence for reduced exercise-induced oxidative stress in these COPD patients. Furthermore, we observed increased blood GSSG levels after placebo treatment, also indicating increased oxidative stress. However, no differences were observed for neither GSH nor for the GSSG-to-GSH ratio between the two conditions, nor for the activity of the antioxidant enzyme SOD. Therefore, the reduced exercise-induced systemic oxidative stress following DCA is likely to be attributable to a more efficient oxidative metabolism, as DCA is known to increase the overall contribution of oxidative pathways at the onset of exercise. DCA infusion activates muscle PDC at rest, reducing inertia in mitochondrial energy delivery at the onset of exercise and thereby diminishing non-oxidative (anaerobic) energy production. PDC is a key enzyme in controlling the selection of different respiratory substrate fuels. To meet the demands of an increasing workload as occurs during strenuous exercise, PDC has been reported to stimulate the relative contribution of glucose at the expense of fatty acids as substrate. Therefore, it is reasonable to assume that shifting the balance from fatty acids to carbohydrate oxidation results in greater efficiency of ATP production since oxidation of glucose requires less oxygen per unit ATP produced than oxidation of fatty acids. This is supported by higher RER after DCA observed in this study, which might indicate a preferential utilization of carbohydrate over fatty acids during exercise. It has also been hypothesized that decreasing fatty acid oxidation and increasing glucose oxidation improves the "coupling" between glycolysis and glucose oxidation, thereby preventing proton accumulation and hence less intracellular acidosis [29]. This is in agreement with lower blood lactate accumulation after DCA observed in this study. In the placebo condition, on the other hand, a reduced aerobic ATP production lead to a greater reliance on non-oxidative sources through anaerobic pathways and increased blood lactate levels. These conditions may induce an increased leakage of electrons from a disrupted respiratory chain and the generation of more ROS 
[30]. Taken together, these results indicate that in COPD, a more efficient oxidative metabolism during exercise could reduce the exercise-induced systemic oxidative stress response, although we were unable to find significant correlations between changes in markers of oxidative and metabolic stress. This may be due to differences in kinetics of formation and disposal of ammonia, lactate and oxidation products. However, further research is necessary to elucidate the underlying mechanisms responsible for the reduced exercise-induced oxidative stress response following DCA treatment.

A marked increase of plasma IL-6 levels after exercise has been a consistent finding in healthy controls [31]. It has therefore been suggested that contractioninduced IL-6 production in skeletal muscle may mediate several diverse metabolic and physiological effects. IL-6 has been proposed to mediate glucose homeostasis during exercise by stimulation of hepatic glucose production. In the present study, plasma IL-6 levels were significantly increased after exercise in the DCA condition only. Moreover, a negative correlation between changes in IL- 6 and TNF- $\alpha$ levels was observed after DCA treatment. This is in line with previous studies showing that increased IL-6 levels inhibit the production of the pro-inflammatory cytokine TNF- $\alpha$ [32-34]. Furthermore, data have been provided by Petersen et al. [35] that support the hypothesis that IL-6 has important anti-inflammatory effects in relation to exercise. Altogether, the above proposed functions suggest that the exercise-induced increased IL-6 levels after DCA are a normal physiological response.

\section{Clinical implications}

Our data suggest that exercise in the absence of DCA dampened the IL-6 response, and given the inverse relationship of IL- 6 with TNF- $\alpha$ after DCA treatment it could be speculated that DCA may have an anti-inflammatory effect in COPD. Moreover, DCA attenuated the systemic oxidative stress response during exercise in COPD. It is suggested that daily life activities can cause regularly bursts of systemic inflammation and oxidative stress in COPD that may be involved in muscle wasting. In this respect, DCA might have important clinical implications especially in the subgroup of COPD patients with muscle wasting. In this point of view it would be interesting to study the role of DCA in muscle wasted COPD patients.

\section{Limitations of the study}

We found significant differences of exercise within both conditions. A main limitation of this study however is related to a relatively small number of patients included which may not have enough statistical power for the between-group comparison of the exercise response. However, an exercise-induced change of urinary uric acid and plasma IL- 6 was found between both conditions. Another limitation of the 
Chapter 6

current study is that we did not directly measure the activity of PDC, but the data on activation by DCA in this dose is fairly robust $[13,36,37]$.

In summary, we have demonstrated that DCA infusion administered before a maximal exercise test reduces exercise-induced systemic oxidative stress which was accompanied by an improved exercise performance. In light of the current observation, it would be of interest to study PDC as a target to modulate the exerciseinduced oxidative stress response.

\section{ACKNOWLEDGEMENTS}

We thank Jeff Graham in the Pharmacy Department at Nottingham University Hospitals NHS Trust, University Hospital Campus (UK), and Eoin Barrett in the Pharmacy Department at Leicester Royal Infirmary, University Hospitals of Leicester NHS Trust (UK) for supervising the preparation of DCA and placebo and allocation of randomization.

\section{ABBREVIATION LIST}

COPD: chronic obstructive pulmonary disease

DCA: dichloroacetate

FFM: fat free mass

GSH: reduced glutathione

GSSG: oxidized glutathione

$\mathrm{Hb}$ : hemoglobin

MDA: malondialdehyde

PDC: pyruvate dehydrogenase complex

RER: respiratory exchange ratio

ROS: reactive oxygen species

SOD: superoxide dismutase 


\section{REFERENCES}

1. Skeletal muscle dysfunction in chronic obstructive pulmonary disease. A statement of the American Thoracic Society and European Respiratory Society. Am J Respir Crit Care Med 1999: $159(4 \mathrm{Pt}$ 2): $\$ 1-40$.

2. Agusti AG. Systemic effects of chronic obstructive pulmonary disease. Proc Am Thorac Soc 2005: 2(4): 367-370; discussion 371-362.

3. Berton $E$, Antonucci R, Palange P. Skeletal muscle dysfunction in chronic obstructive pulmonary disease. Monaldi Arch Chest Dis 2001: 56(5): 418-422.

4. Heunks LM, Vina J, van Herwaarden CL, Folgering HT, Gimeno A, Dekhuijzen PN. Xanthine oxidase is involved in exercise-induced oxidative stress in chronic obstructive pulmonary disease. Am J Physiol 1999: 277 (6 Pt 2): R1697-1704.

5. Mercken EM, Hageman GJ, Schols AM, Akkermans MA, Bast A, Wouters EF. Rehabilitation decreases exercise-induced oxidative stress in chronic obstructive pulmonary disease. Am J Respir Crit Care Med 2005: 172(8): 994-1001.

6. Maltais F, LeBlanc P, Simard C, Jobin J, Berube C, Bruneau J, Carrier L, Belleau R. Skeletal muscle adaptation to endurance training in patients with chronic obstructive pulmonary disease. Am J Respir Crit Care Med 1996: 154(2 Pt 1): 442-447.

7. Gosker HR, van Mameren H, van Dijk PJ, Engelen MP, van der Vusse GJ, Wouters EF, Schols AM. Skeletal muscle fibre-type shifting and metabolic profile in patients with chronic obstructive pulmonary disease. Eur Respir J 2002: 19(4): 617-625.

8. Maltais $F$, LeBlanc $P$, Whittom $F$, Simard $C$, Marquis $K$, Belanger $M$, Breton $M J$, Jobin $J$. Oxidative enzyme activities of the vastus lateralis muscle and the functional status in patients with COPD. Thorax 2000: 55(10): 848-853.

9. Steiner MC, Evans R, Deacon SJ, Singh SJ, Patel P, Fox J, Greenhaff PL, Morgan MD. Adenine nucleotide loss in the skeletal muscles during exercise in chronic obstructive pulmonary disease. Thorax 2005: 60(11): 932-936.

10. Randle PJ, Garland PB, Hales CN, Newsholme EA. The glucose fatty-acid cycle. Its role in insulin sensitivity and the metabolic disturbances of diabetes mellitus. Lancet 1963: 1(7285): 785-789.

11. Stacpoole PW, Nagaraja NV, Hutson AD. Efficacy of dichloroacetate as a lactate-lowering drug. J Clin Pharmacol 2003: 43(7): 683-691.

12. Stacpoole PW, Harman EM, Curry SH, Baumgartner TG, Misbin RI. Treatment of lactic acidosis with dichloroacetate. N Engl J Med 1983: 309(7): 390-396.

13. Timmons JA, Gustafsson T, Sundberg CJ, Jansson E, Greenhaff PL. Muscle acetyl group availability is a major determinant of oxygen deficit in humans during submaximal exercise. Am J Physiol 1998: 274(2 Pt 1): E377-380.

14. Howlett RA, Heigenhauser GJ, Hultman E, Hollidge-Horvat MG, Spriet LL. Effects of dichloroacetate infusion on human skeletal muscle metabolism at the onset of exercise. Am J Physiol 1999: 277(1 Pt 1): E18-25.

15. Calvert LD, Shelley R, Singh SJ, Greenhaff PL, Bankart J, Morgan MD, Steiner MC. Dichloroacetate Enhances Performance and Reduces Blood Lactate during Maximal Cycle Exercise in COPD. Am J Respir Crit Care Med 2008: 177(10): 1090-1094.

16. Calvert LD, Singh SJ, Greenhaff PL, Morgan MD, Steiner MC. The plasma ammonia response to cycle exercise in COPD. Eur Respir J 2008: 31(4): 751-758.

17. Rabe KF, Hurd S, Anzueto A, Barnes PJ, Buist SA, Calverley P, Fukuchi $Y$, Jenkins $C$, Rodriguez-Roisin R, van Weel $C$, Zielinski J. Global strategy for the diagnosis, management, and 
prevention of chronic obstructive pulmonary disease: GOLD executive summary. Am J Respir Crit Care Med 2007: 176(6): 532-555.

18. Quanjer PH, Tammeling GJ, Cotes JE, Pedersen OF, Peslin R, Yernault JC. Lung volumes and forced ventilatory flows. Report Working Party Standardization of Lung Function Tests, European Community for Steel and Coal. Official Statement of the European Respiratory Society. Eur Respir J Suppl 1993: 16: 5-40.

19. Steiner MC, Barton RL, Singh SJ, Morgan MD. Bedside methods versus dual energy X-ray absorptiometry for body composition measurement in COPD. Eur Respir J 2002: 19(4): 626631.

20. Lepage G, Munoz G, Champagne J, Roy CC. Preparative steps necessary for the accurate measurement of malondialdehyde by high-performance liquid chromatography. Anal Biochem 1991: 197(2): 277-283.

21. Lux $O$, Naidoo $D$, Salonikas $C$. Improved HPLC method for the simultaneous measurement of allantoin and uric acid in plasma. Ann Clin Biochem 1992: 29 ( Pt 6): 674-675.

22. Falco GL, Lloret SM, Gomez FB, Cabeza AS, Legua CM. Creatinine determination in urine samples by batchwise kinetic procedure and flow injection analysis using the Jaffe reaction: chemometric study. Talanta 2001: 55: 1079-1089.

23. Sun Y, Oberley LW, Li Y. A simple method for clinical assay of superoxide dismutase. Clin Chem 1988: 34(3): 497-500.

24. Van Kampen EJ, Zijlstra WG. Determination of hemoglobin and its derivatives. Adv Clin Chem 1965: 8: 141-187.

25. Tschakovsky ME, Hughson RL. Interaction of factors determining oxygen uptake at the onset of exercise. J Appl Physiol 1999: 86(4): 1101-1113.

26. Vandeputte C, Guizon I, Genestie-Denis I, Vannier B, Lorenzon G. A microtiter plate assay for total glutathione and glutathione disulfide contents in cultured/isolated cells: performance study of a new miniaturized protocol. Cell Biol Toxicol 1994: 10(5-6): 415-421.

27. Roberts PA, Loxham SJ, Poucher SM, Constantin-Teodosiu D, Greenhaff PL. The acetyl group deficit at the onset of contraction in ischaemic canine skeletal muscle. J Physiol 2002: 544(Pt 2): 591-602.

28. Timmons JA, Poucher SM, Constantin-Teodosiu D, Macdonald IA, Greenhaff PL. Metabolic responses from rest to steady state determine contractile function in ischemic skeletal muscle. Am J Physiol 1997: 273(2 Pt 1): E233-238.

29. Stanley WC, Lopaschuk GD, Hall JL, McCormack JG. Regulation of myocardial carbohydrate metabolism under normal and ischaemic conditions. Potential for pharmacological interventions. Cardiovasc Res 1997: 33(2): 243-257.

30. Stacpoole PW. Lactic acidosis and other mitochondrial disorders. Metabolism 1997: 46(3): 306-321.

31. Febbraio MA, Pedersen BK. Muscle-derived interleukin-6: mechanisms for activation and possible biological roles. Faseb J 2002: 16(11): 1335-1347.

32. Starkie R, Ostrowski SR, Jauffred $S$, Febbraio $M$, Pedersen BK. Exercise and IL-6 infusion inhibit endotoxin-induced TNF-alpha production in humans. Faseb J 2003: 17(8): 884-886.

33. Matthys $P$, Mitera $T$, Heremans $H$, Van Damme J, Billiau A. Anti-gamma interferon and antiinterleukin-6 antibodies affect staphylococcal enterotoxin B-induced weight loss, hypoglycemia, and cytokine release in D-galactosamine-sensitized and unsensitized mice. Infect Immun 1995: 63(4): 1158-1164.

34. Mizuhara $H$, O'Neill $E$, Seki $N$, Ogawa $T$, Kusunoki $C$, Otsuka $K$, Satoh $S$, Niwa $M$, Senoh $H$, Fujiwara $\mathrm{H}$. T cell activation-associated hepatic injury: mediation by tumor necrosis factors and protection by interleukin 6. J Exp Med 1994: 179(5): 1529-1537. 
35. Petersen AM, Pedersen BK. The anti-inflammatory effect of exercise. J Appl Physiol 2005: 98(4): 1154-1162.

36. Greenhaff PL, Campbell-O'Sullivan SP, Constantin-Teodosiu D, Poucher SM, Roberts PA, Timmons JA. Metabolic inertia in contracting skeletal muscle: a novel approach for pharmacological intervention in peripheral vascular disease. British journal of clinical pharmacology 2004: 57(3): 237-243.

37. Heigenhauser GJ, Parolin ML. Role of pyruvate dehydrogenase in lactate production in exercising human skeletal muscle. Advances in experimental medicine and biology 1999: 474: 205-218. 


\section{CHAPTER 7 \\ General discussion and future directions}

The data presented in this thesis show that COPD patients are characterized by an increased pulmonary and systemic oxidative stress response at rest as well as induced by exercise compared to healthy controls, which was not paralleled by enhanced pro-inflammatory cytokines. Intriguingly, in contrast to healthy controls, our data suggest a blunted exercise-induced expression of cytokines, antioxidants, heat shock proteins and survival factors in skeletal muscle of COPD patients. Moreover, our data are supportive of an inadequate antioxidant and $\beta$-oxidation capacity leading to an adaptive upregulation of uncoupling protein-3 (UCP3) during exercise in skeletal muscle of patients with COPD. Interestingly, in COPD patients not suffering from muscle wasting we showed that increased exercise capacity after pulmonary rehabilitation was associated with reduced exercise-induced oxidative stress. These intriguing observations will be placed in a broader perspective in the following section.

\section{THE EXERCISE-INDUCED OXIDATIVE STRESS PARADOX}

Exercise-induced oxidative stress and inflammation have gained a lot of attention in the last decade. Previous studies showed an increased systemic oxidative stress response after strenuous whole body exercise in patients with COPD (1-3). However, the effect of exercise intensity on systemic oxidative stress and potential differential effects on pulmonary oxidative stress have not been clearly defined and are described in Chapter 2. This study showed that clinically and weight stable patients with moderate COPD are chronically exposed to low-grade pulmonary as well as systemic oxidative stress, which further increased after both maximal (highintensity) and submaximal (moderate intensity) exercise. Therefore, these patients might also frequently be exposed to repeated episodes of oxidative stress during activities of daily living. These studies focused on whole body exercise during which the ventilatory system is in most patients the dominant limiting factor of exercise intolerance $(4,5)$. Moreover, under these circumstances, it is difficult to identify the specific source of exercise-induced oxidative stress in COPD: lungs, peripheral skeletal muscles, respiratory muscles or maybe even other sites. Therefore, in Chapter 3, the effect of a constant work rate single leg ergometer test on systemic inflammation and oxidative stress as well as on pulmonary oxidative stress was evaluated in patients with COPD. In line with the increased systemic oxidative 
stress response observed after whole body exercise, COPD patients also showed a greater susceptibility to local exercise-induced systemic oxidative stress, without evidence of increased levels of systemic inflammation during exercise. The increased pulmonary oxidative stress observed after maximal whole body exercise in COPD, as described in Chapter 2, could be contributed to increased ventilatory demands. Remarkably, even despite the low cardioventilatory responses, an increased pulmonary oxidative stress response was also observed after a localized quadriceps exercise in patients with COPD, but not in healthy controls indicating an enhanced production of reactive oxygen species (ROS) in the airways of these patients. Possible mechanisms that might play a role in the exercise-induced pulmonary stress response include increased xanthine oxidase activity in epithelial cells, an inappropriate NADPH oxidase activation and/or an intensified pulmonary inflammatory response. Further research will have to elucidate whether these or other mechanisms may indeed be involved in the exercise-induced pulmonary oxidative stress response. Interestingly, our data demonstrated that the susceptibility of exercise intolerance was not homogenous among patients with COPD as was reflected in a subgroup that had to quit the exercise prematurely. These so called quitters were characterized by a reduced metabolic capacity, indicating a greater reliance on anaerobic metabolism, which may limit local quadriceps endurance capacity. Moreover, they showed a less pronounced oxidative stress response compared to non-quitters which could be explained by the fact that the oxidative stress threshold was not reached due to early muscle fatigue in the quitters. Based on these findings, it could be speculated that nutritional or pharmacological intervention will be more beneficial in specific subgroups of patients and that more extensive phenotyping of COPD patients is indicated to achieve optimal benefits of pulmonary rehabilitation.

Besides increased basal systemic oxidative stress, we observed enhanced oxidative stress in skeletal muscle of patients with COPD, as documented in Chapter 4. Intriguingly, the higher oxidative stress within the skeletal muscle of COPD patients was not paralleled by elevated pro-inflammatory cytokines. This suggests that inflammation and oxidative stress do not coexist in COPD patients at rest. Increased oxidative stress in skeletal muscle of patients with COPD is a relative consistent finding in the literature (6-8). However, a controversy exists regarding inflammatory markers at rest in skeletal muscle of COPD patients. Some studies support the presence of local inflammation in skeletal muscle of patients with $\operatorname{COPD}(9,10)$ whereas others do not support this finding (11-13). To date, it is still unclear whether a local muscle inflammatory response is beneficial or detrimental in patients with COPD. Although several reports have clearly linked cytokine-mediated effects, particularly tumor necrosis factor alpha (TNF- $\alpha$ ), to muscle dysfunction, muscle atrophy and inhibition of muscle regeneration (14-16), there is also evidence that 
these cytokines are essential to repair processes (17-20). It appears that, depending on timing, duration, magnitude, and composition of inflammatory response, muscle regeneration may be beneficially or detrimentally affected by TNF- $\alpha$. Consequently, further studies should be designed to address this apparent controversy. Whether peripheral skeletal muscle is a potential source of exercise-induced oxidative stress and inflammation was further confirmed with needle biopsies of the vastus lateralis in Chapter 3 and Chapter 4. Herein, it was demonstrated that a submaximal cycle ergometer test can indeed produce oxidative stress within the skeletal muscle. Conversely, Rabinovich and colleagues (21) were unable to document increased muscle oxidative stress after whole body exercise at a lower intensity. However, Couillard et al. (22) showed that a local quadriceps exercise performed until exhaustion produced oxidative stress within the contracting muscle. Therefore, it could be argued that both whole body and local exercise, if sufficiently intense, are able to produce oxidative stress within the skeletal muscle of patients with COPD.

Although exercise training is highly recommended in the pulmonary rehabilitation setting for the purpose of improving physical performance and health related quality of life, exercise-induced increases in oxidative stress may adversely affect outcome in COPD $(3,22)$. This 'exercise paradox' was evaluated in Chapter 3 by exploring the effects of pulmonary rehabilitation on markers of exercise-induced oxidative stress in COPD patients. Interestingly, in COPD patients, pulmonary rehabilitation resulted in significant improvements in exercise capacity which was associated with reduced exercise-induced systemic oxidative stress, especially after a submaximal exercise. Therefore, this study indicates that exercise training is a preventive treatment of exercise-induced systemic oxidative stress in COPD and hence it is reasonable that physical exercise training can reduce potential adverse effects associated with daily activities. The reduced exercise-induced systemic oxidative stress response may be attributed to adaptive responses involving a more efficient oxidative metabolism or an increased capacity of endogenous antioxidative systems. Knowledge about adaptation of the skeletal muscle antioxidant defense system to exercise training in COPD is limited. However, the former may likely occur since Rabinovich and colleagues (21) reported that patients with COPD had a reduced ability to adapt to endurance training, as reflected by a lower capacity to synthesize reduced glutathione.

In view of both an increased resting and exercise-induced oxidative stress in COPD and the positive effect of exercise training on oxidative stress, it is of interest to investigate whether nutritional or pharmacological supplementation with antioxidants as adjunct to exercise training further modifies basal or exercise-induced systemic oxidative stress and thereby improves outcome of rehabilitation. Only limited data are available on the effects of specific nutritional intervention on oxida- 
tive stress in COPD. Firstly, it has been shown that exercise-induced oxidative stress can be (partially) prevented by the antioxidant $\mathrm{N}$-acetylcysteine (NAC) in COPD (1). Secondly, it has also been reported that oral supplementation with NAC reduced basal disturbance in the pro-oxidant system and prevented the exerciseinduced oxidative stress in patients with COPD (3). Moreover, short-term high dose NAC treatment improved quadriceps endurance in COPD (3). However, long-term improvement of patients is obviously the ultimate goal. At present, as part of the ENIGMA (European Network for investigating the global mechanisms of muscle abnormalities in COPD) project, the effects of prolonged NAC supplementation ( 3 months) on muscle function and oxidative stress at rest is investigated in patients with COPD. Moreover, we are currently performing a double-blind randomized study in which the effect of nutritional supplementation enriched with antioxidants as adjunct to exercise training on exercise-induced systemic oxidative stress and exercise capacity is assessed in COPD.

More recent studies have underlined the importance of an altered energy metabolism as mechanism for development of peripheral muscle dysfunction. Several reports have shown a reduced oxidative energy metabolism in skeletal muscle from COPD patients, which is even more compromised after exercise, indicating an imbalance between the utilization and resynthesis of ATP in COPD (23-26). Recently, it has been shown in COPD patients that by modulating skeletal muscle oxidative energy metabolism using dichloroacetate (DCA) infusion before a maximal exercise challenge, blood lactate and ammonia accumulation decreased and exercise performance improved (27). Whether an increased muscle energy status could additionally decrease exercise-induced oxidative stress was explored in Chapter 6. It was shown that by triggering skeletal muscle oxidative energy metabolism in COPD with DCA, a reduced exercise-induced systemic oxidative stress response was observed compared to placebo. A likely explanation for the reduced systemic exercise-induced oxidative stress following DCA is attributable to a more efficient oxidative (aerobic) metabolism, as DCA has the ability to reduce the inertia in aerobic mitochondrial ATP generation and the reliance on anaerobic ATP resynthesis at the onset of exercise. Therefore, based on the results described in Chapter 3 , it could be hypothesized that triggering skeletal muscle energy metabolism would probably benefit exercise performance more in quitting COPD patients since they already have a more compromised metabolic oxidative capacity than non-quitters. 


\section{UCP3: AN ADAPTIVE MECHANISM AGAINST LIPOTOXICITY?}

At present, the functional role of mitochondrial uncoupling protein-3 (UCP3) in skeletal muscle metabolism is still controversial and incomplete. The existing evidence points towards a function for UCP3 in the prevention of ROS formation (28) and/or the export of fatty acid anions from the mitochondrial matrix (29). However, regardless of the exact mechanism of UCP3, the physiological implication of these two functions is that UCP3 is related to the protection of mitochondria against lipotoxicity. In this context, it is noteworthy to mention that COPD patients, in addition to a blunted muscle antioxidant capacity as documented in this thesis, are characterized by an impaired fatty acid $\beta$-oxidation (25), which both may result in oxidative stress-induced muscle lipotoxicity. Interestingly, 3-hydroxyacyl-CoA dehydrogenase (HAD), a key enzyme of the $\beta$-oxidation of fatty acids, has consistently been shown to be reduced in COPD patients compared to healthy controls, which implies a reduced fatty acid oxidation in COPD (25). Accordingly, Gosker and colleagues (30) previously showed that muscle UCP3 levels increased by exercise training in COPD patients with a blunted response of the $\beta$-oxidation, suggesting that UCP3 was upregulated in response to an insufficient capacity to oxidize free fatty acids (FFAs). Because an acute bout of exercise not only results in increased oxidative stress but also increases FFAs levels and fat oxidation, we tested the hypothesis whether muscle UCP 3 gene expression in COPD is upregulated during an acute bout of exercise as an adaptation to a blunted response of the antioxidant defense system and $\beta$-oxidation (Chapter 5). This work indicated that COPD patients, but not healthy controls responded to an acute bout of exercise by increasing skeletal muscle UCP3. Concomitantly, this response was associated with a blunted antioxidant system and impaired oxidative capacity which led to enhanced exerciseinduced muscle lipid peroxidation, as assessed by 4-hydroxy-2-nonenal (4-HNE). These findings are supportive of an adaptive role for UCP3 in protecting the muscle cell against ROS-induced lipotoxicity. Moreover, these results provide a plausible link between the two proposed physiological functions of UCP3. It is likely that due to an impaired $\beta$-oxidation observed in COPD, fatty acid delivery to the muscle exceeds its oxidizing capacity, and will accumulate and flip-flop into the mitochondrial matrix as fatty acid anions (31). Moreover, as a result of the blunted antioxidant system, increased ROS production in the mitochondria might attack these fatty acid anions inevitably leading to the formation of lipid peroxidation products, such as 4HNE. Interestingly, 4-HNE has recently been identified as a strong activator of UCP3 and subsequently reduced mitochondrial ROS formation (32). Consequently, therapeutic strategies to decrease ROS production should be focused on two approaches, selective uncoupling of mitochondria, and increasing the antioxidant defense. Therefore, in light of the current observation it would be of interest to study 
the effect of antioxidant supplementation combined with exercise training on UCP3 mRNA and protein levels. It is important to keep in mind that in peripheral muscle of COPD there is a shift in muscle fiber type from type I (slow twitch, oxidative fibers) to type II (fast twitch glycolytic) fibers (24). Nevertheless, the marked increase in the proportion of type II is accompanied by selective atrophy of type II fibers, as reported recently (24). Additional studies need to be undertaken to explore whether the exercise-induced UCP3 upregulation in COPD is related to muscle fiber composition, since UCP3 is predominantly expressed in glycolytic type II fibers (33). Moreover, further research is required in order to unravel the underlying mechanism behind this adaptation that is likely to be shared by other chronic conditions, such as chronic heart failure. Eventually, this may result in novel targets for therapies for peripheral muscle dysfunction in this disease.

\section{DISTINCTIVE ROLE OF NF-KB BETWEEN PHYSIOLOGICAL AND PAHTOPHYSIOLOGICAL CONDITION (EPISODIC / CHRONIC)}

Existing data indicate that an acute bout of exercise activates the expression of a number of genes, including genes associated with stress, inflammation, survival and tissue repair in skeletal muscle of healthy controls. It is conceivable that this response to exercise is necessary for adequate muscle contractile function, adequate remodeling of injured skeletal muscle and to provide considerable protection against oxidative damage. Whether the adaptive response of skeletal muscle of patients with COPD to exercise is different compared with healthy controls was examined in Chapter 4. Intriguingly, in contrast to healthy controls, our findings suggest that skeletal muscle of patients with COPD had an impaired response to acute exercise which was reflected in a blunted expression of inflammatory cytokines, antioxidants, heat shock proteins and survival factors. The blunted cellular protective response strongly indicates that COPD patients are more susceptible to oxidative stress/damage which can negatively affect muscle function and contribute to the development of fatigue, a prominent feature of peripheral muscle dysfunction (34). There is evidence that under normal physiological conditions inflammatory cytokines may be necessary for an adequate remodeling of injured skeletal muscle. In this regard, the attenuated response observed in COPD may impair the regenerative capacity of skeletal muscles and ultimately contribute to muscle wasting. This attenuated response is reflected in decreased levels of myogenic differentiation factor (MyoD) in COPD patients, since MyoD has a key role in regulating muscle differentiation and regeneration. A key question that remains to be determined is whether this attenuated ability of skeletal muscle to adapt to the oxidative exerciseinduced challenge may be due to altered redox signaling cascades. There is now 
considerable evidence that the ROS generated by skeletal muscle play an important role in influencing redox-regulated processes that control, at least some of, the adaptive responses to exercise. Thus, ROS generation during exercise may have a 'two faced' character: the infliction of oxidative stress and damage, and the stimulation of adaptive responses favoring long-term protection. One of the most important signaling pathways that could be modulated by ROS involves the transcription factor nuclear protein $\mathrm{KB}$ (NF-KB) (for review see (35)). NF- $\mathrm{kB}$ has been studied most extensively for its pivotal role in the regulation of innate immunity, inflammation and apoptosis. However, its physiological and pathological roles in tissues outside of the immune system are less well understood. Sustained activation of NF-KB by oxidative stress has been suggested to play a central role in the etiology of systemic features of COPD (36). In particular, recent findings have highlighted an important role for chronic unopposed activation of NF-KB in cachexia and other muscle wasting syndromes $(16,37)$. This raises intriguing questions about what effect episodic activation of NF- $\mathrm{KB}$, as occurs during exercise, might have on skeletal muscle of COPD. Interestingly, consistent with the blunted expression of inflammatory cytokines, antioxidants and heat shock proteins in response to exercise, a reduced $1 \kappa B \alpha$ expression in skeletal muscle of COPD patients compared to healthy controls was demonstrated, indicating an attenuated NF-KB activation in COPD after exercise (Chapter 4). One may argue that the reduced NF- $\mathrm{KB}$ mediated gene expression observed in COPD may be due to an altered intracellular redox state by the changes in the rates of ROS production. This might emphasize a fine-tuned balance between the production of oxidants which is necessary for the protective adaptive response of skeletal muscle or excessive production of oxidants, as likely occurs in COPD, which will lead to cell damage. In this context, it is plausible that administration of antioxidants during physical exercise may be a requirement for augmented tolerance of skeletal muscle to exercise-induced oxidative stress. Collectively, exercise-mediated NF-KB activation has probably many different roles, but at least three potential roles conferred at the transcriptional level of regulation are postulated; antioxidant defense, tissue regeneration and metabolism. Therefore, it emerges that NF-KB has diverse roles, particularly in the context of episodic versus chronic cellular stress. Additionally, it seems that differential NF- $\mathrm{KB}$ regulated genes may be selectively activated in skeletal muscle of patients with COPD compared to healthy age-matched controls in response to exercise (Figure 1). Obviously, further research is necessary to delineate the specific role of redox-regulated pathways in exercise-induced adaptations in patients with COPD. More insight into redox mechanisms and oxidative stress in skeletal muscle will provide a clearer picture of muscle function and will broaden our understanding of the process of muscle fatigue and muscle damage. A major challenge that lies ahead in this field is to understand how exercise exerts its effects on gene and protein expression in skeletal 
muscle under physiological and pathophysiological conditions. Also the link between redox-regulated gene expression and adaptation to exercise training in COPD is at an exciting stage and merits further clarification.

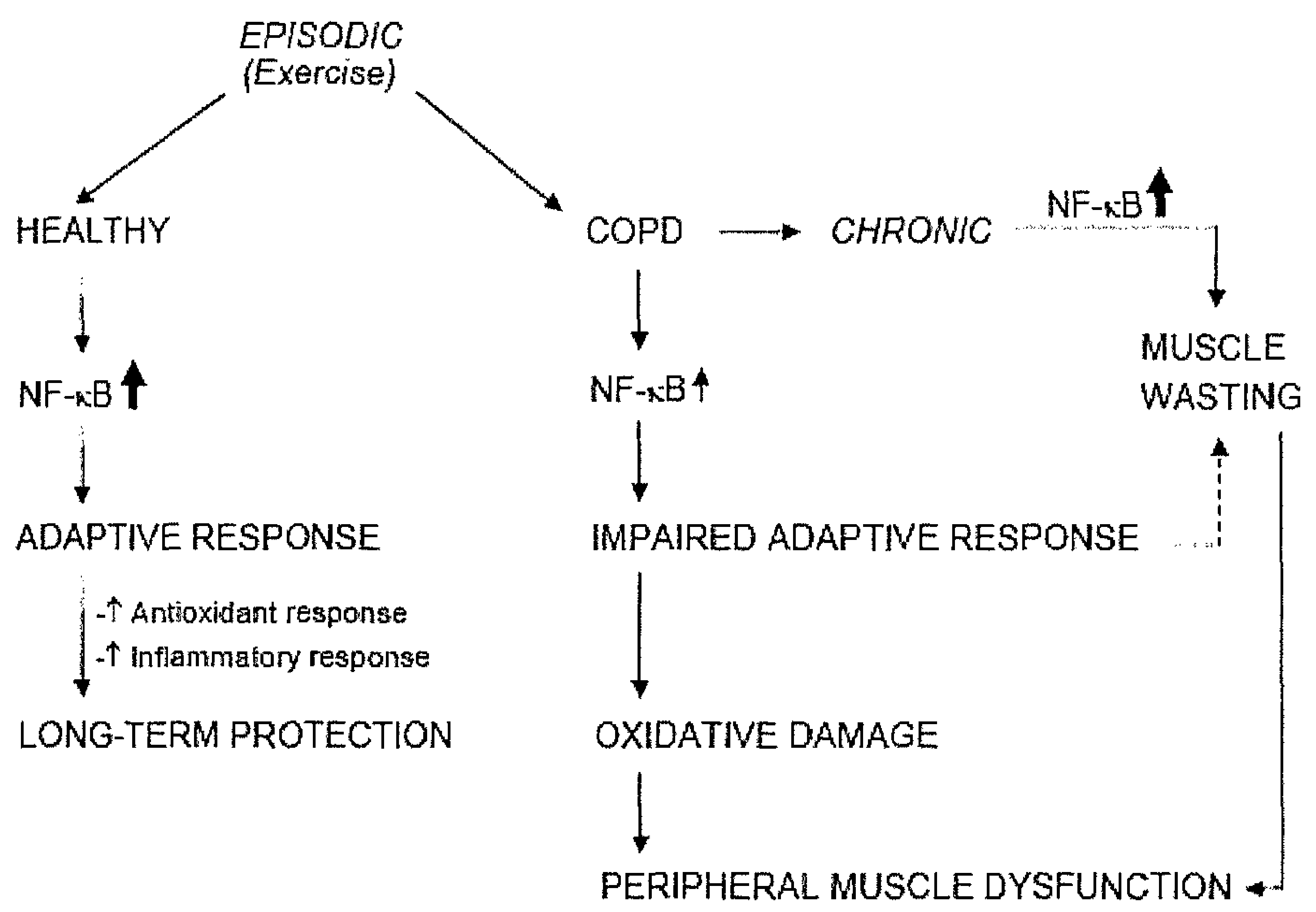

Figure 1. NF-kB paradox

\section{FUTURE DIRECTIONS}

The research conducted in this thesis focused on well-designed clinical studies and clearly indicates that COPD patients are characterized by increased oxidative stress, both at rest and induced by different types of exercise. However, as indicated above, further research is necessary to delineate these findings. An intriguing observation that is not addressed in this thesis is that oxidative stress seemed to be associated with apoptosis which may eventually lead to muscle atrophy. Skeletal muscle atrophy is a prominent and disabling feature of COPD, and even an independent predictor of mortality. Because muscle atrophy is associated with reduced exercise capacity and quality of life in patients with COPD, the elucidation of its mechanisms appears to be relevant with respect to therapeutic interventions. 
Recently, apoptosis has emerged as an important contributor to muscle disuseinduced atrophy. However, to date only few studies have been undertaken to identify the molecular mechanisms underlying this cell loss in patients with COPD. Thus the challenge is to unravel the underlying mechanisms responsible for linking oxidative stress to apoptosis. One molecular mechanism that might induce apoptosis is poly-(ADP-ribose) polymerase-1 (PARP)-mediated myocyte cell death. Preliminary evidence showed that the nuclear enzyme PARP-1 is activated after exercise in skeletal muscle of patients with COPD. PARP-1 is a multifunctional protein important for maintenance of genomic integrity and RNA transcription in cells $(38,39)$. During conditions of oxidative stress, as observed in COPD, PARP-1 is overactivated and may contribute to myocyte cell death (38). A possible molecular mechanism behind PARP-mediated myocyte cell death is that PARP-1 overactivation depletes cellular $\mathrm{NAD}^{+}$content, thereby suppressing the activity of other $N A D^{+}$dependent cellular processes. Another crucial family of proteins that is greatly affected by changes in cellular $\mathrm{NAD}^{+}$levels is the class III histone deacetylases, also called sirtuins. They have been implicated in chromatin silencing, cell survival and aging (for review see (40)). Therefore, in future research we will investigate the possible role of repression of SIRT1 by PARP-1 in myocyte cell death ex vivo and subsequently in translational studies. This could ultimately lead to new therapeutic strategies aimed at repressing apoptosis as opposed to currently used anabolic stimuli of the skeletal muscle. 


\section{REFERENCES}

1. Heunks LM, Vina J, van Herwaarden CL, Folgering HT, Gimeno A, and Dekhuijzen PN. Xanthine oxidase is involved in exercise-induced oxidative stress in chronic obstructive pulmonary disease. Am J Physiol 1999;277(6 Pt 2):R1697-704.

2. Couillard A, Koechlin C, Cristol JP, Varray A, and Prefaut C. Evidence of local exerciseinduced systemic oxidative stress in chronic obstructive pulmonary disease patients. Eur Respir J 2002;20(5):1123-9.

3. Koechlin C, Couillard A, Simar D, Cristol JP, Bellet H, Hayot M, and Prefaut C. Does oxidative stress alter quadriceps endurance in chronic obstructive pulmonary disease? Am J Respir Crit Care Med 2004;169(9):1022-7.

4. Richardson RS, Leek BT, Gavin TP, Haseler LJ, Mudaliar SR, Henry R, Mathieu-Costello O, and Wagner PD. Reduced mechanical efficiency in chronic obstructive pulmonary disease but normal peak VO2 with small muscle mass exercise. Am $J$ Respir Crit Care Med 2004;169(1):89-96.

5. Dolmage TE, and Goldstein RS. Response to one-legged cycling in patients with COPD. Chest 2006;129(2):325-32.

6. Barreiro E, Gea J, Corominas JM, and Hussain SN. Nitric oxide synthases and protein oxidation in the quadriceps femoris of patients with chronic obstructive pulmonary disease. $A m \mathrm{~J}$ Respir Cell Mol Biol 2003;29(6):771-8.

7. Allaire J, Maltais F, LeBlanc P, Simard PM, Whittom F, Doyon JF, Simard C, and Jobin J. Lipofuscin accumulation in the vastus lateralis muscle in patients with chronic obstructive pulmonary disease. Muscle Nerve 2002;25(3):383-9.

8. Barreiro E, Gea J, Matar G, and Hussain SN. Expression and carbonylation of creatine kinase in the quadriceps femoris muscles of patients with chronic obstructive pulmonary disease. Am $J$ Respir Cell Mol Biol 2005;33(6):636-42.

9. Rabinovich RA, Figueras M, Ardite E, Carbo N, Troosters T, Filella X, Barbera JA, FernandezCheca JC, Argiles JM, and Roca J. Increased tumour necrosis factor-alpha plasma levels during moderate-intensity exercise in COPD patients. Eur Respir $J$ 2003;21(5):789-94.

10. Montes de Oca M, Torres SH, De Sanctis J, Mata A, Hernandez N, and Talamo C. Skeletal muscle inflammation and nitric oxide in patients with COPD. Eur Respir J 2005;26(3):390-7.

11. Gosker HR, Kubat B, Schaart G, van der Vusse GJ, Wouters EF, and Schols AM. Myopathological features in skeletal muscle of patients with chronic obstructive pulmonary disease. Eur Respir J 2003;22(2):280-5.

12. Koechlin C, Maltais F, Saey D, Michaud A, Leblanc P, Hayot M, and Prefaut C. Hypoxemia enhances peripheral muscle oxidative stress in chronic obstructive pulmonary disease. Thorax 2005.

13. Barreiro E, Schols AM, Polkey MI, Galdiz JB, Gosker HR, Swallow EB, Coronell C, and Gea J. Cytokine Profile in Quadriceps Muscles of Patients with Severe Chronic Obstructive Pulmonary Disease. Thorax 2007.

14. Langen RC, Schols AM, Kelders MC, van der Velden JL, Wouters EF, and Janssen-Heininger YM. Muscle wasting and impaired muscle regeneration in a murine model of chronic pulmonary inflammation. Am J Respir Cell Mol Biol 2006;35(6):689-96.

15. Reid MB, Lannergren $\mathrm{J}$, and Westerblad $\mathrm{H}$. Respiratory and limb muscle weakness induced by tumor necrosis factor-alpha: involvement of muscle myofilaments. Am J Respir Crit Care Med 2002;166(4):479-84. 
16. Langen RC, Schols $A M$, Kelders MC, Wouters EF, and Janssen-Heininger YM. Inflammatory cytokines inhibit myogenic differentiation through activation of nuclear factor-kappaB. Faseb $J$ $2001 ; 15(7): 1169-80$.

17. Contreras-Shannon V, Ochoa O, Reyes-Reyna SM, Sun D, Michalek JE, Kuziel WA, McManus $L M$, and Shireman PK. Fat accumulation with altered inflammation and regeneration in skeletal muscle of CCR2- mice following ischemic injury. Am J Physiol Cell Physiol 2007;292(2):C953-67.

18. Chen $S E$, Jin $B$, and $L i$ YP. TNF-alpha regulates myogenesis and muscle regeneration by activating p38 MAPK. Am J Physiol Cell Physiol 2007;292(5):C1660-71.

19. Chen SE, Gerken E, Zhang Y, Zhan M, Mohan RK, LI AS, Reid MB, and Li YP. Role of TNF\{alpha\} signaling in regeneration of cardiotoxin-injured muscle. Am J Physiol Cell Physiol 2005;289(5):C1179-87.

20. Warren GL, Hulderman T, Jensen N, McKinstry M, Mishra M, Luster MI, and Simeonova PP. Physiological role of tumor necrosis factor alpha in traumatic muscle injury. Faseb $J$ 2002;16(12):1630-2.

21. Rabinovich RA, Ardite E, Troosters T, Carbo N, Alonso J, Gonzalez de Suso JM, Vilaro J, Barbera JA, Polo MF, Argiles JM, Fernandez-Checa JC, and Roca J. Reduced muscle redox capacity after endurance training in patients with chronic obstructive pulmonary disease. Am J Respir Crit Care Med 2001;164(7):1114-8.

22. Couillard A, Maltais F, Saey D, Debigare R, Michaud A, Koechlin C, LeBlanc P, and Prefaut C. Exercise-induced quadriceps oxidative stress and peripheral muscle dysfunction in patients with chronic obstructive pulmonary disease. Am J Respir Crit Care Med 2003;167(12):1664-9.

23. Maltais F, Simard AA, Simard C, Jobin J, Desgagnes $P$, and LeBlanc P. Oxidative capacity of the skeletal muscle and lactic acid kinetics during exercise in normal subjects and in patients with COPD. Am J Respir Crit Care Med 1996;153(1):288-93.

24. Gosker HR, van Mameren H, van Dijk PJ, Engelen MP, van der Vusse GJ, Wouters EF, and Schols AM. Skeletal muscle fibre-type shifting and metabolic profile in patients with chronic obstructive pulmonary disease. Eur Respir J 2002;19(4):617-25.

25. Maltais F, LeBlanc $P$, Whittom F, Simard $C$, Marquis $K$, Belanger M, Breton MJ, and Jobin J. Oxidative enzyme activities of the vastus lateralis muscle and the functional status in patients with COPD. Thorax 2000;55(10):848-53.

26. Steiner MC, Evans R, Deacon SJ, Singh SJ, Patel P, Fox J, Greenhaff PL, and Morgan MD. Adenine nucleotide loss in the skeletal muscles during exercise in chronic obstructive pulmonary disease. Thorax 2005.

27. Calvert LD, Shelley R, Singh SJ, Greenhaff PL, Bankart J, Morgan MD, and Steiner MC. Dichloroacetate Enhances Performance and Reduces Blood Lactate during Maximal Cycle Exercise in COPD. Am J Respir Crit Care Med 2008.

28. Brand MD. Uncoupling to survive? The role of mitochondrial inefficiency in ageing. Exp Gerontol 2000;35(6-7):811-20.

29. Dulloo $A G$, and Samec $S$. Uncoupling proteins: their roles in adaptive thermogenesis and substrate metabolism reconsidered. Br J Nutr 2001;86(2):123-39.

30. Gosker HR, Schrauwen P, Broekhuizen R, Hesselink MK, Moonen-Kornips $E$, Ward KA, Franssen FF, Wouters EF, and Schols AM. Exercise training restores uncoupling protein-3 content in limb muscles of patients with chronic obstructive pulmonary disease. Am J Physiol Endocrinol Metab 2005.

31. Schrauwen $P$, Hinderling $V$, Hesselink MK, Schaart $G$, Kornips $E$, Saris WH, WesterterpPlantenga $M$, and Langhans $W$. Etomoxir-induced increase in UCP3 supports a role of uncoupling protein 3 as a mitochondrial fatty acid anion exporter. Faseb J 2002;16(12):1688-90. 
Chapter 7

32. Murphy MP, Echtay KS, Blaikie FH, Asin-Cayuela J, Cocheme HM, Green K, Buckingham JA, Taylor ER, Hurrell F, Hughes G, Miwa S, Cooper CE, Svistunenko DA, Smith RA, and Brand $M D$. Superoxide activates uncoupling proteins by generating carbon-centered radicals and initiating lipid peroxidation: studies using a mitochondria-targeted spin trap derived from alphaphenyl-N-tert-butylnitrone. J Biol Chem 2003;278(49):48534-45.

33. Hesselink MK, Keizer HA, Borghouts LB, Schaart G, Kornips CF, Slieker LJ, Sloop KW, Saris $W H$, and Schrauwen P. Protein expression of UCP3 differs between human type 1, type 2a, and type $2 b$ fibers. Faseb $J$ 2001;15(6):1071-3.

34. Reid MB. Invited Review: redox modulation of skeletal muscle contraction: what we know and what we don't. J App/ Physiol 2001;90(2):724-31.

35. Pantano $C$, Reynaert NL, van der Vliet $A$, and Janssen-Heininger $Y M$. Redox-sensitive kinases of the nuclear factor-kappaB signaling pathway. Antioxid Redox Signal 2006;8(9-10):1791-806.

36. Reid MB, and Durham WJ. Generation of reactive oxygen and nitrogen species in contracting skeletal muscle: potential impact on aging. Ann N Y Acad Sci 2002;959:108-16.

37. Cai D, Frantz JD, Tawa NE, Jr., Melendez PA, On BC, Lidov HG, Hasselgren PO, Frontera WR, Lee J, Glass DJ, and Shoelson SE. IKKbeta/NF-kappaB activation causes severe muscle wasting in mice. Cell 2004;119(2):285-98.

38. Burkle A. Physiology and pathophysiology of poly(ADP-ribosyl)ation. Bioessays 2001;23(9):795-806.

39. Virag $L$, and Szabo $C$. The therapeutic potential of poly(ADP-ribose) polymerase inhibitors. Pharmacol Rev 2002;54(3):375-429.

40. North BJ, and Verdin E. Sirtuins: Sir2-related NAD-dependent protein deacetylases. Genome Biol 2004;5(5):224. 


\section{CHAPTER 8}

\section{Summary}

Peripheral muscle dysfunction is a common and disabling systemic feature of patients with chronic obstructive pulmonary disease (COPD) which contributes to exercise intolerance, impaired quality of life and survival. There are several mechanisms proposed that could explain the peripheral muscle dysfunction but the precise contribution of each is yet unknown. Among them, chronic inflammation and oxidative stress are prominent features of COPD that may be implicated in the etiology of peripheral muscle dysfunction. Exercise training is beneficial for patients with COPD, in part by improving exercise intolerance, but paradoxically, exercise is known, if sufficiently intense, to elicit an oxidative stress response in healthy controls. This thesis describes the effects of acute and prolonged exercise on pulmonary, systemic and muscle oxidative stress, and inflammatory responses in patients with COPD.

In Chapter 2, we examined the effects of different exercise intensities and the effect of intensive supervised pulmonary rehabilitation on systemic and pulmonary oxidative stress. Clinically and weight stable patients with moderate COPD were chronically exposed to low-grade pulmonary and systemic oxidative stress compared to healthy age-matched controls, which was observed to further increase in COPD patients after both maximal and submaximal exercise. This suggests that healthy control subjects are able to tolerate exercise more effectively than patients with COPD. Importantly, intensive pulmonary rehabilitation was associated with reduced systemic exercise-induced oxidative stress. This decrease was accompanied by a significant improvement in exercise capacity after rehabilitation in patients with COPD. As COPD patients are characterized by an increased oxidative stress response at rest as induced by exercise, it will be interesting to study whether specific nutritional or pharmacological modulation as adjunct to exercise training can reduce this oxidative stress even further.

Most studies to date have focused on whole body exercise in which the ventilatory system is, in most patients, the dominant limiting factor of exercise intolerance. Under these circumstances, it is difficult to disentangle the relative contributions of lung versus muscle to exercise-induced oxidative stress in COPD. We examined in Chapter 3 whether and to what extent systemic inflammation and oxidative stress as well as pulmonary oxidative stress are differentially triggered by contracting peripheral muscle of COPD patients versus healthy controls. In line with the in- 
Chapter 8

creased systemic oxidative stress response observed after whole body exercise (Chapter 2), COPD patients also showed a greater susceptibility to local exerciseinduced systemic oxidative stress, without evidence of increased levels of systemic inflammation. An important finding was that, even despite the low cardioventilatory responses, an increased pulmonary oxidative stress response was observed after a localized quadriceps exercise in patients with COPD.

Chronic activation of the transcription factor NF- $\mathrm{KB}$ by oxidative stress has been suggested to play a role in the etiology of the systemic features of COPD including muscle wasting. Paradoxically, evidence exists that an acute bout of exercise potently activates NF- $\mathrm{KB}$ signaling in skeletal muscle of healthy controls. Therefore, in Chapter 4 the question we addressed was whether NF- $\mathrm{kB}$ is activated and if NF$\mathrm{KB}$ activity and downstream effectors were induced in skeletal muscle of patients with COPD in response to an acute exercise bout. Our data reveal differential NF$\mathrm{KB}$ mediated gene expression in skeletal muscle of patients with COPD compared to healthy age-matched controls in response to acute exercise. Skeletal muscle of COPD patients was characterized by an impaired response to acute exercise as reflected by a blunted expression of inflammatory cytokines, antioxidants, heat shock proteins and survival factors. This suggests that muscle NF-KB activation is a physiological response to exercise-induced adaptations to cellular stress that may be impaired in COPD and it may contribute to peripheral muscle dysfunction in COPD. Therefore, NF-KB emerges as having diverse roles, particularly in the context of episodic versus chronic cellular stress.

Besides a disturbed muscle oxidant/antioxidant balance, COPD patients are characterized by an impaired oxidative capacity. Both may result in oxidative stressinduced muscle lipotoxicity which could be exaggerated after exercise. Uncoupling protein-3 (UCP3) is considered to be a key player in the protection of mitochondria against lipotoxicity. Therefore, Chapter 5 focused on the role of muscular UCP3 gene expression after an acute exercise in patients with COPD compared to healthy controls. The main finding of the present study was that an acute bout of exercise upregulates UCP3 gene transcription in skeletal muscle of COPD, but not in healthy controls. This response is associated with a blunted antioxidant defense system and $\beta$-oxidation in COPD in combination with enhanced intramuscular lipid peroxidation. We hypothesize that the upregulation of UCP3 in peripheral muscle of patients with COPD could very well be a compensatory mechanism against this lipotoxicity. The differences found between COPD patients and healthy controls emphasize the importance to further unravel the underlying mechanisms by which UCP3 affects the ROS-induced lipotoxicity. 
A reduction in skeletal muscle mitochondrial oxidative energy capacity has been observed in patients with COPD, which may also contribute to exercise intolerance. Therefore, the effect of a pharmacological agent, dichloroacetate (DCA), on systemic exercise-induced oxidative stress and inflammation in COPD patients was explored in Chapter 6. DCA specifically targets skeletal muscle oxidative energy metabolism and improves exercise performance in COPD. We demonstrated that DCA infusion administered before a maximal exercise test reduces exerciseinduced systemic oxidative stress and enhanced the anti-inflammatory cytokine interleukin (IL)-6 response in patients with COPD. Another important finding of the present study was the inverse relationship between exercise-induced changes in IL6 and the pro-inflammatory cytokine tumour necrosis factor-alpha (TNF- $\alpha$ ) levels after DCA treatment, suggesting that DCA treatment may have an anti-inflammatory effect in patients with COPD. It is known that DCA improves the supply of ATP and thereby attenuates adenine nucleotide loss, as measured indirectly by a reduction in ammonia accumulation. Consequently this enhanced mitochondrial energy production could play a role in decreasing the exercise-induced systemic oxidative stress and pro-inflammatory response in COPD patients.

In conclusion, this thesis has demonstrated that COPD patients are characterized by an increased pulmonary and systemic oxidative stress response at rest as well as induced by exercise when compared to healthy controls. We hope that our findings contribute to tailored therapies, from physical to nutritional or pharmacological interventions to improve the quality and prospective of life for this complex and heterogenic chronic disorder. 


\section{CHAPTER 9}

\section{Samenvatting}

Verlies van spiermassa is een veel voorkomend probleem bij patiënten met chronisch obstructief longlijden (COPD) en draagt bij tot een verminderd inspanningsvermogen, een verminderde kwaliteit van leven en een verhoging van het sterfterisico. Ondanks het feit dat de preciese oorzaak van het verlies van spiermassa nog niet is opgehelderd, wordt verondersteld dat een sluimerende chronische ontstekingsactiviteit en oxidatieve stress een belangrijke rol spelen in de etiologie van spierfunctieverlies. Oxidatieve stress is een toestand waarbij de balans verstoord is tussen de vorming (pro-oxidatieve werking) en de eliminatie (anti-oxidatieve werking) van toxische zuurstofverbindingen. Lichamelijke inspanning is gunstig om het inspanningsvermogen van COPD patiënten te verbeteren maar aan de andere kant is bij gezonde mensen aangetoond dat zeer intensieve inspanning een oxidatieve stress respons teweeg kan brengen. Dit proefschrift beschrijft de acute en lange termijn effecten van lichamelijke inspanning op de ontstekingsrespons en op de oxidatieve stress respons die systemisch (hele lichaam), pulmonaal (long) en in de spier optreedt in patiënten met COPD.

In Hoofdstuk 2, hebben we zowel het effect van verschillende inspanningsintensiteiten als het effect van een intensieve longrevalidatie op systemische en pulmonale oxidatieve stress onderzocht. In vergelijking met gezonde controles, die met de patiëntengroep overeenkwamen wat betreft leeftijd en geslacht, zijn patiënten met matig COPD continu blootgesteld aan pulmonale en systemische oxidative stress. Deze oxidatieve stress respons was zelfs meer uitgesproken na zowel een maximale als een submaximale inspanningstest in COPD patiënten. Dit suggereert dat gezonde controles beter in staat zijn om oxidatieve stress te tolereren dan patiënten met COPD. Een opmerkelijke bevinding was dat regelmatig bewegen (longrevalidatie) een gunstig effect had op de inspannings-geînduceerde oxidatieve stress respons in COPD. Bovendien hadden COPD patiënten een verbeterde inspanningscapaciteit na revalidatie. Omwille van de verhoogde oxidatieve stress respons zowel in rust als gedurende inspanning, en vanwege het gunstige effect van regelmatig bewegen is het interessant om nader te onderzoeken of een specifieke voedings- of farmacologische modulatie in combinatie met inspanningstraining deze oxidatieve stress respons verder kan doen afnemen.

Tot op heden lag de focus in de meeste studies op een inspanning waarbij het hele lichaam actief betrokken is. Bij deze inspanningstest is het ventilatoire systeem in 
Chapter 9

het merendeel van de COPD patiënten de grootste beperkende factor voor het verminderde inspanningsvermogen. Bovendien is het onder deze omstandigheden moeilijk om de relatieve bijdrage van de longen ten op zichte van de skeletspieren aan de inspannings-geïnduceerde oxidatieve stress respons in COPD te onderscheiden. Daarom werd in Hoofdstuk 3 onderzocht in welke mate een lokale beenspiertest oxidatieve stress induceert in COPD patiënten in vergelijking met gezonde controles. In lijn met de toegenomen systemische oxidatieve stress na een lichaamsinspanning (hoofdstuk 2), vertoonden COPD patiënten ook een grotere gevoeligheid voor een door lokale inspannings-geïnduceerde systemische oxidatieve stress respons. Echter, dit ging gepaard zonder een verhoogde systemische ontstekingsrespons. Een belangrijke bevinding was dat ondanks de minimale cardiale (hart)- en ventilatoire belasting van de lokale beenspiertest, een toegenomen oxidatieve stress respons in de longen werd aangetoond in patiënten met COPD.

Chronische activatie van de transcriptiefactor NF-kB vervult een belangrijke rol in spiervezelverschuiving en verlies van spiermassa bij COPD. NF-KB wordt echter acuut geactiveerd in de skeletspier van gezonde controles na een lichamelijke inspanning. Naar aanleiding hiervan hebben we in Hoofdstuk 4 de effecten van acute inspanning op NF- $\mathrm{KB}$ activiteit en NF-KB gemedieerde genexpressie onderzocht bij patiënten met COPD. Onze data toonden aan dat NF-KB gemedieerde gen expressie in de skeletspier van COPD patiënten na een acute inspanning verschillend was in vergelijking met leeftijdsgematchte gezonde controles. De skeletspier van COPD patiënten werd na een acute inspanning gekenmerkt door een verstoorde respons die zich weerpspiegelde in een verlaagde expressie van ontstekingseiwitten, antioxidanten, stress eiwitten, en overlevingfactoren. Dit suggereert dat NF$\mathrm{KB}$ activiteit in de spier een normale reactie is op inspannings-geïnduceerde stress. Deze inspannings-geïnduceerde adaptatie lijkt verstoord te zijn in COPD en dit zou vervolgens kunnen bijdragen aan spierfunctieverlies in COPD. Hieruit blijkt dat NF$\mathrm{KB}$ diverse functies heeft, in het bijzonder in de context van acute versus chronische cellulaire stress.

Naast een verstoorde oxidant/antioxidant balans in de spier worden COPD patiënten ook gekenmerkt door een verminderde oxidatieve capaciteit en beiden kunnen resulteren in oxidatieve stress geïnduceerde lipotoxiciteit (stapeling van vetten) in de spieren. Dit proces zou versneld kunnen worden door lichamelijke inspanning. Uncoupling protein-3 (UCP3) wordt veronderseld een belangrijke sleutelrol te vervullen in de bescherming van mitochondria (energiefabriekjes van de cel) tegen stapeling van vetten in de spier. In Hoofdstuk 5 werd de rol van UCP3 in de spier na een acute inspanning in gezonde controles en patiënten met COPD nader 
onderzocht. Opvallend was dat UCP3 gentranscriptie in de skeletspier van patiënten met COPD wel verhoogd was na een acute inspanning, maar niet in gezonde controles. Deze respons ging gepaard met een verlaagd antioxidant afweersysteem en $\beta$-oxidatie (vetafbraak) in COPD wat resulteerde in een verhoogde vetperoxidatie (vorming van toxische oxidatieproducten van vetten) in de spier. Deze resultaten geven aan dat de verhoging van UCP3 in de skeletspier van patiënten met COPD een compensatoir mechanisme zou kunnen zijn tegen deze stapeling van toxische vetoxidatieproducten. De verschillen tussen COPD patiënten en gezonde controles in deze studie benadrukken het belang van de verdere opheldering van de onderliggende regulatiemechanismen van UCP3.

Er zijn aanwijzingen gevonden voor een afname van het oxidatieve energiemetabolisme in mitochondriën in de skeletspier van patiënten met COPD. Dit zou kunnen bijdragen aan de beperkte inspanningscapaciteit in deze patiënten. Het effect van een farmacologische interventie met dichloroacetate (DCA), op de inspanningsgeïnduceerde systemische oxidatieve stress en ontstekingsrespons wordt beschreven in Hoofdstuk 6. DCA prikkelt specifiek het oxidatief energiemetabolisme in de skeletspier en verbetert acuut de inspanningscapaciteit bij COPD. In deze studie toonden we aan dat DCA, toegediend kort vóór een maximale inspanningstest, de inspannings-geïnduceerde systemische oxidatieve stress respons verlaagd. Daarnaast was het onstekingsremmende cytokine interleukin (IL)- 6 in patiënten met COPD verhoogd na inspanning. De inspannings-geïnduceerde veranderingen in IL6 na DCA behandeling waren omgekeerd evenredig gerelateerd aan de niveau's van het onstekingsbevorderende cytokine tumor necrose factor-alfa (TNF- $\alpha$ ). Dit suggereert dat DCA behandeling een ontstekingsremmend effect zou kunnen hebben in patiënten met COPD. Het is algemeen bekend dat DCA de voorraad van ATP aanvult en daardoor adenine nucleotide verlies afzwakt, zoals indirect gemeten was door een verlaging van ammonia ophoping. Geconcludeerd kan worden dat de verhoogde mitochondriële energieproductie een rol kan spelen in de verlaagde inspannings-geïnduceerde systemische oxidatieve stress- en ontstekingsremmende respons die werd gevonden in COPD patiënten na DCA toediening.

We concluderen in dit proefschrift dat COPD patiënten in vergelijking met gezonde controles gekarakteriseerd worden door een verhoogde pulmonale en systemische oxidatieve stress respons zowel in rust als gedurende inspanning. We hopen dat onze bevindingen leiden tot de ontwikkeling van verschillende soorten therapieën, van fysieke tot voedings- of farmacologische interventies, die resulteren in een verbeterde kwaliteit van leven en een verhoogde levensverwachting in patiënten met COPD. 


\section{DANKWOORD}

Op deze laatste bladzijden wil ik graag alle mensen bedanken die de afgelopen jaren een steentje hebben bijgedragen aan de totstandkoming van dit proefschrift. Bovendien sluit ik hiermee niet alleen dit proefschrift af, maar ook een erg leuke periode in mijn leven, zodat ik graag van de gelegenheid gebruik wil maken om vrienden en familie te bedanken.

Allereerst een bijzonder woord van dank aan alle patiënten en vrijwilligers die aan het onderzoek hebben deelgenomen want zonder jullie medewerking, motivatie en enthousiasme zou dit proefschrift nooit tot stand zijn gekomen! Bloed prikken, verschillende inspanningstestjes en zelfs meerdere spierbiopten.... niets was voor jullie teveel! Bedankt!!

Speciale dank gaat uit naar mijn promotieteam. Mijn promotores Annemie Schols en Professor Wouters en copromotor Geja Hageman zou ik graag willen bedanken voor de steun, begeleiding en het vertrouwen die onmisbaar waren voor het volbrengen van dit promotieonderzoek. Beste Annemie, ik wil je bedanken voor je kennis en je waardevolle adviezen. Ik bewonder je passie en grenzeloze enthousiasme voor onderzoek. Met name je hulp bij de laatste zware loodjes heb ik erg op prijs gesteld en dat je mijn stukken ongekend snel van commentaar en correcties hebt voorzien. Ik waardeer erg je bezoek aan de NIA en hoop dan ook dat ik in de toekomst nog vaak op je kennis kan terug vallen. Prof. Wouters, je hebt altijd een belangrijke rol gespeeld in mijn promotieonderzoek, meestal enigsinds achter de schermen maar niet te min aanwezig met je advies en je leerde me altijd om het onderzoek in een breder kader te plaatsen. Ik heb ook steeds geweten dat ik bij je terecht kan als dat nodig zou blijken. Bedankt hiervoor! Geja, hartelijk bedankt voor de aangename samenwerking in de afgelopen jaren. $\mathrm{k}$ wil je bedanken voor alle raad en ondersteuning, je gedrevenheid en de vele uren die je aan het onderzoek besteed hebt. Ik kon altijd bij je aankloppen met alle mogelijke vragen en je leerde me kritisch naar de resultaten te kijken, waarvoor ik je erg dankbaar ben.

Ik had het geluk om met verscheidene mensen uit verschillende disciplines samen te werken. Allereerst wil ik graag mijn collega's van de vakgroep Pulmonologie bedanken voor de fijne samenwerking en aangename werksfeer. Aan de 'mannen' van de spierlijn heb ik veel te danken. Harry, bedankt voor het oplossen van de vele en tijdrovende computer probleempjes van de afgelopen jaren, de hulp met de figuren en je kritische blik en inbreng op de manuscripten. Ramon, in het bijzonder bedankt voor de goede en leerzame adviezen met betrekking tot de NF-kB paper. 
En beiden, bedankt voor de vele potentiële en stimulerende discussies. Jullie deur stond altijd voor me open. Mercikes!!

Niki, ik kon me geen betere persoon voorstellen om als kamergenoot (en peroonlijke Thesaurus) te hebben. Je enthousiasme, je gedrevenheid, je inspiratie hebben een grote indruk op mij gemaakt! Bedankt voor alle nuttige tips en adviezen en niet te vergeten de hulp met de Scientific Travel Award!!! Ik kijk er al naar uit om ooit een gezamelijk projectje te schrijven! Mijn ex-kamergenootjes Roelinka en Erica mag ik zeker ook niet vergeten! Roelinka, bedankt voor de leuke babbels en hopelijk verliezen we elkaar niet uit het oog! Erica, onze koffiemomenten zal ik nooit vergeten...

Daarnaast wil ik alle andere (ex)collega's en AlO's bedanken voor de steun, de gezelligheid en het plezier zowel tijdens als buiten het werk. Alex, bedankt voor de erg leuke congresbezoeken (ons posteravontuur zal ik nooit vergeten), de vele klets-pauzes, en niet te vergeten de café-uitstapjes. Veel succes nog met je afronding van je proefschrift. Céline, ik ben blij dat ik je toch nog heb leren kennen, maar ik hoop dat we zeker nog contact houden en wens je veel succes met je promotieonderzoek!! Bettine, bedankt voor de vele gezellige momenten toen we naast elkaar in de 'hood' zaten... Alex, Céline en Bettine nogmaals bedankt voor me wegwijs te maken in de celkweek. Ine (of was het Tina?), ik hoop dat je het naar je zin hebt gehad in mijn huisje en wens je veel succes met je avontuur in de VS. En ik kijk al uit naar het volgend feestje samen met jullie!!! Marco, jou wil ik ook nog speciaal bedanken voor de samenwerking en je hulp met de EMSA's. Ook gaat mijn dank uit naar Frits, Jos, Pascal, Anon, Jodil, Roy, Bram, Nicky, Koen en Valéry en tenslotte de dames van de longlijn: Juanita, Mieke, Astrid, Nadja, Gonda, en Claudia. Ook het secreatriaat wil ik graag bedanken, met in het bijzonder Fabienne, Manon, France and Gaby.

Mijn promotietijd was mede onvergetelijk dankzij mijn collega's van de afdeling Farmacologie en Toxicologie! Beste Aalt, hartelijk bedankt dat ik altijd welkom was in je lab. Ik wil dan ook Els, Roger, Hilde, Liesbeth, Saskia, Eric, Agnes en Vanessa van Toxicologie bedanken voor de prettige samenwerking, de hulp, de vele gezellige lunchpauzes en de middag-uitstapjes naar Themby's. In het bijzonder Marc en Marie-José, bedankt dat jullie altijd bereid waren om me te helpen! Marc, om het even met welke vraag ik weer voor je deur stond, het was je nooit teveel! Van harte bedankt! Ik wens je erg veel succes met je nieuwe baan! Marie-José, vooral bedankt voor de labtechnische hulp gedurende het eerste jaar.

Ook mensen van andere afdelingen hebben me op de een of andere manier geholpen. Joyce, het was erg leuk om een artikel met je te schrijven, al waren we er snel achter dat statistiek toch niet onze sterkste kant was. Ralph, bedankt voor alle hulp met het ontwikkelen van de primers, het mogen lenen van cDNA en de hulp met de 
Dankwoord

vele PCRs. Fazzi, bedankt voor de hulp met de kleuringen! Jane, thanks for helping me with the PARP stainings.

De verschillende studies beschreven in dit proefschrift zouden niet mogelijk geweest zijn zonder CIRO in Horn. Het team van bewegingsagogen, laboratorium en longfunctie verdienen een speciaal woordje van dank! Jérôme, Tom, Remco, Anne, en Marco zelfs tijdens jullie lunchpauzes stonden jullie klaar om me te helpen met de fietstesten. Bedankt hiervoor!! De dames van het lab (Annelies, Gonny, Monique en Peggy) en longfunctie (Kitty, Marianne, Martine en jongeheer Joost) bedankt voor de gezellige babbels tijdens de koffietijd, de adviezen en alle hulp in het lab, en de assistentie bij het nemen van spierbiopten. En tenslotte, Joan en Herman-Jan bedankt voor het nemen van de spierbiopten! Jüre, thanks for taking the biopsies even with a broken finger!! Bedankt allen voor de geweldige tijd in Hornerheide!

Beste paranimfen, woorden schieten tekort om jullie te bedanken!! Jullie zijn van onschatbare waarde voor me geweest tijdens de afgelopen jaren. Niet alleen op het werk, maar ook erbuiten. Bedankt voor de (be)zorgzaamheid in moeilijkere tijden, dat heb ik ontzettend gewaardeerd!! Els bedankt voor de vele babbels tijdens onze dagelijkse koffie-pauzes, de vele shop-dates en ik wens je véél succes met jullie drietjes!!! Roger, je energie, je positivisme, je behulpzaamheid, kortweg niets was je teveel!! In stressvolle momenten wist jij altijd weer een lach op mijn gezicht te toveren.....boefje:) en nogmaals bedankt voor het ontwerpen van de geweldige kaft!! Ik wil jullie bedanken voor de ongelofelijke tijd en ik ben blij dat jullie straks naast me staan!

De leden van de beoordelingscommissie wil ik bedanken voor het beoordelen van dit proefschrift: Prof. F.J. van Schooten, Prof. E. Blaak, Prof. C.D.A. Stehouwer. Prof. B.K. Pedersen and Prof. C. Préfaut thank you for your time and your critical assessment of the thesis.

Promoveren kan niet zonder afwisseling, ontspanning en afleiding. Wat dat betreft, ben ik mijn collega's van Jantjes (Peggy, Kathleen en Marielle) en het Casino (Ellen, Silvie, Sarah en Sofie) veel dank verschuldigd. Jullie gaven me de afwisseling en energie die ik nodig had. Bedankt voor de hartverwarmende samenwerking en de vele gezellige feestjes! Ik heb echt supertijden met jullie beleeft!! Jef, Gerard en Palm bedankt, want het was niet altijd makkelijk met ons achter de toog!!! Flip (wat was het ook alweer, fatty acids:), Walter, Eddy, Bert en Tim bedankt voor de gezellige werk en tooguurtjes!! En tevens wil ik mijn schoolvriendinnen Anja, Marij en Caroline bedanken. Op julie kan ik altijd rekenen! 
Mijn looppartners Mieke en Josianne en tennispartners Els, Sabine, Nathalie en Chris bedankt voor de vele sportieve uurtjes! Hopelijk mogen er nog vele volgen ...

Tant, Albert, Sandra, Stefan, mijn metekindje Jirne en Rory. Bij jullie kan ik altijd terecht! Oma, 'bomma', een speciaal woordje voor jou, het is al een tijdje geleden dat je toch wel plots bent moeten gaan, en het was altijd je wens om je kleinkinderen te zien opgroeien. Ik weet dat je trots op me bent en mijn proefschrift draag ik dan ook op aan jou!

Mama en papa. Bedankt voor jullie onvoorwaardelijke steun en vertrouwen. Bedankt dat jullie altijd voor me klaarstaan.

Tot slot, voor iedereen die zijn naam hier mist, ik ben je niet vergeten, maar toch bedankt voor alles!

Evi 


\section{LIST OF PUBLICATIONS}

\section{Full papers}

Mercken EM, Hageman GJ, Schols AM, Akkermans MA, Bast A and Wouters EF. Rehabilitation decreases exercise-induced oxidative stress in chronic obstructive pulmonary disease. Am J Respir Crit Care Med 172: 994-1001, 2005.

Mercken EM, Hageman GJ, Langen RC, Wouters EF and Schols AM. Reduced NF$\mathrm{KB}$ mediated gene expression in skeletal muscle of patients with COPD in response to acute exercise. Submitted.

Mercken EM, Gosker HR, Hageman GJ, Wouters EF and Schols AM. Acute exercise triggers muscle UCP3 in COPD: adaptive mechanism against lipotoxicity? Submitted.

Mercken EM, Gosker HR, Rutten EP, Wouters EF, Bast A, Hageman GJ and Schols $A M$. Systemic and pulmonary oxidative stress after single leg exercise in COPD. Submitted.

Mercken EM, Calvert LD, Hageman GJ, Schols AM, Steiner MC. Dichloroactetate reduces exercise-induced systemic stress response in COPD. Submitted.

Houben JM, Mercken EM, Ketelslegers HB, Bast A, Wouters EF, Hageman GJ and Schols AM. Telomere shortening in chronic obstructive pulmonary disease. Repir Med 2008 [epub ahead of print].

Spruit MA, Mercken EM, Wouters EFM and Schols AMWJ. Role of exercise testing in defining the response to interventions in COPD patients. European Respiratory Monograph 40: 208-20, 2007.

Dentener MA, Creutzberg EC, Pennings HJ, Rijkers GT, Mercken E, Wouters EF. Effect of infliximab on local and systemic inflammation in chronic obstructive pulmonary disease: a pilot study. Respiration 76(3): 275-82, 2008. 


\section{Abstracts}

Mercken EM, Hageman GJ, Schols AM, Akkermans MA, Bast A and Wouters EF. Rehabilitation decreases exercise-induced oxidative stress in chronic obstructive pulmonary disease. European Respiratory Society (ERS) 2004.

Mercken EM, Hageman GJ, Langen RC, Wouters EF and Schols AM. Reduced NF$\kappa \mathrm{B}$ mediated gene expression in skeletal muscle of patients with COPD in response to acute exercise. Society for Free Radicals (SFFR) 2007.

Mercken EM, Gosker HR, Hageman GJ, Wouters EF and Schols AM. Acute exercise triggers muscular uncoupling protein-3 expression in chronic obstructive pulmonary disease. American Thoracic Society (ATS) 2007.

Mercken EM, Gosker HR, Hageman GJ, Wouters EF and Schols AM. Acute exercise triggers muscular uncoupling protein-3 expression in chronic obstructive pulmonary disease. European Society for Clinical Nutrition and Metabolism. ESPEN, Travel Fellowship, 2008.

Mercken EM, Calvert LD, Hageman GJ, Schols AM and Steiner MC. Dichloroacetate reduces exercise-induced systemic stress response in chronic pulmonary disease. European Respiratory Society (ERS), Travel Grant for Best Posters, 2008. 


\section{CURRICULUM VITAE}

Evi Mercken was born on the first of March 1978 in Bilzen, Belgium. After obtaining her secondary degree, she started to study Nutrition at the Rega School in Leuven, where she graduated in 2000. Thereafter, she started studying 'Biological Health Science' at the Faculty of Health Sciences 'at the University of Maastricht, The Netherlands. The topic of her graduate research project was "Specific inhibition of CMV-transcripts by RNA interference mediated by 21-nucleotide dsRNAs (small interfering and short hairpin RNAs)". From June 2003 until June 2004, she worked as a research assistant at the Department of Respiratory Medicine at the University of Maastricht on a research project named poly(ADP-ribose) polymerase (PARP) activation during exercise-induced oxidative stress in patients with chronic obstructive pulmonary disease (COPD): its effects on $\mathrm{NAD}^{+}$status, cellular energy metabolism and skeletal muscle weakness. In June 2004, she continued working at the Department of Respiratory Medicine as a PhD student. The title of her thesis is "The exercise-induced oxidative stress paradox in COPD". At the ESPEN conference in 2008 she was awarded a Travel Fellowship and she received a Travel Grant for Best Posters from the European Respiratory Society. In December 2007, she received a Scientific Travel award from the Dutch Asthma Foundation and she was able to perform a 6 months fellowship at the Laboratory of Experimental Gerontology (headed by Dr. de Cabo) at the National Institute on Aging (NIA), NIH, U.S.A. Currently, she has a position as a visiting post-doctoral fellow at the Laboratory of Experimental Gerontology at the NIA. Her research will focus on the role of skeletal muscle atrophy in aging and its impact on metabolism, health-span and longevity. 